
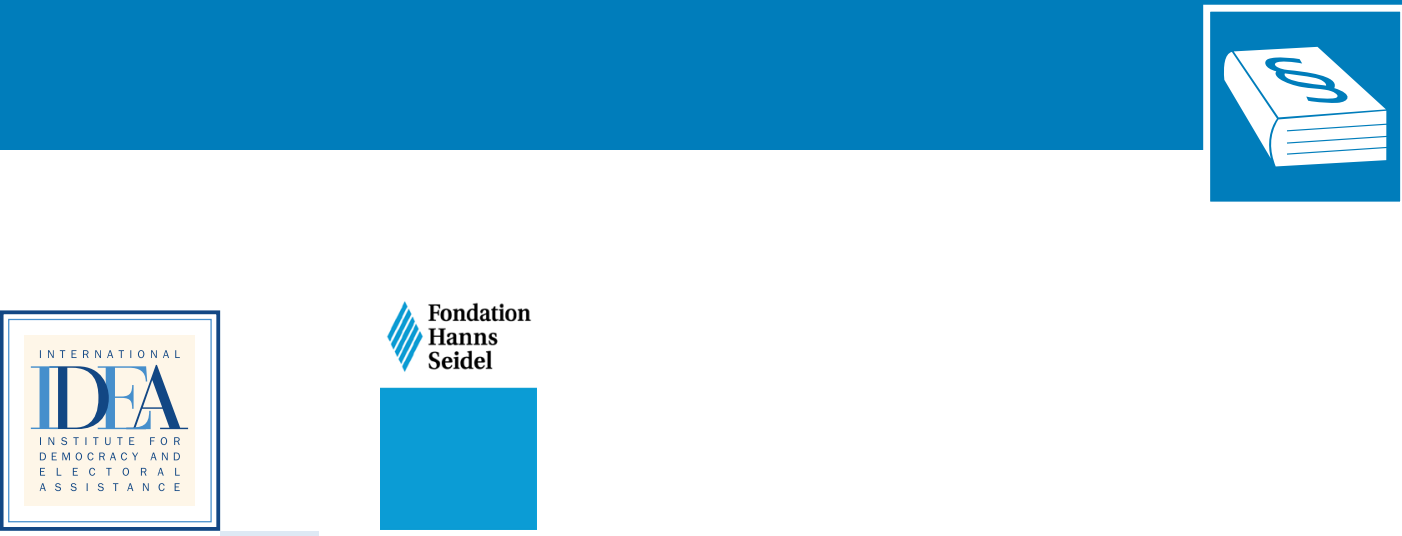

Les juridictions constitutionnelles en Afrique de l'Ouest

Analyse comparée 


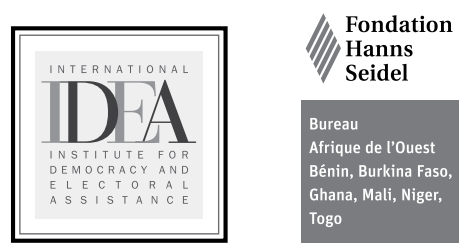

\section{Les juridictions}

constitutionnelles en Afrique

de l'Ouest

Analyse comparée 


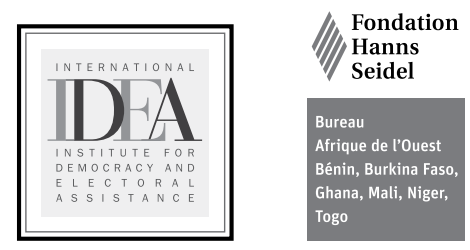

\title{
Les juridictions
}

\section{constitutionnelles en Afrique}

de l'Ouest

Analyse comparée

\author{
Auteurs \\ Markus Böckenförde \\ Babacar Kante \\ Yuhniwo Ngenge \\ H. Kwasi Prempeh
}


Ressources d'IDEA International sur les processus d'élaboration constitutionnelle

(c) 2016 Institut international pour la démocratie et l'assistance électorale

(C) 2016 Fondation Hanns Seidel

IDEA International

Strömsborg

SE-103 34 STOCKHOLM

SUÈDE

Tél. : +46869837 00, fax : +468202422

Courriel : info@idea.int, site Internet : www.idea.int

Fondation Hanns Seidel

Lazarettstraße 33

80636 Munich

Allemagne

Tél. : +4989 1258-0| Fax : -356

Courriel: info@hss.de, site internet:www.hss.de

La version électronique de cette publication est disponible sous licence Creative Commons Attribute NonCommercial-ShareAlike 3.0 (non commerciale). Vous pouvez librement reproduire, distribuer et diffuser cette publication, et y effectuer des modifications ou adaptations pour un usage strictement non commercial, pour autant que vous en citiez la source de manière adéquate et que vous la diffusiez sous le même type de licence. Pour plus d'informations sur cette licence, consultez: <http:// creativecommons.org/licenses/by-nc$\mathrm{sa} / 3.0 />$.

Les publications d'IDEA International sont indépendantes de tout intérêt spécifique national ou politique. Les opinions exprimées dans cet ouvrage ne représentent pas nécessairement celles d'IDEA International ou de la Fondation Hanns Seidel ni celles des membres de leurs conseils d'administration respectifs.

Conception graphique : Turbo Design

ISBN : 978-91-7671-099-9 


\section{Table des matières}

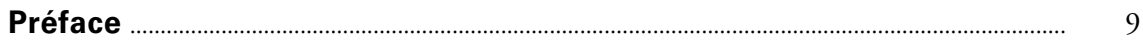

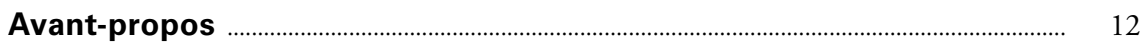

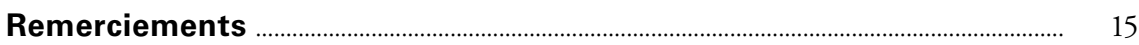

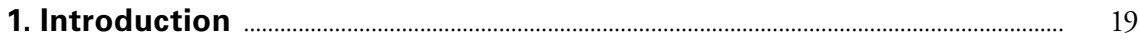

Markus Böckenförde

2. La justice constitutionnelle en Afrique de l'Ouest :

origines historiques et traditionnelles

Yuhniwo Ngenge

3. Les modèles institutionnels de justice constitutionnelle en Afrique de l'Ouest contemporaine

Yuhniwo Ngenge

4. Les dispositions constitutionnelles encadrant

l'indépendance des juridictions compétentes en matière

de contrôle de constitutionnalité

Markus Böckenförde et Yuhniwo Ngenge

5. Les Conseils supérieurs de la magistrature

Babacar Kante et $H$. Kwasi Prempeh

6. La composition des juridictions compétentes en matière de justice constitutionnelle

Markus Böckenförde

7. Le contrôle de la constitutionnalité des lois

Yuhniwo Ngenge

8. Les autres attributions des juridictions compétentes en matière de contrôle de constitutionnalité

Babacar Kante et H. Kwasi Prempeh

9. La saisine des juridictions compétentes en matière de contrôle de constitutionnalité 
10. L'autorité des décisions des juridictions compétentes en matière de contrôle de constitutionnalité

Babacar Kante et H. Kwasi Prempeh

11. Le contrôle et la responsabilité des instances chargées du contrôle de la constitutionnalité

Markus Böckenförde

12. Conclusion et perspectives

Markus Böckenförde et Yuhniwo Ngenge

Annexe : Questionnaire type

Glossaire

Références bibliographiques et lectures complémentaires

À propos des auteurs

À propos d'IDEA International

À propos de la Fondation Hanns Seidel 


\section{Liste des tableaux et illustrations}

Tableau 1.1. Systèmes juridiques en Afrique de l'Ouest, types d'institutions et durée du mandat des juges

Tableau 1.2. Valeurs d'indice, déviations par rapport à la France et indicateurs de concordance entre les anciennes colonies françaises et le modèle français

Tableau 1.3. Intégration du droit coutumier et religieux dans les constitutions et systèmes judiciaires d'Afrique de l'Ouest

Tableau 2.1. Évolution historique des systèmes de justice constitutionnelle en Afrique

Tableau 4.1. Autonomie budgétaire et protection de la rémunération des juges constitutionnels en Afrique de l'Ouest

Tableau 5.1. Conseils supérieurs de la magistrature en Afrique de l'Ouest

Tableau 6.1. Aperçu de la composition et du processus de révocation des membres des juridictions compétentes en matière de justice constitutionnelle en Afrique de l'Ouest

Tableau 7.1. Types de contrôle de constitutionnalité et d'actes juridiques soumis à ce contrôle dans les pays francophones et lusophones de l'Afrique de l'Ouest

Tableau 7.2. Types de contrôle de constitutionnalité et d'actes juridiques soumis à ce contrôle dans les pays anglophones et lusophones de l'Afrique de l'Ouest

Tableau 8.1. Autres attributions des juridictions compétentes en matière de justice constitutionnelle en Afrique de l'Ouest

Tableau 10.1. Décisions des juridictions compétentes en matière de contrôle de constitutionnalité en Afrique de l'Ouest 
Figure 3.1. L'Afrique de l'Ouest dans la répartition mondiale des modèles de contrôle de constitutionnalité par voie juridictionnelle

Figure 3.2. Répartition des modèles de contrôle de constitutionnalité par voie juridictionnelle en Afrique de l'Ouest

Figure 3.3. Répartition des juridictions de type kelsénien en Afrique de l'Ouest

Figure 3.4. Modèles purs et modifiés juridictions de type kelsénien en Afrique de l'Ouest

Figure 6.1. Désignation par le pouvoir législatif à la majorité qualifiée

Figure 6.2. Désignation au terme d'un processus consécutif

Figure 6.3. Désignation par différentes autorités

Figure 6.4. Nomination par le chef de l'État 


\section{Préface}

Au cours des dernières décennies, les pays africains ont fait le choix d'approfondir l'intégration du continent, afin de protéger et de promouvoir leurs intérêts communs dans une société globalisée, mais extrêmement compétitive. Cette évolution a encouragé la création d'organisations régionales en vue de favoriser une coopération plus étroite - initialement dans le domaine du commerce et de l'économie, mais de plus en plus dans le domaine de la gouvernance politique et du développement - entre les États membres. La Communauté économique des États de l'Afrique de l'Ouest (CEDEAO), fondée en 1975, a ainsi enregistré des progrès importants depuis sa création, en particulier dans les secteurs du commerce et du développement économique et social de la sous-région.

En réponse aux défis persistants auxquels la démocratie est confrontée en Afrique, la CEDEAO a également élargi son mandat pour y inclure la promotion de l'État de droit. Cette initiative a permis d'approfondir la coopération et de renforcer les moyens d'action entre les États membres, par exemple en sanctionnant ceux qui ne respectent pas ses valeurs, et a contribué à asseoir les normes relatives à l'État de droit dans la région. La création d'une Cour de justice régionale en 1991, dont les compétences incluent les violations des droits humains dans les États membres, confirme l'intérêt porté à l'État de droit ainsi que le rôle précieux joué par les instances judiciaires dans sa protection.

Cet intérêt n'est pas surprenant. L'État de droit reste un élément central dans le développement, le renforcement et la consolidation de la gouvernance démocratique et constitutionnelle. Il offre également un cadre en matière de responsabilité, d'équilibre des pouvoirs et de respect des droits fondamentaux. Cependant, dans de nombreux pays d'Afrique de l'Ouest, l'enracinement de ces valeurs reste une préoccupation majeure, en dépit de la création de Cours suprêmes et constitutionnelles (ou de Conseils constitutionnels) chargées de veiller au respect de l'État de droit en assurant un contrôle par voie juridictionnelle. 
La plateforme offerte par la Cour de justice de la CEDEAO facilite grandement la coopération dans les domaines relevant de son mandat. Toutefois, de manière plus générale, le dialogue et la coopération judiciaires entre les États de la région restent insuffisants. L'importance d'une bonne coopération entre ces pays, de traditions et de cultures juridiques différentes, ne saurait être exagérée, car elle contribue à renforcer la culture de l'État de droit, de la démocratie et des droits humains grâce à une pollinisation croisée des meilleures pratiques, des expériences et des idées entre des pays où les systèmes judiciaires opèrent de manière compartimentée. Pour y parvenir, il est essentiel de comprendre le cadre juridique et constitutionnel des institutions issues de ces cultures juridiques différentes.

Cette étude comparative d'IDEA International et de la Fondation Hanns Seidel, réalisée en collaboration avec le Centre for Global Cooperation Research, entend faciliter cette première étape. Ses différents chapitres offrent, entre autres, un aperçu de l'évolution historique des systèmes de justice constitutionnelle dans la région, ainsi que des grandes tendances actuelles dans l'organisation, la structure et les mandats des instances chargées du contrôle juridictionnel et de la justice constitutionnelle dans 16 pays d'Afrique de l'Ouest. Cette région présente un contexte unique pour une telle étude, car elle juxtapose les deux principales traditions et cultures juridiques - common law et civil law (ce dernier d'inspiration tant française que portugaise) également utilisées dans le reste de l'Afrique subsaharienne.

Le public trouvera plusieurs intérêts à cet ouvrage, qui a bénéficié des contributions de nombreux chercheurs - originaires de l'Afrique de l'Ouest anglophone, francophone et lusophone - ayant une connaissance approfondie du sujet et de la région. Pour les décideurs politiques nationaux, il met en lumière les faiblesses dans la conception des systèmes de justice constitutionnelle, soulignant la nécessité de réformer pour améliorer l'efficacité des institutions et renforcer la promotion de l'État de droit.

Aux universitaires, il apporte une contribution importante au développement du droit constitutionnel comparé, sur un thème dans lequel les travaux de recherche souffrent de lacunes. En outre, les questionnaires remplis lors de la phase de recherche préliminaire pour la préparation de cette étude (publiés sur le site Internet d'IDEA International à l'adresse www.constitutionNet. org) offrent des informations utiles aux chercheurs. À la communauté des professionnels, notamment des avocats constitutionnalistes, des juges et des conseillers juridiques, il offre un outil d'apprentissage et d'échanges mutuels concernant les différents systèmes de justice constitutionnelle de la région. 
Cependant, si les instances de contrôle juridictionnel - au travers de leur fonction de garants de la constitutionnalité - continuent d'exercer une influence majeure sur la manière dont les pays font face aux défis démocratiques, cette publication ouvre également la voie à d'autres initiatives pour renforcer l'État de droit, en encourageant le dialogue et la coopération entre ces instances au niveau régional. Nous espérons et sommes convaincus que l'approfondissement des échanges sur les meilleures pratiques et questions conceptuelles contribuera à promouvoir l'État de droit et le constitutionnalisme - et, in fine, la démocratie - dans la région.

Yves Leterme

Secrétaire général IDEA International
Ursula Männle

Présidente

Fondation Hanns Seidel 


\section{Avant-propos}

Cet ouvrage inédit sur les juridictions constitutionnelles en Afrique de l'Ouest publié par la Fondation HANNS SEIDEL et l'Institut international pour la démocratie et l'assistance électorale (IDEA International), avec la collaboration d'autres institutions partenaires, est le résultat d'un pari hasardeux au départ. Il n'a pu être remporté que grâce à une ténacité digne d'éloges de ses concepteurs et à une détermination à toute épreuve de ses auteurs. Depuis l'ouverture des pays africains vers ce qu' il est convenu d'appeler la transition démocratique et l'émergence qui s'en est suivie des juridictions constitutionnelles telles qu'elles sont connues aujourd'hui, plusieurs centres ou instituts de recherche de même que des chercheurs ont, sans aucun doute, déjà caressé l'idée de travailler sur une analyse comparée de l'organisation et du fonctionnement de ces institutions devenues la clé de voûte des systèmes politiques africains. Mais cet ouvrage est le premier à aborder la complexité du sujet d'une manière compréhensive et profonde.

Si en raison de l'importance grandissante jouée par ces juridictions dans l'ancrage de l'État de droit et de la démocratie dans les pays africains, notamment de l'Afrique de l'Ouest, une telle recherche s'avère nécessaire, elle n'en reste pas moins délicate. Le champ de l'étude couvre en effet 16 pays qui appartiennent à trois espaces linguistiques (francophone, anglophone et lusophone) et deux traditions juridiques (common law et civil law), correspondant à des systèmes politiques différents. Les uns sont cités, à tort ou à raison, comme des modèles sur le continent, alors que d'autres sont en crise. Ainsi, derrière l'unité géographique, toute relative d'ailleurs, des pays étudiés, on note une grande diversité des régimes juridiques et politiques.

Aussi, pour réaliser ce projet, ses initiateurs ont-ils mis sur pied une équipe internationale de chercheurs de haut niveau, dont les profils recoupent les différents systèmes juridiques. Cette équipe a mis en œuvre une méthodologie particulièrement rigoureuse fondée sur une exégèse des dispositions constitutionnelles ou des lois organiques relatives aux juridictions constitutionnelles sous un angle comparatif et quantitatif. Les 
conclusions des différents chapitres font l'objet, chaque fois que de besoin, de tableaux ou de graphiques; ce qui rend l'utilisation de l'ouvrage facile et agréable. En outre, une telle approche présente au moins un double intérêt. Le premier est d'ordre didactique du fait que l'ouvrage produit du savoir sur l'organisation et le fonctionnement des juridictions constitutionnelles, dont il rend compte à partir des textes qui les créent et les régissent. Le second est pédagogique en raison de son utilité pratique pour un dialogue des juges, dans la perspective d'une réforme éventuelle du système d'organisation de la justice constitutionnelle qui se cherche encore en Afrique.

À travers leur analyse, les auteurs de cet ouvrage ont jeté des regards croisés sur ces juridictions. Ils ont, en 11 chapitres, abordé un large spectre des questions soulevées par l'étude des juridictions constitutionnelles en Afrique. Ils sont ainsi partis de l'analyse du contexte traditionnel et précolonial de l'émergence de ces juridictions constitutionnelles jusqu'à des sujets encore tabous comme le contrôle des juridictions constitutionnelles elles-mêmes, en passant par des questions aussi techniques que les compétences de ces juridictions ou les systèmes et types de contrôle de constitutionnalité, les voies d'accès au juge constitutionnel, l'autorité des décisions rendues et des thèmes sensibles comme la composition de ces juridictions, le statut des juges qui les composent et leurs rapports avec d'autres institutions.

Au terme de leur étude, les auteurs ont relevé des ressemblances et identifié des différences entre ces juridictions. L'exploitation des synthèses exposées devrait permettre de favoriser le dialogue des juges avec l'espoir, à terme, d'une intégration ou d'une harmonisation du droit constitutionnel sous régional en Afrique de l'Ouest. Ce droit s'internationalise en effet de plus en plus et les pays de l'Afrique de l'Ouest devraient impulser le mouvement au lieu de le subir. Par ailleurs, cette somme sur les juridictions constitutionnelles pourrait servir d'outil pour un renouvellement de la formation et de la recherche en droit constitutionnel dans les établissements d'enseignement supérieur tant en Afrique qu'en dehors du continent. Dans la sous-région, cette formation reste encore classique et largement centrée sur l'analyse des régimes politiques.

Mais, en réalité, cet ouvrage n'est que la première étape d'un projet plus vaste tendant à renforcer l'État de droit en Afrique de l'Ouest. Son objectif était de rendre compte du droit tel qu'il résulte des textes portant création et organisation des juridictions constitutionnelles en Afrique de l'Ouest. Dans un deuxième temps, il s'agira en effet, à partir des conclusions de l'ouvrage, de réfléchir cette fois sur la mise en ouvre pratique des dispositions analysées. Il sera question d'étudier, in concreto, le fonctionnement de ces juridictions constitutionnelles par une analyse de leurs jurisprudences respectives pour en dégager le sens et la portée. 
On ne peut que féliciter les initiateurs de ce projet et souhaiter à cet ouvrage de connaître le succès qu'il mérite.

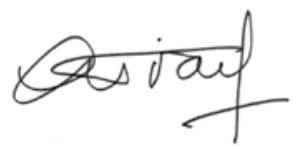

Abdou DIOUF

Ancien Président de la République du Sénégal et ancien Secrétaire général de la Francophonie 


\section{Remerciements}

Cette publication est le résultat des contributions et de l'appui précieux apporté par de nombreux individus et institutions.

IDEA International et la Fondation Hanns Seidel remercient chaleureusement les auteurs pour leurs contributions : Markus Böckenförde (Centre for Global Cooperation Research), Babacar Kante (Université Gaston Berger) et Kwasi Prempeh (Seton Hall Law School). Nous saluons également le rôle central d'Yuhniwo Ngenge (IDEA International), qui a non seulement rédigé plusieurs chapitres de ce livre, mais a fait preuve d'un dévouement et d'une patience remarquables en tant que point focal pour la coordination des principales étapes de son élaboration, notamment les premières relectures des différents chapitres, ainsi que pour les échanges avec les autres auteurs.

Nous exprimons également notre gratitude aux chercheurs nationaux, dont les rapports ont fourni des données locales précieuses pour l'analyse : Kangnikoe Bado et Chadidscha Schoepffer (Université de Giessen, Allemagne), Omar Hamady (Max Planck Institute for Comparative Public and International Law), Lisa Heemann (Université de Giessen, Allemagne), Abou Jeng (Opération hybride Union africaine-Nations Unies au Darfour), Emilio Kafft Kosta (Université de Lisbonne), Joseph Hindogbae Kposowa (Sierra Leone), Christiane Roth (Fondation Hanns Seidel), Anne Winter (Université de Munster) et Larba Yarga (Université de Ouagadougou, Burkina Faso). Nous remercions par ailleurs le Centre for Global Cooperation Research pour son aide dans l'élaboration du questionnaire utilisé pour la rédaction des rapports de pays, ainsi que Christina Murray (Université du Cap), Xavier Philippe (Institut Louis Favoreu-GERJC) et Cheryl Saunders (Université de Melbourne) pour leurs commentaires lors de cette étape. Nous saluons en outre le rôle du Réseau africain de droit constitutionnel (African Network of Constitutional Lawyers) dans l'identification des personnes et ressources adéquates dans le cadre du travail de recherche. 
Nos sincères remerciements vont également aux participants à l'atelier de révision organisé à Saint-Louis, au Sénégal, en octobre 2014 et aux relecteurs qui ont fait part de leurs remarques et suggestions afin de donner forme à l'ouvrage et d'approfondir la réflexion amorcée dans les versions préliminaires. Il s'agit de Frédéric Joël Aivo (Université d'Abomey, Bénin), Kangnikoe Bado (Université de Giessen), Ould Bouboutt Ahmed Salem (Université de Nouakchott, Mauritanie), Janneh Semega Ebironkeh (Semega Chambers, Banjul, Gambie), Ameze Guobadia (Nigerian Institute of Advanced Legal Studies), Omar Hamady (Max Planck Institute for Comparative Public and International Law), Lisa Heemann (Université de Giessen), Sébastien Lath (University d'Abidjan, Côte d'Ivoire), Aristide Lima (Cour constitutionnelle du Cabo Verde), André Mangu (Université de Pretoria), Oumarou Narey (Cour constitutionnelle du Niger), Isaac Yankhoba Ndiaye (Conseil constitutionnel du Sénégal), Milton Paiva (Université du Cabo Verde) et Larba Yarga (Université de Ouagadougou, Burkina Faso). Nous remercions également l'Université Gaston Berger de Saint-Louis du Sénégal d'avoir facilité l'organisation de cet atelier.

D'importants moyens logistiques, administratifs et de recherche mobilisés par différentes personnes, tant au sein d'IDEA International et de la Fondation Hanns Seidel que d'autres institutions, ont rendu possible la publication de cet ouvrage. À cet égard, nous tenons à souligner les contributions de Katalin Dobias et Izabela Rybarcyzk (IDEA International); Liana Lücke, Demian Regehr, Christiane Roth et Uta Staschewski (Fondation Hanns Seidel); et d'Eric Sutton (William and Mary Law School).

Nous remercions sincèrement l'équipe chargée des publications au sein d'IDEA International pour sa gestion du cycle de production, de l'ébauche à l'impression. Il est difficile de nommer chacune des nombreuses personnes ayant contribué d'une manière ou d'une autre à la réalisation de ce projet. Toutefois, nous tenons à mentionner Thilo Marauhn et son équipe de chercheurs à l'Université de Giessen (Allemagne), dont les travaux sur le contrôle juridictionnel et la démocratisation en Afrique de l'Ouest francophone et les ateliers organisés dans ce contexte ont été une source d'inspiration constante pour ce projet.

Nous adressons à nouveau nos remerciements à Babacar Kante (Université Gaston Berger) et Yuhniwo Ngenge (IDEA International) ainsi qu'à Maurice Engueleguele (IDEA International) pour la relecture du texte français. Nous remercions également Lisa Hagman (IDEA International) pour la supervision du projet de traduction et le bon déroulement de la production de cette version française. 
Enfin, nous saluons le rôle de supervision de Ralf Wittek, chef du bureau régional Afrique de l'Ouest de la Fondation Hanns Seidel, et de Sumit Bisarya, chef du Programme sur les processus d'élaboration constitutionnelle d'IDEA International. 
1. Introduction 


\title{
1. Introduction
}

\author{
Markus Böckenförde
}

Les systèmes juridiques des pays d'Afrique de l'Ouest sont uniques dans leur diversité ${ }^{1}$. Ils se fondent sur différents héritages issus de la colonisation et ont été influencés par un grand nombre de normes coutumières et religieuses, ce qui affecte la structure du système judiciaire de chaque pays. Parallèlement, cette région se développe collectivement sous les auspices de la Communauté économique des États de l'Afrique de l'Ouest (CEDEAO). Créée initialement en 1975 pour promouvoir l'intégration économique et régionale, les pressions exercées par les conflits armés et leurs conséquences, l'autoritarisme et la faiblesse de la culture démocratique qui ont caractérisé la région dans les années 1990 ont ensuite conduit la CEDEAO à redéfinir son mandat en 1993 pour y inclure la coopération dans le domaine politique et de la gouvernance. La création d'institutions régionales telles qu'un Parlement et une Cour de justice, ainsi que l'adoption d'instruments tels qu'un protocole (2001) sur la démocratie et la bonne gouvernance (avec ses principes de la convergence constitutionnelle), illustrent cette évolution et signalent l'intérêt croissant porté à l'État de droit et au constitutionnalisme dans la région. Cela exige par conséquent une bonne connaissance des différents concepts juridiques appliqués dans chaque pays. Ce savoir collectif facilite le progrès et la coopération et permet d'éviter les incompréhensions mutuelles.

Ces dernières années, les constitutions des pays d'Afrique de l'Ouest et d'ailleurs ont eu tendance à accorder au pouvoir judiciaire la compétence en matière de contrôle de la constitutionnalité des lois. D'après Constitute, base de données en ligne répertoriant les constitutions actuellement en vigueur dans plus de 194 pays, $80 \%$ des constitutions prévoient un mécanisme formel de contrôle de constitutionnalité (majoritairement par voie juridictionnelle) chargé de vérifier la conformité des actions et décisions des autorités publiques par rapport à la Constitution. Ce processus vise à combler l'écart qui peut

Dans le cadre du présent ouvrage, l'Afrique de l'Ouest désigne l'ensemble des États membres de la CEDEAO (Bénin, Burkina Faso, Cabo Verde, Gambie, Ghana, Guinée, Guinée Bissau, Côte d'Ivoire, Libéria, Mali, Niger, Nigéria, Sénégal, Sierra Leone et Togo) ainsi que la Mauritanie, ancien membre de la CEDEAO. 
exister entre une constitution écrite purement sémantique et une constitution normative qui restreint et régule de manière effective l'exercice du pouvoir politique et protège les droits humains. Bien que la portée de l'autorité accordée aux institutions nationales chargées du contrôle de constitutionnalité varie grandement en fonction des pays, toutes les constitutions de la région prévoient un certain degré de contrôle de constitutionnalité par voie juridictionnelle.

Le présent ouvrage poursuit deux objectifs. Tout d'abord, il compare les différentes instances chargées de la justice constitutionnelle dans 16 pays d'Afrique de l'Ouest et analyse les différentes manières selon lesquelles elles rendent la justice et encouragent le développement de la démocratie. Il n'existe pas d'approche unique optimale : différentes traditions juridiques donnent généralement naissance à différentes configurations. Ensuite, il cherche à faciliter l'apprentissage et la compréhension mutuelle entre les pays de la région, en particulier ceux dont les systèmes juridiques sont différents, dans le but de tracer les grandes lignes d'un système commun ouest-africain. L'ouvrage est conçu pour servir de référence dans les 16 pays, comme une base à l'analyse comparée ou comme un recueil de bonnes pratiques, afin de promouvoir les réformes et d'identifier des éléments de comparaison. L'étude comparative s'appuie sur des questionnaires nationaux remplis par des experts locaux dans le cadre du projet ${ }^{2}$. Elle donne un aperçu des lois telles qu'elles ont été codifiées; elle n'examine pas dans quelle mesure celles-ci sont appliquées ou respectées, sauf lorsque cela s'avère essentiel à titre d'exemple. Elle ne prend pas non plus en compte les conventions non écrites et les dynamiques informelles qui peuvent influencer la justice constitutionnelle. Ces aspects seront examinés lors d'une phase ultérieure, sur la base d'activités conduites avec les parties prenantes concernées dans chaque pays.

Les pays de la région ont mis en place différents modèles de contrôle de constitutionnalité, non seulement en raison de la diversité de leurs systèmes politiques, mais parce qu'ils viennent de familles juridiques distinctes fondées sur différents concepts : les systèmes dits de common law et ceux de civil law ont des approches tout à fait différentes du contrôle de constitutionnalité, en dépit de certains traits communs, comme l'illustre le tableau 1. De plus, la traduction des principaux termes juridiques peut donner lieu à de mauvaises interprétations. Par exemple, dans certains contextes de common law, "sur la recommandation de" (on the advice of) se rapportant au processus de nomination des juges, pourrait s'interpréter comme contraignant et non simplement consultatif comme pourrait le suggérer le langage commun.

2 Le questionnaire est reproduit à l'annexe 1. Les questionnaires remplis sont disponibles pour chaque pays à l'adresse <http://www.constitutionnet.org/rule_of_law_questionnaires>. 


\section{Tableau 1.1. Systèmes juridiques en Afrique de I'Ouest, types d'institutions et durée du mandat des juges}

\begin{tabular}{|c|c|c|c|c|c|c|}
\hline Pays & $\begin{array}{l}\text { Système } \\
\text { juridique }\end{array}$ & Type d'institution & $\begin{array}{c}\text { Qualifications } \\
\text { en droit requises } \\
\text { pour tous les } \\
\text { membres? }\end{array}$ & $\begin{array}{c}\text { Examen ex } \\
\text { ante des } \\
\text { lois? }\end{array}$ & $\begin{array}{c}\text { Mandat } \\
\text { à vie des } \\
\text { membres? }\end{array}$ & $\begin{array}{c}\text { Population } \\
\text { (millions) }\end{array}$ \\
\hline Bénin & $\begin{array}{l}\text { Civil law } \\
\text { (fr) }\end{array}$ & $\begin{array}{l}\text { Cour } \\
\text { constitutionnelle }\end{array}$ & Non (art. 115) & Oui (art. 117) & Non (art. 115) & 10,3 \\
\hline $\begin{array}{l}\text { Burkina } \\
\text { Faso }\end{array}$ & $\begin{array}{l}\text { Civil law } \\
\text { (fr) }\end{array}$ & $\begin{array}{l}\text { Conseil } \\
\text { constitutionnel }\end{array}$ & Non (art. 153) & Oui (art. 155) & $\begin{array}{l}\text { Non } \\
\text { (art. 153) }\end{array}$ & 16,9 \\
\hline Cabo Verde & $\begin{array}{l}\text { Civil law } \\
\text { (po) }\end{array}$ & $\begin{array}{l}\text { Cour } \\
\text { constitutionnelle }\end{array}$ & Oui (art. 215 (3)) & $\begin{array}{l}\text { Non (sauf cas } \\
\text { exceptionnels) }\end{array}$ & Non (art. 215) & 0,5 \\
\hline $\begin{array}{l}\text { Côte } \\
\text { d'Ivoire }\end{array}$ & $\begin{array}{l}\text { Civil law } \\
\text { (fr) }\end{array}$ & $\begin{array}{l}\text { Conseil } \\
\text { constitutionnel }\end{array}$ & Non (art. 89) & Oui (art. 95) & Non (art. 90) & 20,3 \\
\hline Gambie & $\begin{array}{l}\text { Common } \\
\text { law }\end{array}$ & Cour suprême & $\begin{array}{l}\text { Oui (art. } 139 \\
\text { (2)(3)) }\end{array}$ & Non & $\begin{array}{l}\text { Non (art. } 141 \\
\text { (2)) }\end{array}$ & 1,8 \\
\hline Ghana & $\begin{array}{l}\text { Common } \\
\text { law }\end{array}$ & Cour suprême & Oui (art. $128(4))$ & Non & $\begin{array}{l}\text { Non (art. } 145 \\
\text { (2a)) }\end{array}$ & 25,9 \\
\hline Guinée & $\begin{array}{l}\text { Civil law } \\
\text { (fr) }\end{array}$ & $\begin{array}{l}\text { Cour } \\
\text { constitutionnelle }\end{array}$ & Non (art. 100) & $\begin{array}{l}\text { Oui } \\
\text { (art. 94-5) }\end{array}$ & Non (art. 101) & 11,8 \\
\hline $\begin{array}{l}\text { Guinée- } \\
\text { Bissau }\end{array}$ & $\begin{array}{l}\text { Civil law } \\
\text { (po) }\end{array}$ & Cour suprême & Oui & $\begin{array}{l}\text { Non (sauf cas } \\
\text { exceptionnels) }\end{array}$ & $\begin{array}{l}\text { Oui (art. } 33 \\
\text { EMJ) }\end{array}$ & 1,7 \\
\hline Libéria & $\begin{array}{l}\text { Common } \\
\text { law }\end{array}$ & Cour suprême & Oui (art. 66 (b)) & Non (art. 66) & $\begin{array}{l}\text { Non (art. } 72 \\
\text { (b)) }\end{array}$ & 4,3 \\
\hline Mali & $\begin{array}{l}\text { Civil law } \\
\text { (fr) }\end{array}$ & $\begin{array}{l}\text { Cour } \\
\text { constitutionnelle }\end{array}$ & Non (art. 91) & Oui (art. 86) & Non (art. 91) & 15,3 \\
\hline Mauritanie & $\begin{array}{l}\text { Civil law } \\
\text { (fr) }\end{array}$ & $\begin{array}{l}\text { Conseil } \\
\text { constitutionnel }\end{array}$ & $\begin{array}{l}\text { Les lois } \\
\text { juridiques et } \\
\text { constitutionnelles } \\
\text { ne le précisent pas }\end{array}$ & Oui (art. 86) & Non (art. 81) & 3,9 \\
\hline Niger & $\begin{array}{l}\text { Civil law } \\
\text { (fr) }\end{array}$ & $\begin{array}{l}\text { Cour } \\
\text { constitutionnelle }\end{array}$ & Non (art. 121) & Oui (art. 131) & Non (art. 121) & 17,8 \\
\hline Nigéria & $\begin{array}{l}\text { Common } \\
\text { law }\end{array}$ & Cour suprême & Oui (art. 231 (3)) & Non & $\begin{array}{l}\text { Non (art. } 291 \\
\text { (1)) }\end{array}$ & 173,6 \\
\hline Sénégal & $\begin{array}{l}\text { Civil law } \\
\text { (fr) }\end{array}$ & $\begin{array}{l}\text { Conseil } \\
\text { constitutionnel }\end{array}$ & $\begin{array}{l}\text { Non (art. 4) loi } \\
\text { organique }\end{array}$ & $\begin{array}{l}\text { Oui (art. } 92 \\
\text { (1)) }\end{array}$ & Non (art. 89) & 14,1 \\
\hline $\begin{array}{l}\text { Sierra } \\
\text { Leone }\end{array}$ & $\begin{array}{l}\text { Common } \\
\text { law }\end{array}$ & Cour suprême & $\begin{array}{l}\text { Oui (art. 121, } \\
\text { 135) }\end{array}$ & Non & $\begin{array}{l}\text { Oui (art. } 137 \\
\text { (2)) }\end{array}$ & 6,1 \\
\hline Togo & $\begin{array}{l}\text { Civil law } \\
\text { (fr) }\end{array}$ & $\begin{array}{l}\text { Cour } \\
\text { constitutionnelle }\end{array}$ & Non (art. 100) & Oui (art. 104) & $\begin{array}{l}\text { Non } \\
\text { (art. 100) }\end{array}$ & 6,8 \\
\hline \multicolumn{7}{|c|}{ Notes : $(\mathrm{fr})=$ français $;(\mathrm{po})=$ portugais } \\
\hline
\end{tabular}

\section{Légende}

Afrique de l'Ouest francophone

Afrique de l'Ouest anglophone

Afrique de l'Ouest lusophone 
L'ouvrage se concentre sur les différentes options prévues par les constitutions et lois organiques pour l'exercice du contrôle de constitutionnalité. Il s'agit donc, avant tout, d'une étude des normes écrites. Les lois organiques sont des lois quasi constitutionnelles rencontrées dans les pays de tradition civiliste, de portée constitutionnelle et qui ont préséance sur la législation ordinaire. Elles précisent les modalités de fonctionnement pertinentes des institutions créées conformément aux dispositions prévues par la Constitution. Plus important encore dans le cadre de cette étude, toutes les anciennes colonies françaises d'Afrique de l'Ouest (à l'exception du Sénégal), requièrent un contrôle juridictionnel des lois organiques avant leur promulgation; ce qui, de fait, revient à associer le pouvoir judiciaire à la définition/protection de son propre rôle dans le système. L'ouvrage se réfère à l'expression «institutions de contrôle ou de justice constitutionnelle" plutôt qu'à celle de "cour constitutionnelle», car quatre pays utilisent le terme «conseil» et non «cour» ou «tribunal» pour désigner l'organe chargé de ce contrôle. Les débats permanents en France et dans les pays francophones soulignent la pertinence de cette distinction dans la façon dont ces institutions se perçoivent (et la conception qu'en ont les citoyens).

\section{La notion de contrôle de constitutionnalité}

Dès lors qu'un système normatif ordonne ses règles entre, d'une part, les lois suprêmes (Constitution) et, d'autre part, les autres lois et actes, il est nécessaire d'établir des mécanismes pour préserver cette hiérarchie. La plupart des pays ont donné aux tribunaux le pouvoir de contrôler les lois et actes qui seraient contraires à la Constitution (de Andrade 2001 : 997), et considèrent le pouvoir judiciaire comme le principal garant institutionnel de la Constitution (Chen et Maduro 2013 : 97). La décision de confier au pouvoir judiciaire le contrôle de la constitutionnalité des lois peut s'expliquer par le désir d'isoler ce processus des interférences politiques en confiant la décision à un arbitre neutre. Cependant, la dimension politique de ces jugements ne doit pas être ignorée. Le droit constitutionnel est intrinsèquement politique; certains universitaires l'appellent ainsi "droit politique» (Tushnet 2004 : 257). Les litiges portant sur les dispositions constitutionnelles concernent souvent les problématiques politiques les plus sensibles d'un pays (Glenn Bass et Choudhry 2013 : 2). Trancher des questions politiquement sensibles et définir des enjeux politiques dans le cadre d'une constitution qui, par sa nature, utilise des termes relativement abstraits et traduit des concepts et engagements de base n'est pas une affaire purement juridique. Une instance chargée du contrôle de constitutionnalité peut ainsi faire une lecture différente du texte constitutionnel de celle sur laquelle le pouvoir législatif 
s'est implicitement appuyé (Comella 2011 : 272). Pour citer Mark Tushnet, « [l]a rhétorique de la simple application de la loi ne reflète pas la réalité de l'arbitrage constitutionnel» (2004 : 260). En particulier dans les situations où les juridictions ont le pouvoir de contrôler la constitutionnalité d'une loi avant sa promulgation, elles peuvent servir de «troisième chambre, en tant qu'organes capables de refondre le contexte de l'élaboration des politiques et d'encourager certaines solutions législatives tout en affaiblissant certaines autres» (Epstein et Shvetsova $2001: 125)$.

Cependant, le contrôle de constitutionnalité par voie juridictionnelle n'est pas un prérequis pour garantir l'intégrité et l'efficacité d'une constitution écrite (de Andrade 2001 : 977). Par exemple, aux Pays-Bas (article 120) et en Suisse (de Andrade 2001 : 978; Cappelletti 1970 : 1035), aucun tribunal ne peut remettre en cause la constitutionnalité des lois nationales ou les écarter pour cause d'inconstitutionnalité. D'autres pays confient explicitement la fonction du contrôle de constitutionnalité à des organes politiques. En Éthiopie, les articles 83 et 84 de la Constitution placent cette autorité entre les mains de la seconde chambre législative, et jusqu'en 1991, les dispositions de la Constitution de la Guinée-Bissau prévoyaient que les tribunaux s'adressent au Parlement en cas de doute sur la constitutionnalité d'un texte, lui seul ayant la compétence d'en vérifier la conformité à Constitution (articles 56 et 98).

\section{L'influence des systèmes juridiques sur l'architecture des instances chargées du contrôle de constitutionnalité}

Les pays ont conçu leurs systèmes juridiques en fonction de leur histoire et de leurs cultures propres, y compris les traditions juridiques précoloniales et coutumières. Cependant, les systèmes juridiques des puissances coloniales ont eu une influence majeure surl'architecture institutionnelle de leurs mécanismes et institutions chargés du contrôle de constitutionnalité. Ce développement n’a pas toujours été consécutif : après leur indépendance, la plupart des pays francophones d'Afrique de l'Ouest ont opté pour une variante du modèle de Cour suprême. Dans celui-ci, la Cour suprême, outre sa compétence en dernier recours pour toutes les affaires judiciaires, conserve la compétence exclusive et définitive en matière de contentieux constitutionnel. C'est le principe de l'unité de juridiction, par opposition au dualisme juridictionnel adopté en France, l'ancienne puissance coloniale. Après les réformes des années 1990, certains éléments de l'architecture française ont été introduits à différents degrés dans les systèmes judiciaires des anciennes colonies. Une étude récente, conduite par Stroh et Heyl (2015) s'est penchée sur le degré de concordance de la structure du contrôle de constitutionnalité des anciennes 
colonies françaises avec le modèle français avant la réforme intervenue en 2008 (voir tableau 1.2).

\section{Tableau 1.2. Valeurs d'indice, déviations par rapport à la France et indicateur de concordance entre les anciennes colonies françaises et le modèle français}

\begin{tabular}{|l|c|c|c|c|c|c|c|c|c|} 
& Bénin & $\begin{array}{c}\text { Burkina } \\
\text { Faso }\end{array}$ & $\begin{array}{c}\text { Côte } \\
\text { d'lvoire }^{\prime}\end{array}$ & Guinée & Mali & Mauritanie & Niger & Sénégal & Togo \\
\hline $\begin{array}{l}\text { Concordance } \\
\text { par rapport à } \\
\text { la France }\end{array}$ & $57 \%$ & $86 \%$ & $82 \%$ & $71 \%$ & $75 \%$ & $89 \%$ & $75 \%$ & $75 \%$ & $75 \%$ \\
\hline
\end{tabular}

Remarques : I'indice s'appuie sur 11 paramètres différents portant sur l'architecture institutionnelle d'une instance indépendante chargée du contrôle de constitutionnalité. Parmi ces paramètres, la structure du Conseil constitutionnel en France (avant la réforme de 2008) a été comparée à celle qu'ont adoptée neuf pays d'Afrique de l'Ouest francophone. Ces paramètres sont les suivants : 1. Un large accès à l'instance ou au contrôle de constitutionnalité décentralisé; 2 . Une instance dotée de compétences larges et d'une grande portée politique; 3 . La diversification des acteurs impliqués dans la nomination des juges; 4. La nécessité d'atteindre la majorité qualifiée pour forcer une désignation consensuelle des juges; 5. L'exigence de compétences professionnelles suffisantes pour les juges; 6 . Des mandats de longue durée, non renouvelables; 7. La protection des juges contre une révocation pour raison politique; 8. La protection constitutionnelle des compétences et de la structure de l'instance; 9 . La sécurité matérielle des juges avec un salaire adéquat; 10. La protection contre une modification trop aisée du texte précisant les droits de l'instance; 11. Une portée juridique étendue des décisions rendues par l'instance.

Source : Stroh A. et Heyl C., "Institutional diffusion, strategic insurance and the creation of West African constitutional courts" [Développement institutionnel, assurance stratégique et création des cours constitutionnelles en Afrique de I'Ouest], Comparative Politics, 47/2 (2015), p. 176.

Les quatre anciennes colonies britanniques (la Gambie, le Ghana, le Nigéria et la Sierra Leone) et l'unique ancienne colonie américaine (le Libéria) sont influencées par la common law, tandis que les anciennes colonies portugaises et françaises s'inspirent de leurs traditions respectives tirées du système de civil law. Bien que le Royaume-Uni ne dispose pas d'une constitution écrite et, par conséquent, d'aucune hiérarchie des normes sur laquelle fonder un contrôle de constitutionnalité, cette dernière notion n'est pas inconnue des colonies britanniques. L'Empire britannique avait fait adopter par le Parlement des constitutions écrites pour ses colonies. Les tribunaux coloniaux étaient théoriquement habilités à contrôler si une disposition adoptée par le législateur colonial était contraire à la Constitution (Chen et Maduro 2013 : 98). Toutefois, en pratique, ces tribunaux étaient trop soumis à l'administration coloniale pour exercer un contrôle efficace (cf. chapitre 2).

Bien que les traditions issues de la common law et du civil law trouvent leurs origines dans la pensée et la pratique juridique occidentales, les différentes trajectoires historiques de ces deux cultures juridiques ont laissé 
des divergences notoires dans le rôle du pouvoir judiciaire en tant que troisième pouvoir. Le rôle des juges, leur formation et l'évolution de leur carrière, le type de raisonnement juridique et la variété des recours reflètent ces différences (Fleiner et Saunders 2013 : 28). Par conséquent, la notion de contrôle de constitutionnalité s'est également développée de diverses manières et selon différentes logiques. Il existe des nuances au sein même de la famille du civil law; c'est particulièrement flagrant dans le contexte du contrôle de constitutionnalité. En général, l'approche fondée sur la conception civiliste s'inspire de la doctrine kelsénienne de concentration du contrôle des lois et de leur conformité à la Constitution au sein d'une seule institution judiciaire (une cour constitutionnelle).

L'approche française, qui a opté pour un "conseil» constitutionnel plutôt qu'une "cour", reste toutefois singulière et la nature juridique de l'institution - organe politique ou judiciaire - a pendant longtemps fait l'objet de débat entre constitutionnalistes français. La saisine du Conseil constitutionnel était uniquement possible avant la promulgation d'une loi et la compétence du Conseil se limitait au contrôle du respect, par le pouvoir législatif, des limites imposées par la Constitution et du principe de séparation des pouvoirs dans l'élaboration de la loi. Les différences entre les approches de civil law et de common law se sont érodées avec le temps, mais les caractéristiques pertinentes de ce modèle ont influencé les types de structure en Afrique de l'Ouest francophone (Fleiner et Saunders 2013 : 27) lors des réformes menées dans les années 1990.

D’un côté, le degré auquel les instances chargées de la justice constitutionnelle en Afrique de l'Ouest reflètent l'une ou l'autre des traditions juridiques se traduit dans une certaine mesure dans leur structure institutionnelle, dans la forme et le moment du contrôle. D'un point de vue institutionnel, les cinq pays de common law s'appuient sur un modèle de Cour suprême dont les juges sont nommés à vie (jusqu'au départ à la retraite). Par opposition, toutes les anciennes colonies françaises ont opté pour une Cour ou un Conseil constitutionnel(le) distinct(e) de l'ordre juridictionnel ordinaire, les juges étant nommés pour une durée déterminée. La compétence des Cours et les méthodes d'élaboration des décisions diffèrent également : aucun des pays de common law n'autorise, au sens strict, le contrôle a priori des lois (avant leur promulgation), tandis que c'est le cas pour tous les pays francophones. Cette distinction est traitée au chapitre 7.

De l'autre côté, certains pays d'Afrique de l'Ouest ont surmonté les différences entre familles juridiques en empruntant aux deux systèmes. Par exemple, la majorité des pays de common law de la région (la Gambie, le Ghana, le Libéria et la Sierra Leone) n'appliquent pas le concept de contrôle de constitutionnalité 
décentralisé, selon lequel tout tribunal dans l'ordre juridictionnel peut annuler, dans le cadre d'une procédure, une loi qu'il considère contraire à la Constitution. Au contraire, si des doutes sur la constitutionnalité d'une loi sont émis devant les juridictions inférieures, ces dernières doivent suspendre le procès et en référer à la Cour suprême et attendre sa décision.

\section{La prise en compte du droit coutumier et religieux}

Les 16 pays d'Afrique de l'Ouest étudiés ont plusieurs systèmes juridiques : ils diffèrent dans la manière dont les lois officielles et écrites coexistent et dont le droit traditionnel et/ou religieux est pris en compte. L'articulation entre les différents systèmes normatifs a son importance pour la notion de contrôle de constitutionnalité. Si la structure constitutionnelle inclut le droit coutumier et les instances correspondantes, la loi (écrite) tient compte de la réalité juridique sur le terrain et offre un cadre initial à une coexistence cohérente. Au fil du temps, une relation fructueuse se développera éventuellement. Toutefois, si la Constitution ne mentionne pas l'existence du droit coutumier et de ses institutions, ce dernier continue d'exister, mais opère de manière informelle, séparément (et dans une certaine mesure dans l'ignorance) de la loi suprême du pays. En Afrique de l'Ouest, il existe trois grands types d'articulation entre le droit coutumier et la Constitution.

Le premier reconnaît explicitement le droit coutumier et ses institutions. Les exemples les plus notables sont les constitutions du Ghana et du Nigéria. Ces deux pays disposent d'instances judiciaires de droit traditionnel qui opèrent principalement en parallèle des tribunaux de droit commun, mais qui sont intégrées au niveau supérieur. Les décisions définitives des tribunaux coutumiers (Nigéria) ou de la Chambre nationale des chefs/comités judiciaires (Ghana) peuvent être contestées devant les instances supérieures de droit commun.

Le second type reconnaît l'existence du droit coutumier dans la Constitution et peut lui accorder une certaine marge de fonctionnement, mais la Constitution ne prévoit pas de dispositions spécifiques quant au statut institutionnel ou à la relation entre les deux systèmes de droit. La Gambie, le Bénin et le Libéria en sont des exemples.

Dans le troisième type, les constitutions ne mentionnent pas l'existence du droit coutumier (cas des pays lusophones et du Mali, du Sénégal et du Burkina Faso). Cela ne signifie pas que le droit écrit de la personne n'est pas influencé par les coutumes traditionnelles ou religieuses ou qu'il n'existe aucune référence à ces coutumes dans les réglementations locales pertinentes, mais que le débat n'a pas lieu au niveau constitutionnel. 
La prise en compte du droit coutumier dans le contexte constitutionnel nécessite également de l'intégrer dans la hiérarchie des normes. Là aussi, différentes règles s'appliquent. Par exemple au Libéria et au Ghana, la Constitution dispose explicitement que les coutumes doivent se conformer à ses dispositions. Les normes traditionnelles qui ne respectent pas celles de la Constitution sont nulles. Une hiérarchie claire et stricte est donc ainsi établie, dont la mise en œuvre peut s'avérer difficile étant donné que les traditions culturelles et les coutumes mettent parfois du temps à évoluer. Si elles sont considérées comme inconstitutionnelles, il est possible qu'elles continuent à être appliquées de manière informelle. D'autres constitutions exemptent explicitement les dispositions coutumières du respect de certaines normes constitutionnelles. Par exemple, la Gambie et la Sierra Leone excluent certaines dispositions coutumières dans le domaine du droit de la personne de la clause de non-discrimination prévue par la Constitution (et donc d'un contrôle de constitutionnalité). Certains pays ont opté pour une voie médiane entre les deux extrêmes que sont, d'une part, la non-prise en compte des lois traditionnelles et, de l'autre, la préservation de certaines d'entre elles en les excluant de quelques interdictions posées par la Constitution. C'est le cas du Niger, de la Côte d'Ivoire et du Togo, où le législateur peut (ou doit) identifier une procédure permettant de constater et d'harmoniser les coutumes avec les principes fondamentaux de la Constitution. Il n'est toutefois pas précisé dans quelle mesure ce processus affecte le niveau de contrôle de constitutionnalité, étant donné que la conformité n'est généralement pas requise du moment que les coutumes respectent les principes fondamentaux de la Constitution.

La majorité des pays francophones d'Afrique de l'Ouest ont hérité de la doctrine de la laïcité - une approche française selon laquelle les coutumes religieuses peuvent influencer le droit commun, mais le droit religieux luimême ne fait pas partie de l'ordre juridique formel. La Mauritanie est une exception notable : sa constitution affirme, dans son préambule, que l'islam est la seule source de la loi. Deux pays anglophones ont officiellement établi des instances judiciaires religieuses dans leur constitution. Au Nigéria, des tribunaux de la charia peuvent être créés en parallèle des tribunaux de droit coutumier au niveau des États, tandis que la Constitution de la Gambie donne compétence aux tribunaux cadi pour les questions portant sur le mariage, le divorce et la succession si les parties concernées sont musulmanes ${ }^{3}$.

L'intégralité du texte de la plupart des constitutions mentionnées dans ce rapport peut être consultée sur le site internet d'IDEA International, ConstitutionNet, <http://www.constitutionnet.org/ resources $>$, et sur le site internet du projet Constitute, <https://www.constituteproject.org/>. 


\section{Tableau 1.3. Intégration du droit coutumier et religieux dans les constitutions et systèmes judiciaires d'Afrique de l'Ouest}

\begin{tabular}{|c|c|c|c|}
\hline & $\begin{array}{l}\text { La Constitution reconnaît-elle } \\
\text { le droit coutumier/religieux? }\end{array}$ & $\begin{array}{l}\text { Tribunaux établis par } \\
\text { la Constitution avec } \\
\text { compétence explicite en } \\
\text { matière de droit coutumier/ } \\
\text { religieux }\end{array}$ & $\begin{array}{c}\text { Articles } \\
\text { correspondants } \\
\text { dans la } \\
\text { Constitution }\end{array}$ \\
\hline Bénin & $\begin{array}{l}\text { La Constitution n'y fait pas directement } \\
\text { référence, mais indique que l'État doit } \\
\text { protéger et promouvoir les traditions } \\
\text { culturelles. En outre, toutes les } \\
\text { communautés composant la nation } \\
\text { béninoise jouiront de la liberté de } \\
\text { développer leur propre culture dans } \\
\text { le respect de celle des autres. }\end{array}$ & $\begin{array}{l}\text { La loi organique établit des } \\
\text { tribunaux de conciliation qui } \\
\text { peuvent appliquer le droit } \\
\text { coutumier. }\end{array}$ & Article 23 (2) \\
\hline Burkina Faso & Non & Non & \\
\hline Cabo Verde & Non & Non & \\
\hline Côte d'Ivoire & $\begin{array}{l}\text { La Constitution dispose que } \\
\text { l'État a le devoir de protéger } \\
\text { et de promouvoir les valeurs } \\
\text { nationales de civilisation ainsi } \\
\text { que les traditions culturelles qui } \\
\text { ne sont pas contraires à la loi ou } \\
\text { aux bonnes mœurs. L'Assemblée } \\
\text { nationale doit adopter une loi } \\
\text { détaillant la procédure selon laquelle } \\
\text { les coutumes sont constatées et } \\
\text { harmonisées avec les principes } \\
\text { fondamentaux de la Constitution. }\end{array}$ & Non & Articles 7, 71 \\
\hline Gambie & $\begin{array}{l}\text { Oui. La Constitution précise que les } \\
\text { lois gambiennes incluent le droit } \\
\text { coutumier et la charia (en ce qui } \\
\text { concerne les mariages, divorces } \\
\text { et successions), qui s'appliquent } \\
\text { aux membres des communautés } \\
\text { concernées. La Constitution } \\
\text { dispose explicitement que la clause } \\
\text { de non-discrimination ne s'applique } \\
\text { pas "aux membres d'une race ou } \\
\text { d'une tribu de droit coutumier et ce, } \\
\text { pour toute question concernant les } \\
\text { personnes qui, en vertu de cette loi, } \\
\text { y sont soumises". }\end{array}$ & $\begin{array}{l}\text { La Constitution établit des } \\
\text { tribunaux cadi et des conseils } \\
\text { cadi en appel, mais ne précise } \\
\text { rien en ce qui concerne les } \\
\text { tribunaux coutumiers. }\end{array}$ & $\begin{array}{l}\text { Articles } 33 \text { (5) } \\
\text { (d), } 37\end{array}$ \\
\hline Ghana & $\begin{array}{l}\text { Oui. La Constitution reconnaît } \\
\text { formellement l'existence du droit } \\
\text { coutumier et interdit toute pratique } \\
\text { coutumière déshumanisante ou } \\
\text { portant atteinte au bien-être } \\
\text { physique et mental de la personne. }\end{array}$ & $\begin{array}{l}\text { Le chapitre } 22 \text { de la Constitution } \\
\text { établit des Chambres des chefs } \\
\text { et leurs comités judiciaires, } \\
\text { qui disposent du pouvoir de } \\
\text { décision pour les questions } \\
\text { relevant de la chefferie. Ils sont } \\
\text { intégrés à l'ordre juridictionnel } \\
\text { dans la mesure où une } \\
\text { procédure d'appel passe de la } \\
\text { Chambre nationale des chefs à } \\
\text { la Cour suprême. }\end{array}$ & Article $11(2)(3)$ \\
\hline Guinée & Non & Non & \\
\hline
\end{tabular}




\begin{tabular}{|c|c|c|c|}
\hline $\begin{array}{l}\text { Guinée- } \\
\text { Bissau }\end{array}$ & Non & Non & \\
\hline Libéria & $\begin{array}{l}\text { La Constitution reconnaît } \\
\text { indirectement le droit coutumier } \\
\text { en affirmant la primauté de la } \\
\text { Constitution; par conséquent, } \\
\text { «les coutumes et réglementations } \\
\text { jugées contraires seront, } \\
\text { dans la limite des dispositions } \\
\text { incompatibles, considérées } \\
\text { comme nulles et sans effet». Elle } \\
\text { reconnaît également ce type de } \\
\text { droit en appelant à «préserver, } \\
\text { protéger et promouvoir la culture } \\
\text { libérienne, en veillant à ce que les } \\
\text { valeurs traditionnelles compatibles } \\
\text { avec les politiques publiques et le } \\
\text { progrès national soient adoptées et } \\
\text { développées». }\end{array}$ & $\begin{array}{l}\text { Non. Le pouvoir judiciaire est } \\
\text { confié à la "Cour suprême et à } \\
\text { toute instance subordonnée que } \\
\text { le législatif pourra, à l'occasion, } \\
\text { établir de temps en temps" } \\
\text { (aucune mention explicite des } \\
\text { tribunaux coutumiers). "Les } \\
\text { tribunaux appliqueront le droit } \\
\text { ordinaire et coutumier en } \\
\text { fonction des normes édictées } \\
\text { par le pouvoir législatif. " }\end{array}$ & $\begin{array}{l}\text { Articles } 2 \text { (2), } \\
5,65\end{array}$ \\
\hline Mali & Non & $\begin{array}{l}\text { Non, mais d'après la loi } \\
\text { organique, les tribunaux de } \\
\text { première instance, les cours } \\
\text { d'appel et la Cour suprême } \\
\text { appliquent le droit coutumier } \\
\text { ou religieux en matière de droit } \\
\text { civil. }\end{array}$ & \\
\hline Mauritanie & $\begin{array}{l}\text { Oui, en ce qui concerne le droit } \\
\text { religieux : la charia est considérée } \\
\text { comme la seule source du droit }\end{array}$ & Non & Préambule \\
\hline Niger & $\begin{array}{l}\text { Oui, indirectement : "La loi fixe les } \\
\text { règles concernant... la procédure } \\
\text { selon laquelle les coutumes sont } \\
\text { constatées et mises en harmonie } \\
\text { avec les principes fondamentaux de } \\
\text { la Constitution." }\end{array}$ & $\begin{array}{l}\text { La Constitution reconnaît } \\
\text { l'autorité des chefs dans } \\
\text { leur fonction de décideurs : } \\
\text { "L'État reconnaît la chefferie } \\
\text { traditionnelle comme } \\
\text { dépositaire de l'autorité } \\
\text { coutumière. Â ce titre, elle } \\
\text { participe à l'administration du } \\
\text { territoire de la République dans } \\
\text { les conditions déterminées } \\
\text { par la loi. La chefferie } \\
\text { traditionnelle est tenue à une } \\
\text { stricte obligation de neutralité } \\
\text { et de réserve. Elle est protégée } \\
\text { contre tout abus de pouvoir } \\
\text { tendant à la détourner du rôle } \\
\text { que lui confère la loi. . }\end{array}$ & Articles 99, 167 \\
\hline Nigéria & Oui & $\begin{array}{l}\text { Oui. La Constitution prévoit } \\
\text { l'établissement d'une cour } \\
\text { d'appel coutumière et d'une } \\
\text { cour d'appel de la charia au } \\
\text { niveau des États fédérés ainsi } \\
\text { qu'au niveau du territoire de la } \\
\text { capitale fédérale. Les décisions } \\
\text { de ces tribunaux peuvent être } \\
\text { déférées devant une cour } \\
\text { d'appel. }\end{array}$ & $\begin{array}{l}\text { Liste II, } n^{\circ} 61 \text {; } \\
\text { article 237; Article } \\
260 \mathrm{ss} \text {, Article } \\
275 \mathrm{ss}\end{array}$ \\
\hline Sénégal & Non & $\begin{array}{l}\text { Non-cohabitation/(loi sur les } \\
\text { autorités locales) }\end{array}$ & \\
\hline
\end{tabular}




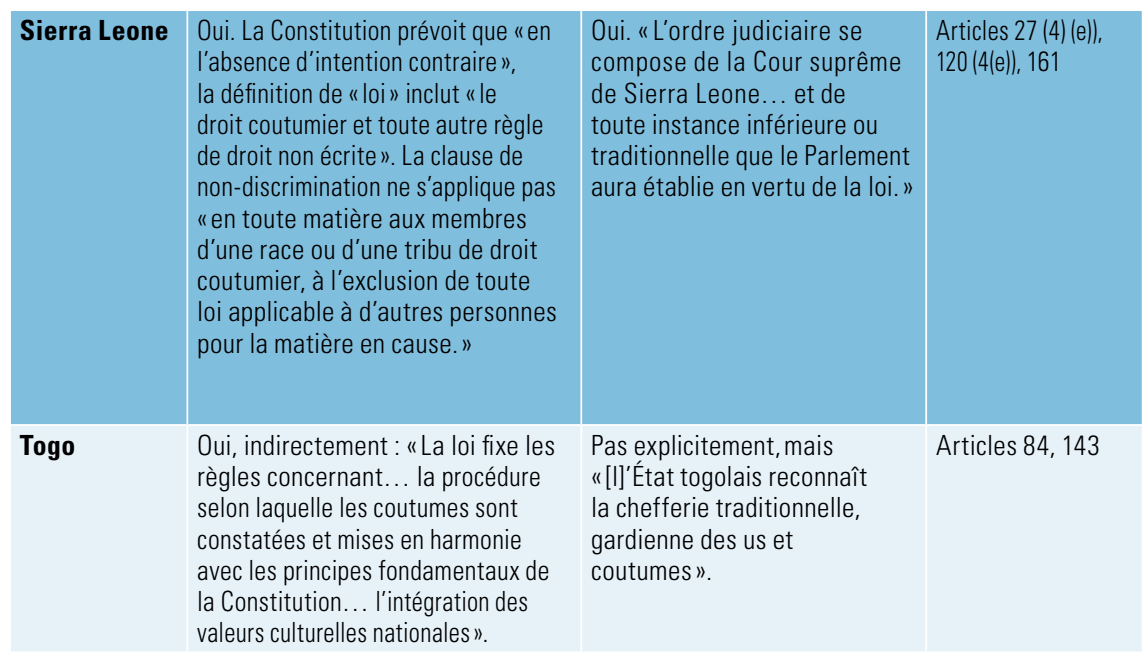

\section{Légende}

Afrique de l'Ouest francophone

Afrique de l'Ouest anglophone

Afrique de l'Ouest lusophone 

2. La justice

constitutionnelle

en Afrique de

l'Ouest : origines

historiques et

traditionnelles 


\title{
2. La justice constitutionnelle en Afrique de l'Ouest : origines historiques et traditionnelles
}

\author{
Yuhniwo Ngenge
}

Lanalyse contemporaine de l'évolution de la justice constitutionnelle en Afrique de l'Ouest commence généralement pendant la période postcoloniale. D'après certains universitaires, tels que Prempeh (1999 : 140), dans les décennies qui ont immédiatement suivi les indépendances africaines, le pouvoir judiciaire a renoncé à ses responsabilités en faveur de l'exécutif. D'autres suggèrent que de véritables systèmes de justice constitutionnelle, capables de promouvoir le constitutionnalisme et l'État de droit, n'ont commencé à voir le jour qu'au cours de la troisième vague de démocratisation, dans les années 1990 (Fombad 2011 : 1017; Prempeh 2006 : 3-5). C'est notamment le cas de l'Afrique de l'Ouest francophone où, selon Kanté, « la justice constitutionnelle n'a commencé à découvrir une certaine autonomie [...] qu'au début des transitions démocratiques de la fin des années 1990 " (2008 : 158-59). Ces transitionsont été, d'après son argument, "l'élément fondateur d'un nouvel ordre [...] juridique en Afrique francophone " (2008: 159).

Ces analyses se focalisent sur les modèles institutionnels et les pratiques de justice constitutionnelle hérités des régimes coloniaux ou plus tard empruntés à l'Occident, et ignorent les régimes politiques, les ordres juridiques et les modèles de gouvernance en place avant la colonisation. Si l'on passe outre les qualificatifs de "sombre ", " hors de propos ", "primitif " et "chaotique " si souvent associés à l'organisation politique du continent avant son découpage, l'Afrique précoloniale jouissait de solides structures politiques et de gouvernance. Cette architecture reposait sur des fonctions exécutives, législatives et judiciaires bien délimitées, ainsi que sur un système transparent d'équilibre des pouvoirs, d'État de droit et de prévention des abus de pouvoir par les dépositaires de l'autorité publique.

Les notions d'État de droit, d'équilibre des pouvoirs et de contrôle des abus de pouvoir impliquent l'existence d'une norme supérieure réglementant l'autorité politique et publique. Par conséquent, toute étude exhaustive de l'évolution 
historique de la justice constitutionnelle en Afrique de l'Ouest (ou ailleurs sur le continent) doit tenir compte de ces précédents précoloniaux.

La première partie de ce chapitre retrace les origines de la justice constitutionnelle en Afrique de l'Ouest avant la colonisation. La deuxième partie examine son évolution durant la période coloniale, tandis que la dernière partie se penche sur l'ère postcoloniale.

\section{L'Afrique de l'Ouest avant la colonisation}

Cette section se penche sur les questions suivantes : quel était, le cas échéant, le système de justice constitutionnelle ou le cadre équivalent en vigueur en Afrique de l'Ouest à la veille de la colonisation européenne ${ }^{4}$ ? Comment cette forme de justice était-elle organisée et appliquée dans la région avant la colonisation? Pour y répondre, il est important de comprendre le fonctionnement des systèmes politiques avant le découpage colonial. Dans quel cadre organisationnel s'opérait la gouvernance politique? Quelle était la source du pouvoir politique? Comment l'exercice de ce pouvoir était-il régulé, et par quel type de mécanisme institutionnel?

\section{L'organisation et l'exercice du pouvoir politique}

Les sociétés africaines précoloniales, tout en reconnaissant l'existence des fonctions exécutives, législatives et judiciaires dans l'architecture de la gouvernance politique, ne distinguaient pas nécessairement les différentes institutions ou postes exerçant ces fonctions (Alabi 2006 : 119). Par conséquent, ces divers offices et institutions (et les pouvoirs qui y étaient associés) étaient souvent exercés par une même personne - généralement un dirigeant traditionnel de haut rang - qui s'acquittait de ces charges par l'intermédiaire ou avec l'aide d'autorités et d'institutions traditionnelles. La répartition et l'exercice de ce pouvoir différaient en fonction des communautés politiques. Cependant, dans la plupart des cas, les unités de gouvernement étaient constituées d'un roi, dirigeant suprême (jouissant de l'autorité suprême en matière législative, exécutive et judiciaire), d'un conseil privé et d'un conseil des aînés ou des chefs qui, dans certains contextes, supervisait les sous-divisions administratives du régime. Ces conseils avaient

Pour les besoins de cette section, la définition de la justice constitutionnelle est élargie pour y inclure toute forme d'action conduite par un organe distinct (ou agissant en vertu de pouvoirs réservés) et pouvant résulter en des sanctions, soit pour (a) limiter et réguler l'exercice du pouvoir politique par le monarque ou les institutions dépositaires de cette autorité, soit pour (b) garantir la conformité à un ordre normatif ou un système de croyances ou de conventions sociales supérieures, que ceux-ci prennent la forme d'une constitution écrite ou non. 
principalement pour but d'aider le monarque dans les différents aspects de la gouvernance comme l'élaboration des lois et l'administration locale; mais ils représentaient également la première ligne de défense contre le despotisme royal (Degu $2002: 133)$.

Ce type de structure organisationnelle prévalait principalement dans les sociétés dites de chefferie ou acéphales. De nombreux chercheurs travaillant sur les systèmes politiques en Afrique précoloniale, tels qu'Ayittey (2006: 106, 112-16), définissent ces sociétés comme celles disposant d'une autorité centralisée, avec des fonctions exécutives, législatives et judiciaires clairement définies. Les sociétés sans chefferie ou " non acéphales " désignant par opposition celles n'ayant pas établi une telle structure. Pour Ohaegbulam (1990 : 98-9), le Soudan occidental - à savoir l'Afrique de l'Ouest actuelle - offre le meilleur exemple d'une société de chefferie. Dans le pays yoruba du Nigéria précolonial par exemple, l'oba ou alafin (roi) dirigeait la structure organisationnelle de chaque ville yoruba et exerçait l'autorité gouvernementale suprême, sur les plans législatif, exécutif et judiciaire (Alabi 2006 : 114). Sous son autorité, l'Oyo Mesi (conseil des chefs), dirigé par un basorun (Premier ministre), représentait la lignée non royale de la communauté yoruba. Le conseil exerçait une fonction de contrepoids aux pouvoirs du roi et assurait le lien entre le peuple et le palais. Venaient ensuite les chefs de districts ou baales, qui exerçaient des fonctions similaires (Alabi 2006). Les grands royaumes du Mali et de Songhaï, ainsi que les Fantis au Ghana et les Mossis au Burkina Faso sont d'autres exemples de communautés politiques du Soudan occidental fonctionnant sur un modèle de gouvernance politique similaire.

\section{La régulation institutionnelle du pouvoir politique}

Comme mentionné ci-dessus, ce qui distingue les sociétés acéphales de celles dites non acéphales est le degré de concentration de l'exercice de l'autorité législative, exécutive et judiciaire par un gouvernement central. Or un tel pouvoir ne pouvait surgir du néant. En général, le droit coutumier non écrit servait de fondement normatif à l'exercice de tout pouvoir. Ce droit trouvait à son tour sa source dans une convention supérieure, non écrite, constituée de valeurs traditionnelles anciennes, de croyances et de normes culturelles développées et transmises oralement au fil des générations. Ces lois et valeurs ont été intégrées à l'identité commune et ont constitué avec le temps une norme de légitimité populaire immuable, collective et patrimoniale. Les monarques et autres dirigeants traditionnels étaient tenus (par contrat) de se conformer à cet ordre supérieur dans l'exercice de leurs devoirs publics. À cet égard, l'ordre normatif supérieur représentait la norme "constitutionnelle» à l'égard de laquelle toute action, décision ou loi du gouvernement était évaluée. Le dirigeant était donc responsable devant son peuple de l'application 
de lois développées dans le respect du patrimoine commun; il/elle agissait uniquement en tant que représentant(e) de la communauté et en appliquait les lois, sans pouvoir imposer les siennes propres (cf. également Mboup 2011 : 76).

Cette construction - même si elle n'est pas formulée en termes de souveraineté populaire, d'État de droit, de gouvernance constitutionnelle, de contrat social, de séparation ou d'équilibre des pouvoirs - ressemble à celles que proposaient les philosophes classiques de la doctrine européenne du libéralisme du XVIII ${ }^{\mathrm{e}}$ siècle, tels que Locke, Voltaire, Rousseau et Montesquieu (Akinjide et Elias 1988 : 36). Au cœur de la philosophie de ces penseurs, on trouve l'argument selon lequel les pouvoirs publics - exercés au nom du peuple qui reste souverain - ne sont pas soumis à l'arbitraire, et que des mécanismes de contrôle sont nécessaires pour maîtriser ou sanctionner toute violation de ce principe.

L'organisation politique des sociétés précoloniales ouest-africaines reflétait fréquemment cette pensée. De fait, tout en confiant l'autorité suprême de juge, de législateur et d'administrateur en chef au monarque, elles avaient mis en place des institutions chargées de maintenir la stabilité et de protéger de l'arbitraire et du chaos le système et l'ordre social fondamental. Pour s'acquitter de cette mission, ces institutions exerçaient un bon nombre de fonctions de contrôle importantes, sans doute tant sur le plan politique que judiciaire.

Premièrement, les conseils privés et les conseils des aînés, nous l'avons mentionné plus haut, représentaient la première ligne de défense contre le despotisme. À cet égard, le pays yoruba fournit une nouvelle fois un exemple utile. L'Oyo Mesi servait d'important mécanisme de contrôle de l'autorité politique du monarque; il confirmait le couronnement de chaque roi et veillait à ce que ce dernier exerce son pouvoir conformément aux exigences de la tradition ou de la Constitution (Alabi 2006 : 117). Son président, le basorum, qui remplaçait souvent le monarque, inspirait respect et crainte à tous, y compris au roi (Alabi 2006). Théoriquement, ce dernier exerçait le rôle de juge, de législateur et d'administrateur en chef. Toutefois, il devait consulter l'Oyo Mesi avant de prendre ses décisions, et ne pouvait se maintenir au pouvoir que tant qu'il conservait la confiance du conseil, qui pouvait le forcer à abdiquer par suicide lorsque cette confiance venait à se rompre. L'Ogboni était une société secrète composée de nobles, qui se réunissait en dehors de cette structure et exerçait une fonction globale de contrôle et d'équilibre des pouvoirs tant de l'alafin que de l'Oyo Mesi (Alabi 2006). Les Ogbonis servaient de "gardiens des prérogatives et des libertés publiques" et disposaient de contre-pouvoirs en cas d'oppression politique extrême ou de violation de ce qui était perçu comme l'ordre social ou constitutionnel; 
ils pouvaient ainsi infliger de lourdes sanctions aux dirigeants autoritaires, impopulaires ou corrompus (Mboup 2011).

Les Ogboni travaillaient avec et contrôlaient tant le monarque que les institutions et les collaborateurs chargés de le conseiller (Alabi 2006 : 117). Si le monarque faisait l'objet d'une enquête nécessitant l'ouverture d'une procédure judiciaire, un panel de juges sélectionnés dans l'Ogboni et l'Oyo Mesi était chargé d'arbitrer l'affaire. Les charges de corruption, de tyrannie et de mépris flagrant des valeurs et coutumes traditionnelles sacro-saintes constituaient vraisemblablement des actes de trahison. Les sanctions imposées aux monarques jugés coupables de telles offenses incluaient l'abdication forcée par suicide ou l'exil involontaire (Alabi 2006). Par exemple, selon les archives orales, Daaw Demba, roi Wolof de Sénégambie, aurait été envoyé en exil en 1647 en raison du caractère abusif et répressif de son règne (Mboup 2011 : 77).

Nombreux sont les cas similaires dans l'ensemble des sociétés précoloniales d'Afrique de l'Ouest. Ajayi et Epsie (1965 : 333-34) décrivent les peuples jukun des fleuves Niger et Bénoué comme jouissant d'un équilibre des pouvoirs reposant sur de solides institutions, notamment un Conseil privé dirigé par un abo (Premier ministre) qui, en collaboration avec le Conseil des prêtres, servait à prévenir tout exercice tyrannique du pouvoir par le roi divin. Au Ghana précolonial, le roi du peuple akan présidait un empire extrêmement hiérarchisé dominant la majeure partie du sud du Ghana et des territoires bordant ses frontières à l'est, et son pouvoir était sujet à des limites constitutionnelles. Un conseil d'érudits avait le pouvoir d'examiner des doléances et de destituer le roi s'il était reconnu coupable des charges qui lui étaient reprochées (Prempeh 2015).

Bien que l'étendue géographique du royaume akan et du pouvoir du roi soit bien différente aujourd'hui, ce modèle de gouvernance constitutionnelle, qui persiste également dans le sud du Ghana, a largement survécu (Crook 2005 : 1). Dans certaines communautés précoloniales du Libéria et de la Sierra Leone actuels, le conseil Poro - une société secrète qui appuyait le rôle du chef tout en exerçant une forte influence culturelle, religieuse et politique au sein de la communauté - servait à contrôler l'exercice du pouvoir par le chef (Fulton 1972 : 122; Little 1965 : 349-65, 1966 : 63, 66-72).

Le royaume précolonial du Dahomey (actuel Bénin) avait mis en place un système de contrôle encore plus institutionnalisé, dans lequel les lois émanant du roi ne devenaient juridiquement contraignantes qu'une fois approuvées par un conseil des ministres qui conservait le pouvoir de refuser les lois qu'il jugeait «impolitiques» (Skertchly $1874: 443-44)$. Au XIX ${ }^{\mathrm{e}}$ siècle, le royaume a mis en place une cour d'appel, dans le but de restreindre l'autorité absolue des seigneurs locaux sur les sujets du Dahomey (Monroe 2014 : 101-02). 
Si l'on conçoit le contrôle juridictionnel ou la justice constitutionnelle comme une fonction relevant typiquement des organes judiciaires, en particulier des Cours ou Conseils constitutionnel(le)s et des Cours suprêmes, alors ces exemples correspondent sans doute à l'exercice, dans une certaine mesure, de la justice constitutionnelle ou du contrôle juridictionnel. Toutefois, ce dernier crée un mécanisme institutionnel permettant d'annuler ou de restreindre la portée de certains actes des dépositaires du pouvoir (plutôt que les individus eux-mêmes), sans nécessairement remettre en cause la légitimité de leur pouvoir. On peut donc considérer ces exemples - à l'exception peut-être du Dahomey - davantage comme des modèles de limitation ou de restriction du pouvoir plutôt que comme des systèmes de contrôle constitutionnel ou juridictionnel en soi, étant donné que les sanctions en cas de violation des normes constitutionnelles traditionnelles se limitaient rarement à la violation en question. Cependant, le fait que le mécanisme de limitation ou de restriction d'un tel pouvoir était, d'une part, institutionnalisé et reposait, d'autre part, sur un ordre normatif coutumier préétabli, montre que les États d'Afrique précoloniale avaient intégré les notions de limitation et de séparation des pouvoirs qui préfigurent celle de justice constitutionnelle.

\section{La justice constitutionnelle en Afrique de l'Ouest pendant la colonisation}

Les relations entre l'Europe et l'Afrique - établies à partir des XIVe et $\mathrm{XV}^{\mathrm{e}}$ siècles - ont pris un virage impérialiste en 1884 , lorsque les puissances européennes organisèrent une conférence à Berlin pour se partager le continent. Par conséquent, les systèmes politiques précoloniaux de la région du Soudan occidental sont passés sous le contrôle direct de la France (qui s'est vu accorder la part du lion en échange de concessions dans d'autres domaines), de l'Angleterre, de l'Allemagne et du Portugal. Chacune de ces puissances a cherché à introduire ses propres politiques coloniales en matière de gouvernance, sans nécessairement refléter ou tenir compte des systèmes de gouvernance politique locaux préexistants.

Certaines, comme l'Angleterre, ont adopté une approche indirecte, considérant leurs colonies comme des entités distinctes dont les institutions et les coutumes pouvaient être adaptées et utilisées au service de leurs objectifs coloniaux (Lugard 1922 : 193-229). Au contraire, la France et le Portugal considéraient leurs territoires africains comme des parties intégrantes ou provinces d'outre-mer, que le gouvernement de la métropole se devait d'administrer de la même manière que le territoire principal. Cette politique éphémère de gouvernance directe ou d'assimilation a d'abord cherché à transformer la population autochtone en citoyens français, soumis aux lois françaises. Cette politique s'est ensuite transformée en politique d'association, une forme de 
coexistence distincte dans laquelle les populations locales servaient d'agents de l'administration coloniale, sur le modèle britannique de gouvernance indirecte. En dépit des similitudes entre la politique d'«association» et celle de "gouvernance indirecte», l'approche française impliquait généralement une restructuration plus poussée de l'infrastructure de gouvernance politique précoloniale pour faciliter l'administration des territoires, tandis que les Anglais se montraient moins invasifs (Crowder 1964 : 197-205). Par conséquent, les unités politiques, lois, coutumes et modes de vie autochtones - et, par extension, le système précolonial de justice constitutionnelle - ont été davantage préservés dans les territoires britanniques que dans ceux sous contrôle français (Crowder 1964), pour autant qu'ils passaient le «test de compatibilité». L'Angleterre s'appuyait sur ce test dans ses colonies pour déterminer la validité et l'applicabilité du droit autochtone : les lois et coutumes locales étaient conservées si elles n'entraient pas en conflit avec le «droit naturel, l'équité et la bonne conscience» et n'étaient pas incompatibles avec l'application de la loi anglaise.

Les règles de compatibilité offrent dans une certaine mesure une norme de contrôle similaire à l'examen qui a lieu dans le cadre du contrôle juridictionnel. Toutefois, l'administration coloniale ne souscrivait pas nécessairement aux principes de séparation et d'équilibre des pouvoirs, qui auraient nécessité un organe judiciaire distinct chargé de déterminer les infractions aux normes. Une dépêche de 1891, envoyée par le secrétaire d'État aux Colonies britanniques et adressée à Sir Claude MacDonald, consul général de l'Oil Rivers Protectorate au Nigéria, illustre ce propos. Tout en conseillant au consul général de ne pas s'immiscer outre mesure dans l'administration de la justice locale, la dépêche l'autorisait à "[faire] comprendre aux chefs que leurs pouvoirs seraient retirés en cas de mal gouvernance» et à assurer - $s$ 'il considérait cela comme essentiel au bénéfice des populations autochtones - «les pouvoirs judiciaires et administratifs du chef» (Nwabueze 1982 : 15-16).

Cet exemple suggère que des agents du pouvoir colonial ou d'occupation, au lieu du pouvoir judiciaire ou d'une institution indépendante, étaient chargés de déterminer la compatibilité ou non des lois et coutumes. Cela s'explique en partie par la structure de l'administration coloniale, centralisée et hiérarchisée, avec à sa tête un gouverneur général, déléguant son autorité à des gouverneurs (ou lieutenants-gouverneurs dans les unités coloniales plus modestes) nommés par le pouvoir en métropole. Ces fonctionnaires étrangers exerçaient de nombreuses fonctions législatives et judiciaires. Par exemple, le gouverneur de l'Afrique de l'Ouest britannique était souvent aussi le président du Conseil législatif - en théorie, la branche législative de l'administration coloniale - et pouvait s'opposer à certaines lois, en proclamer d'autres et 
gouverner par décret (Davidson 1992). Le pouvoir judiciaire, également sous contrôle du gouverneur, n'était pas habilité à contrôler ses décisions; son rôle était de servir l'administration coloniale (Prempeh 2006 : 25).

Les Français et Portugais ont adopté une approche similaire de l'administration coloniale en Afrique de l'Ouest. Les colonies françaises étaient dirigées par un ministre des Colonies (basé à Paris) disposant de nombreuses prérogatives, notamment celle de légiférer par décret, et par un gouverneur général (son représentant dans les colonies) disposant de pouvoirs judiciaires «ne pouvant faire l'objet d'aucune forme de recours" (Suret-Canale 1971 : 308, 332). En effet, le gouverneur avait la possibilité d'empêcher des individus souhaitant remettre en cause un acte législatif ou exécutif de l'administration coloniale de saisir les tribunaux coloniaux (Bing 1968 : 221). Kwame Nkrumah, le premier président du Ghana indépendant, déclara dans les années 1950 que "dans un régime colonial, les pouvoirs judiciaire et exécutif ne font qu'un » (Prempeh 2006 : 25). Les responsables ou administrateurs de district servaient d'intermédiaires entre les autorités centrales et locales pour faire appliquer les décrets pris par le ministre des Colonies et le gouverneur général. Cependant, cette relation dépassait celle de simple supérieur à subordonné, étant donné que les responsables ou administrateurs de district exerçaient les fonctions judiciaires et exécutives au niveau local (Bing 1968 : 221).

L'organisation pyramidale et extrêmement centralisée des administrations coloniales a empêché l'émergence d'un système efficace de justice constitutionnelle capable de restreindre et de contrôler les actions exécutives et législatives des autorités coloniales : "l'État colonial était par excellence un État par le droit, et non un État de droit» (Prempeh 2006 : 24; italiques dans l'original). Par conséquent, la période coloniale a été marquée par l'absence de justice constitutionnelle, étant donné qu'aucun mécanisme (juridictionnel ou autre) ne permettait de veiller à ce que les autorités administratives coloniales se conforment à un ordre juridique supérieur. Toutes les approches précoloniales de l'État de droit et de la gouvernance constitutionnelle furent détruites dans les colonies françaises et diluées dans les territoires sous contrôle britannique.

Seules les anciennes colonies portugaises que sont aujourd'hui le Cabo Verde et la Guinée-Bissau disposaient d'une forme de juridiction constitutionnelle. Tandis que les autorités coloniales de ces pays jouissaient de pouvoirs étendus et hautement centralisés comme leurs homologues des colonies françaises et britanniques, certaines de leurs décisions applicables aux colonies étaient soumises à un contrôle du conseil ultra-marin. En vertu de l'article $1^{\text {er }}$ de la loi exécutive $n^{\circ} 49146$ du 25 juillet 1969, le conseil servait, outre d'organe supérieur permanent de conseil du ministre de l'Outre-mer pour les questions politiques et administratives, d'instance chargée des questions de constitutionnalité, de 
tribunal administratif suprême et de tribunal de résolution des conflits de juridictions dans les colonies. Larticle 7 de la loi lui confère explicitement la compétence de décider la constitutionnalité de la législation adoptée par les autorités coloniales. Cependant, étant donné que le ministre de l'Outre-mer (membre de l'exécutif) présidait ce conseil, son impact en tant que véritable instance de justice constitutionnelle reste à débattre.

\section{La justice constitutionnelle en Afrique de l'Ouest contemporaine}

Par opposition aux institutions politiques de l'Afrique de l'Ouest précoloniale (qui développèrent une forme autochtone de justice constitutionnelle fonctionnelle) et de l'Afrique de l'Ouest coloniale (où pratiquement aucune culture de justice constitutionnelle ne s'est développée), l'évolution de la justice constitutionnelle au cours de l'ère postcoloniale se caractérise par une alternance de phases de dormance et de résurgence. Pour comprendre l'évolution de la justice constitutionnelle pendant cette période, il est donc utile de se pencher sur deux périodes distinctes : (a) la période immédiatement après les indépendances (de la fin des années 1960 à la fin des années 1980), période d'émergence ou de résurgence de régimes à parti unique, et (b) la période caractérisée par le rétablissement d'une démocratie multipartite (à partir des années 1990).

\section{L'après-indépendance : 1960-1989}

La fin de la Seconde Guerre mondiale et l'émergence d'un nouveau système international sous les auspices des Nations Unies, dont la charte fondatrice embrasse le principe de l'autodétermination des territoires assujettis, portèrent un coup fatal à l'entreprise coloniale. Le colonialisme fut dénoncé et largement discrédité. Encouragés par l'ordre international émergent, les mouvements anticolonialistes, qui bénéficiaient d'un vaste soutien dans et à l'extérieur des colonies, luttèrent contre la colonisation et menèrent les colonies vers l'indépendance. Dans les années 1970, de nombreuses anciennes colonies ouest-africaines - à commencer par le Ghana en 1957- devinrent des États souverains avec de nouvelles constitutions établissant des gouvernements autochtones indépendants. Si ces constitutions furent significativement modifiées au cours de la décennie suivant les indépendances, la plupart d'entre elles mirent en place des systèmes politiques inspirés de ceux de l'Occident en particulier des anciennes puissances coloniales.

Par conséquent, ces systèmes politiques avaient pour trait commun l'existence d'un pouvoir judiciaire chargé de rendre la justice. Ces fonctions incluaient, 
dans certains cas, tant la justice constitutionnelle et la promotion $\mathrm{du}$ constitutionnalisme que la protection des droits humains et de l'État de droit, quoique de nombreux chercheurs remettent en cause le rôle du pouvoir judiciaire sur ce dernier point (Odinkalu 1996 : 124; Nwabueze 1977 : 30 ; Seidman $1974: 827)$.

Les mécanismes institutionnels mis en place pour assurer le contrôle juridictionnel dans de nombreuses constitutions effectives entre 1960 et 1989 varient en fonction de la puissance coloniale qui avait le contrôle du territoire. En Afrique francophone et anglophone, le pouvoir d'interpréter la Constitution ou de confirmer (ou non) la conformité des normes de catégorie inférieure vis-à-vis de la loi suprême était généralement confié à une ou plusieurs juridictions supérieures, qui exerçaient également la compétence en appel pour les autres questions de droit commun soulevées par les instances inférieures ${ }^{5}$. Par exemple, lors de l'indépendance et durant la plus grande partie de la période allant jusqu'en 1990, en Afrique de l'Ouest francophone, seuls les juges constitutionnels de la Cour suprême, située au sommet de la hiérarchie judiciaire dans les nouveaux États, jouissaient de cette autorité ${ }^{6}$.

Les pays de common law (essentiellement anglo-saxons) ont adopté des dispositions similaires ${ }^{7}$. Dans la plupart de ces juridictions - par exemple en Gambie (1970, article 93[1]), au Ghana et en Sierra Leone (1978, article 105) -, seule la Cour suprême avait compétence pour les questions relatives à la Constitution ${ }^{8}$. Dans d'autres, comme le Nigéria, tant la Cour suprême que le tribunal de grande instance (High Court) (ou parfois la Cour d'appel) disposaient

Contrairement à l'Afrique francophone, où les juridictions supérieures consistaient normalement uniquement d'une cour suprême et d'une cour d'appel, en Afrique de l'Ouest de tradition de common law, il existait également un tribunal de grande instance (High Court).

6 Les cours suprêmes étaient généralement composées de plusieurs sections spécialisées dans différents domaines juridiques. Ainsi, outre la section constitutionnelle, elles comprenaient aussi souvent des sections administrative, civile et pénale.

7 Jusqu'à l'abolition de nombreux régimes parlementaires au profit d'un régime présidentiel à parti unique, peu de temps après l'indépendance, au milieu des années 1960, la Cour d'appel ouestafricaine et le comité judiciaire du conseil privé (Privy Council), dans cet ordre, étaient compétents en dernier ressort pour toutes les affaires judiciaires y compris - probablement - les questions de constitutionnalité.

8 Les articles 42 (2), 106 (1) et 118 (1) des constitutions du Ghana (1960, 1969 et 1979 respectivement), confiaient la responsabilité du contrôle juridictionnel à la Cour suprême. Ce contrôle a été interrompu au Ghana en 1972 et 1981, lorsque l'armée a suspendu les constitutions de 1969 et 1979 respectivement. 
de cette prérogative ${ }^{9}$. Le Libéria constituait peut-être la seule exception. Contrairement à sa Constitution de 1847 (article 4) - qui, suivant le modèle américain qui l'inspirait, ne légiférait pas explicitement sur la compétence relative au contrôle juridictionnel - les articles 2 et 66 de la Constitution de 1987, lus ensemble, disposent : «La Cour suprême, en vertu de son pouvoir de contrôle juridictionnel, peut déclarer inconstitutionnelle toute loi incompatible avec la Constitution [et] sera le juge en dernier ressort des questions de constitutionnalité.» Cette formulation suggère un modèle plus diffus de type américain que dans les autres juridictions ouest-africaines inspirées de la common law. De fait, la Cour suprême libérienne a confirmé cette position dans sa jurisprudence en réinterprétant le terme "définitif» (voir chapitre 3).

En Afrique de l'Ouest lusophone, cependant, il serait erroné de parler d'un contrôle « juridictionnel », car aucune instance judiciaire n'était impliquée. Les constitutions du Cabo Verde (1980, article 62) et de la Guinée-Bissau (1984, article 98) autorisent toutes deux un contrôle parlementaire "de principe» de la constitutionnalité des lois ${ }^{10}$.

Les constitutions du Ghana (1979, article 35 [1]) et de la Sierra Leone (1978, article 18) confiaient initialement la compétence aux tribunaux de grande instance - les recours en appel passant de ces derniers aux deux autres Cours supérieures - pour juger des violations des droits humains garantis par la Constitution. L'Afrique de l'Ouest francophone et lusophone, pour sa part, ne confiait pas cette responsabilité à la section constitutionnelle des Cours suprêmes ou des autres institutions spécialisées. Il y a deux explications possibles à cela. L'une est la valeur constitutionnelle différente attachée aux droits humains dans les différents systèmes. Dans les systèmes de common law de l'Afrique de l'Ouest anglophone, par exemple, tous les pays étudiés ont accordé un statut constitutionnel aux droits fondamentaux en incluant des chartes des droits (Bill of Rights) détaillées dans les constitutions adoptées ou révisées durant cette période : Gambie (1970), Ghana (1969, 1979), Libéria (1987), Nigéria (1963 et 1979) et Sierra Leone (1978).

$9 \quad$ Voir par exemple les articles 115-19 et 125 (1c-d) de la Constitution du Nigéria (1963) portant sur les compétences du Tribunal fédéral de grande instance (Federal High Court) et de la Cour suprême en matière de constitutionnalité; l'article 4 (1-2) de la Constitution de 1979 sur la compétence spéciale du Tribunal de grande instance (High Court) dans l'application de la Charte des droits (Bill of Rights); et les articles 213 et 220 concernant la compétence exclusive de la Cour suprême et de la Cour d'appel en matière d'interprétation de la constitution.

10 Ce type de contrôle de constitutionnalité n'est pas totalement inédit. Au plus fort de l'hostilité de la classe politique française à l'égard des tribunaux après la chute de l'Ancien Régime, cette forme de contrôle de constitutionnalité a été établie par les constitutions françaises de 1799 et 1855 . Cuba, en tout cas dans sa constitution de 1976, et l'Éthiopie ont également testé (ou conservent) ce système de contrôle de constitutionnalité. 
Au contraire, des 11 pays lusophones ou francophones étudiés, seule une poignée de constitutions de cette période tenaient compte de manière exhaustive des droits humains, notamment le Cabo Verde (1980, articles 2244), la Guinée-Bissau (1984, articles 24-45), le Sénégal (1960 et 1963, Titre II), le Togo (1963, Titre II) et la Guinée-Conakry (1982, Titre II). Les autres confiaient au Parlement la tâche de légiférer sur la question, ignoraient celle-ci totalement ou bien incluaient des références d’ordre général aux conventions internationales sur les droits humains : Côte d'Ivoire (1960, article 41), Mauritanie (1960, article 33 modifié jusqu'en 1985). La seconde explication possible aux différences d'approche entre pays anglophones et francophones/lusophones tient au fait que les plaintes en matière de droits humains étaient traitées par les tribunaux ordinaires, et ce n'est que par la suite que ces systèmes, reconnaissant l'importance de ces plaintes, ont veillé à ce que les citoyens puissent directement saisir des instances spécialisées de la justice constitutionnelle.

\section{Des années 1990 à nos jours}

L'évolution historique de la justice constitutionnelle en Afrique de l'Ouest a connu une nouvelle phase de transformation lors des changements politiques à l'œuvre sur tout le continent dans les années 1990. Cela a été particulièrement flagrant dans les pays francophones, où des constitutions révisées ou entièrement nouvelles ont radicalement transformé l'architecture institutionnelle existante en matière de justice constitutionnelle. Le principe de l'unité de juridiction, qui a caractérisé la décennie précédente, a largement cédé le pas au principe de dualisme des ordres juridictionnels. Par conséquent, la justice ordinaire, qui exerçait sa compétence en matière de justice constitutionnelle en vertu de l'autorité exclusive de la Cour suprême (section constitutionnelle) dans ce domaine, a perdu cette responsabilité. À sa place, des instances spécialisées sur le modèle kelsénien - désignées de manière variable comme cour ou conseil constitutionnel(le) - ont vu le jour, dotées de la compétence exclusive en matière de constitutionnalité. Pour Ngenge (2013 : 445), le développement de cours constitutionnelles spécialisées dans ce contexte était une réaction à l'autoritarisme de l'État africain postcolonial, comme l'a été en Europe la montée en puissance des tribunaux constitutionnels après la Seconde Guerre mondiale. Le Cabo Verde et la Guinée-Bissau lusophones ont également remplacé le contrôle de constitutionnalité parlementaire par un organe judiciaire. Tandis que la Guinée-Bissau a maintenu la section constitutionnelle au sein de la Cour suprême, un modèle courant dans la décennie suivant les indépendances dans les pays francophones, le Cabo Verde a opté pour le modèle kelsénien centralisé de cour constitutionnelle. Les pays anglophones de common law 
ont en grande partie conservé ou rétabli l'architecture institutionnelle de justice constitutionnelle développée avant 1989. Par conséquent, les instances supérieures - le tribunal de grande instance, la Cour d'appel et la Cour suprême - ont continué à exercer différents niveaux de compétence dans le domaine du contrôle de constitutionnalité et dans la résolution des litiges y afférents ${ }^{11}$.

Le présent chapitre a démontré que la notion de justice constitutionnelle n'était pas entièrement étrangère à l'Afrique de l'Ouest à la veille de la colonisation occidentale. Comme l'illustre le tableau $\mathrm{n}^{\circ} 2$, de nombreux pays avaient développé des formes traditionnelles de contrôle de la conformité aux principes informels des normes fondamentales traditionnelles. La colonisation occidentale a largement modifié ces systèmes, notamment en termes de structures institutionnelles. Le cadre institutionnel de l'Afrique contemporaine est en grande partie le résultat de l'influence occidentale et est radicalement différent de l'architecture qui existait en matière de justice constitutionnelle juste avant le découpage du continent. Cependant, les valeurs et idéaux qui sous-tendent la notion de justice constitutionnelle - l'État de droit et le respect d'un ordre juridique supérieur - sont intrinsèquement restés les mêmes.

Il est par ailleurs important de noter qu'il existe des différences non seulement entre les différentes périodes (précoloniale, coloniale et postcoloniale), mais également au sein de ces périodes. Par exemple, au-delà des changements dans la structure institutionnelle en Afrique francophone dans les années 1990, des modifications opérationnelles et fonctionnelles importantes ont aussi touché les nouvelles institutions. Le chapitre 8 décrit comment l'application et la protection des droits fondamentaux sont devenues des éléments centraux du mandat des nouveaux conseils/cours constitutionnel(le)s dans la région. De la même manière, les règles d'accès à ces institutions (chapitre 9) ont été élargies dans la plupart des juridictions, facilitant la saisine de ces instances par des personnes privées ou d'autres acteurs non étatiques.

11 Voir en général les constitutions de la Gambie (1997), du Ghana (1992), du Nigéria (1999) et de la Sierra Leone (1991). 


\section{Tableau 2.1. L'évolution historique des systèmes de justice constitutionnelle en Afrique}

\begin{tabular}{|c|c|c|c|}
\hline Période & Pays/communauté & $\begin{array}{l}\text { Instance chargée } \\
\text { de la justice } \\
\text { constitutionnelle } \\
\text { (ou cadre similaire) }\end{array}$ & Fonctions \\
\hline \multirow{8}{*}{$\begin{array}{l}\text { Afrique } \\
\text { de l'Ouest } \\
\text { précoloniale } \\
\text { (avant 1800) }\end{array}$} & \multirow[t]{2}{*}{$\begin{array}{l}\text { Nigéria (pays yoruba) } \\
\text { Ogboni (société secrète) }\end{array}$} & $\begin{array}{l}\text { Oyo Mesi (Conseil des } \\
\text { chefs) }\end{array}$ & $\begin{array}{l}\text { Première ligne de défense contre } \\
\text { le despotisme royal; gardiens de } \\
\text { la Constitution ou des lois du pays }\end{array}$ \\
\hline & & $\begin{array}{l}\text { Contrôle du roi (oba/ } \\
\text { alafin) et de l'Oyo } \\
\text { Mesi; examine } \\
\text { et sanctionne les } \\
\text { violations. }\end{array}$ & \\
\hline & $\begin{array}{l}\text { Niger-Bénoué (royaume Jukun) } \\
\text { Conseil des prêtres Juju }\end{array}$ & $\begin{array}{l}\text { Conseil privé dirigé } \\
\text { par un abo (Premier } \\
\text { ministre) }\end{array}$ & $\begin{array}{l}\text { Tient l'aku (roi divin) responsable } \\
\text { de ses actes et veille à leur } \\
\text { conformité à l'égard de la } \\
\text { coutume }\end{array}$ \\
\hline & Sénégambie (royaume Wolof) & $\begin{array}{l}\text { Conseil traditionnel } \\
\text { des notables } \\
\text { (kingmakers) }\end{array}$ & $\begin{array}{l}\text { Garant des libertés publiques; } \\
\text { examine et sanctionne les } \\
\text { violations. }\end{array}$ \\
\hline & Ghana (Akan) & $\begin{array}{l}\text { Conseil traditionnel } \\
\text { des notables } \\
\text { (kingmakers) }\end{array}$ & $\begin{array}{l}\text { Garant des libertés publiques; } \\
\text { examine et sanctionne les } \\
\text { violations. }\end{array}$ \\
\hline & \multirow[t]{2}{*}{$\begin{array}{l}\text { Bénin (Dahomey) } \\
\text { Cour d'appel }\end{array}$} & Conseil des ministres & $\begin{array}{l}\text { Examine et valide les édits } \\
\text { royaux }\end{array}$ \\
\hline & & $\begin{array}{l}\text { Agit comme } \\
\text { contre-pouvoir à } \\
\text { l'autorité absolue des } \\
\text { seigneurs et vassaux } \\
\text { locaux }\end{array}$ & \\
\hline & Sierra Leone/Libéria (Kpelle) & Poro (société secrète) & $\begin{array}{l}\text { Contre-pouvoir, légitimise les } \\
\text { pouvoirs du chef (lai-kalon) }\end{array}$ \\
\hline \multirow[t]{2}{*}{$\begin{array}{l}\text { Afrique } \\
\text { de l'Ouest } \\
\text { coloniale } \\
\text { (1884-1970) }\end{array}$} & $\begin{array}{l}\text { Colonies britanniques et } \\
\text { françaises }\end{array}$ & $\begin{array}{l}\text { Pas d'institution } \\
\text { distincte : ces } \\
\text { fonctions étaient } \\
\text { assurées par le chef } \\
\text { de l'administration } \\
\text { coloniale, le } \\
\text { gouverneur général } \\
\text { et ses subordonnés } \\
\text { au sein de l'exécutif } \\
\text { colonial commun }\end{array}$ & $\begin{array}{l}\text { Rend la justice; évalue la } \\
\text { compatibilité ou non (colonies } \\
\text { britanniques) des lois locales } \\
\text { avec la conception britannique } \\
\text { du droit }\end{array}$ \\
\hline & Colonies portugaises & $\begin{array}{l}\text { Conseil de I'Outremer } \\
\text { (Conselho } \\
\text { Ultramarino) }\end{array}$ & $\begin{array}{l}\text { Détermine la constitutionnalité } \\
\text { de la législation et des actes } \\
\text { adoptés par le gouvernement } \\
\text { colonial. }\end{array}$ \\
\hline
\end{tabular}




\begin{tabular}{|c|c|c|c|c|}
\hline \multicolumn{5}{|c|}{ Afrique de l'Ouest postcoloniale (des années 1960 à nos jours) } \\
\hline \multirow[t]{10}{*}{ (i) 1960-1989 } & \multirow[t]{8}{*}{$\begin{array}{l}\text { Afrique } \\
\text { de l'Ouest } \\
\text { anglophone }\end{array}$} & Gambie & Cour suprême & $\begin{array}{l}\text { Interprétation et contrôle de } \\
\text { constitutionnalité; applique le Bill } \\
\text { of Rights (Charte des droits) }\end{array}$ \\
\hline & & \multirow[t]{2}{*}{ Ghana } & Cour suprême & $\begin{array}{l}\text { Interprétation et contrôle de } \\
\text { constitutionnalité }\end{array}$ \\
\hline & & & $\begin{array}{l}\text { Tribunal de grande } \\
\text { instance (High Court) }\end{array}$ & $\begin{array}{l}\text { Tranche les plaintes liées au Bill } \\
\text { of Rights constitutionnel }\end{array}$ \\
\hline & & Libéria & $\begin{array}{l}\text { Toutes les instances } \\
\text { du système judiciaire }\end{array}$ & $\begin{array}{l}\text { Interprétation et contrôle de } \\
\text { constitutionnalité }\end{array}$ \\
\hline & & \multirow[t]{2}{*}{ Nigéria } & $\begin{array}{l}\text { Cour suprême, Cour } \\
\text { d'appel }\end{array}$ & $\begin{array}{l}\text { Interprétation et contrôle de } \\
\text { constitutionnalité }\end{array}$ \\
\hline & & & $\begin{array}{l}\text { Tribunal de grande } \\
\text { instance (High Court) }\end{array}$ & $\begin{array}{l}\text { Tranche les plaintes liées au Bill } \\
\text { of Rights constitutionnel }\end{array}$ \\
\hline & & \multirow[t]{2}{*}{ Sierra Leone } & Cour suprême & $\begin{array}{l}\text { Interprétation et contrôle de } \\
\text { constitutionnalité }\end{array}$ \\
\hline & & & $\begin{array}{l}\text { Tribunal de grande } \\
\text { instance (High Court) }\end{array}$ & $\begin{array}{l}\text { Tranche les plaintes liées au Bill } \\
\text { of Rights constitutionnel }\end{array}$ \\
\hline & \multicolumn{2}{|c|}{$\begin{array}{l}\text { Afrique de l'Ouest } \\
\text { francophone }\end{array}$} & Cour suprême & $\begin{array}{l}\text { Interprétation et contrôle de } \\
\text { constitutionnalité }\end{array}$ \\
\hline & \multicolumn{2}{|c|}{ Afrique de l'Ouest lusophone } & Parlement & $\begin{array}{l}\text { Interprétation et contrôle de } \\
\text { constitutionnalité }\end{array}$ \\
\hline \multirow[t]{5}{*}{$\begin{array}{l}\text { (i) } 1990- \\
\text { présent }\end{array}$} & \multicolumn{2}{|c|}{$\begin{array}{l}\text { Afrique de l'Ouest } \\
\text { anglophone }\end{array}$} & $\begin{array}{l}\text { Comme ci-dessus } \\
\text { sauf pour la Gambie : } \\
\text { sa Constitution de } \\
1997 \text { transferre la } \\
\text { compétence relative } \\
\text { au Bill of Rights de } \\
\text { la Cour suprême au } \\
\text { Tribunal de grande } \\
\text { instance }\end{array}$ & $\begin{array}{l}\text { Comme ci-dessus sauf pour } \\
\text { la Gambie : sa constitution de } \\
1997 \text { transfère la compétence } \\
\text { relative au Bill of Rights de la Cour } \\
\text { suprême au tribunal de grande } \\
\text { instance }\end{array}$ \\
\hline & \multirow[t]{2}{*}{$\begin{array}{l}\text { Afrique } \\
\text { de l'Ouest } \\
\text { francophone }\end{array}$} & $\begin{array}{l}\text { Bénin, } \\
\text { Guinée, } \\
\text { Mali, Niger, } \\
\text { Togo }\end{array}$ & $\begin{array}{l}\text { Cour } \\
\text { constitutionnelle }\end{array}$ & $\begin{array}{l}\text { Interprétation et contrôle de } \\
\text { constitutionnalité; applique le Bill } \\
\text { of Rights }\end{array}$ \\
\hline & & $\begin{array}{l}\text { Burkina } \\
\text { Faso, Côte } \\
\text { d'llvoire, } \\
\text { Mauritanie, } \\
\text { Sénégal }\end{array}$ & $\begin{array}{l}\text { Conseil } \\
\text { constitutionnel }\end{array}$ & $\begin{array}{l}\text { Interprétation et contrôle de } \\
\text { constitutionnalité; applique le Bill } \\
\text { of Rights }\end{array}$ \\
\hline & \multirow{2}{*}{$\begin{array}{l}\text { Afrique } \\
\text { de l'Ouest } \\
\text { lusophone }\end{array}$} & Cabo Verde & $\begin{array}{l}\text { Cour } \\
\text { constitutionnelle }\end{array}$ & $\begin{array}{l}\text { Interprétation et contrôle de } \\
\text { constitutionnalité }\end{array}$ \\
\hline & & $\begin{array}{l}\text { Guinée- } \\
\text { Bissau }\end{array}$ & Cour suprême & $\begin{array}{l}\text { Interprétation et contrôle de } \\
\text { constitutionnalité }\end{array}$ \\
\hline
\end{tabular}


3. Les modèles

institutionnels

de justice

constitutionnelle

en Afrique

de l'Ouest

contemporaine

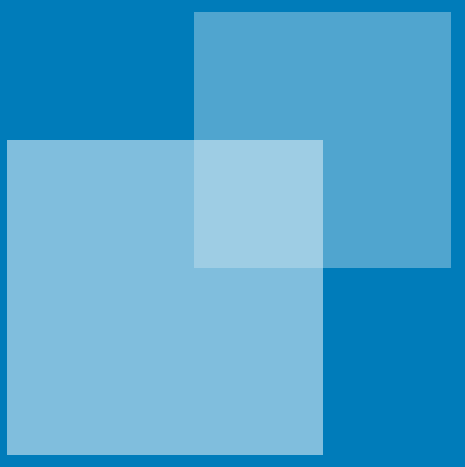




\title{
3. Les modèles institutionnels de justice constitutionnelle en Afrique de l'Ouest contemporaine
}

\author{
Yuhniwo Ngenge
}

Dans le précédent chapitre, nous avons examiné l'évolution historique de la justice constitutionnelle en Afrique de l'Ouest en détaillant les systèmes de justice - constitutionnelle ou similaire - en place avant la colonisation. Cependant, les fameux propos du juge Marshall, président de la Cour suprême américaine, dans le cadre de l'affaire Marbury v. Madison en 1803 selon lesquels «l'interprétation des lois est sans conteste l'apanage et le devoir du pouvoir judiciaire» - restent la pierre angulaire sur laquelle se sont ensuite fondées les approches contemporaines de la justice constitutionnelle. Le contrôle de constitutionnalité n’a vu le jour en Europe qu'à partir de 1920 177 ans après l'affaire Marbury. Le présent chapitre se penche sur les modèles actuels de justice constitutionnelle dans les 16 pays d'Afrique de l'Ouest étudiés. Tout d'abord, il donne un aperçu des différentes approches actuelles du contrôle de constitutionnalité. Il explore ensuite le type de structures institutionnelles chargées de la justice constitutionnelle dans les différents systèmes de l'Afrique de l'Ouest francophone, lusophone et anglophone.

\section{Les types de juridictions compétentes en matière de contrôle de constitutionnalité}

Lanalyse des systèmes de justice constitutionnelle du point de vue de leur architecture institutionnelle permet de classer celle-ci en deux catégories, selon que le contrôle de constitutionnalité prend une forme juridictionnelle ou politique. Dans le premier cas, un ensemble d'institutions judiciaires est responsable du contrôle de constitutionnalité, tandis que dans le second, ce sont les institutions politiques qui assurent cette charge.

\section{Les modèles juridictionnels}

Il est possible d'opérer d'autres sous-distinctions au sein de ce modèle, en fonction du degré de concentration du contrôle effectué soit de manière diffuse par différents types de juridictions, soit par une instance centrale, ou encore en associant ces deux possibilités. 


\section{Le modèle diffus (Cour suprême)}

Également désigné sous les termes de modèle américain, décentralisé ou déconcentré, le signe distinctif de ce type de contrôle est la multiplicité des juridictions, à différents niveaux, impliquées dans le processus de contrôle de constitutionnalité. On le rencontre généralement dans les pays de common law ou de tradition juridique anglo-américaine. Ces juridictions sont des institutions de la justice ordinaire et le contrôle de constitutionnalité ne constitue qu'une partie de leurs fonctions. Une Cour suprême ou de cassation se situe à la tête de ce système et est chargée des renvois en appel (y compris pour les questions de constitutionnalité) émanant des autres organes du système judiciaire. Au sein de ce sous-modèle de Cour suprême, l'on peut aussi distinguer les variantes décentralisée (américaine) et centralisée (ghanéenne). Le modèle centralisé de Cour suprême était également courant dans de nombreux pays d'Afrique francophone au moment de leur indépendance et avant l'émergence de Cours ou Conseils constitutionnel(le)s spécialisés dans les années 1990.

\section{Le modèle concentré}

Ce modèle, également qualifié de modèle centralisé, est une invention européenne et est généralement associé aux pays de tradition juridique de civil law. Sa principale caractéristique est la concentration de la fonction de contrôle de constitutionnalité au sein d'une seule institution spécialisée - une Cour ou un Conseil constitutionnel(le), souvent située en dehors de l'appareil judiciaire ordinaire. Ce modèle a été développé tardivement : la Constitution autrichienne a établi la première Cour constitutionnelle en 1920. Hans Kelsen, juriste autrichien et principal auteur de cette Constitution, défendait une alternative à l'approche américaine qui, selon lui, en confiant à différents tribunaux le pouvoir de contrôler la constitutionnalité des lois, manquait de prévisibilité et ne permettait pas de promouvoir l'unité et l'uniformité du droit, résultant en une incertitude juridique (Kelsen 1928 : 197-257). Il affirmait que puisque le pouvoir judiciaire en Europe était assujetti à d'autres branches du pouvoir, une institution indépendante était nécessaire pour assurer un contrôle effectif de l'action gouvernementale.

\section{Le modèle hybride}

Le modèle hybride, qui prévaut en Amérique latine, a deux caractéristiques principales qui reflètent certains aspects tirés à la fois du modèle centralisé et du modèle diffus (Navia et Rios-Figueroa 2005 : 191). L'une est l'existence d'une chambre spécialisée faisant partie de l'ordre juridictionnel ordinaire avec compétence exclusive pour le contrôle de constitutionnalité, en 
particulier au sein de la Cour suprême. La seconde est que les tribunaux ordinaires peuvent examiner et refuser d'appliquer une législation considérée comme inconstitutionnelle, comme leurs homologues du système de contrôle décentralisé. Cependant, comme ils n’ont pas le pouvoir de déclarer la loi invalide ou inconstitutionnelle, l'effet de leur décision se limite aux parties impliquées dans le litige en question. Le pouvoir d'annuler une loi est détenu principalement par une seule instance - généralement une Cour suprême, ou dans les systèmes de contrôle centralisé, une Cour ou un Conseil constitutionnel(le).

Le projet d'étude comparée des constitutions (Comparative Constitutions Project), qui a développé un ensemble de données historiques couvrant plusieurs pays et portant sur toutes les constitutions écrites adoptées depuis 1789, a constaté que, en 2013, 154 pays avaient adopté le modèle juridictionnel de contrôle de constitutionnalité (Ginsburg 2014). Environ 10 \% d'entre eux, comme l'illustre la figure 3.1, se situent en Afrique de l'Ouest. Sur ce total, $34 \%$ (52 pays) ont un système décentralisé ou de Cour suprême, $61 \%$ (94 pays) utilisent un modèle de Cour/Conseil constitutionnel(le) et $5 \%$ (huit pays) ont adopté un système hybride (Ginsburg 2014).

Figure 3.1. L'Afrique de l'Ouest dans la répartition mondiale des modèles de contrôle de constitutionnalité par voie juridictionnelle

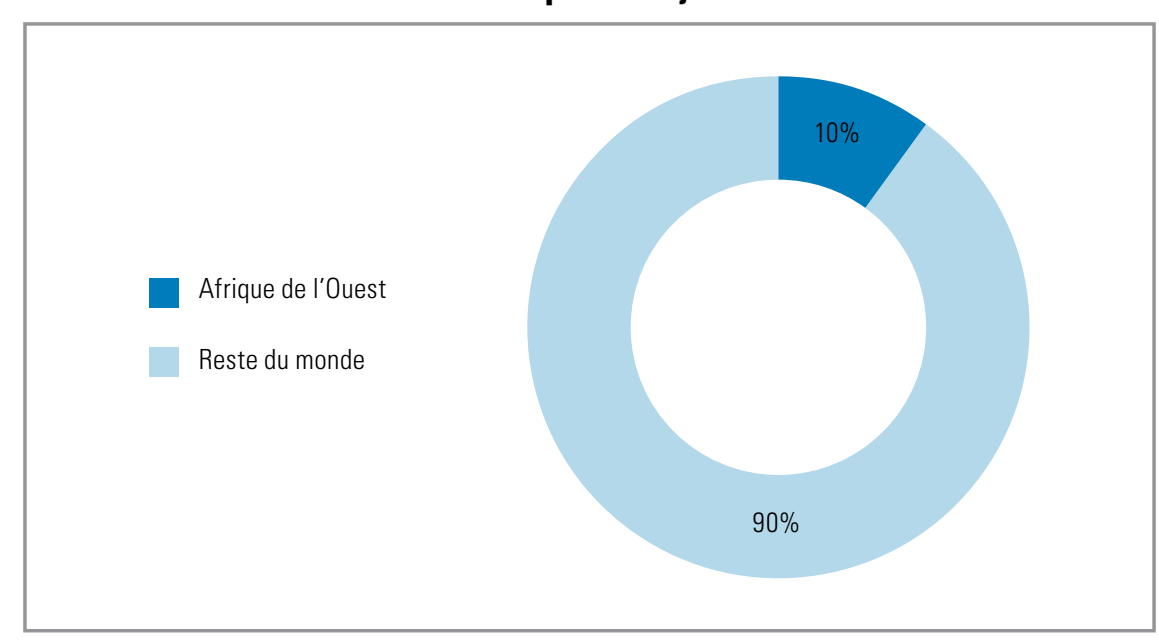




\section{Les modèles politiques}

Moins courant de nos jours, le modèle politique confie l'autorité suprême en matière de contrôle de constitutionnalité aux institutions politiques (telles que le parlement ou un organe au sein de celui-ci [parfois quasi juridictionnel]), plutôt quaux instances judiciaires. Les pays qui utilisent ce modèle ou ses variantes incluent la Chine (2004, article 67), Cuba (2002, article 75), l'Éthiopie (1994, articles 83-84) et la Finlande (2011, article 74). Ailleurs en Europe, les tribunaux britanniques ne peuvent mettre de côté une loi dûment adoptée par le Parlement, tandis que l'article 120 de la Constitution néerlandaise interdit aux tribunaux de contrôler la constitutionnalité des lois en raison du principe de primauté parlementaire, qui donne aux Parlements de ces deux pays la souveraineté absolue sur l'ensemble des autres organes. Par conséquent, aucune institution ne peut contrôler leurs actions. Étant donné que des institutions politiques plutôt que judiciaires sont responsables de ce processus, il est plus adéquat de le considérer comme un contrôle de nature politique.

\section{Les juridictions compétentes en matière de justice constitutionnelle en Afrique de l'Ouest contemporaine}

Comme le montre la figure 3.1, l'Afrique de l'Ouest contemporaine représente $10 \%$ de la répartition mondiale des systèmes reposant sur un modèle de contrôle de constitutionnalité par voie juridictionnelle. Les 16 pays del'Afrique de l'Ouest étudiés ici en font partie et se classent en trois catégories distinctes. La première, celle du contrôle centralisé, compte 10 pays - principalement de civil law - qui ont adopté une instance de type kelsénien sous la forme d'une Cour ou d'un Conseil constitutionnel. La seconde, celle des tenants du contrôle décentralisé, comprend deux pays ayant adopté le modèle américain, et les quatre pays restants (tant de common law que de civil law) utilisent un modèle centralisé de Cour suprême (figure 3.2). 
Figure 3.2. Répartition des modèles de contrôle de constitutionnalité par voie juridictionnelle en Afrique de l'Ouest

Contrôle centralisé

(tous des pays de civil law)

Contrôle décentralisé

(pays de common law)

Autre

(pays de common law ou de civil law

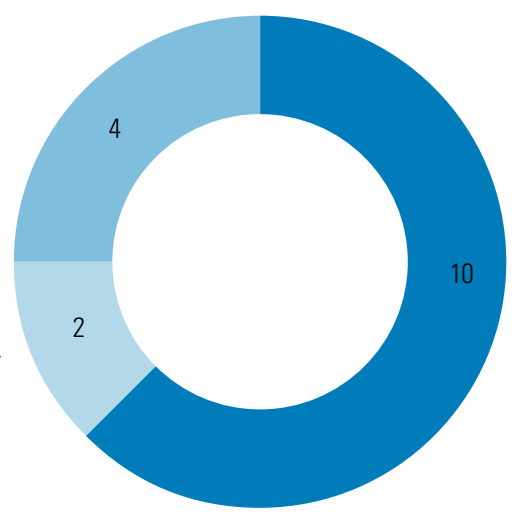

\section{Les pays ayant adopté des juridictions de type kelsénien}

Dix pays de la sous-région ont établi une institution chargée du contrôle de constitutionnalité sur le modèle kelsénien. À l'exception du Cabo Verde, pays lusophone, il s'agit de pays d'Afrique de l'Ouest francophone - le Bénin, le Burkina Faso, la Guinée, la Côte d'Ivoire, le Mali, la Mauritanie, le Niger, le Sénégal et le Togo. Au Bénin, au Cabo Verde, en Guinée, au Mali, au Niger et au Togo, il s'agit de Cours constitutionnelles, tandis qu'au Burkina Faso, en Côte d'Ivoire, en Mauritanie et au Sénégal ce sont des Conseils constitutionnels (figure 3.3). 
Figure 3.3. Répartition des juridictions de type kelsénien en Afrique de l'Ouest

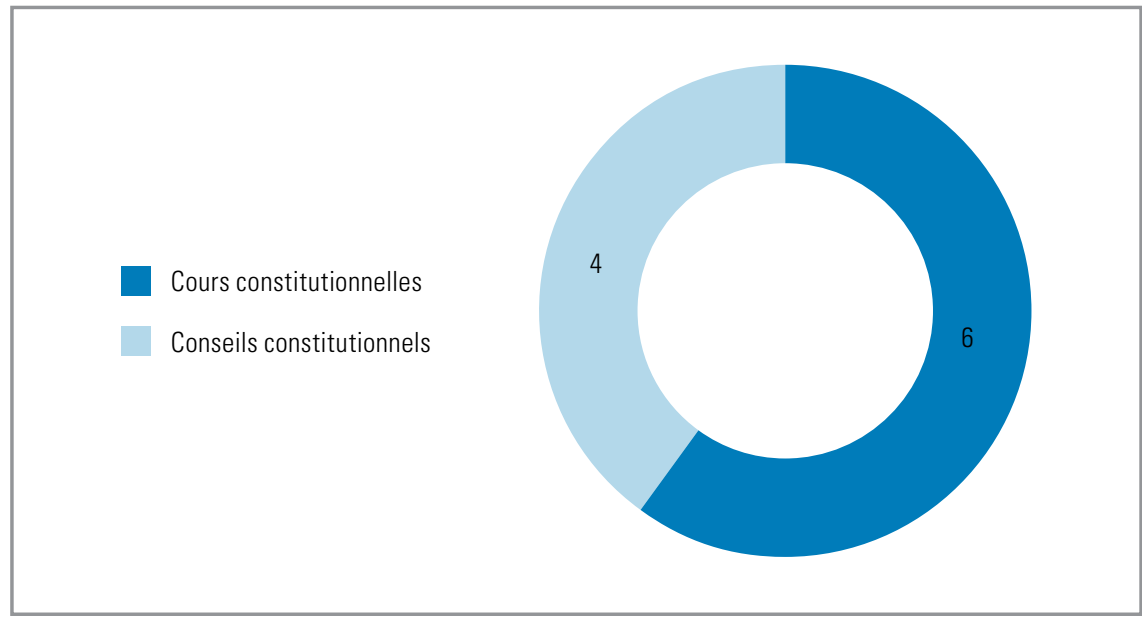

Le degré d'intégration de ces instances dans le reste du système judiciaire est fonction de la "pureté" à l'égard du modèle kelsénien (centralisé). À proprement parler, les instances chargées du contrôle de constitutionnalité dans le modèle kelsénien doivent remplir trois critères cumulatifs. Tout d'abord, l'institution doit être un organe distinct et indépendant de l'appareil juridictionnel ordinaire. Ensuite, elle doit se spécialiser uniquement dans le contentieux constitutionnel et ne partager cette compétence avec aucune autre instance judiciaire. Enfin, les décisions de l'institution doivent être définitives (pas de recours en appel) et contraignantes pour l'ensemble du régime politique (et non uniquement pour les parties à l'affaire).

Dans sept des dix pays de type kelsénien étudiés, les instances chargées du contrôle de constitutionnalité peuvent être considérées comme suivant le modèle pur - au Bénin, au Burkina Faso, en Côte d'Ivoire, en Guinée, au Mali, en Mauritanie et au Togo. Les autres - le Cabo Verde, le Niger et le Sénégal - soit ne jouissent pas du monopole de compétence, soit situent ces instances au sein (et au sommet) de l'ordre juridictionnel ordinaire (voir figure 3.4).

Au Cabo Verde, la Cour constitutionnelle est indépendante du reste du système judiciaire ordinaire dans la mesure où elle ne fait pas partie du "pouvoir judiciaire»; sa compétence exclusive en matière de contrôle de constitutionnalité est limitée aux cas de contrôle abstrait (article 278). La formulation de l'article 281 (1-2) de la Constitution - «sera déféré en appel 
à la Cour constitutionnelle " - laisse penser que sa compétence en matière de contrôle concret intervient en appel et en dernier ressort, mais n'est pas nécessairement exclusive. Cette approche semble s'inspirer du Portugal, le seul autre système de Cour constitutionnelle à utiliser le modèle américain pour le contrôle concret $a$ posteriori et le modèle européen pour le contrôle abstrait.

À l'inverse, la Cour constitutionnelle du Niger et le Conseil constitutionnel du Sénégal ont compétence exclusive pour les litiges de nature constitutionnelle, mais ils ne sont pas indépendants du reste du système judiciaire ordinaire étant donné que, d'un point de vue constitutionnel, ils font partie intégrante de l'appareil judiciaire. Le titre VI de la Constitution du Niger (2010) dispose que : «Le pouvoir judiciaire est exercé par la Cour constitutionnelle, la Cour de cassation, [...] les cours et tribunaux». C'est le cas également au Sénégal, où le titre VIII de la Constitution (2001) s'ouvre sur une disposition prévoyant que : «Le pouvoir judiciaire [...] est exercé par le Conseil constitutionnel, la Cour suprême, la Cour des comptes et les cours et tribunaux». Techniquement, il est donc peut-être plus adéquat de considérer le Niger et le Sénégal comme des institutions à compétence spécialisée au sein du système judiciaire global que comme des entités distinctes existant hors de ce dernier.

\section{Figure 3.4. Modèles purs et modifiés de juridictions de type kelsénien en} Afrique de l'Ouest

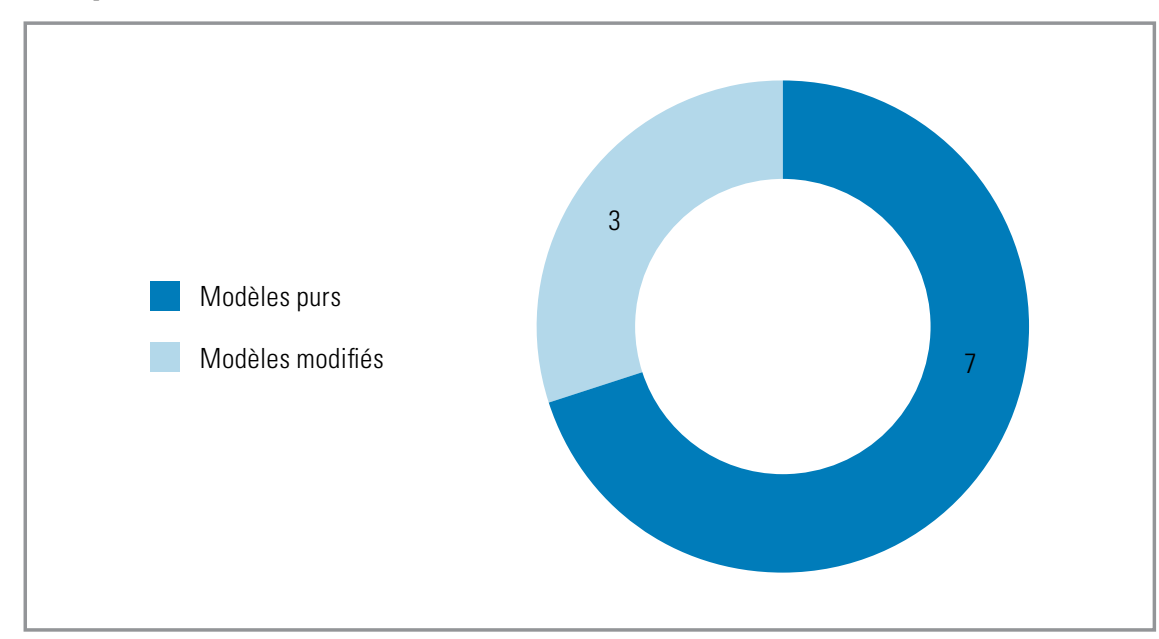




\section{Les juridictions sur le modèle décentralisé de Cour suprême}

La caractéristique principale de ce modèle est que de multiples niveaux de juridiction, au sein d'un même ordre juridictionnel, sont chargés de la justice constitutionnelle et peuvent donc effectuer un contrôle par voie juridictionnelle. En Afrique de l'Ouest, seuls deux pays - le Libéria et le Nigéria - ont adopté des solutions se rapprochant le plus de ce modèle. L'infrastructure institutionnelle du Nigéria en matière de contrôle par voie juridictionnelle - dans la mesure où ce dernier se rapporte à la Constitution fédérale - comprend la Cour suprême fédérale, la Cour d'appel fédérale, le Tribunal fédéral de grande instance et les tribunaux de grande instance des États. Seuls les tribunaux de première instance (Magistrate Courts), en vertu de l'article 295(1), ne peuvent effectuer le contrôle de constitutionnalité ${ }^{12}$. Le système nigérian donne par ailleurs aux tribunaux de grande instance le pouvoir d'examiner en premier ressort non seulement les questions relatives aux droits fondamentaux, mais également celles relatives à l'application et à l'interprétation de la Constitution. D'après les articles 233(2b-c) et 241(1) de la Constitution, la Cour suprême et la Cour d'appel conservent uniquement une compétence en appel en matière d'application et d'interprétation de la Constitution, y compris le contentieux lié aux droits fondamentaux. Les instances inférieures nigérianes restent donc les principales actrices du processus de contrôle juridictionnel, ce qui en fait une véritable infrastructure décentralisée.

Les mêmes conclusions s'appliquent au Libéria - le seul autre pays de common law de la région à avoir adopté un système de contrôle strictement décentralisé. Larticle 2 de la Constitution libérienne donne à la Cour suprême le pouvoir d'exercer le contrôle juridictionnel. Cependant, cette compétence n'est ni de premier ressort ni exclusive. L'article 66 écarte explicitement cette éventualité par une formulation à la fois inclusive et exclusive. La formulation inclusive identifie la Cour suprême uniquement comme "juge en dernier ressort" des questions de constitutionnalité. Il lui accorde en outre "la compétence définitive en appel pour tous les cas émanant des tribunaux». Lutilisation du terme "définitive» laisse penser que la compétence de la Cour en matière de constitutionnalité est une compétence en appel. La formulation exclusive énumère explicitement les cas pour lesquels la Cour a compétence en premier ressort : ceux impliquant "des ambassadeurs, des ministres, ou les cas pour lesquels un État est partie»; il s'agit d'une liste exhaustive qui n'inclut pas

12 Voir également les règles de procédure des tribunaux de première instance de Lagos (procédure civile). 
les questions de constitutionnalité ou l'interprétation de la Constitution ${ }^{13}$. L'article 26 écarte également toute exclusivité en donnant au tribunal de première instance (Claims Court) la compétence en premier ressort pour les affaires portant sur les droits fondamentaux, les pourvois en appel étant directement interjetés devant la Cour suprême.

La Cour suprême du Libéria s'est penchée sur la question de l'exclusivité de sa compétence en matière de contrôle de constitutionnalité et l'interprétation de la Constitution. Traditionnellement, l'opinion admise était qu'elle relevait de la compétence exclusive de la Cour, mais celle-ci a récemment revu sa position, se concentrant sur l'interprétation du terme "définitif" employé à l'article $66{ }^{14}$. Dans sa décision re Petition of Benjamin Cox, la Cour suprême a dû déterminer si le plaignant avait droit à un jugement déclaratoire sur la constitutionnalité d'une disposition statutaire empêchant les étrangers d'être admis au barreau libérien. Parmi les questions préliminaires auxquelles la Cour a dû répondre, il fallait déterminer si avant de renvoyer l'affaire, le tribunal avait une quelconque compétence pour résoudre les questions de constitutionnalité soulevées. La Cour y a répondu favorablement. Le recours au terme "définitif» de l'article 66, a fait valoir la Cour, "infère clairement que la question doit d'abord avoir été examinée par une instance inférieure [...] si cela n'était pas le cas, le terme unique aurait été employé» ${ }^{15}$. En d'autres termes, rien dans la formulation de l'article 66 n'empêche d'autres tribunaux de trancher les questions de constitutionnalité qui leur sont soumises.

Étant donné qu'il s'agissait d'un protectorat américain, le choix qu’a fait le Libéria d'un modèle de contrôle décentralisé peut s'expliquer par l'influence de l'ancienne puissance. Cependant, l'utilisation du même modèle au Nigéria pourrait s'expliquer - outre sa tradition héritée de la common law - par la taille importante de son territoire et de sa population, qui semble être un trait commun à la plupart des pays ayant adopté un système décentralisé de justice constitutionnelle. L'Argentine, l'Australie, le Brésil, le Canada, l'Inde, le Mexique et les États-Unis, par exemple, ont tous un territoire étendu, de même que le Nigéria. Il est par conséquent raisonnable de penser que par souci d'efficacité et de commodité, une instance centralisée unique - adaptée à des pays de taille plus modeste en comparaison, ce qui est le cas de la plupart

13 Voir également la section 2.1 de la loi judiciaire (Judiciary Law - 1972). Elle contient une formulation exclusive similaire, qui dispose que «la Cour suprême exerce la compétence en premier ressort pour toutes les affaires impliquant des ambassadeurs ou autres ministres publics et consuls, et celles pour lesquelles un État s'est constitué partie».

14 Morris v Reeves, 27 Liberian Law Report 334, 337 (1978) ; Fazzah v National Economy Committee, 8 Liberian Law Report 85, 105 (1943)

1536 Liberia Law Report 850 (1990). Voir également Gonsahn v. Vinton, qui réaffirme la position de la Cour, 37 Liberia Law Report 47, 56-57 (1992). 
ayant adopté ce système - peut ne pas convenir aux États dont la population importante est répartie sur un large territoire, ce qui explique la prévalence du système décentralisé dans ces pays.

\section{Les juridictions sur le modèle centralisé de Cour suprême}

Contrairement aux deux premiers groupes, qui comprennent les pays clairement de civil law ou de common law, cette catégorie regroupe des pays se réclamant de ces deux traditions. Le principal pays de civil law ayant adopté ce modèle est la Guinée-Bissau, lusophone, tandis que le Ghana, la Gambie et la Sierra Leone anglophones sont les principaux pays de common law à l'utiliser. À l'exception de la compétence partagée des Cours suprêmes avec les tribunaux de grande instance (qui exercent la compétence exclusive en premier ressort) et la cour d'appel (qui exerce la compétence en appel) pour les questions relatives aux droits fondamentaux dans les trois pays de common law, le trait distinctif de ce modèle est le rôle dominant joué par la Cour suprême dans ces quatre pays ${ }^{16}$.

Au Ghana, par exemple, l'article 130 de la Constitution accorde à sa Cour suprême une "compétence exclusive et en premier ressort" pour toutes les questions liées à l'application et à l'interprétation de la Constitution. Dans l'exercice de cette compétence, la Cour suprême seule peut déterminer si une autorité ou un individu a agi au-delà des pouvoirs qui lui sont conférés par la Constitution. La section 3(2) de la loi ghanéenne sur le fonctionnement des tribunaux (Ghana Courts Act) invoque une formulation similaire en disposant que lorsqu'une question liée à l'application ou à l'interprétation de la Constitution est soulevée devant une autre instance que la Cour suprême, cette instance doit suspendre la procédure et renvoyer l'affaire devant la Cour suprême pour décision. Larticle 124 (1-2) de la Constitution de la Sierra Leone suit la même approche, selon une formulation remarquablement similaire. C'est également le cas de la Gambie : en vertu de l'article 127(1), sa Cour suprême conserve la compétence en premier ressort, à l'exclusion de toutes les autres instances, pour les questions relatives à l'application et à l'interprétation de la Constitution. L'article 124(1) requiert par ailleurs que l'ensemble des tribunaux renvoient sans délai devant la Cour suprême toutes les questions dans ce domaine.

Cette formulation implique qu'en Gambie, au Ghana ou en Sierra Leone, les tribunaux inférieurs ne peuvent examiner des questions importantes de

\footnotetext{
Voir, d'une manière générale, l'article 127 (1) de la Constitution gambienne, lu concomitamment avec les articles $18-33$ et 36, l'article 130 (1) de la Constitution du Ghana lu concomitamment avec l'article 33, et l'article 124 (1) de la Constitution de la Sierra Leone concomitamment avec l'article 122.
} 
constitutionnalité dans le cadre des affaires qu'ils ont à juger. Par conséquent, ils ne peuvent pas non plus faire de déclarations quant au caractère constitutionnel ou non d'une législation. De la même manière, en GuinéeBissau, le seul pays de civil law de la région à ne pas faire appel à une institution de type kelsénien, un tribunal judiciaire suprême, au sommet de la hiérarchie judiciaire (comme les Cours suprêmes du Ghana, de la Gambie et de la Sierra Leone) reste la principale structure institutionnelle chargée du contrôle de constitutionnalité. D'après l'article 126 de la Constitution de la Guinée-Bissau, la Cour suprême (c.-à-d. le tribunal judiciaire suprême), siégeant en plénière, conserve seule le droit de connaître des questions de constitutionnalité et de déclarer, le cas échéant, des lois ou décrets comme inconstitutionnels. Le rôle extrêmement dominant joué par les Cours suprêmes, en dépit du fait qu'elles font partie des tribunaux de l'ordre judiciaire ordinaire, fait sans doute d'elles des institutions plus proches du modèle kelsénien que du modèle américain de Cour suprême. Comme nous l'avons suggéré dans la section précédente, cela peut éventuellement s'expliquer par la taille relativement modeste de ces pays.

Il ressort donc de notre analyse que l'architecture institutionnelle des systèmes de justice constitutionnelle en Afrique de l'Ouest est généralement centralisée : 14 des 16 pays de la région font appel à un modèle de contrôle juridictionnel davantage concentré (soit sous la forme d'une institution de type kelsénien indépendante du système judiciaire, soit sous celle d'une Cour suprême dominante au sein du système judiciaire ordinaire). Il est également important de noter que si le modèle choisi en matière de justice constitutionnelle reflète souvent le système juridique particulier d'un pays, qui dans de nombreux cas est influencé par l'héritage colonial, cela n'a pas toujours été le cas. Par exemple, la Gambie, le Ghana et la Sierra Leone sont majoritairement des pays de common law, mais ils ont adopté le modèle centralisé de Cour suprême, qui se rapproche plus du modèle utilisé dans les pays de civil law. Quant au Cabo Verde, son modèle (quoique kelsénien en principe) opère davantage selon le système décentralisé dans les cas de contrôle concret a posteriori. 
4. Les dispositions constitutionnelles

encadrant I'in-

dépendance des

juridictions com-

pétentes en matière

de contrôle de constitutionnalité 


\section{Les dispositions \\ constitutionnelles encadrant I'indépendance des \\ juridictions compétentes en matière de contrôle de constitutionnalité}

\section{Markus Böckenförde et Yuhniwo Ngenge}

Il est communément admis que l'indépendance judiciaire constitue un prérequis au maintien de l'État de droit et de la croissance économique (Melton et Ginsburg 2014 : 187). À l'échelle mondiale, la majorité des constitutions partagent cette volonté de garantir l'indépendance du pouvoir judiciaire et les pays d'Afrique de l'Ouest ne font pas exception. Il n'existe pas de définition commune du concept d'indépendance judiciaire ni de la manière dont celle-ci peut être mesurée. Toutefois, un certain nombre de caractéristiques principales ont été identifiées : l'indépendance et l'impartialité des juges, l'autonomie du pouvoir judiciaire et l'effet de ses décisions. Les lignes directrices, normes et initiatives internationales dressent une liste des principes et garanties de ces aspects de l'indépendance judiciaire et les universitaires ont fait l'inventaire des principaux facteurs institutionnels pouvant contribuer à déterminer le niveau d'indépendance de jure de tout conseil ou cour (Stroh et Heyl 2015 : 174).

Les constitutions de la région ont pris en compte ces facteurs à différents degrés, mais leur mise en œuvre reste problématique. Les universitaires africains ont illustré les difficultés rencontrées lors de la mise en pratique de ces normes constitutionnelles au sein du pouvoir judiciaire, qui permettent aux juges d'appliquer la loi sans crainte ni parti pris (Prempeh 2006 : 66). Le fait que le pouvoir judiciaire dispose de la compétence en matière de contrôle de constitutionnalité - et décide par conséquent si les actes législatifs et exécutifs sont conformes à la Constitution - a une incidence majeure sur les dynamiques à l'œuvre dans l'équilibre des pouvoirs. La robustesse du cadre constitutionnel qui protège l'autonomie de l'institution de toute ingérence excessive est fonction de l'influence qu'elle exerce dans ces débats au moyen d'une jurisprudence détaillée. Les institutions chargées de la justice constitutionnelle, en particulier les cours/conseils constitutionnel(le)s, sont en position de relative faiblesse par rapport aux autres branches du pouvoir : ils ne détiennent ni les cordons de la bourse, comme le pouvoir législatif, ni la force du glaive, apanage de l'exécutif. 
D’une manière générale, le présent rapport se concentre sur les normes écrites. Toutefois, pour évaluer l'indépendance des institutions chargées de la justice constitutionnelle, il est particulièrement important d'identifier les dispositions juridiques (de jure) prévues par la Constitution pour renforcer l'indépendance réelle (de facto). Des analyses statistiques récentes dans ce domaine indiquent que certaines composantes de l'indépendance judiciaire sont notamment importantes pour transformer l'indépendance de jure en une autonomie judiciaire de facto (Melton et Ginsburg 2014 : 195). Ces facteurs comprennent : (a) l'affirmation symbolique de l'indépendance de l'instance judiciaire concernée par rapport aux autres branches du pouvoir; (b) la durée du mandat des juges siégeant au sein des organes chargés du contrôle de constitutionnalité; (c) la procédure de nomination; (d) la procédure de révocation et les conditions de celle-ci et (e) l'autonomie budgétaire et la protection des salaires. Les procédures de nomination et de révocation ont à elles deux l'impact le plus important sur l'indépendance de facto. Le présent chapitre identifie et analyse les dispositions prévues par les constitutions/lois organiques respectives des pays d'Afrique de l'Ouest portant sur les instances chargées de la justice constitutionnelle et leur influence sur l'indépendance de ces organes.

\section{Les éléments constitutifs de l'indépendance de jure}

\section{L'affirmation de l'indépendance du pouvoir judiciaire}

Les pays d'Afrique de l'Ouest étudiés prévoient généralement dans leur constitution des dispositions protégeant les différentes composantes de l'autonomie judiciaire. À l'exception de celle du Libéria, toutes les constitutions de la région contiennent une affirmation explicite de l'indépendance du pouvoir judiciaire ou des cours/conseils. Parfois, les garanties de cette indépendance sont limitées. Par exemple, l'article 24(1) de la Constitution gambienne dispose que les garanties ne s'appliquent qu'aux «tribunaux ou autres instances juridictionnelles établis par la loi pour déterminer le bien fondé des procédures ou affaires pénales ou déterminer l'existence ou la portée des droits ou obligations des citoyens et citoyennes». Dans les pays faisant appel à une cour ou un conseil constitutionnel, il est important d'examiner dans quelle mesure l'affirmation de l'indépendance des "autorités judiciaires " s'applique à ces institutions. Le Niger et le Sénégal incluent spécifiquement leur Cour ou Conseil constitutionnel(le) dans l'ordre judiciaire. La Constitution du Cabo Verde accorde également aux membres de sa Cour constitutionnelle les mêmes garanties que celles données aux juges des autres juridictions. À l'inverse, dans les Constitutions du Bénin et de la Côte d'Ivoire, les Cours/ 
Conseils constitutionnel(le)s n'apparaissent pas dans la liste des instances exerçant les "pouvoirs judiciaires» indépendants. Dans d'autres cas, la constitution ne précise pas si la Cour constitutionnelle fait partie de l'autorité judiciaire dont l'indépendance est garantie ou s'il faut la considérer comme une institution à part.

\section{Les conditions de nomination et la durée du mandat des juges siégeant au sein des juridictions compétentes en matière de contrôle de constitutionnalité}

La forme adoptée par les institutions chargées de la justice constitutionnelle - Cour/Conseil constitutionnel(le) ou Cour suprême au sommet d'un ordre juridictionnel - a également un impact sur la durée du mandat des juges. Une fois nommés, les juges des pays dotés d'une Cour suprême siègent jusqu'à l'âge de leur retraite qui, dans ces pays, s'étale de 65 à 70 ans au plus tard, sauf en cas de dérogation spéciale. Cet âge avancé de départ à la retraite est important, car toute limite inférieure pourrait inciter les juges inquiets pour leur situation après leur départ à la retraite à prendre certains partis au cours de leur mandat; ce qui s'est produit en Inde, par exemple. Le mandat à durée indéterminée associé à une limite d'âge élevée contribue donc à protéger les juges des caprices des pouvoirs législatif ou exécutif. Les juges siégeant au sein des Cours ou Conseils constitutionnel(le)s, à l'inverse, ont des mandats limités de cinq à neuf ans. Du point de vue de l'indépendance de la justice, une durée déterminée entraîne le risque, pour les juges qui souhaitent planifier la suite de leur carrière, de briguer des postes politiques ou dans le secteur privé. Dans les pays où ce type de parcours professionnel est courant, l'indépendance réelle est plus difficile à évaluer étant donné que l'évolution de la carrière d'un juge à la fin de son mandat peut être influencée par les conséquences des décisions prises en tant que magistrat. L'indépendance et l'impartialité des juges peuvent également être remises en question si leur mandat est de courte durée, mais renouvelable - en particulier lorsque les affaires traitées portent sur les actions des institutions impliquées dans la procédure de renouvellement (par exemple une loi du parlement, un décret, etc.). En Afrique de l'Ouest, trois pays autorisent le renouvellement du mandat des juges après un premier mandat de sept ans (Mali, Togo) ou de cinq ans (Bénin). Au Bénin et au Mali, ce renouvellement n'est possible qu'une fois.

\section{La procédure de nomination}

La procédure de nomination des juges doit refléter leur rôle spécifique dans le contexte constitutionnel et diffère donc parfois des procédures utilisées pour les autres instances. Nous l'avons signalé plus haut, le contrôle définitif de la constitutionnalité de l'action gouvernementale a un impact politique 
majeur. Il est par conséquent communément admis que les acteurs politiques ont une influence sur la désignation des juges, afin de les encourager à se plier aux décisions qui ne seraient pas en leur faveur. L'implication de différents acteurs et institutions politiques dans le processus accroît également la probabilité de constituer une cour politiquement équilibrée. À l'exception du Cabo Verde et du Sénégal, où le Parlement et le président respectivement gardent seuls le contrôle du processus de désignation, la majorité des pays d'Afrique de l'Ouest suivent l'un ou l'autre des deux modèles de désignation, qui impliquent une grande diversité de parties prenantes politiques. Dans les pays de common law, le processus de désignation repose sur la participation consécutive de différentes institutions politiques, dont le nombre varie de deux (Gambie, Libéria) à quatre (Ghana). Il part du principe que le consentement ou l'implication de multiples institutions évite la sélection de juges ayant un parti pris pour l'une ou l'autre de ces institutions. La plupart des pays francophones ont recours à une tout autre approche : les différentes institutions nomment leurs candidats directement et unilatéralement (cf. chapitre 6). Par conséquent, si les candidats sont sensibles à l'un ou l'autre des acteurs politiques, ces partis pris s'équilibrent mutuellement étant donné que plusieurs acteurs politiques/institutions (dont le président et l'Assemblée nationale) participent à la désignation des juges.

\section{La révocation des juges : motifs et procédure}

Même les meilleures procédures de sélection de juges indépendants s'avèrent futiles si, une fois nommés, ces derniers restent à la merci d'une révocation de leur mandat. C'est pourquoi, afin de permettre aux institutions chargées de la justice constitutionnelle de fonctionner de manière indépendante, il est important que la Constitution ou une loi organique détermine les conditions précises et les procédures applicables à la révocation d'un juge. Les motifs de révocation sont généralement similaires d'un pays à l'autre et incluent notamment un handicap physique ou mental permanent, une mauvaise conduite comme un manquement avéré, une faute professionnelle grave, une condamnation par une instance judiciaire pour trahison, corruption ou autre délit grave, le non-respect du serment prêté, ou une accusation de crime ou d'inconduite notoire. Dans les pays où la durée du mandat des juges est courte, l'acceptation d'une autre charge incompatible avec celle exercée au sein de la Cour ou du Conseil constitutionnel(le) est également un motif de révocation. Il est utile de le noter, car cela reflète le postulat selon lequel les juges ne sont pas autorisés à assumer d'autres fonctions au cours de leur mandat.

La procédure de révocation diffère en fonction des systèmes juridiques. Dans les pays de common law, elle implique systématiquement des institutions 
externes, tandis que dans la plupart des pays de civil law, elle reste une affaire interne soit à la Cour soit au pouvoir judiciaire.

Tous les pays d'Afrique de l'Ouest se réclamant de la common law ont établi une procédure de révocation qui implique des acteurs externes. Tout en étant fondées sur la même approche, les procédures de ces cinq pays (Gambie, Ghana, Libéria, Nigéria et Sierra Leone) diffèrent considérablement (cf. tableau 6.1 au chapitre 6). En Gambie et au Libéria, l'initiative repose sur le pouvoir législatif, tandis qu'en Sierra Leone et au Ghana, un comité ad hoc est mis en place pour examiner l'affaire; au Nigéria, il revient au Conseil supérieur de la magistrature d'enclencher la procédure.

Dans la plupart des autres pays, les constitutions et lois organiques restent silencieuses ou ambigües quant au processus de révocation. En Mauritanie par exemple, ni la Constitution ni la loi organique ne contiennent de dispositions précisant si les membres du Conseil constitutionnel peuvent être révoqués ni sous quelles conditions. Au Bénin, au Togo, en Guinée, au Sénégal et en Côte d'Ivoire, les membres des instances chargées de la justice constitutionnelle ne peuvent être révoqués au cours de leur mandat sauf de leur propre initiative, mais ils peuvent être arrêtés, incarcérés et poursuivis pour infraction pénale ou en cas de flagrant délit avec l'aval de la Cour ou du Conseil constitutionnel. Au Bénin, la Cour suprême peut également s'impliquer. Des dispositions similaires sont en vigueur au Mali. Le type de sanction qu'entraînerait un verdict de culpabilité dans le cadre d'une procédure pénale n'est pas précisé, mais il serait logique que le juge incriminé soit révoqué. Le Burkina Faso semble être le seul pays d'Afrique de l'Ouest - de civil law - à considérer explicitement une condamnation pénale comme motif de révocation.

\section{L'autonomie budgétaire et la protection des salaires}

Le degré d'autonomie dont bénéficient les instances chargées du contrôle de constitutionnalité en matière de budget, d'administration et de gestion financière constitue un autre point important pour l'indépendance du pouvoir judiciaire. Une telle autonomie comporte deux dimensions : l'autonomie personnelle ou individuelle et l'autonomie institutionnelle. La première (que nous détaillerons ci-dessous dans la section relative à la protection des salaires) porte sur les traitements et autres allocations accordées aux juges à titre individuel. L'autonomie institutionnelle, budgétaire et administrative, concerne quant à elle le pouvoir judiciaire dans son ensemble, en tant qu'institution. D'un point de vue administratif et budgétaire, l'autonomie institutionnelle repose sur un certain nombre d'éléments importants, à savoir la possibilité d'embaucher et de gérer son personnel, de gérer ses finances, de planifier et de préparer son propre budget - qui peut ensuite être soumis au 
Parlement pour approbation, soit séparément, soit dans le cadre du budget général de l'État. Les instances chargées du contrôle de constitutionnalité dans les pays étudiés jouissent d'une indépendance administrative et budgétaire à des degrés divers.

\section{L'administration et la gestion des ressources}

La plupart des pays étudiés ont tendance à accorder au pouvoir judiciaire une plus grande indépendance dans la gestion des affaires administratives et financières générales que dans celle relative aux questions budgétaires. En Afrique de l'Ouest, le ministère de la Justice, en tant qu'agence de la branche exécutive du pouvoir, est généralement exclu de la gestion des affaires administratives et financières générales, tant dans les pays de common law que de civil law. Dans neuf des 11 pays de civil law étudiés, lusophones ou francophones, les constitutions et les lois organiques pertinentes accordent directement aux présidents des Cours ou des Conseils constitutionnel(le)s les pleins pouvoirs en matière de gestion administrative ou financière. Ils peuvent donc engager et gérer leur propre personnel et contrôler leurs finances. En Guinée-Bissau (lusophone) et en Guinée (francophone), le Conseil supérieur de la magistrature dispose de l'autorité administrative sur les instances chargées du contrôle de constitutionnalité. En Afrique de l'Ouest anglophone, il existe toutefois deux approches. Au Nigéria et en Sierra Leone, la Constitution place le pouvoir administratif entre les mains du Conseil supérieur de la magistrature. En Gambie, au Ghana et au Libéria, les constitutions confèrent explicitement le pouvoir administratif et d'encadrement au président de la Cour suprême. Un examen des systèmes de common law en Afrique de l'Ouest anglophone donne cependant à penser que la question de savoir qui conserve les pouvoirs de gestion administrative et financière n'a que peu d'importance, étant donné que dans tous ces pays, la direction du Conseil supérieur de la magistrature est assurée par le président de la Cour suprême.

\section{L'autonomie budgétaire}

L'autonomie budgétaire d'une institution peut être appréciée selon deux critères : (a) la possibilité d'élaborer son propre budget et (b) la possibilité d'élaborer et de soumettre directement au Parlement son propre budget. Ici aussi, notre analyse révèle des différences entre les pays. Dans certaines juridictions de common law, par exemple, le pouvoir de l'instance chargée du contrôle de constitutionnalité est limité à la préparation du budget qui doit être soumis au président de la République (ou à une agence placée sous son autorité), qui le présente à son tour devant le Parlement. C'est le cas en Gambie, au Ghana et au Libéria (voir tableau 4.1). C'est aussi le cas dans la plupart des pays de civil law d'Afrique de l'Ouest francophone, ainsi quau 
Cabo Verde lusophone. Dans ces pays - à l'exception de la République de Guinée, dont la Constitution reste silencieuse sur ce point -, les constitutions ou les lois organiques pertinentes ont également accordé aux Cours ou Conseils constitutionnel(le)s une certaine autonomie dans l'élaboration de leur budget. Cependant, comme en Gambie, au Ghana et au Libéria, ils doivent soumettre leur proposition au ministère des Finances, qui exerce la responsabilité finale en matière de consolidation et de soumission du budget au Parlement. Dans d'autres pays, en revanche, l'instance chargée du contrôle de constitutionnalité ou le Conseil supérieur de la magistrature est responsable de la préparation et de la présentation du budget au Parlement pour approbation. Lorsque c'est le cas, par exemple au Nigéria et en Sierra Leone, l'autonomie budgétaire est en théorie plus marquée.

Qu'ils soient préparés et soumis au Parlement directement ou par l'intermédiaire du gouvernement, il est important de souligner que les budgets des juridictions chargées du contrôle de constitutionnalité font partie intégrante du budget global de l'État et ce, tant dans les pays francophones qu'anglophones ou lusophones. Toutefois, les similitudes s'arrêtent là, car toutes les institutions chargées du contrôle de constitutionnalité des pays lusophones n'ont pas la capacité juridique de préparer leur propre budget et, encore moins, de le soumettre directement au Parlement pour validation. Au Cabo Verde, la Cour constitutionnelle, en vertu de la loi 56/6/05 du 28 février 2005, bénéficie d'un certain degré d'autonomie dans ce domaine, mais rien n'atteste qu'en Guinée-Bissau, son Tribunal judiciaire suprême, la principale instance chargée du contrôle de constitutionnalité, soit directement impliqué dans l'élaboration de son propre budget. De plus, en vertu de l'article $87 \mathrm{de}$ la loi 3/02 sur le pouvoir judiciaire (modifiée par la loi 6/2011), le Conseil supérieur de la magistrature de la Guinée-Bissau est responsable de la gestion des allocations financières accordées par le gouvernement à la Cour.

\section{La protection des salaires}

En ce qui concerne l'indépendance financière individuelle, les pays de common law se distinguent à nouveau de ceux de civil law (voir le tableau 4.1). Quatre des cinq pays de common law prévoient explicitement dans la Constitution des dispositions régissant le traitement et les avantages dont bénéficient les juges, et trois de ces quatre pays protègent explicitement les salaires contre des variations qui leur seraient préjudiciables. Les quatre pays étendent cette protection à toutes les institutions judiciaires. Les constitutions de la région inspirées du civil law ne traitent pas de la rémunération des juges ni dans la constitution ni - à l'exception de la Côte d'Ivoire - dans les lois organiques. Cependant, l'indépendance financière individuelle ne dépend pas uniquement de la protection des juges contre toute diminution de leur 
traitement ou de leurs avantages, mais contre toute augmentation importante et spontanée décidée par les autres branches du pouvoir. En effet, les juges pourraient ne plus sembler si indépendants si leurs salaires et avantages augmentaient soudainement à la veille d'une décision importante. Pourtant, aucune constitution de la région ne les protège de ce type d'influence.

\section{Tableau 4.1. Autonomie budgétaire et protection de la rémunération des juges constitutionnels en Afrique de l'Ouest}

\begin{tabular}{|c|c|c|}
\hline Pays & Degré d'autonomie budgétaire et administration & Protection des salaires \\
\hline Bénin & $\begin{array}{l}\text { Loi organique : le président de la Cour est responsable de la } \\
\text { gestion du budget, et intègre directement ce dernier dans le } \\
\text { plan budgétaire national (article 18) }\end{array}$ & $\begin{array}{l}\text { Aucune disposition dans } \\
\text { la Constitution/les lois } \\
\text { organiques }\end{array}$ \\
\hline Burkina Faso & $\begin{array}{l}\text { Règles de procédure internes du Conseil : le président du } \\
\text { Conseil constitutionnel est responsable de la gestion du } \\
\text { budget et supervise sa préparation avec l'aide d'un membre du } \\
\text { ministère des Finances (article 14) }\end{array}$ & $\begin{array}{l}\text { Aucune disposition dans } \\
\text { la Constitution/les lois } \\
\text { organiques }\end{array}$ \\
\hline Cabo Verde & $\begin{array}{l}\text { La Cour constitutionnelle prépare son budget et le soumet au } \\
\text { gouvernement pour consolidation et intégration au budget } \\
\text { général. La Cour est responsable de la gestion du budget avec } \\
\text { l'appui d'un conseil administratif }\end{array}$ & $\begin{array}{l}\text { Aucune disposition dans } \\
\text { la Constitution/les lois } \\
\text { organiques }\end{array}$ \\
\hline Côte d'Ivoire & $\begin{array}{l}\text { Textes réglementaires : le président du Conseil constitutionnel } \\
\text { supervise l'élaboration du budget, préparé par la Direction du } \\
\text { trésor et de la comptabilité publique (article 42) }\end{array}$ & $\begin{array}{l}\text { Une loi organique } \\
\text { réglemente le traitement } \\
\text { des juges }\end{array}$ \\
\hline Gambie & $\begin{array}{l}\text { Le pouvoir judiciaire est autonome sur le plan comptable : } \\
\text { le comptable général transfère l'allocation budgétaire } \\
\text { directement aux tribunaux, sur demande du président de la } \\
\text { Cour, qui en est également l'administrateur et le responsable } \\
\text { (article 144[1]) }\end{array}$ & $\begin{array}{l}\text { Le traitement, les } \\
\text { allocations, les } \\
\text { indemnités de fin de } \\
\text { carrière et la pension de } \\
\text { retraite ne peuvent être } \\
\text { modifiés au détriment du } \\
\text { juge (article 142 [1]) }\end{array}$ \\
\hline Ghana & $\begin{array}{l}\text { Constitution : les dépenses administratives du pouvoir } \\
\text { judiciaire sont imputées au fonds consolidé; les fonds votés } \\
\text { par le Parlement seront versés au pouvoir judiciaire (articles } \\
127[4], 127[1], 179)\end{array}$ & $\begin{array}{l}\text { Le traitement, les } \\
\text { allocations, l'indemnité } \\
\text { de fin de carrière et la } \\
\text { pension de retraite ne } \\
\text { peuvent être modifiés } \\
\text { au détriment du juge } \\
\text { (article 127[4]) }\end{array}$ \\
\hline Guinée & Aucune disposition dans la Constitution/les lois organiques & $\begin{array}{l}\text { Aucune disposition dans } \\
\text { la Constitution/les lois } \\
\text { organiques }\end{array}$ \\
\hline Guinée-Bissau & $\begin{array}{l}\text { Le Tribunal judiciaire suprême ne jouit d'aucune autonomie } \\
\text { budgétaire ou administrative; le Conseil supérieur de la } \\
\text { magistrature est responsable de la gestion financière des } \\
\text { ressources allouées par le gouvernement }\end{array}$ & $\begin{array}{l}\text { Aucune disposition dans } \\
\text { la Constitution }\end{array}$ \\
\hline
\end{tabular}




\begin{tabular}{|c|c|c|}
\hline Libéria & $\begin{array}{l}\text { La Cour suprême prépare son propre budget qui, une fois } \\
\text { approuvé, est géré par le président de la Cour (article 23[1], } \\
\text { loi organique) }\end{array}$ & $\begin{array}{l}\text { Le salaire, les allocations } \\
\text { et avantages sont } \\
\text { réglementés; les } \\
\text { allocations et avantages } \\
\text { ne peuvent être réduits } \\
\text { sauf dans le cadre d'un } \\
\text { programme national } \\
\text { adopté par le pouvoir } \\
\text { législatif (le salaire } \\
\text { n'est pas mentionné } \\
\text { (article 72[a]) }\end{array}$ \\
\hline Mali & $\begin{array}{l}\text { Loi organique : la Cour constitutionnelle prépare son propre } \\
\text { budget, qui est ensuite intégré dans la loi de finances } \\
\text { nationale (article 15) }\end{array}$ & $\begin{array}{l}\text { Aucune disposition dans } \\
\text { la Constitution/les lois } \\
\text { organiques }\end{array}$ \\
\hline Mauritanie & $\begin{array}{l}\text { Loi organique : le président du Conseil gère le budget; la } \\
\text { proposition est soumise au ministère des Finances, qui ne peut } \\
\text { la modifier (seul le Parlement dispose de cette prérogative) }\end{array}$ & $\begin{array}{l}\text { Aucune disposition dans } \\
\text { la Constitution/les lois } \\
\text { organiques }\end{array}$ \\
\hline Niger & $\begin{array}{l}\text { Le président de la Cour constitutionnelle supervise } \\
\text { l'élaboration du budget qui est ensuite intégré au plan } \\
\text { budgétaire national par le ministère des Finances (article 27) }\end{array}$ & $\begin{array}{l}\text { Aucune disposition dans } \\
\text { la Constitution/les lois } \\
\text { organiques }\end{array}$ \\
\hline Nigéria & $\begin{array}{l}\text { Le Conseil supérieur de la magistrature (National Judicial } \\
\text { Council) (qui comprend le président de la Cour et d'autres } \\
\text { juges confirmés) prépare le budget et le défend devant le } \\
\text { Parlement puis supervise sa gestion }\end{array}$ & $\begin{array}{l}\text { Le traitement, la } \\
\text { rémunération et les autres } \\
\text { allocations perçus par } \\
\text { les juges ne peuvent être } \\
\text { modifiés à leur détriment }\end{array}$ \\
\hline Sénégal & $\begin{array}{l}\text { Loi organique : le président du Conseil constitutionnel gère } \\
\text { le budget alloué à l'institution (article 9) }\end{array}$ & $\begin{array}{l}\text { Aucune disposition dans } \\
\text { la Constitution/les lois } \\
\text { organiques }\end{array}$ \\
\hline Sierra Leone & $\begin{array}{l}\text { Le président de la Cour, sur les conseils du Conseil supérieur } \\
\text { de la magistrature, est responsable de la gestion }\end{array}$ & $\begin{array}{l}\text { Le traitement, les } \\
\text { allocations, l'indemnité } \\
\text { de fin de carrière et la } \\
\text { pension de retraite ne } \\
\text { peuvent être modifiés } \\
\text { au détriment des juges } \\
\text { (article 138[3]) }\end{array}$ \\
\hline Togo & $\begin{array}{l}\text { Le président de la Cour constitutionnelle gère le budget qui } \\
\text { est préparé et soumis pour intégration dans le budget de } \\
\text { l'État par le ministère des Finances. II/elle peut également } \\
\text { autoriser des modifications au budget (articles } 15-16 \text { du } \\
\text { règlement intérieur de la Cour; article } 26 \text { de la loi organique } \\
\text { relative à la Cour) }\end{array}$ & $\begin{array}{l}\text { Aucune disposition dans } \\
\text { les lois organiques }\end{array}$ \\
\hline
\end{tabular}

\section{Légende}

Afrique de l'Ouest anglophone

Afrique de l'Ouest francophone

Afrique de l'Ouest lusophone 
5. Les Conseils supérieurs de la magistrature 


\title{
5. Les Conseils supérieurs de la magistrature
}

\author{
Babacar Kante et H. Kwasi Prempeh
}

À l'exception du Libéria, chacun des pays étudiés ici désigne dans sa Constitution un organe ou une commission chargés de désigner les juges et d'assurer d'autres fonctions relatives à la magistrature (voir tableau 5.1). Dans ces pays, le Conseil supérieur de la magistrature participe au processus de nomination des magistrats ${ }^{17}$. Le Libéria suit le modèle américain : seuls le président de la République et la chambre haute - le Sénat - jouent un rôle formel dans la sélection des juges. La structure, l'organisation et les attributions des Conseils supérieurs de la magistrature varient en fonction des pays.

\section{Tableau 5.1. Conseils supérieurs de la magistrature en Afrique de I'Ouest}

\begin{tabular}{|c|c|c|c|c|}
\hline Pays & Principales attributions & $\begin{array}{c}\text { Composition } \\
\text { (y compris } \\
\text { membres } \\
\text { d'office) }\end{array}$ & $\begin{array}{c}\text { Relation avec } \\
\text { I'instance } \\
\text { chargée de la } \\
\text { justice consti- } \\
\text { tutionnelle }\end{array}$ & $\begin{array}{c}\text { Dispositions } \\
\text { constitution- } \\
\text { nelles ou lois } \\
\text { organiques } \\
\text { pertinentes }\end{array}$ \\
\hline Bénin & $\begin{array}{l}\text { - Donne son avis sur la nomination } \\
\text { des juges et les cas de grâce } \\
\text { présidentielle; } \\
\text { - assiste le pouvoir exécutif dans son } \\
\text { rôle de garant de l'indépendance } \\
\text { judiciaire. }\end{array}$ & 12 membres & Aucun lien direct & $\begin{array}{c}\text { Articles 127-30 } \\
\text { (Constitution) }\end{array}$ \\
\hline
\end{tabular}

\footnotetext{
Dans ce chapitre, nous faisons référence de manière générale au Conseil supérieur de la magistrature, mais le nom donné à cette instance varie selon les pays. Dans les pays francophones et lusophones, c'est ce terme même qui est utilisé; dans les pays de common law (y compris la Gambie), cette instance est dénommée Judicial Service Commission; elle est également connue comme Judicial Council au Ghana et comme Judicial and Legal Service Commission en Sierra Leone. Le Nigéria est le seul pays de la région à avoir confié à de multiples organes les fonctions généralement attribuées au Conseil supérieur de la magistrature, à savoir le National Judicial Council et la Federal Judicial Service Commission, complétés par des Judicial Service Commissions dans chacun des États de la fédération. Le National Judicial Council émet des recommandations au président et aux gouverneurs des États en matière d'affectation à certains postes judiciaires (à partir d'une liste de personnes proposées) ou de révocation des juges.
} 


\begin{tabular}{|c|c|c|c|c|}
\hline $\begin{array}{l}\text { Burkina } \\
\text { Faso }\end{array}$ & $\begin{array}{l}\text { - Assiste le pouvoir exécutif dans son } \\
\text { rôle de garant de l'indépendance } \\
\text { judiciaire; } \\
\text { - donne son avis sur les cas de grâce; } \\
\text { - fait des propositions en matière } \\
\text { de nomination et d'affectation des } \\
\text { juges; } \\
\text { - donne son avis sur les propositions } \\
\text { de nomination des autres juges. }\end{array}$ & 22 membres & Aucun lien direct & $\begin{array}{l}\text { Articles 131-4 } \\
\text { (Constitution) }\end{array}$ \\
\hline Cabo Verde & $\begin{array}{l}\text { - Sanctionne les juges et gère leur } \\
\text { carrière; } \\
\text { - gère les ressources humaines et } \\
\text { financières du pouvoir judiciaire. }\end{array}$ & 18 membres & Aucun lien direct & $\begin{array}{l}\text { Article } 223 \\
\text { (Constitution) }\end{array}$ \\
\hline $\begin{array}{l}\text { Côte } \\
\text { d'Ivoire }\end{array}$ & $\begin{array}{l}\text { - Émet des recommandations quant à } \\
\text { la nomination des magistrats; } \\
\text { - donne son avis sur les promotions } \\
\text { au sein de l'ordre judiciaire; } \\
\text { - assure le respect de la discipline } \\
\text { dans la magistrature. }\end{array}$ & 17 membres & $\begin{array}{l}\text { Aucun lien } \\
\text { spécifique }\end{array}$ & $\begin{array}{l}\text { Articles } 104-6 \\
\text { (Constitution) } \\
\text { Article } 3 \text { (loi } \\
\text { organique) }\end{array}$ \\
\hline Gambie & $\begin{array}{l}\text { - Conseille le président en matière de } \\
\text { nomination des magistrats; } \\
\text { - administre et gère le secteur } \\
\text { judiciaire; } \\
\text { - assume les autres fonctions qui lui } \\
\text { sont dévolues par la législation. }\end{array}$ & 6 membres & $\begin{array}{l}\text { Le président de } \\
\text { la Cour dirige le } \\
\text { Judicial Council; } \\
\text { pas d'autre lien } \\
\text { spécifique }\end{array}$ & $\begin{array}{l}\text { Articles 145-7 } \\
\text { (Constitution) }\end{array}$ \\
\hline Ghana & $\begin{array}{l}\text { - Émet des recommandations à } \\
\text { l'intention du gouvernement } \\
\text { concernant les réformes de la } \\
\text { justice; } \\
\text { - assure la gestion et l'administration } \\
\text { efficace du secteur judiciaire; } \\
\text { - assume les autres fonctions qui lui } \\
\text { sont dévolues par la législation ou } \\
\text { la Constitution. }\end{array}$ & 19 membres & $\begin{array}{l}\text { Le président de } \\
\text { la Cour dirige le } \\
\text { Judicial Council }\end{array}$ & $\begin{array}{l}\text { Articles 153-4 } \\
\text { (Constitution) }\end{array}$ \\
\hline Guinée & $\begin{array}{l}\text { - Approuve les nominations de } \\
\text { magistrats décidées par le } \\
\text { président; } \\
\text { - donne son avis sur l'indépendance } \\
\text { de la justice et l'avancement des } \\
\text { juges; } \\
\text { - examine et conseille le président } \\
\text { sur les demandes de grâce; } \\
\text { - assure la discipline au sein de la } \\
\text { magistrature. }\end{array}$ & 17 membres & $\begin{array}{l}\text { Aucun lien } \\
\text { spécifique }\end{array}$ & $\begin{array}{l}\text { Articles 109, } \\
111-12 \\
\text { (Constitution) }\end{array}$ \\
\hline $\begin{array}{l}\text { Guinée- } \\
\text { Bissau }\end{array}$ & $\begin{array}{l}\text { - Gère la carrière des magistrats; } \\
\text { - propose des recommandations en } \\
\text { matière de réforme de la justice; } \\
\text { - élabore le plan annuel d'inspection; } \\
\text { - organise les inspections et } \\
\text { contrôles des services judiciaires. }\end{array}$ & 15 membres & $\begin{array}{l}\text { Certains de ses } \\
\text { membres sont } \\
\text { membres de la } \\
\text { Cour suprême, } \\
\text { qui est aussi } \\
\text { la principale } \\
\text { instance } \\
\text { de justice } \\
\text { constitutionnelle }\end{array}$ & $\begin{array}{l}\text { Articles, 120, } \\
126 \\
\text { (Constitution) } \\
\text { Article } 61 \text { (loi } \\
\text { organique) }\end{array}$ \\
\hline Libéria & - inapplicable & inapplicable & Inapplicable & inapplicable \\
\hline
\end{tabular}




\begin{tabular}{|c|c|c|c|c|}
\hline Mali & $\begin{array}{l}\text { - Assiste le pouvoir exécutif dans } \\
\text { la protection de l'indépendance } \\
\text { judiciaire; } \\
\text { - gère la carrière des magistrats. }\end{array}$ & 21 membres & $\begin{array}{l}\text { Aucun lien } \\
\text { spécifique }\end{array}$ & $\begin{array}{l}\text { Article } 82 \\
\text { (Constitution) }\end{array}$ \\
\hline Mauritanie & $\begin{array}{l}\text { - Recrute les magistrats, évalue et } \\
\text { développe leur carrière; } \\
\text { - assiste le pouvoir exécutif dans } \\
\text { la protection de l'indépendance } \\
\text { judiciaire. }\end{array}$ & 11 membres & $\begin{array}{l}\text { Aucun lien } \\
\text { spécifique }\end{array}$ & $\begin{array}{l}\text { Articles } 81-2 \\
\text { (Constitution) }\end{array}$ \\
\hline Niger & $\begin{array}{l}\text { - Assiste le pouvoir exécutif dans } \\
\text { la protection de l'indépendance } \\
\text { judiciaire. }\end{array}$ & $\begin{array}{l}7 \text { membres } \\
\text { minimum }\end{array}$ & $\begin{array}{l}\text { Aucun lien } \\
\text { spécifique }\end{array}$ & $\begin{array}{l}\text { Article } 119 \\
\text { (Constitution) }\end{array}$ \\
\hline Nigéria & $\begin{array}{l}\text { - Conseille le président sur les } \\
\text { questions judiciaires fédérales; } \\
\text { - conseille les gouverneurs des États } \\
\text { sur les questions judiciaires de leur } \\
\text { ressort; } \\
\text { - propose des recommandations } \\
\text { quant à l'affectation/la révocation } \\
\text { des magistrats d'État; } \\
\text { - propose des recommandations } \\
\text { quant à l'affectation/la révocation } \\
\text { des magistrats fédéraux. }\end{array}$ & $\begin{array}{l}\text { National } \\
\text { Judicial } \\
\text { Council (19 } \\
\text { membres) }\end{array}$ & $\begin{array}{l}\text { Différents } \\
\text { liens du fait de } \\
\text { leur pouvoir } \\
\text { en matière de } \\
\text { nomination/ } \\
\text { révocation; } \\
\text { ce sont } \\
\text { généralement } \\
\text { les mêmes } \\
\text { personnes qui } \\
\text { siègent au sein } \\
\text { des différentes } \\
\text { institutions }\end{array}$ & $\begin{array}{l}\text { Liste II, } \\
\text { Partie 1, } \\
\text { Articles 12-13 } \\
\text { (Constitution) }\end{array}$ \\
\hline Sénégal & $\begin{array}{l}\text { - Gère la carrière des juges } \\
\text { (recrutement, affectation et } \\
\text { révocation); } \\
\text { - veille à la discipline au sein de la } \\
\text { magistrature. }\end{array}$ & 15 membres & $\begin{array}{l}\text { Aucun lien } \\
\text { spécifique }\end{array}$ & $\begin{array}{l}\text { Article } 90 \\
\text { (Constitution) }\end{array}$ \\
\hline $\begin{array}{l}\text { Sierra } \\
\text { Leone }\end{array}$ & $\begin{array}{l}\text { - Conseille le président de la Cour } \\
\text { suprême quant à l'administration de } \\
\text { la magistrature. }\end{array}$ & 7 membres & $\begin{array}{l}\text { Le président de } \\
\text { la Cour suprême } \\
\text { est également } \\
\text { président de la } \\
\text { Commission; } \\
\text { pas d'autre lien } \\
\text { spécifique }\end{array}$ & $\begin{array}{l}\text { Article } 140 \\
\text { (Constitution) }\end{array}$ \\
\hline Togo & $\begin{array}{l}\text { - Garantit l'indépendance de la } \\
\text { justice; } \\
\text { - sanctionne les juges; } \\
\text { - Donne son avis sur le recrutement } \\
\text { du personnel judiciaire; } \\
\text { - effectue des recommandations } \\
\text { quant à la nomination des } \\
\text { magistrats; } \\
\text { - donne son avis sur le recrutement } \\
\text { des fonctionnaires au sein du } \\
\text { ministère public. }\end{array}$ & 7 membres & Aucun lien & $\begin{array}{l}\text { Articles 116-17 } \\
\text { (Constitution) }\end{array}$ \\
\hline
\end{tabular}

\section{Légende}

Afrique de l'Ouest francophone

Afrique de I'Ouest anglophone

Afrique de l'Ouest lusophone 


\section{L'organisation et le fonctionnement des Conseils supérieurs de la magistrature}

La structure et le fonctionnement des conseils supérieurs de la magistrature varient en fonction des pays étudiés. Les différences sont nombreuses, notamment en matière de composition et d'attributions, selon la tradition juridique dont ils se réclament.

\section{La composition des Conseils supérieurs de la magistrature}

Le nombre et le profil de membres qui composent les Conseils supérieurs de la magistrature, ainsi que leur mode de désignation, varient considérablement à l'échelle de la région. Ils comprennent entre six (Gambie) et 22 membres (Burkina Faso) et il n'y a généralement aucune corrélation entre la taille du territoire ou de la population d'un pays et l'effectif de l'institution. Par exemple, 19 membres siègent au sein du National Judicial Council du Nigéria, le pays le plus important par sa taille et sa population, soit un nombre comparable à celui des organes équivalents au Ghana et en Côte d'Ivoire, dont la taille du territoire et de la population est relativement modeste. De la même manière, le Conseil supérieur de la magistrature du Mali, dont la superficie est comparable à celle du Nigéria, mais avec une densité de population bien inférieure, compte 21 membres.

Les Conseils supérieurs de la magistrature de la région comprennent généralement trois catégories de membres. Premièrement, les membres d'office, qui siègent de droit au sein du Conseil en vertu de la fonction qu'ils occupent au sein de la magistrature (par exemple le président de la Cour suprême ou de la cour d'appel) ou du gouvernement (par exemple le ministre de la Justice ou le procureur général). Les 15 pays ayant établi ce type d'institution prévoient dans leur Constitution des dispositions spécifiques concernant ces membres d'office. Deuxièmement, les membres nommés ou élus par leurs pairs au sein de la juridiction ou du niveau de juridiction à laquelle ils appartiennent ou parmi les membres du barreau. Troisièmement, les personnes ayant des qualifications spécifiques nommées par une autorité politique ou judiciaire déterminée, comme le président de la République, le président du Parlement ou le président de la Cour suprême, avec ou sans la participation des autres institutions. Dans certaines juridictions, notamment dans le système de civil law, certaines (ou toutes) ces nominations sont effectuées sur désignation préalable par d'autres institutions, les candidats devant satisfaire à certains critères prédéterminés par la Constitution ou la législation, ce qui permet d'éviter les nominations discrétionnaires. Cependant, dans d'autres systèmes, les membres relevant de cette catégorie sont désignés en toute discrétion ou presque, par exemple pour les postes réservés aux femmes ou aux non-juristes. 
En général, les Conseils supérieurs de la magistrature des pays de common law et lusophones de la région peuvent être distingués de ceux des pays francophones par la diversité professionnelle de leurs membres et la relation qu'entretient le Conseil avec les autorités politiques. Deux différences majeures sont à signaler. La première est la présence de non-juristes (ou non-spécialistes) au sein du Conseil. Les constitutions du Ghana (article 153), du Nigéria (liste II, partie 1C, para. 20), de la Sierra Leone (article 140) et du Cabo Verde (articles 245-6) réservent toutes un nombre déterminé de sièges au sein du Conseil à des personnes extérieures à la justice. En Gambie, l'autre pays de common law de notre étude, deux sièges sur les six que compte le Conseil sont réservés à des individus sans qualification déterminée; le président et l'Assemblée nationale en nomment chacun un. Les juges et autres juristes, cependant, constituent la majorité des membres des Conseils supérieurs de la magistrature en Afrique de l'Ouest de tradition common law. À l'inverse, dans les pays francophones, tous les membres du Conseil supérieur de la magistrature sont des juristes issus de la magistrature, du ministère public, du barreau ou des facultés de droit.

La seconde différence porte sur la relation entre les membres du Conseil et le pouvoir politique, notamment la présidence de l'institution. Dans les pays anglophones, le président de la Cour suprême est d'office président du Conseil supérieur de la magistrature. Il en va de même en Guinée-Bissau. Au Cabo Verde, le président est désigné par la Commission et nommé par le président de la République. En revanche, dans les pays francophones, le Conseil supérieur de la magistrature a à sa tête le président de la République et le juge le plus gradé - le président de la Cour de cassation ou de la Cour suprême - prend généralement la fonction de vice-président.

\section{Les fonctions et attributions des Conseils supérieurs de la magistrature}

Tous les Conseils supérieurs de la magistrature de la région proposent des candidats ou émettent des recommandations pour la nomination (par le président de la République) des juges siégeant au sein des tribunaux de l'ordre juridictionnel. Au-delà de cette simple fonction de choix des magistrats, les Conseils exercent différentes charges en fonction des pays (voir tableau 5.1). Dans les pays francophones, le rôle de président du Conseil supérieur de la magistrature, assuré par le président de la République, reflète une tradition constitutionnelle ancienne selon laquelle le président est le "garant de l'indépendance de la justice». Dans ce contexte, le Conseil supérieur de la magistrature sert simplement d'organe de conseil du président pour les questions relatives à la justice. À ce titre, le Conseil assiste le président pour les décisions portant sur les grâces présidentielles, la nomination des procureurs 
et pour les questions relatives à la promotion, la réaffectation ou la sanction des juges. Dans les pays anglophones et lusophones, les Conseils font partie de la structure institutionnelle de l'autogouvernance judiciaire, et assistent les instances dirigeantes de la justice dans la gestion et l'administration des tribunaux. Par exemple, le National Judicial Council du Nigéria est habilité à «traiter de toutes les autres questions portant sur les aspects d'ordre général et administratif» relatifs au pouvoir judiciaire. Au Ghana, le Judicial Council aide le président de la Cour suprême dans l'exercice de ses fonctions de chef de la magistrature. Certains conseils ont également un rôle explicite dans la budgétisation et la gestion financière du système judiciaire. Par exemple, les Conseils de la Guinée-Bissau et du Cabo Verde produisent un plan annuel d'inspection des tribunaux et contribuent à l'élaboration et à la gestion du budget de l'appareil judiciaire. Le Conseil du Nigéria est par ailleurs responsable de la collecte, de la distribution et du contrôle de l'allocation budgétaire accordée à la justice par le gouvernement. Les conseils de la magistrature anglophones jouent également un rôle dans le recrutement, la sanction et la révocation des juges et greffiers siégeant dans les tribunaux de première instance ou de "niveau inférieur». En Sierra Leone, il conseille aussi le président quant à la nomination du procureur général.

\section{Le rôle dans le fonctionnement des juridictions constitutionnelles}

Les Conseils supérieurs de la magistrature sont supposés jouer un rôle dans la règlementation du fonctionnement du système judiciaire. Leur création et les modalités de leur fonctionnement indiquent souvent le degré d'autonomie ou d'indépendance du pouvoir judiciaire du pays. Pourtant, ils jouent un rôle limité et, dans le meilleur des cas, indirect dans la justice constitutionnelle. Bien qu'ils ne prennent pas part au contentieux, les Conseils supérieurs de la magistrature peuvent, au fil du temps, influencer la composition générale et la qualité de la magistrature - et, par conséquent, la jurisprudence - du fait de leur rôle dans le recrutement, l'évaluation, la promotion et la sanction des juges ainsi que dans l'affectation de ceux-ci aux plus hautes fonctions judiciaires. Cependant, dans les systèmes où les juridictions constitutionnelles ne font pas partie du système judiciaire ordinaire, et ne sont donc pas soumises à l'autorité du conseil supérieur de la magistrature, ce type d'influence indirecte et limitée sur la justice constitutionnelle est généralement sans objet. 



\section{La composition des juridictions compétentes en matière de justice constitutionnelle}

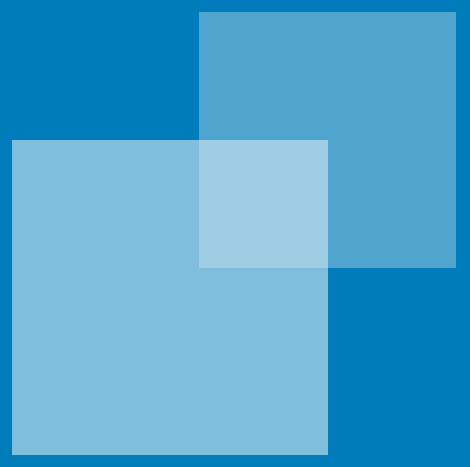




\section{La composition des \\ juridictions compétentes \\ en matière de justice \\ constitutionnelle}

Markus Böckenförde

Compte tenu de la nature politique des affaires traitées par les instances chargées de la justice constitutionnelle, la composition de ces dernières nécessite une grande attention et peut rapidement se révéler politiquement sensible. Le nombre de membres, leur formation, les critères de sélection et de révocation, ainsi que la durée du mandat et la possibilité de le renouveler influencent le rôle de l'instance et les dynamiques en son sein.

\section{Le nombre de membres}

À l'exception de la Guinée-Bissau, toutes les constitutions de l'Afrique de l'Ouest fixent des paramètres quant au nombre de juges pouvant siéger au sein de la Cour ou du Conseil constitutionnel ou de la Cour suprême. Ce nombre varie grandement, allant de (minimum) trois (au Cabo Verde) à (maximum) 21 au Nigéria, mais la majorité des pays (10) prévoient entre cinq et neuf membres. Plusieurs facteurs expliquent ces différences, notamment la charge de travail anticipée et l'efficacité dans le traitement des dossiers. Cela dépend également de la position éventuelle de l'institution au sommet de la hiérarchie judiciaire et de sa fonction de tribunal de dernière instance pour les affaires non constitutionnelles.

Dans sept pays, le nombre de juges n'est pas déterminé - la Constitution se contente de fixer un seuil minimum (Burkina Faso, Cabo Verde, Gambie, Ghana, Côte d'Ivoire, Sierra Leone) ou maximum (Nigéria). Au Burkina Faso et en Côte d'Ivoire, les anciens présidents sont membres d'office à vie, ce qui rend impossible de déterminer à l'avance un nombre maximum. Toutefois, dans ces deux pays, le nombre de membres ordinaires est invariable. À l'exception du Cabo Verde, les autres pays dans lesquels le nombre de juges peut varier suivent le modèle de Cour suprême (Gambie, Ghana et Sierra Leone) et ce choix peut s'expliquer par la volonté de préserver une marge d'adaptation en fonction de la charge de travail. Cependant, cet usage limité ne figure explicitement dans aucune de ces constitutions, qui ne précisent 
pas non plus qui dispose de l'autorité d'accroître le nombre de juges. Une telle souplesse est généralement traitée avec beaucoup de prudence, étant donné que les autres branches du pouvoir pourraient être tentées d'accroître le nombre de juges dans l'espoir d'obtenir des décisions en leur faveur après avoir pris le contrôle politique des institutions impliquées dans le processus de désignation. C'est ce qui s'est produit en Égypte (2001) et en Hongrie (2011); en revanche, une tentative similaire a échoué aux États-Unis en 1937. Toutes les instances chargées de la justice constitutionnelle en Afrique de l'Ouest prévoient un nombre impair de membres, très probablement pour éviter toute égalité lors des votes.

\section{L'expérience professionnelle et les exigences en matière de formation juridique}

Les différentes conceptions du rôle des instances chargées du contrôle de constitutionnalité au sein d'un système politique peuvent influencer les qualifications professionnelles ou les critères d'accession à la fonction. Si l'institution siège également au sommet de l'appareil judiciaire, il semble naturel que ses membres soient des juges ou, à défaut, d'éminents juristes. En effet, dans tous les pays d'Afrique de l'Ouest se réclamant du modèle de Cour suprême, une formation juridique et un certain nombre d'années d'expérience dans le domaine sont des prérequis. Dans les deux pays lusophones, un diplôme universitaire en droit est l'exigence minimum pour le poste.

Dans les neuf pays francophones, cette évolution a pris une voie différente. Il existe trois règlementations distinctes. Certaines constitutions et lois organiques restent silencieuses quant à la formation juridique (Mauritanie), d'autres exigent une expérience juridique ou administrative. Cette approche reconnaît que l'examen d'affaires politiquement sensibles et la définition d'enjeux politiques dans le cadre de la Constitution - qui formule des principes et engagements de base - ne sont pas exclusivement une affaire de droit. D'autres pays prévoient un contingent minimum de membres issus du milieu juridique. Tandis que le Togo, par exemple, ne détaille pas d'exigences, disposant simplement que la sélection de trois des neuf membres doit se faire sur les qualifications juridiques, d'autres pays se font plus précis : au Bénin, trois des sept membres doivent être des magistrats et deux des professeurs de droit ou des avocats bénéficiant d'une longue expérience. Lorsqu'une expérience juridique est requise, sa durée varie considérablement, de cinq à 20 ans. Tous les pays ne fixent pas d'âge minimum, mais lorsque c'est le cas, le seuil est fixé entre 25 et 40 ans. 


\section{Les mécanismes de désignation}

Dans la plupart des pays, la procédure de désignation des membres des juridictions chargées de la justice constitutionnelle diffère de celle prévue pour les autres magistrats. Compte tenu du caractère politique des affaires traitées par les Cours/Conseils constitutionnel(le)s ou les Cours suprêmes, les acteurs politiques des pouvoirs exécutif et législatif participent souvent à la nomination des membres, comme le montre le tableau 6.1. Cette implication est un élément indispensable de l'équilibre des pouvoirs et peut les encourager à accepter les décisions ultérieures prises par ces instances. La difficulté est de veiller à ce que le mécanisme de désignation isole complètement les juges de toute influence ou manipulation politique en aval.

Il est utile de noter que la signification du terme "nomination" peut varier en fonction de la culture juridique du pays. Souvent, les processus de choix des juges impliquent une nomination entérinée par le chef de l'État après désignation par d'autres acteurs. Ailleurs, le terme implique que l'autorité de nomination a un droit de veto effectif et peut refuser les propositions de nomination qui lui sont transmises. Quelques constitutions ont récemment adopté une formulation explicite pour éviter toute ambiguïté à cet égard. Par exemple, en ce qui concerne la nomination des fonctionnaires, y compris les juges, la Constitution libérienne prévoit que «le Président nomme et, avec le consentement du Sénat, désigne et affecte» (article 54). La Constitution de la Sierra Leone (article 135) contient une disposition similaire.

Quatre types de procédure de nomination sont utilisés dans le monde, en fonction du contexte :

1. Désignation par le pouvoir législatif à la majorité qualifiée

2. Désignation au terme d'un processus consécutif

3. Désignation par différentes autorités

4. Nomination par le chef de l'État

Tous ces modèles sont représentés en Afrique de l'Ouest, les modèles 2 et 3 étant de loin les plus courants.

\section{Modèle 1 : Désignation par le pouvoir législatif à la majorité qualifiée}

Dans certains pays, seul le pouvoir législatif peut choisir les juges (s'il s'agit d'un modèle bicaméral, les deux chambres sont généralement impliquées). Une large majorité de suffrages est souvent requise, de manière à inclure 
l'opposition dans le processus de sélection. Lorsqu'il existe des forces d'opposition organisées, le processus nécessite que les partis représentés au sein du pouvoir législatif s'accordent entre eux et assurent une composition plus équilibrée de l'institution. En Afrique de l'Ouest, seuls les membres du Tribunal constitutionnel du Cabo Verde sont désignés exclusivement par le pouvoir législatif : ce dernier élit les trois membres de la Cour à la majorité des deux tiers. Au Togo, ce seuil de deux tiers est précisé dans la Constitution, mais le Parlement ne désigne que six des neuf candidats (trois par l'Assemblée nationale et trois par le Sénat); le président nomme les trois autres membres.

Accorder au pouvoir législatif un rôle dominant dans le processus de désignation accentue le risque de politisation (Sadurski 2001 : 4), en particulier lorsque des coalitions (et le marchandage politique qui en résulte) sont nécessaires pour former une majorité des deux tiers. Cependant, cette approche a également le mérite de permettre la désignation de candidats de consensus, renforçant ainsi la légitimité et l'acceptabilité des décisions des cours composées de cette manière.

\section{Figure 6.1. Désignation par le pouvoir législatif à la majorité qualifiée}

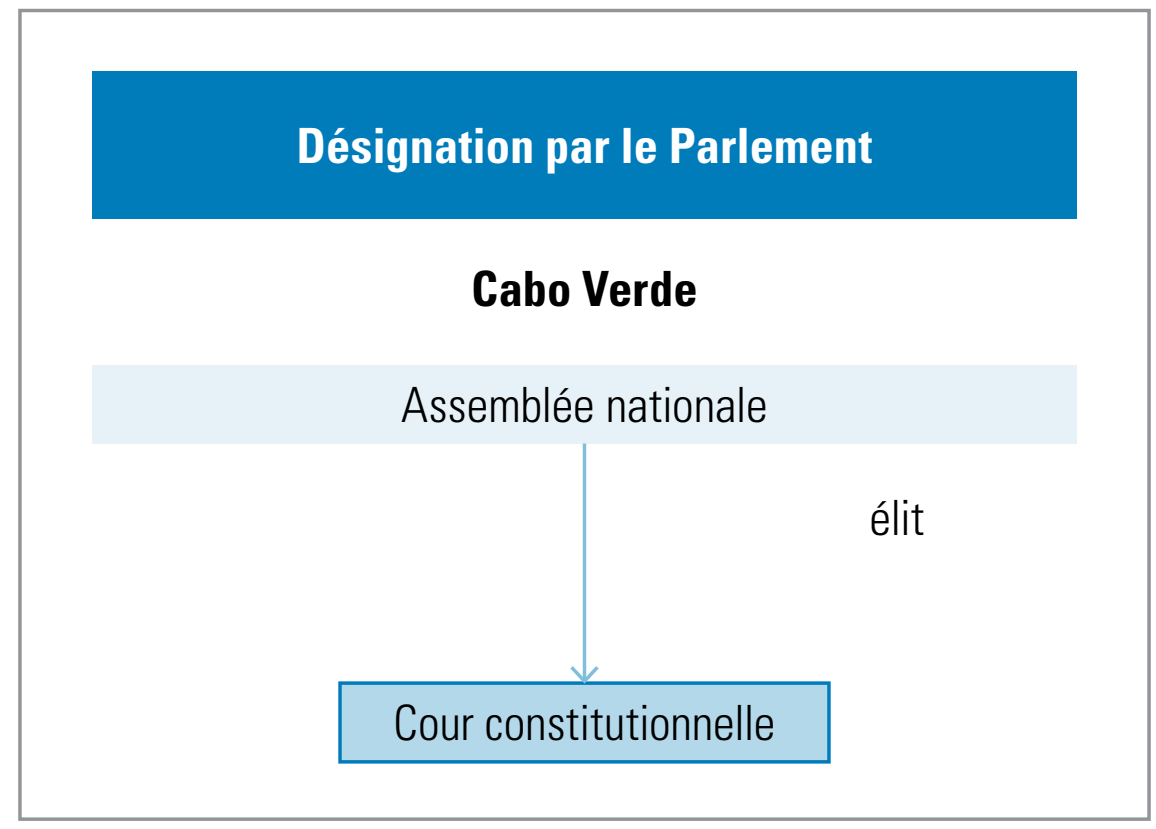




\section{Modèle 2: Désignation au terme d'un processus consécutif}

Une autre option consiste à impliquer de multiples acteurs - souvent issus des différentes branches du pouvoir - aux différentes étapes du processus de nomination, fréquemment au moyen d'une procédure de désignation et de nomination/validation. Cette approche cherche à équilibrer la composition de l'institution en identifiant des candidats de consensus soutenus par l'ensemble des institutions. En Afrique de l'Ouest, quatre pays de tradition common law ou anglo-américaine avec un modèle de Cour suprême suivent cette approche. Le Libéria se conforme au modèle américain, dans lequel le président nomme des candidats soumis à l'approbation du Sénat. La Sierra Leone et le Nigéria ont ajouté un acteur : le Conseil supérieur de la magistrature, qui fournit une liste de candidats parmi lesquels le président choisit les juges qui sont ensuite confirmés par le pouvoir législatif (chambre haute au Nigéria). Au Ghana, le Conseil d'État, composé d'éminentes personnalités et de représentants élus des régions, est également consulté. Le rôle du Conseil judiciaire fait l'objet d'un débat permanent au Ghana : la Constitution prévoit que le président nomme les juges «sur la recommandation» du Conseil judiciaire, mais il n'est pas précisé si cet avis est contraignant.

\section{Figure 6.2. Désignation au terme d'un processus consécutif}

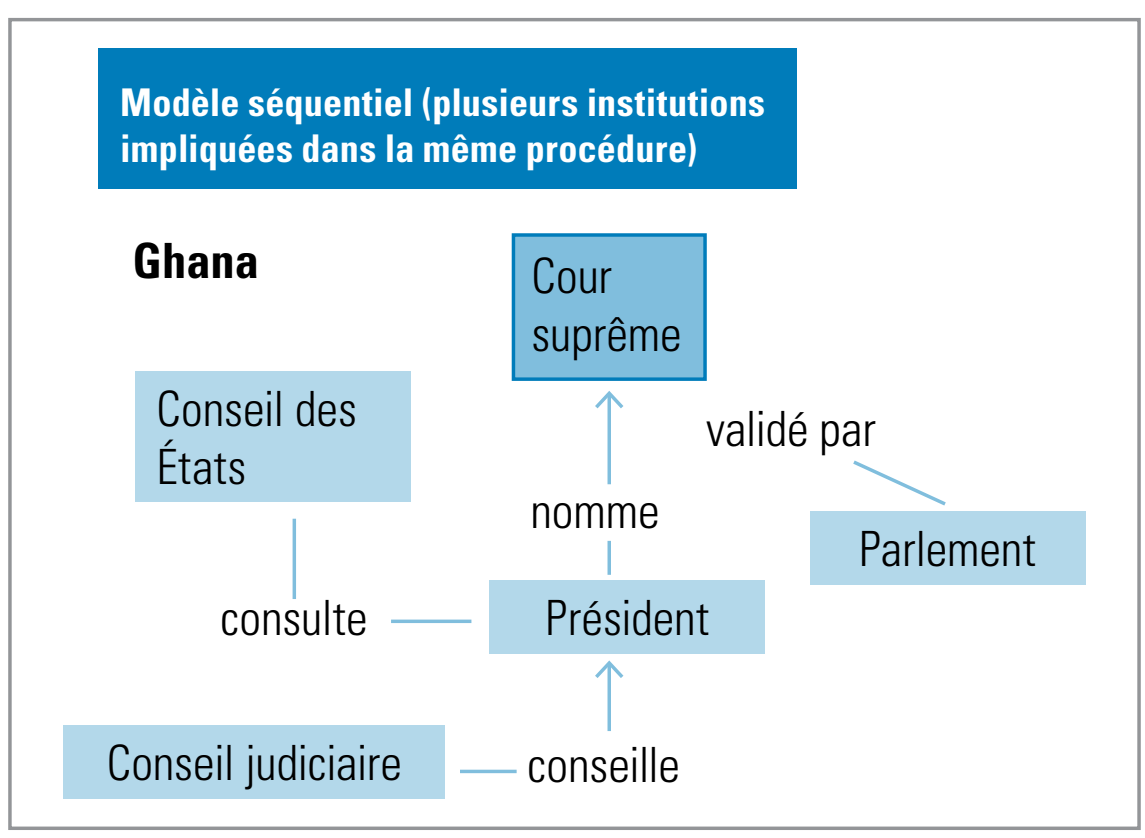




\section{Modèle 3 : Désignation par différentes autorités}

Dans la majorité des pays d'Afrique de l'Ouest, différentes «autorités de désignation" jouent un rôle dans la désignation des membres des institutions chargées de la justice constitutionnelle. Comme pour le modèle précédent, l'idée est d'impliquer de multiples acteurs issus des différents pouvoirs dans le processus de nomination. Contrairement à l'approche séquentielle, dans laquelle les acteurs doivent parvenir à un consensus sur les nominations, dans ce modèle chaque autorité choisit ses candidats séparément. Les neuf pays d'Afrique de l'Ouest appliquant cette méthode se réclament du modèle de Cour/Conseil constitutionnel(le) dans lequel l'institution chargée du contrôle de constitutionnalité ne se trouve pas à la tête de l'ordre juridictionnel ordinaire. Le nombre d'acteurs impliqués va de deux (Bénin, Côte d'Ivoire) à six (Niger, Guinée). Dans tous les cas, les institutions directement élues - le président et le législatif - font partie des autorités de recrutement (dans les pays à législature bicamérale, les deux chambres forment souvent chacune une autorité de nomination distincte [Togo, Mauritanie, Burkina Faso]). Certains pays considèrent également le Conseil supérieur de la magistrature comme une autorité de désignation, confiant ainsi à chacune des branches du pouvoir la possibilité de nommer certains des membres. Le Niger et la Guinée ont la gamme la plus étendue d'acteurs : outre le président et l'Assemblée nationale, les représentants des magistrats, des avocats et des facultés de droit peuvent désigner des membres de leur groupe. Ces deux pays donnent également collectivement aux institutions chargées de la protection des droits humains la possibilité de choisir au moins un représentant. 
Figure 6.3. Désignation par différentes autorités

\section{Modèle de nomination impliquant plusieurs autorités}

\section{Niger}

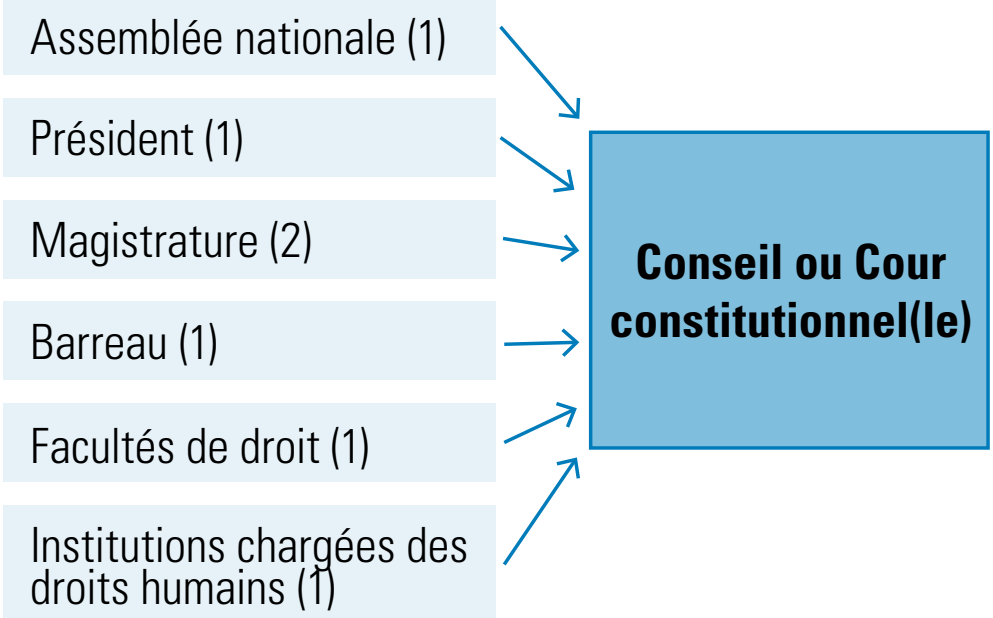

Cette approche se fonde sur le postulat selon lequel l'équilibre de la Cour peut être obtenu non pas uniquement en nommant des candidats de consensus, mais également en composant un organe dont les membres reflètent le paysage politique d'une manière globale. Par conséquent, la recherche du compromis a lieu lors de la préparation des décisions. Dans ce contexte, il est utile de noter que, conformément à la tradition française, ces dernières sont toujours consensuelles; le résultat des votes n'est pas rendu public et les opinions individuelles, qu'elles soient dissidentes ou concordantes, ne sont pas autorisées.

\section{Modèle 4 : Désignation par le chef de l'État}

Au Sénégal, seul le président dispose de l'autorité de nommer les membres $\mathrm{du}$ Conseil constitutionnel. Une loi organique détermine les critères d'éligibilité. Étant donné que les pays d'Afrique de l'Ouest sont souvent confrontés à des "présidents empereurs", ce modèle peut accentuer les 
difficultés à créer une institution indépendante capable de contrôler l'exécutif de manière effective. Pour autant, la capacité de chaque modèle à préserver la diversité et l'indépendance politique des juridictions chargées du contrôle de constitutionnalité dépend souvent du contexte. Par exemple, si un parti dispose de la majorité des deux tiers au sein du pouvoir législatif, il ne sera pas tenu de rechercher le consensus dans la désignation des juges. De la même manière, comme l'illustre l'exemple des États-Unis, le résultat du modèle 2 est largement influencé par la composition partisane des institutions impliquées. Le pouvoir de validation accordé au Sénat se révèle extrêmement important lorsque différents partis contrôlent les pouvoirs exécutif et législatif. Les présidents issus du même parti que celui majoritaire au Sénat ont vu leurs nominations confirmées dans $88 \%$ des cas - contre $55 \%$ en cas de «cohabitation» (Peri 2012 : 16). Bien sûr, si le président et le Sénat sont de la même famille politique, il est probable que les juges nommés seront eux aussi du même bord.

\section{Figure 6.4. Nomination par le chef de l'État}

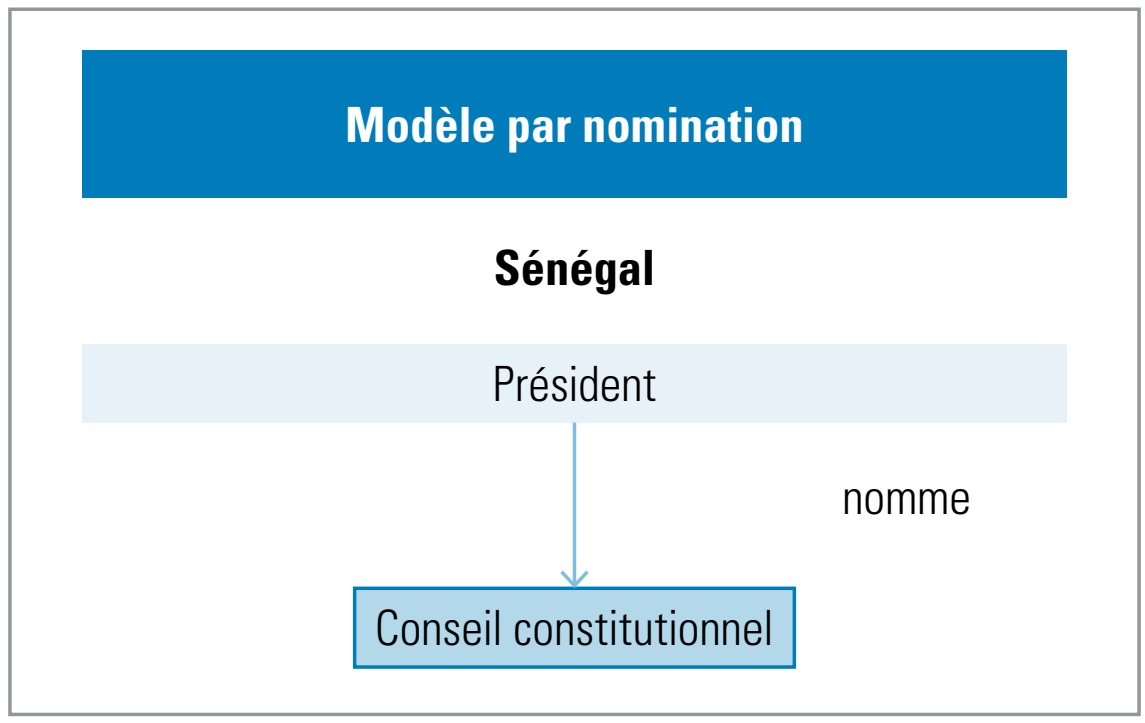

\section{La durée du mandat et la réélection}

La durée du mandat des membres, associée à la question de leur éventuelle réélection, a une influence majeure sur le fonctionnement de la juridiction. Ces facteurs peuvent affecter le taux de renouvellement, l'éventualité d'un 
changement politique au sein de la cour, l'indépendance des juges et la stabilité institutionnelle.

En général, les mandats à durée illimitée présentent des risques en termes de gérontisme, de renouvellement limité des membres et de rigiditéinstitutionnelle de manière globale (Commission de Venise 1997 : 9), ce qui entraîne une jurisprudence en décalage avec les mours et les convictions politiques de la société et de ses représentants (Comella 2011 : 270). Les mandats à durée limitée sont systématiques dans les pays faisant appel à un(e) Cour/Conseil constitutionnel(le), tandis que les mandats à vie - jusqu'à l'âge de la retraite - sont encore largement répandus dans les systèmes de Cour suprême. L'une des explications possibles à cette différence est que la Cour suprême fait partie intégrante du système judiciaire, fonctionnant comme une cour d'appel en dernier ressort pour d'autres questions. Les juges de Cour suprême bénéficient donc des mêmes garanties d'emploi que leurs collègues d'autres juridictions supérieures. À l'inverse, les juges des Cours/Conseils constitutionnel(le)s jouissent d'une position unique au sein du régime politique qui lie leur mandat aux dynamiques politiques. Dans les six pays étudiés suivant le modèle de Cour suprême, le mandat des juges s'achève à l'âge de la retraite, entre 60 et 70 ans. Quatre de ces six pays offrent la possibilité d'un départ à la retraite anticipée cinq à dix ans avant l'âge légal.

La durée des mandats à durée déterminée varie de cinq ans (Bénin, Cabo Verde) à neuf ans (Burkina Faso, Guinée, Mauritanie). Généralement, le parti au pouvoir n'a pas la possibilité de nommer tous les juges. Pour cette raison, le mandat des juges ne doit pas coïncider avec les mandats des parlementaires ou du président. Pour dissocier encore davantage la composition de la Cour des dynamiques politiques gouvernementales, des mandats longs et échelonnés dans le temps (de sorte que les sièges ne soient pas tous vacants en même temps) sont recommandés afin d'éviter un glissement politique soudain au sein de la Cour. Le Burkina Faso, la Guinée, la Côte d’Ivoire et le Sénégal prévoient explicitement dans leur Constitution un tel échelonnement du remplacement des membres.

Outre la durée du mandat, la possibilité de son renouvellement fait également débat. En Afrique de l'Ouest, trois des onze pays qui nomment leurs membres pour une durée limitée permettent un renouvellement des fonctions (Bénin, Mali et Togo). La question de savoir si le mandat peut être renouvelé reflète en partie la quête de l'équilibre adéquat entre indépendance et responsabilité. Pour certains universitaires, des mandats non renouvelables peuvent être une faiblesse, car il n'existe alors aucune contrainte incitant les juges à prendre leurs décisions de manière impartiale et sans arrière-pensée politique ni sanction en cas de mauvaise performance (Glenn Bass et Choudhry 2013 : 3). 
Par conséquent, les pays souhaitant renforcer la responsabilité des juges choisissent souvent des mandats courts avec possibilité de réélection ou de renouvellement. Toutefois, cette option est souvent perçue comme une menace pour l'indépendance de la justice. Les mandats renouvelables augmentent la probabilité d'ingérence politique dans la composition de la Cour. Les juges candidats à un second mandat peuvent engager leur responsabilité politique sur les questions à fort enjeu - en particulier si celles-ci concernent les actions des institutions impliquées dans le processus de renouvellement (des lois, ou des décrets, etc.). Il est utile de noter que la Cour constitutionnelle du Bénin, dont la compétence est la plus étendue parmi toutes les instances chargées de la justice constitutionnelle en Afrique de l'Ouest et qui a la réputation d'être la plus active de la région (voir chapitre 8), prévoit des mandats plutôt courts, mais renouvelables pour ses membres.

\section{La représentation des minorités}

Les prescriptions en matière de représentation des minorités, en vue de refléter la diversité (ethnique, linguistique, religieuse, etc.) du pays dans la composition des institutions chargées de la justice constitutionnelle sont rares et souvent fondées sur une pratique politique plutôt que sur une règle de droit. Les pays peuvent inclure une telle clause dans leur constitution en raison de leur passé immédiat ou de tensions sous-jacentes dans la société. Par exemple, la Constitution sud-africaine dispose que la composition du pouvoir judiciaire, y compris la Cour constitutionnelle, doit «refléter de manière globale la composition raciale et de genre» du pays, et la Constitution intérimaire du Soudan prévoyait "une représentation adéquate du Soudan méridional» au sein de la Cour constitutionnelle.

Les constitutions de l'Afrique de l'Ouest ne prévoient pas de telles clauses. Lorsque la désignation d'un juge nécessite la majorité qualifiée au sein du pouvoir législatif, différents partis politiques doivent s'accorder sur les candidats et il est donc possible de former un consensus pour choisir un juge issu de l'opposition ou d'une minorité. Par ailleurs, la Constitution du Nigéria prévoit que la Cour suprême soit composée de juges connaissant le droit musulman du statut personnel ou le droit coutumier. 


\section{Tableau 6.1. Aperçu de la composition et du processus de révocation des membres des juridictions compétentes en matière de justice constitutionnelle en Afrique de I'Ouest}

\begin{tabular}{|c|c|c|c|c|c|c|}
\hline & $\begin{array}{l}\text { Nombre } \\
\text { de juges }\end{array}$ & $\begin{array}{l}\text { Processus de } \\
\text { nomination }\end{array}$ & $\begin{array}{c}\text { Nomina- } \\
\text { tion du } \\
\text { président } \\
\text { de l'in- } \\
\text { stance }\end{array}$ & $\begin{array}{l}\text { Durée du } \\
\text { mandat } \\
\text { (années) }\end{array}$ & $\begin{array}{c}\text { Renou- } \\
\text { vellement } \\
\text { possible? }\end{array}$ & $\begin{array}{l}\text { Procédure de } \\
\text { révocation }\end{array}$ \\
\hline Bénin & $\begin{array}{l}7 \text { (article } \\
115[1] \text { ) }\end{array}$ & $\begin{array}{l}\text { Deux autorités distinctes } \\
\text { sont chargées du } \\
\text { recrutement : I'Assemblée } \\
\text { nationale (4 : } 2 \text { magistrats } \\
\text { avec au moins } 15 \text { ans } \\
\text { d'expérience, } 1 \text { éminent } \\
\text { juriste (professeur ou } \\
\text { avocat) avec au moins } \\
15 \text { ans d'expérience, } \\
1 \text { personne de grande } \\
\text { réputation professionnelle); } \\
\text { et le président de la } \\
\text { République (3: } 1 \text { magistrat } \\
\text { avec au moins } 15 \text { ans } \\
\text { d'expérience, un éminent } \\
\text { juriste (professeur ou } \\
\text { avocat) avec au moins } \\
15 \text { ans d'expérience, } \\
1 \text { personne de grande } \\
\text { réputation professionnelle) } \\
\text { (article } 115[3] \text { ) }\end{array}$ & $\begin{array}{l}\text { Élu par } \\
\text { ses pairs } \\
\text { parmi de la } \\
\text { profession } \\
\text { juridique } \\
\text { (article 116) }\end{array}$ & $\begin{array}{l}5 \text { (article } \\
115[1])\end{array}$ & $\begin{array}{l}\text { Oui, une fois } \\
\text { (article 115[1]) }\end{array}$ & $\begin{array}{l}\text { Irrévocables pour la durée } \\
\text { de leur mandat. Motifs: } \\
\text { aucune procédure prévue } \\
\text { par la Constitution, mais } \\
\text { d'après la loi organique } \\
\text { § 7-14 les motifs peuvent } \\
\text { inclure un handicap } \\
\text { physique permanent ou } \\
\text { la violation du serment } \\
\text { prêté, considéré comme } \\
\text { un acte de trahison: } \\
\text { ils jurent de «bien et } \\
\text { fidèlement remplir leurs } \\
\text { fonctions, de les exercer en } \\
\text { toute impartialité dans le } \\
\text { respect de la Constitution, } \\
\text { de garder le secret des } \\
\text { délibérations et des votes, } \\
\text { de ne prendre aucune } \\
\text { position publique, de ne } \\
\text { donner aucune consultation } \\
\text { sur les questions relevant } \\
\text { de la compétence de la } \\
\text { Cour». } \\
\text { Procédure : prévue au § } 13 \text {, } \\
\text { à la majorité des membres } \\
\text { de la Cour. }\end{array}$ \\
\hline $\begin{array}{l}\text { Burkina } \\
\text { Faso }\end{array}$ & $\begin{array}{l}12+\text { (article } \\
153[1])\end{array}$ & $\begin{array}{l}\text { Membres d'office + } \\
3 \text { institutions distinctes } \\
\text { chargées de la désignation : } \\
3 \text { membres (magistrats) } \\
\text { nécessitent un processus } \\
\text { de désignation en deux } \\
\text { temps : } 3 \text { par le président } \\
\text { de la République sur } \\
\text { proposition du ministre } \\
\text { de la Justice; } 3 \text { par le } \\
\text { président seul (dont au } \\
\text { moins un juriste), } 3 \text { par le } \\
\text { président de l'Assemblée } \\
\text { nationale (dont au moins un } \\
\text { juriste), } 3 \text { par le président } \\
\text { du Sénat (dont au moins un } \\
\text { juriste); anciens présidents } \\
\text { (article } 153[1] \text { ) }\end{array}$ & $\begin{array}{l}\text { Élu par ses } \\
\text { pairs (arti- } \\
\text { cle 153[2]) }\end{array}$ & $\begin{array}{l}9 \text { (article } \\
153[2] \text { ) }\end{array}$ & $\begin{array}{l}\text { Non (arti- } \\
\text { cle 153[3]) }\end{array}$ & $\begin{array}{l}\text { Motif : aucune procédure } \\
\text { prévue dans la Constitution, } \\
\text { mais d'après la loi } \\
\text { organique, à la demande } \\
\text { du juge ou en raison d'une } \\
\text { incapacité physique ou en } \\
\text { cas de condamnation pour } \\
\text { crime }\end{array}$ \\
\hline
\end{tabular}




\begin{tabular}{|c|c|c|c|c|c|c|}
\hline $\begin{array}{l}\text { Cabo } \\
\text { Verde }\end{array}$ & $3+$ & $\begin{array}{l}\text { Désignés par l'Assemblée } \\
\text { nationale à la majorité des } \\
\text { deux tiers (article 181[1a]) }\end{array}$ & $\begin{array}{l}\text { Élu par ses } \\
\text { pairs (arti- } \\
\text { cle } 215[4] \text { ) }\end{array}$ & $\begin{array}{l}9 \text { (article } \\
215[5])\end{array}$ & $\begin{array}{l}\text { Non (arti- } \\
\text { cle 215[5]) }\end{array}$ & $\begin{array}{l}\text { Motif : handicap physique } \\
\text { ou mental permanent, } \\
\text { procédure pénale ou } \\
\text { disciplinaire. } \\
\text { Procédure : soumise à } \\
\text { vérification de la Cour } \\
\text { elle-même }\end{array}$ \\
\hline $\begin{array}{l}\text { Côte } \\
\text { d'Ivoire }\end{array}$ & $\begin{array}{l}7+\text { (article } \\
89 \text { ) }\end{array}$ & $\begin{array}{l}\text { Sept sont nommés par } \\
\text { le président (y compris } \\
\text { le président du Conseil } \\
\text { constitutionnel), dont } 3 \text { sont } \\
\text { désignés par le président } \\
\text { de l'Assemblée nationale; } \\
\text { les anciens présidents sont } \\
\text { membres d'office (articles } \\
\text { 90-1) }\end{array}$ & $\begin{array}{l}\text { Nommé par } \\
\text { le président } \\
\text { (article 90) }\end{array}$ & $\begin{array}{l}6 \text { (articles } \\
90-1 \text { ) }\end{array}$ & $\begin{array}{l}\text { Non } \\
\text { (articles 90-1) }\end{array}$ & $\begin{array}{l}\text { Motif : décès, démission ou } \\
\text { incapacité absolue (article 92) } \\
\text { Ils bénéficient de l'immunité, } \\
\text { que seul le Conseil } \\
\text { constitutionnel peut décider } \\
\text { de lever (article 93). }\end{array}$ \\
\hline Gambie & $\begin{array}{l}5+\text { (article } \\
125 \text { ) }\end{array}$ & $\begin{array}{l}\text { Par le président sur } \\
\text { recommandation du Conseil } \\
\text { supérieur de la magistrature } \\
\text { (article 138) }\end{array}$ & $\begin{array}{l}\text { Par le pré- } \\
\text { sident après } \\
\text { consultation } \\
\text { du Conseil } \\
\text { supérieur } \\
\text { de la } \\
\text { magistrature } \\
\text { (article 138) }\end{array}$ & $\begin{array}{l}\text { Départ à } \\
\text { la retraite } \\
\text { possible à } \\
\text { partir de } \\
65 \text { ans et } \\
\text { à } 70 \text { ans } \\
\text { maximum } \\
\text { (article } \\
\text { 141[1]) }\end{array}$ & Non & $\begin{array}{l}\text { Motif : incapacité à assurer } \\
\text { les fonctions en raison d'un } \\
\text { handicap physique ou mental, } \\
\text { ou en cas de mauvaise } \\
\text { conduite (article 141[4)) } \\
\text { Procédure : enquête lancée sur } \\
\text { motion d'au moins la moitié } \\
\text { des membres de l'Assemblée } \\
\text { nationale et avec l'approbation } \\
\text { d'au moins deux tiers des } \\
\text { membres. Un tribunal composé } \\
\text { de } 3 \text { membres est désigné, } \\
\text { dirigé par un (ancien) magistrat } \\
\text { de haut rang. Le verdict du } \\
\text { tribunal, si positif, doit être } \\
\text { confirmé par l'Assemblée } \\
\text { nationale à une majorité des } \\
\text { deux tiers de ses membres } \\
\text { (article 141[5-6]) } \\
\text { Les juges bénéficient de } \\
\text { I'immunité dans l'exercice de } \\
\text { leurs fonctions judiciaires }\end{array}$ \\
\hline
\end{tabular}




\begin{tabular}{|c|c|c|c|c|c|c|}
\hline Ghana & $\begin{array}{l}10+\text { (article } \\
128[1])\end{array}$ & $\begin{array}{l}\text { Quatre étapes } \\
\text { consécutives : par } \\
\text { le président sur la } \\
\text { recommandation du Conseil } \\
\text { de la magistrature, en } \\
\text { consultation avec le Conseil } \\
\text { d'État et avec l'aval du } \\
\text { Parlement. Le président de } \\
\text { l'instance est nommé par le } \\
\text { président de la République } \\
\text { en consultation avec le } \\
\text { Conseil d'État et avec l'aval } \\
\text { du Parlement (article 144[2]) }\end{array}$ & $\begin{array}{l}\text { Par le } \\
\text { président de } \\
\text { la République } \\
\text { en consul- } \\
\text { tation avec } \\
\text { le Conseil } \\
\text { d'État et } \\
\text { avec l'aval } \\
\text { du Parlement } \\
\text { (article } \\
\text { 144[1]) }\end{array}$ & $\begin{array}{l}\text { Départ à } \\
\text { la retraite } \\
\text { possible à } \\
\text { partir de } \\
60 \text { ans et } \\
\text { à } 70 \text { ans } \\
\text { maximum } \\
\text { (article } \\
145[2 a] \text { ) }\end{array}$ & Non & $\begin{array}{l}\text { Motif : inconduite notoire, } \\
\text { incompétence ou incapacité à } \\
\text { remplir les fonctions en raison } \\
\text { d'un handicap physique ou } \\
\text { mental (article 146[1]) } \\
\text { Procédure : plusieurs } \\
\text { étapes : la demande de } \\
\text { révocation est déposée } \\
\text { auprès du président, qui la } \\
\text { transmet au président de } \\
\text { l'instance, qui peut à son } \\
\text { tour établir un comité en } \\
\text { cas d'affaire prima facie } \\
\text { (constitué de } 3 \text { juges des } \\
\text { instances supérieures ou } \\
\text { présidents des tribunaux } \\
\text { régionaux ou les deux, } \\
\text { nommés par le conseil de la } \\
\text { magistrature et de } 2 \text { autres } \\
\text { personnes qui ne sont pas } \\
\text { des membres du Conseil } \\
\text { d'État ou du Parlement } \\
\text { ou juristes et qui sont } \\
\text { désignées par le président } \\
\text { de la Cour suprême sur } \\
\text { recommandation du Conseil } \\
\text { d'État); toute suspension } \\
\text { est décidée par le président } \\
\text { conformément à l'avis du } \\
\text { Conseil d'État (article } 146 \\
\text { [2-5]) }\end{array}$ \\
\hline Guinée & $\begin{array}{l}9 \text { (article } \\
100)\end{array}$ & $\begin{array}{l}\text { Six institutions } \\
\text { distinctes chargées } \\
\text { de la désignation: } \\
\text { bureau de l'Assemblée } \\
\text { nationale (une éminente } \\
\text { personnalité); président } \\
\text { de la République (une } \\
\text { éminente personnalité); } \\
\text { corps de la magistrature } \\
\text { (3 magistrats avec } 20 \text { ans } \\
\text { d'expérience); barreau } \\
\text { (un avocat avec } 20 \text { ans } \\
\text { d'expérience); facultés } \\
\text { de droit (un professeur } \\
\text { avec } 20 \text { ans d'expérience); } \\
\text { Institut national des droits } \\
\text { humains (2 représentants) } \\
\text { (article 100) }\end{array}$ & $\begin{array}{l}\text { Élu par ses } \\
\text { pairs } \\
\text { (article } 101 \\
\text { [2]) }\end{array}$ & $\begin{array}{l}9 \text { (article } \\
100[1])\end{array}$ & $\begin{array}{l}\text { Non (ar- } \\
\text { ticle 100[1]) }\end{array}$ & $\begin{array}{l}\text { Irrévocables pour la } \\
\text { durée de leur mandat } \\
\text { (article 102[1]) } \\
\text { Leur immunité ne peut } \\
\text { être levée que par la Cour } \\
\text { constitutionnelle (sauf en } \\
\text { cas de flagrant délit). En cas } \\
\text { de crime ou d'inconduite, } \\
\text { ils peuvent être jugés } \\
\text { par la Cour suprême } \\
\text { (article 102[3]) }\end{array}$ \\
\hline $\begin{array}{l}\text { Guinée- } \\
\text { Bissauu }\end{array}$ & & $\begin{array}{l}\text { Propositions du } \\
\text { Conseil supérieur de la } \\
\text { magistrature et nomination } \\
\text { par le président } \\
\text { (article 120[1]) }\end{array}$ & & $\begin{array}{l}\text { Âge de la } \\
\text { retraite : } \\
60 \text { ans } \\
\text { (article } 33 \\
\text { EMJ) }\end{array}$ & Non & $\begin{array}{l}\text { Motif : infractions } \\
\text { disciplinaires } \\
\text { (articles 123[3], } 47 \text { EMJ) }\end{array}$ \\
\hline
\end{tabular}




\begin{tabular}{|c|c|c|c|c|c|c|}
\hline $\begin{array}{l}\text { Libé- } \\
\text { ria }\end{array}$ & $\begin{array}{l}5 \\
\text { (article 67) }\end{array}$ & $\begin{array}{l}\text { Deux étapes } \\
\text { consécutives : désignés/ } \\
\text { nommés par le président } \\
\text { avec l'aval du Sénat. Les } \\
\text { candidats doivent être } \\
\text { des citoyens libériens } \\
\text { et avoir pratiqué le droit } \\
\text { pendant au moins } 5 \text { ans } \\
\text { (article68) }\end{array}$ & $\begin{array}{l}\text { Nommé } \\
\text { par le } \\
\text { président } \\
\text { avec l'aval } \\
\text { du Sénat } \\
\text { (article 68) }\end{array}$ & $\begin{array}{l}\text { Âge de la } \\
\text { retraite : } \\
70 \text { ans (ar- } \\
\text { ticle } 72[\mathrm{~b}] \text { ) }\end{array}$ & - & $\begin{array}{l}\text { Motif : inconduite avérée, } \\
\text { faute professionnelle } \\
\text { grave, incapacité à } \\
\text { assurer les fonctions ou } \\
\text { condamnation par une cour } \\
\text { de justice pour trahison, } \\
\text { corruption ou autre délit } \\
\text { (article 71) Procédure: } \\
\text { par le pouvoir législatif } \\
\text { (article 71) }\end{array}$ \\
\hline Mali & $\begin{array}{l}9 \\
\text { (article 81) }\end{array}$ & $\begin{array}{l}\text { Trois institutions distinctes } \\
\text { chargées du recrutement : } \\
\text { président de la République } \\
\text { (3, dont } 2 \text { juristes); } \\
\text { Assemblée nationale (3 } \\
\text { dont } 2 \text { juristes); Conseil } \\
\text { supérieur de la } \\
\text { magistrature (3, tous } \\
\text { magistrats) (article 91) }\end{array}$ & $\begin{array}{l}\text { Élu par ses } \\
\text { pairs } \\
\text { (article 92) }\end{array}$ & $\begin{array}{l}7 \\
\text { (article 91) }\end{array}$ & $\begin{array}{l}\text { Oui, } \\
\text { une fois } \\
\text { (article 91) }\end{array}$ & $\begin{array}{l}\text { Motif : uniquement } \\
\text { dans la loi organique : } \\
\text { si un membre de la } \\
\text { Cour a accepté une } \\
\text { fonction ou un poste } \\
\text { incompatible avec sa } \\
\text { fonction, perte des droits } \\
\text { civiques et politiques, } \\
\text { ou manquement aux } \\
\text { obligations générales ou } \\
\text { spécifiques } \\
\text { (articles } 3 \text { et } 10 \text { de la loi } \\
\text { organique) } \\
\text { Procédure : précisée dans la } \\
\text { loi organique uniquement: } \\
\text { procédure interne à la Cour }\end{array}$ \\
\hline $\begin{array}{l}\text { Mau- } \\
\text { ritanie }\end{array}$ & $\begin{array}{l}9 \\
\text { (article 81) }\end{array}$ & $\begin{array}{l}\text { Trois institutions } \\
\text { distinctes chargées de la } \\
\text { désignation : président de } \\
\text { la République (4); président } \\
\text { de l'Assemblée nationale } \\
\text { (3); président du Sénat (2) } \\
\text { (article 81) }\end{array}$ & $\begin{array}{l}\text { Par le } \\
\text { président } \\
\text { parmi les } \\
\text { candidats } \\
\text { qu'il a } \\
\text { nommés } \\
\text { (article 81) }\end{array}$ & $\begin{array}{l}9 \text { (article } \\
81)\end{array}$ & $\begin{array}{l}\text { Non } \\
\text { (article 81) }\end{array}$ & $\begin{array}{l}\text { Motifs : uniquement } \\
\text { dans la loi organique : si } \\
\text { un membre de la Cour a } \\
\text { accepté une fonction ou } \\
\text { un poste incompatible } \\
\text { avec sa fonction ou en } \\
\text { cas de handicap physique } \\
\text { permanent } \\
\text { Procédure : interne au Conseil } \\
\text { constitutionnel }\end{array}$ \\
\hline Niger & $\begin{array}{l}7 \text { (article } \\
121 \text { ) }\end{array}$ & $\begin{array}{l}\text { Six institutions } \\
\text { distinctes chargées } \\
\text { de la désignation: } \\
\text { bureau de l'Assemblée } \\
\text { nationale (1 membre } \\
\text { avec expérience } \\
\text { administrative ou } \\
\text { juridique); président de } \\
\text { la République (1 membre } \\
\text { élu par ses pairs); corps } \\
\text { de la magistrature } \\
\text { (2 magistrats); barreau } \\
\text { (1 avocat); facultés } \\
\text { (1 professeur); collectif } \\
\text { des associations } \\
\text { de défense des } \\
\text { droits humains (un } \\
\text { représentant) (article 121) }\end{array}$ & $\begin{array}{l}\text { Élu par } \\
\text { ses pairs } \\
\text { (article 123) }\end{array}$ & $\begin{array}{l}6 \text { (article } \\
121 \text { ) }\end{array}$ & $\begin{array}{l}\text { Non (ar- } \\
\text { ticle 121) }\end{array}$ & $\begin{array}{l}\text { Motif : négligence } \\
\text { manifeste, ou si le } \\
\text { membre ne remplit plus } \\
\text { les exigences pour siéger } \\
\text { à la Cour } \\
\text { Procédure : interne à la Cour } \\
\text { constitutionnelle (précisée } \\
\text { dans la loi organique } \\
\text { uniquement) }\end{array}$ \\
\hline
\end{tabular}




\begin{tabular}{|c|c|c|c|c|c|c|}
\hline Nigéria & $\begin{array}{l}21 \\
\text { maximum } \\
\text { (article 2[a]) }\end{array}$ & $\begin{array}{l}\text { Trois étapes } \\
\text { consécutives: } \\
\text { recommandation } \\
\text { du Conseil de la } \\
\text { magistrature, validation } \\
\text { du Sénat et nomination } \\
\text { par le président } \\
\text { (article 231[1]) }\end{array}$ & $\begin{array}{l}\text { Même } \\
\text { procédure } \\
\text { que pour } \\
\text { les autres } \\
\text { membres } \\
\text { (ar- } \\
\text { ticle 231[1]) }\end{array}$ & $\begin{array}{l}\text { Départ à } \\
\text { la retraite } \\
\text { possible à } \\
\text { partir de } \\
65 \text { ans et } \\
\text { à } 70 \text { ans } \\
\text { maximum } \\
\text { (article } \\
291[1] \text { ) }\end{array}$ & Non & $\begin{array}{l}\text { Motif : en cas } \\
\text { d'incapacité à } \\
\text { assurer leurs } \\
\text { fonctions (handicap } \\
\text { physique ou mental, } \\
\text { inconduite ou } \\
\text { infraction au code de } \\
\text { conduite). } \\
\text { Procédure : par } \\
\text { le président, sur } \\
\text { recommandation } \\
\text { du Conseil de la } \\
\text { magistrature; } \\
\text { le Sénat doit } \\
\text { également approuver } \\
\text { la révocation du } \\
\text { président de la Cour } \\
\text { suprême par une } \\
\text { majorité des deux } \\
\text { tiers (article292[2]) }\end{array}$ \\
\hline Sénégal & $\begin{array}{l}5 \\
\text { (article 89) }\end{array}$ & $\begin{array}{l}\text { Nommé par le président } \\
\text { (article 89); la loi } \\
\text { organique prévoit que } \\
\text { le président nomme au } \\
\text { moins trois magistrats } \\
\text { de haut rang (anciens } \\
\text { ou en fonction); les deux } \\
\text { autres personnes doivent } \\
\text { aussi être juristes }\end{array}$ & $\begin{array}{l}\text { Même } \\
\text { procédure } \\
\text { que pour } \\
\text { les autres } \\
\text { membres } \\
\text { (article 89) }\end{array}$ & $\begin{array}{l}6 \text { (article } \\
89 \text { ) }\end{array}$ & $\begin{array}{l}\text { Non } \\
\text { (article 89) }\end{array}$ & $\begin{array}{l}\text { Aucune prévue par } \\
\text { la Constitution, mais } \\
\text { dans la loi organique } \\
\text { Motif : à leur demande, } \\
\text { ou en cas d'incapacité } \\
\text { physique (article 89) } \\
\text { Procédure : interne au } \\
\text { conseil }\end{array}$ \\
\hline $\begin{array}{l}\text { Sierra } \\
\text { Leone }\end{array}$ & $\begin{array}{l}5+ \\
\text { (article 121) }\end{array}$ & $\begin{array}{l}\text { Trois étapes } \\
\text { consécutives: } \\
\text { avis du Conseil de } \\
\text { la magistrature, } \\
\text { validation du Parlement, } \\
\text { nomination par le } \\
\text { président (article 135[2]) }\end{array}$ & $\begin{array}{l}\text { Même } \\
\text { procédure } \\
\text { que pour } \\
\text { les autres } \\
\text { membres } \\
\text { (article } 135 \\
\text { [1]) }\end{array}$ & $\begin{array}{l}\text { Départ à } \\
\text { la retraite } \\
\text { possible à } \\
\text { partir de } \\
60 \text { ans et } \\
\text { à } 65 \text { ans } \\
\text { maximum } \\
\text { (ar- } \\
\text { ticle 137[2]) }\end{array}$ & Non & $\begin{array}{l}\text { Motif : incapacité à } \\
\text { exercer les fonctions } \\
\text { (handicap physique ou } \\
\text { mental ou inconduite) } \\
\text { Procédure : } 4 \text { étapes } \\
\text { consécutives : sur } \\
\text { l'avis du Conseil de } \\
\text { la magistrature, le } \\
\text { président nomme } \\
\text { un tribunal spécial } \\
\text { chargé d'examiner } \\
\text { l'affaire (3 personnes } \\
\text { remplissant les } \\
\text { conditions pour } \\
\text { être juge à la Cour } \\
\text { suprême); si le } \\
\text { tribunal recommande } \\
\text { la révocation, celle-ci } \\
\text { doit être approuvée } \\
\text { par une majorité } \\
\text { des deux tiers du } \\
\text { Parlement et du Sénat } \\
\text { (article 137) }\end{array}$ \\
\hline
\end{tabular}




\begin{tabular}{|c|c|c|c|c|c|c|}
\hline Togo & $\begin{array}{l}9 \text { (article } \\
100)\end{array}$ & $\begin{array}{l}\text { Trois institutions } \\
\text { distinctes chargées de la } \\
\text { désignation : président } \\
\text { ( } 3 \text { sur la base de } \\
\text { compétences juridiques); } \\
\text { Assemblée nationale } \\
\text { à la majorité des deux } \\
\text { tiers ( } 3 \text {, hors membres } \\
\text { de l'Assemblée, dont } 1 \\
\text { pour ses compétences } \\
\text { juridiques); Sénat à la } \\
\text { majorité des deux tiers (3, } \\
\text { hors membres du sénat, } \\
\text { dont } 1 \text { en fonction de ses } \\
\text { compétences juridiques } \\
\text { (article 100) }\end{array}$ & $\begin{array}{l}\text { Par le pré- } \\
\text { sident parmi } \\
\text { les membres } \\
\text { (article 101) }\end{array}$ & $\begin{array}{l}7 \text { (article } \\
100)\end{array}$ & $\begin{array}{l}\text { Oui (ar- } \\
\text { ticle 100) }\end{array}$ & $\begin{array}{l}\text { Motif : trahison } \\
\text { (violation du } \\
\text { serment); acceptation } \\
\text { de fonctions } \\
\text { incompatibles avec la } \\
\text { charge, perte des droits } \\
\text { civiques et politiques. } \\
\text { Procédure prévue par } \\
\text { la loi organique et non } \\
\text { dans la Constitution. } \\
\text { Leur immunité ne peut } \\
\text { être levée que par la } \\
\text { Cour constitutionnelle } \\
\text { (sauf en cas de flagrant } \\
\text { délit) (article 102) }\end{array}$ \\
\hline
\end{tabular}

\section{Légende}

Afrique de l'Ouest francophone

Afrique de l'Ouest anglophone

Afrique de l'Ouest lusophone 



\section{Le contrôle de la constitutionnalité des lois}




\title{
7. Le contrôle de la constitutionnalité des lois
}

\author{
Yuhniwo Ngenge
}

Comme nous l'avons suggéré dans les chapitres précédents, la principale tâche des institutions chargées de la justice constitutionnelle - qu'elles soient centralisées ou déconcentrées - est de préserver l'État de droit et de veiller au respect des principes constitutionnels. Lun des aspects fondamentaux de cette fonction est l'examen de la constitutionnalité (contrôle de constitutionnalité), dont l'objectif est de protéger les principes et dispositions constitutionnel(le) $s$ de toute atteinte par une législation, une réglementation ou une action gouvernementale qui y contreviendrait (IDEA International $2011: 6$ ). Cette fonction de surveillance peut prendre différentes formes en fonction des juridictions et des systèmes juridiques. Ce chapitre examine la forme et le type de ces différences en Afrique de l'Ouest. Après une présentation des différents modèles et types de contrôle, la réflexion cherche à répondre aux questions suivantes : quelle compétence matérielle les constitutions actuelles accordentelles aux juridictions chargées du contrôle de constitutionnalité dans la région, et quelle est sa portée? Quels types de contrôles peuvent-elles effectuer? Quels sont les domaines soumis (ou non) au contrôle de constitutionnalité?

\section{Les types de contrôle}

Il existe deux principaux modèles de contrôle de constitutionnalité. Le premier cherche à savoir si l'examen d'un acte ou d'une loi en vue d'en confirmer la constitutionnalité est abstrait (distinct de tout litige juridique) ou concret (lié ou consécutif à un litige juridique). Le second modèle dépend du moment auquel a lieu le contrôle - à savoir avant l'intégration de la loi dans le système juridique (a priori) ou après (a posteriori).

\section{Le contrôle abstrait et le contrôle concret}

Le contrôle abstrait peut être appliqué tant aux lois et autres normes déjà en vigueur dans le système juridique qu'à celles encore non adoptées, telles que des projets de loi en cours d'examen au Parlement. Pour autant, ce contrôle 
a généralement lieu indépendamment de tout litige ou affaire. Même lorsque les lois et règlements examinés font déjà partie de l'ordre juridique, la remise en cause de leur constitutionnalité n'est pas fondée sur un litige juridique, mais au contraire sur une disposition de la constitution (de Andrade 2001 : 983). La justification de cette action ne reposant pas sur des faits, la question de constitutionnalité n'est pas un simple élément du dossier, elle représente l'affaire elle-même (de Andrade 2001). Toutefois, la nature abstraite de cette affaire nécessite que le juge invente ou imagine des cas de figure pour donner un contexte dans lequel comprendre la loi contestée et évaluer son impact, ce qui complique les choses, car la gamme de cas de figure à laquelle la loi contestée peut s'appliquer est vaste. Sans aucun doute, certaines lois sont manifestement inconstitutionnelles, de sorte que le résultat du contrôle sera le même, qu'il ait été effectué de manière concrète ou abstraite. Cependant, il n'est pas toujours évident de comprendre ou d'évaluer de manière abstraite les effets inconstitutionnels - réels ou potentiels - d'une loi.

À l'inverse, le contrôle concret ou incident est principalement fondé sur des faits. Il est généralement soulevé dans le cadre d'un litige juridique existant, qui est le principal motif de l'action en justice. De tels contrôles impliquent de remettre en cause une loi (ou l'une de ses dispositions) pour des raisons de constitutionnalité. La juridiction cherche à confirmer si, sur la base d'un ensemble de faits qui lui ont été soumis, l'application d'une loi donnée résultera en une situation inconstitutionnelle. Le contrôle a normalement lieu soit pendant le procès initial, soit en seconde instance ou en appel. Dans ce dernier cas, la compétence de la juridiction pour examiner la loi peut se fonder sur sa compétence exclusive en premier ressort pour les questions de constitutionnalité (comme c'est le cas des Cours/Conseils constitutionnel(le)s et de certaines Cours suprêmes) ou en appel (cas de la plupart des Cours suprêmes). Par conséquent, contrairement au contrôle abstrait, le contrôle concret ne peut avoir lieu qu'a posteriori (une fois la loi promulguée et intégrée au système juridique). Le contrôle concret semble être un trait distinctif des systèmes juridiques appliquant le modèle de contrôle juridictionnel décentralisé, mais de nombreuses autres juridictions suivant le modèle de contrôle centralisé y ont également recours. Imitant d'autres juridictions de modèle centralisé - et certains pays d'Afrique de l'Ouest d'héritage francophone, qui ont introduit le contrôle concret avant cette date - la France a, en 2008, établi la question prioritaire de constitutionnalité, une forme de contrôle concret répondant à la nécessité de mieux protéger et faire appliquer les droits fondamentaux.

Dans les pays de modèle centralisé, le contrôle concret s'effectue de manière différente par rapport aux pays de modèle décentralisé. Par exemple, dans le 
cas des juridictions suivant un modèle strict de Cour suprême décentralisé, la Cour exerce une compétence en appel lorsqu'elle effectue un contrôle de constitutionnalité concret, tandis que dans le modèle centralisé (de type kelsénien ou de Cour suprême), la Cour exerce une compétence originelle et exclusive. Par conséquent, tandis que la Cour suprême du modèle décentralisé doit attendre que l'affaire lui soit soumise après avoir remonté les différents niveaux juridictionnels, la Cour ou le Conseil constitutionnel(le) du modèle centralisé peut s'en saisir immédiatement. En vertu de la loi, les tribunaux inférieurs dans les systèmes décentralisés doivent surseoir à statuer lorsqu'une question de constitutionnalité leur est soumise et renvoyer l'affaire à la juridiction spécialisée pour décision. C’est également le cas dans certains systèmes de Cour suprême où le contrôle est centralisé.

Des différences peuvent également exister au sein des systèmes ayant adopté le même type de contrôle. Dans certaines juridictions de modèle centralisé, comme la France ou l'Allemagne, la procédure de contrôle concret n'est possible que lorsque les violations des droits constitutionnels sont au cœur de la question de constitutionnalité. Dans bon nombre de pays ouest-africains francophones l'ayant adopté, le contrôle concret peut, en revanche, être mis en œuvre dans le cadre de tout recours en constitutionnalité, qu'il s'agisse des droits humains ou non.

\section{Le contrôle a priori et le contrôle a posteriori}

Le contrôle a priori ou préliminaire a lieu avant l'adoption d'un projet de loi ou - si le pouvoir législatif l'a déjà adopté - avant sa promulgation. D’un point de vue technique, le contrôle porte sur un projet de loi et non sur une loi, afin de confirmer sa constitutionnalité avant de l'intégrer au corpus normatif. Bien que les institutions ou hommes politiques (tels que les membres du corps législatif et de l'exécutif) demandent aux juridictions d'effectuer un contrôle a priori, des personnes privées peuvent parfois contester une loi avant son adoption par un recours individuel (Stone Sweet 2012: 823; Ngenge 2013 : 451). Ce type de contrôle a un rôle préventif : filtrer les lois ou actes potentiellement contraires à la Constitution avant qu'ils ne produisent des effets inconstitutionnels (Stone Sweet 2012 : 823; Choudhry 2013 : 8). Il a donc l'avantage de garantir que toutes les lois proposées sont parfaitement valides et certifiées du point de vue constitutionnel. Cependant, il implique la participation de la justice - parfois inutilement - au travail législatif d'élaboration des lois, ce qui brouille le principe de la séparation des pouvoirs.

Le contrôle a priori, parce qu'il a lieu avant qu'un projet de loi n'entre dans l'ordonnancement juridique, est nécessairement abstrait par nature. L'examen est donc parfois quelque peu aléatoire, notamment lorsque le juge doit 
s'imaginer des cas de figure pour comprendre le projet de loi en question et évaluer ses impacts. Il est utilisé principalement dans les pays ayant recours au modèle centralisé ou de Cour constitutionnelle. Cependant, certains pays appartenant au modèle de Cour suprême autorisent également une certaine forme de contrôle a priori, par laquelle le Parlement sollicite un avis sur la constitutionnalité d'un projet de loi auprès d'experts juristes, souvent la magistrature. À l'inverse, le contrôle a posteriori a lieu après qu'une loi ou un acte normatif a intégré le système juridique. Il peut alors être de type concret ou abstrait.

\section{Les types et l'occurrence du contrôle de constitutionnalité en Afrique de l'Ouest}

Cette section examine comment les constitutions de l'Afrique de l'Ouest contemporaine ont défini la compétence matérielle des instances chargées du contrôle de constitutionnalité et le moment choisi pour effectuer celui-ci. Pour cela, il est utile de distinguer entre les juridictions de civil law et celles de common law.

\section{Les juridictions de civil law}

Les juridictions de civil law incluent tous les pays de tradition francophone et lusophone. La majorité de ces pays, comme nous l'avons vu au chapitre 3, ont adopté un modèle de contrôle centralisé, généralement de type kelsénien ou similaire. Au-delà de ce trait commun, il existe des variantes dans le type de contrôle de constitutionnalité mis en place dans chaque pays.

En raison de l'influence dominante du modèle kelsénien de contrôle de constitutionnalité - en particulier sa variante française - les contrôles abstraits et a priori, caractérisés par l'absence d'un litige juridique concret, ont naturellement constitué une partie de la compétence matérielle de la plupart des juridictions chargées du contrôle de la constitutionnalité dans les pays ouest-africains francophones et lusophones. Nous l'avons mentionné plus haut, cela vient s'ajouter au contrôle concret a posteriori, que la plupart de ces juridictions ont adopté bien avant la France, lors de la création des juridictions constitutionnelles dans les années 1990.

En règle générale, le contrôle de constitutionnalité est applicable à trois grandes catégories d'actes juridiques. La première est la législation, qui d'un point de vue technique regroupe les lois issues du pouvoir législatif, dans la mesure où elles sont adoptées par le Parlement ou un autre organe législatif similaire. Les lois dans les pays de civil law peuvent prendre différentes formes, par exemple 
une loi constitutionnelle (qui modifie la Constitution), une loi organique (qui organise et réglemente le fonctionnement des institutions créées par la Constitution), ou des lois ordinaires (qui réglementent un domaine donné et sont adoptées suivant la procédure législative ordinaire). En théorie, toutes les lois adoptées par le pouvoir législatif sont soumises au contrôle. Dans la pratique, en revanche, la portée du contrôle de constitutionnalité des différents textes est sujette à interprétation, car rares sont les constitutions qui traitent de cette question en détail (voir chapitre 8).

La deuxième catégorie d'actes juridiques rassemble les actes réglementaires globalement définis comme les décisions de la branche exécutive du pouvoir-, tels que les décrets présidentiels ou les ordonnances, ainsi que les actes des autres autorités administratives. Dans certains pays comme le Bénin, dans la volonté de renforcer le système de protection des droits humains individuels, les actes réglementaires sont également soumis au contrôle de constitutionnalité. Par conséquent, l'article 22 de la loi organique portant organisation de la Cour constitutionnelle dispose que : «Les actes réglementaires censés porter atteinte aux droits fondamentaux de la personne humaine et aux libertés publiques, et en général, sur la violation des droits de la personne humaine sont transmis à la Cour constitutionnelle.»

La troisième catégorie d'actes juridiques soumis au contrôle inclut certains types de traités et conventions internationales, des décisions de justice et les règlements intérieurs du pouvoir législatif et/ou des autres organes publics. Il convient d'examiner plus avant le traitement des décisions des tribunaux de niveau inférieur dans la hiérarchie judiciaire. Dans les pays de civil law de l'Afrique de l'Ouest, les juridictions chargées de la justice constitutionnelle, du fait de leur spécialisation et de leur place hors du système judiciaire ordinaire, ne contrôlent normalement pas les décisions des tribunaux ordinaires. Toutefois, au Bénin, la Cour constitutionnelle peut examiner les décisions de ces instances. Elle a ainsi statué, dans sa décision 04/107 du 7 décembre 2004, qu'elle avait compétence pour juger en appel les décisions prises par l'ensemble des autres tribunaux lorsqu'il s'agit de cas de violation des droits constitutionnels. 
Tableau 7.1. Types de contrôle de constitutionnalité et des actes juridiques pouvant faire objet d'un tel contrôle dans les pays francophones et lusophones de l'Afrique de l'Ouest

\begin{tabular}{|c|c|c|c|c|c|}
\hline & \multicolumn{3}{|c|}{ Occurrence et types de contrôle } & \multirow[b]{2}{*}{ Actes juridiques } & \multirow[b]{2}{*}{$\begin{array}{l}\text { Dispositions de la } \\
\text { Constitution ou loi } \\
\text { organique }\end{array}$} \\
\hline & $\begin{array}{l}\text { A priori (avant } \\
\text { promulgation) }\end{array}$ & $\begin{array}{c}\text { Concret/ } \\
\text { incident (a } \\
\text { posteriori par } \\
\text { nature) }\end{array}$ & $\begin{array}{l}\text { Abstrait (hors } \\
\text { litige) }\end{array}$ & & \\
\hline \multirow[t]{4}{*}{ Bénin } & Oui & Non & Non & $\begin{array}{l}\text { Règlements } \\
\text { intérieurs des } \\
\text { assemblées }\end{array}$ & \multirow[t]{4}{*}{$\begin{array}{l}\text { Articles 3, 117, 121- } \\
3,144,146 \\
\text { (Constitution) }\end{array}$} \\
\hline & Oui & Oui & Oui & $\begin{array}{l}\text { Loi statutaire/ } \\
\text { Législation }\end{array}$ & \\
\hline & Inapplicable & Oui & Oui & $\begin{array}{l}\text { Actes } \\
\text { réglementaires }\end{array}$ & \\
\hline & Oui & Non & Non & Traités & \\
\hline \multirow[t]{4}{*}{$\begin{array}{l}\text { Burkina } \\
\text { Faso }\end{array}$} & Oui & Non & Non & $\begin{array}{l}\text { Règlements } \\
\text { intérieurs des } \\
\text { assemblées }\end{array}$ & \multirow[t]{4}{*}{$\begin{array}{l}\text { Articles 107, 150, } \\
152,155,157 \\
\text { (Constitution) }\end{array}$} \\
\hline & Oui & Oui & Non & $\begin{array}{l}\text { Loi statutaire/ } \\
\text { Législation }\end{array}$ & \\
\hline & Oui & Oui & Oui & $\begin{array}{l}\text { Actes } \\
\text { réglementaires }\end{array}$ & \\
\hline & Oui & Non & Non & Traités & \\
\hline \multirow[t]{4}{*}{ Cabo Verde } & Non & Oui & Oui & $\begin{array}{l}\text { Règlements } \\
\text { intérieurs des } \\
\text { assemblées }\end{array}$ & \multirow[t]{4}{*}{$\begin{array}{l}\text { Articles 12, 280-1 } \\
\text { (Constitution) }\end{array}$} \\
\hline & Oui & Oui & Oui & $\begin{array}{l}\text { Loi statutaire/ } \\
\text { Législation }\end{array}$ & \\
\hline & Inapplicable & Oui & Oui & $\begin{array}{l}\text { Actes } \\
\text { réglementaires }\end{array}$ & \\
\hline & Oui & Oui & Oui & Traités & \\
\hline \multirow[t]{4}{*}{$\begin{array}{l}\text { Côte } \\
\text { d'Ivoire }\end{array}$} & Oui & Non & Oui & $\begin{array}{l}\text { Règlements } \\
\text { intérieurs des } \\
\text { assemblées }\end{array}$ & \multirow[t]{4}{*}{$\begin{array}{l}\text { Articles 52, 70,75 } \\
88,86,96-7 \\
\text { (Constitution) }\end{array}$} \\
\hline & Oui & Oui & Non & $\begin{array}{l}\text { Loi statutaire/ } \\
\text { Législation }\end{array}$ & \\
\hline & Oui & Oui & Non & $\begin{array}{l}\text { Actes } \\
\text { réglementaires }\end{array}$ & \\
\hline & Oui & Non & Non & Traités & \\
\hline \multirow[t]{4}{*}{ Guinée } & Non & Oui & Oui & $\begin{array}{l}\text { Règlements } \\
\text { intérieurs des } \\
\text { assemblées }\end{array}$ & \multirow[t]{4}{*}{$\begin{array}{l}\text { Articles, 90, 93-5 } \\
\text { (Constitution) }\end{array}$} \\
\hline & Oui & Oui & Non & $\begin{array}{l}\text { Loi statutaire/ } \\
\text { Législation }\end{array}$ & \\
\hline & Oui & Oui & Oui & $\begin{array}{l}\text { Actes } \\
\text { réglementaires }\end{array}$ & \\
\hline & Oui & Non & Non & Traités & \\
\hline
\end{tabular}




\begin{tabular}{|c|c|c|c|c|c|}
\hline \multirow[t]{4}{*}{$\begin{array}{l}\text { Guinée- } \\
\text { Bissau }\end{array}$} & Indéterminé & Indéterminé & Indéterminé & $\begin{array}{l}\text { Règlements } \\
\text { intérieurs des } \\
\text { assemblées }\end{array}$ & \multirow[t]{4}{*}{$\begin{array}{l}\text { Article } 126 \\
\text { (Constitution) }\end{array}$} \\
\hline & Non & Oui & Non & $\begin{array}{l}\text { Loi Statutaire/ } \\
\text { Législation }\end{array}$ & \\
\hline & Non & Oui & Non & $\begin{array}{l}\text { Actes } \\
\text { réglementaires }\end{array}$ & \\
\hline & Oui & Non & Non & Traités & \\
\hline \multirow[t]{4}{*}{ Mali } & Oui & Non & Non & $\begin{array}{l}\text { Règlements } \\
\text { intérieurs des } \\
\text { assemblées }\end{array}$ & \multirow[t]{4}{*}{$\begin{array}{l}\text { Articles 85-6,88, } 90 \\
\text { (Constitution) }\end{array}$} \\
\hline & Oui & Non & Non & $\begin{array}{l}\text { Loi statutaire/ } \\
\text { Législation }\end{array}$ & \\
\hline & Non & Oui & Oui & $\begin{array}{l}\text { Actes } \\
\text { réglementaires }\end{array}$ & \\
\hline & Oui & Non & Non & Traités & \\
\hline \multirow[t]{4}{*}{ Mauritanie } & Oui & Non & Non & $\begin{array}{l}\text { Règlements } \\
\text { intérieurs des } \\
\text { assemblées }\end{array}$ & \multirow[t]{4}{*}{$\begin{array}{l}\text { Articles 86, } 79 \\
\text { (Constitution) }\end{array}$} \\
\hline & Oui & Non & Non & $\begin{array}{l}\text { Loi Statutaire/ } \\
\text { Législation }\end{array}$ & \\
\hline & Indéterminé & Indéterminé & Indéterminé & $\begin{array}{l}\text { Actes } \\
\text { réglementaires }\end{array}$ & \\
\hline & Oui & Non & Non & Traités & \\
\hline \multirow[t]{4}{*}{ Niger } & Oui & Non & Oui & $\begin{array}{l}\text { Règlements } \\
\text { intérieurs des } \\
\text { assemblées }\end{array}$ & \multirow[t]{4}{*}{$\begin{array}{l}\text { Articles, } 106 \\
120,126,131 \\
\text { (Constitution) }\end{array}$} \\
\hline & Oui & Oui & Non & $\begin{array}{l}\text { Loi Statutaire/ } \\
\text { Législation }\end{array}$ & \\
\hline & Oui & Oui & Non & $\begin{array}{l}\text { Actes } \\
\text { réglementaires }\end{array}$ & \\
\hline & Oui & Non & Non & Traités & \\
\hline \multirow[t]{4}{*}{ Sénégal } & Oui & Non & Non & $\begin{array}{l}\text { Règles internes de } \\
\text { procédure }\end{array}$ & \multirow[t]{4}{*}{$\begin{array}{l}\text { Articles } 51,72,92 \\
\text { (Constitution) }\end{array}$} \\
\hline & Oui & Oui & Non & $\begin{array}{l}\text { Loi statutaire/ } \\
\text { Législation }\end{array}$ & \\
\hline & Non & Non & Non & $\begin{array}{l}\text { Actes } \\
\text { réglementaires }\end{array}$ & \\
\hline & Oui & Non & Non & Traités & \\
\hline \multirow[t]{4}{*}{ Togo } & Oui & Non & Oui & $\begin{array}{l}\text { Règlements } \\
\text { intérieurs des } \\
\text { assemblées }\end{array}$ & \multirow[t]{4}{*}{$\begin{array}{l}\text { Articles, } 8699,104- \\
5,139 \text { (Constitution) }\end{array}$} \\
\hline & Oui & Oui & Non & $\begin{array}{l}\text { Loi statutaire/ } \\
\text { Législation }\end{array}$ & \\
\hline & Oui & Non & Non & $\begin{array}{l}\text { Actes réglemen- } \\
\text { taires }\end{array}$ & \\
\hline & Oui & Non & Non & Traités & \\
\hline
\end{tabular}

\section{Légende}

Afrique de l'Ouest francophone

Afrique de I'Ouest lusophone 
Les règlements intérieurs des organes publics sont soumis à un ou plusieurs types de contrôle de constitutionnalité, comme l'illustre le tableau 7.1, dans tous les pays de civil law à l'exception de la Guinée-Bissau où les textes sont silencieux. La liste des institutions publiques dont les règlements intérieurs sont sujets à cet examen varie en fonction des pays. Au Bénin par exemple, la liste fournie à l'article 117 de la Constitution inclut non seulement le Parlement, mais également la Haute autorité de l'audiovisuel et de la communication et le Conseil économique et social. Au Sénégal, en revanche, les textes pertinents font uniquement référence aux règlements intérieurs des assemblées, sans autre précision. Il est important de noter qu'en principe, les règlements intérieurs des assemblées sont soumis à un régime juridique spécifique. En tant que tels, ils doivent se conformer à la Constitution, mais ne forment pas nécessairement un ensemble de normes de référence pour l'examen et la validation des lois adoptées par le Parlement. La seule exception à ce modèle est le Bénin : dans sa décision 98/039 du 14 avril 1998, la Cour constitutionnelle a estimé qu'une loi adoptée sans que les règles de procédure pertinentes aient été appliquées n'est, par extension, pas conforme à la Constitution.

Comme c'est le cas avec les règlements intérieurs des organes publics plus d'une forme de contrôle est possible dans la plupart des cas pour la législation et les actes réglementaires ou ordonnances. À l'exception de la Guinée-Bissau et de la Mauritanie, qui n'autorisent qu'une seule forme de contrôle de la législation, tous les pays de civil law en admettent plusieurs ${ }^{18}$. Sept pays (Bénin, Burkina Faso, Cabo Verde, Côte d'Ivoire, Guinée, Mali et Niger) autorisent plus d'un type de contrôle des actes réglementaires, tandis que la Guinée-Bissau, le Sénégal et le Togo n’en prévoient qu'un. Seule en Mauritanie les textes sont silencieux sur le contrôle des actes règlementaires

Par conséquent, le contrôle de constitutionnalité apparaît plus important - au moins en principe - dans les pays qui autorisent plus d'une forme de contrôle de la législation et des actes réglementaires, et à différents moments. Les possibilités d'engager un recours sont ainsi multipliées par un éventail d'options élargi et l'opportunité d'agir à différents stades. Par exemple, dans neuf des 11 pays de civil law, la législation est soumise à un contrôle (abstrait) a priori et à un contrôle (abstrait et concret) a posteriori. Dans ces juridictions, les erreurs commises lors de l'examen a priori peuvent donc être rectifiées lors d'un contrôle a posteriori. À l'opposé, dans les pays qui n'offrent qu'une possibilité, comme en Guinée-Bissau (où le contrôle s'effectue uniquement de manière concrète, en théorie) et en Mauritanie (où seul le contrôle a priori est possible), le système de contrôle de constitutionnalité est plus faible. En

18 Ici, la référence à la législation ne fait pas de distinction entre lois organiques et lois ordinaires, ce qui est le cas de certaines constitutions. 
Guinée-Bissau, il est ainsi difficile d'atténuer les impacts potentiellement néfastes des lois, car elles ne sont testées ou contrôlées que dans le contexte d'un litige concret, alors que leurs effets négatifs se sont peut-être déjà produits. La Mauritanie répond à ce problème en effectuant un contrôle a priori, avec l'inconvénient d'exclure tout contrôle de constitutionnalité ultérieur.

Pour autant, la Constitution de la Guinée-Bissau donne peu d'informations concernant les types de contrôle possibles, et à quels actes normatifs ils s'appliquent; les conclusions ci-dessus concernant la portée et les formes de contrôle s'appuient sur une interprétation large des dispositions constitutionnelles en la matière. Larticle 126 de la Constitution, par exemple, prévoit que «dans les affaires portées devant le tribunal, les lois contraires à la Constitution ou aux principes qu'elle protège ne peuvent être appliquées». Lu concomitamment avec d'autres segments de la disposition - en particulier le sous-paragraphe 2, qui prévoit qu'«admise [...] , la question de la constitutionnalité est soumise séparément à la Cour suprême» -, l'on peut en déduire que la Constitution permet uniquement un contrôle concret/a posteriori. Cependant, le Parlement a depuis adopté la loi 6/2011 du 4 mai 2011 sur l'organisation des tribunaux, qui, bien qu'elle soit inconstitutionnelle du point de vue technique, semble autoriser le contrôle préliminairela priori de certains actes normatifs. Son article 27 autorise spécifiquement la Cour suprême à effectuer «un contrôle antérieur de la constitutionnalité de toute disposition d'un traité ou d'un accord soumis à la ratification de l'autorité nationale compétente» et à "statuer sur l'inconstitutionnalité de toute règle ou résolution de portée normative matérielle ou de portée individuelle et concrète». La loi aborde clairement la question du contrôle a priori des traités, toutefois elle ne traite pas spécifiquement du contrôle a priori des autres actes normatifs auxquels elle fait référence. En pratique, la Cour suprême a adopté une approche assez incohérente de la question (Bastos 2013 : 22). Dans ses décisions 7/2000 du 5 décembre 2000 et/2010 du 3 novembre 2010, la Cour a souligné que «le seul modèle de contrôle de constitutionnalité prévu par la Constitution [...] est consécutif, incident et concentré» (Bastos 2013). La décision de 2010 vient contredire deux arrêts antérieurs, datant de 2006 et 2008, dans lesquels la Cour reconnaissait la possibilité d'un contrôle abstrait a priori (Bastos 2013).

De plus, en Guinée-Bissau, les lois et traités sont, nous l'avons vu, généralement soumis au contrôle, par une procédure concrète et a priori en vertu de l'article 126. La question de savoir si un contrôle juridictionnel est possible pour d'autres catégories de normes - telles que les actes réglementaires et les règlements intérieurs du Parlement et d'autres organes publics - reste à débattre pour les raisons exposées ci-dessus. D’après Bastos (2013), la 
formulation du texte, qui précise que «la validité des [...] autres actes de l'État [...] dépend de leur conformité à la Constitution ", démontre l'intention de ses rédacteurs d'étendre le contrôle juridictionnel aux actes normatifs autres que la seule législation.

\section{Les juridictions de common law}

Tandis que les constitutions des juridictions de civil law en Afrique de l'Ouest accordent généralement aux instances chargées de la justice constitutionnelle des compétences larges pour effectuer plusieurs formes de contrôle de constitutionnalité sur différentes catégories d'actes normatifs et à diverses étapes, la situation est différente dans les pays de common law de la région, en majorité des pays anglophones. Le contrôle de constitutionnalité s'effectue généralement a posteriori - à savoir après l'adoption d'une loi et dans le cadre d'une procédure concrète.

Les constitutions des pays de common law ne prévoient généralement pas de contrôle a priori, mais une forme d'examen non obligatoire des projets de loi a lieu avant que ceux-ci n'intègrent le système juridique. En Gambie et au Libéria par exemple, un examen préliminaire est généralement possible lors d'une procédure consultative au cours du processus d'élaboration de la loi, dans le cadre de laquelle des experts issus du secteur judiciaire, des universitaires et des membres du barreau donnent un avis non contraignant sur les implications constitutionnelles des projets de loi avant leur adoption. Un tel examen peut également avoir lieu au sein de comités parlementaires spécialisés, comme le comité des affaires constitutionnelles. Par conséquent, en Afrique de l'Ouest anglophone, la culture du contrôle de constitutionnalité n'inclut pas le contrôle juridictionnel préliminaire de principe. Larticle 4(8) de la Constitution du Nigéria semble être une exception : il dispose que "sauf mention contraire dans la présente Constitution, l'exercice du pouvoir législatif [...] sera sujet à la compétence des tribunaux et cours de justice établis par la loi». La nature consultative de la procédure (lorsqu'elle existe) signifie également que les opinions émises ne sont que des avis et n'entraînent aucune obligation pour les institutions.

Le contrôle abstrait n'est généralement pas prévu dans les institutions de common law, quoique la formulation de certaines constitutions, comme celle du Ghana, soit suffisamment large pour l'y inclure. Bien que la Cour suprême ghanéenne ait explicitement statué sur le fait qu'elle ne procède pas à un contrôle abstrait, l'article 2(1) de la Constitution prévoit néanmoins que «toute personne qui reproche à une norme [...] de ne pas être conforme ou de contrevenir aux dispositions de la présente Constitution, pourra se pourvoir devant la Cour suprême pour obtenir une déclaration à cet effet ». L'article 5(1) 
de la Constitution gambienne et l'article 127(1) de la Constitution de la Sierra Leone prévoient des dispositions analogues.

Le contrôle abstrait est en principe impossible au Nigéria et au Libéria, mais il semble que les tribunaux puissent tout de même y recourir lorsque leur indépendance est menacée. L'article 4(8) de la Constitution du Nigéria semble ouvrir cette possibilité en soumettant «l'exercice du pouvoir législatif [...] à la compétence des tribunaux" et en interdisant au Parlement d'adopter "toute loi excluant ou cherchant à exclure la compétence d'un tribunal ou d'une Cour de justice établis par la loi. » Au Nigéria, la loi reste imprécise à cet égard, mais au Libéria - où il apparaît que les tribunaux peuvent également effectuer un contrôle abstrait des lois qui menacent selon eux leur indépendance - la formulation est plus précise. La Cour suprême libérienne a, par deux fois, pris l'initiative d'examiner de manière abstraite une législation qui présentait selon elle une menace pour son indépendance. Dans son arrêt Re Sections 12.5/12.6 of the New Judiciary Law par exemple, la Cour suprême considère "approprié d'effectuer un examen approfondi d'un acte [...] qui dans ses effets et son application interfère avec [l']indépendance et l'autonomie des différentes branches du pouvoir prescrites par la Constitution et qui forment l'esprit et le génie de cette institution démocratique.»

Le contrôle concret est la norme dans les cinq pays anglophones de l'Afrique de l'Ouest, mais le mode opératoire de ce contrôle n'est pas uniforme. Par exemple, à l'exception des questions relatives aux droits fondamentaux pour lesquels elles n'ont compétence qu'en appel, les Cours suprêmes de la Gambie (article 127[1-2]), du Ghana (article 130[1-2]) et de la Sierra Leone (article 124 [1-2] ont la compétence exclusive en premier ressort pour toutes les autres questions relatives à l'application et à l'interprétation de la Constitution, y compris celles soulevées lors d'une affaire soumise à une autre juridiction. En d'autres termes, tous les tribunaux de rang inférieur qui rencontrent une difficulté d'ordre constitutionnel lors de l'examen d'une affaire doivent surseoir à statuer et en référer à la Cour suprême.

En tant que tel, le contrôle concret dans ces juridictions suit quasiment le même procédé que dans les systèmes de contrôle centralisé. À l'inverse, l'article 66 de la Constitution libérienne prévoit que «la Cour suprême est le juge en dernier ressort des questions de constitutionnalité». De même, les articles 241(1) et 233(2) de la Constitution du Nigéria disposent que «le recours en appel des décisions du Tribunal fédéral de grande instance ou d'un tribunal de grande instance sera soumis à la Cour d'appel et [en dernier ressort] à la Cour suprême en ce qui concerne l'interprétation ou l'application de la présente Constitution». Par conséquent, les tribunaux de rang inférieur de ces juridictions semblent jouir de la pleine compétence pour arbitrer les 
questions de constitutionnalité soulevées dans le cadre des litiges qui leur sont soumis, la Cour suprême ne conservant que la compétence en appel (et non exclusive). Le contrôle direct est également possible. Comme dans le système décentralisé, cela semble répondre à la nécessité de protéger et de renforcer les droits constitutionnels. Par exemple, l'article 33 de la Constitution du Ghana donne au tribunal de grande instance la compétence en premier ressort pour examiner les questions de constitutionnalité soulevées par des individus au motif qu'une "disposition de [la] Constitution portant sur les droits et libertés humaines fondamentales a été, est, ou sera probablement violée à [leur] égard. " Des dispositions similaires sont prévues aux articles 37(1) de la Constitution de la Gambie, à l'article 26 de la Constitution libérienne, et à l'article 46(1) de la Constitution du Nigéria.

Il est intéressant de noter que la formulation utilisée par ces dispositions est suffisamment large pour inclure tant les droits humains que les autres cas, ce qui suggère la volonté de permettre aux individus de saisir la justice pour protéger la Constitution d'éventuelles violations. C'est le cas des articles 5(1), 2(1) et 127(1) des Constitutions gambienne, ghanéenne et sierra-léonaise respectivement. Ces articles renvoient plus généralement aux initiatives portant atteinte à "une disposition de la présente Constitution ", et non uniquement aux dispositions relatives aux droits garantis par la Constitution ou au chapitre qui leur est consacré, comme le prévoient les articles 26(1) et 46(1) de la Constitution du Libéria et de celle du Nigéria. Une telle formulation suggère un champ d'application plus vaste. Enfin, il est utile de noter que, contrairement aux pays francophones (et dans une certaine mesure lusophones) de l'Afrique de l'Ouest - dont les constitutions spécifient les différentes catégories d'actes juridiques soumis à examen, telles que la législation (et ses sous-catégories), les actes réglementaires, les règlements intérieurs et les traités internationaux - une telle distinction n'existe pas en Afrique de l'Ouest anglophone. Ces constitutions utilisent généralement les termes textes, législations, actes ou lois indifféremment pour tous les actes juridiques d'origine législative. Le tableau 7.2 détaille les formes de contrôle possible en Afrique de l'Ouest anglophone. 
Table 7.2. Types de contrôle de constitutionnalité et d'actes juridiques soumis à ce contrôle dans les pays anglophones et lusophones de l'Afrique de l'Ouest

\begin{tabular}{|c|c|c|c|c|}
\hline & \multicolumn{3}{|c|}{ Occurrence et type de contrôle } & \multirow{2}{*}{$\begin{array}{c}\text { Dispositions de la } \\
\text { Constitution ou loi } \\
\text { organique }\end{array}$} \\
\hline & $\begin{array}{l}\text { A priori (avant } \\
\text { promulgation) }\end{array}$ & $\begin{array}{c}\text { Concret/incident } \\
\text { (a posterioripar } \\
\text { nature) }\end{array}$ & Abstrait (hors litige) & \\
\hline Gambie & $\begin{array}{l}\text { Oui (avis } \\
\text { consultatif) }\end{array}$ & Oui & Indéterminé & $\begin{array}{l}\text { Articles 5(1), 37(1), } \\
127 \text { (Constitution) }\end{array}$ \\
\hline Ghana & Non & Oui & Non & $\begin{array}{l}\text { Articles 2(1), 33, } \\
130 \text { (Constitution) }\end{array}$ \\
\hline Libéria & $\begin{array}{l}\text { Oui (avis } \\
\text { consultatif) }\end{array}$ & Oui & Oui & $\begin{array}{l}\text { Articles 26(1), } 66 \\
\text { (Constitution) }\end{array}$ \\
\hline Nigéria & Indéterminé & Oui & Indéterminé & $\begin{array}{l}\text { Articles 4(8), 46(1), } \\
\text { 233(1), 241(1) } \\
\text { (Constitution) }\end{array}$ \\
\hline Sierra Leone & Non & Oui & Indéterminé & $\begin{array}{l}\text { Articles 124, 127(1) } \\
\text { (Constitution) }\end{array}$ \\
\hline
\end{tabular}


8. Les autres attributions des juridictions compétentes en matière de contrôle de constitutionnalité

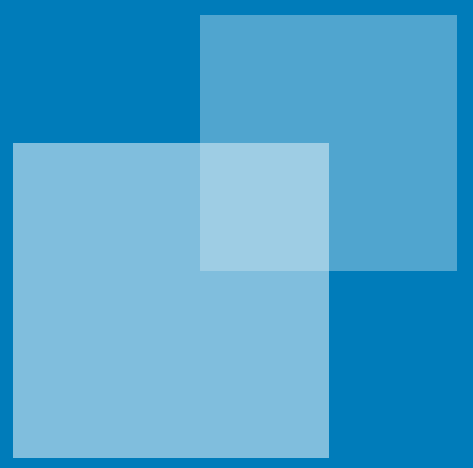




\title{
8. Les autres attributions des juridictions compétentes en matière de contrôle de constitutionnalité
}

\author{
Babacar Kante et H. Kwasi Prempeh
}

L'exercice du pouvoir par les autorités publiques, y compris judiciaires, a des répercussions politiques importantes. C'est notamment le cas des décisions prises par les juridictions compétentes en matière de justice constitutionnelle, dont l'impact est généralement considérable, en particulier dans le domaine des droits humains, de la cohésion sociale et de la sécurité juridique (du Bois de Gaudusson 2007 : 609; Fromont 2013 : 509).

Les attributions des juridictions compétentes en matière de justice constitutionnelle en Afrique suscitent beaucoup d'intérêt, tant du point de vue théorique que politique (Gélard 2007 : 705; Wodie 1996 : 625; Aïvo 2013 : 23; Djedjro 2005 : 304; Mede 2012:458; Diop 2013 : 332; Favoreu 2014 : 1250; Salami et Gandonou 2014 : 492). La place qu'elles occupent dans le système politique dans son ensemble, a fortiori dans les contextes de transition démocratique, peut influencer le résultat des élections et l'exercice du pouvoir qui en découle. Dans certains cas, le juge constitutionnel peut contribuer à résoudre une crise politique à la suite d'un coup d'État ou d'un changement inconstitutionnel de régime. À l'inverse, ses décisions peuvent également précipiter une crise politique ou être source de tensions politiques ou sociales. Pour mieux évaluer la compétence des instances chargées de la justice constitutionnelle, il est important d'en examiner tant la portée que les limites.

\section{Portée de la compétence des juridictions compétentes en matière de contrôle de constitutionnalité}

Une analyse des textes constitutionnels et des lois établissant et régissant le fonctionnement des Cours ou Conseils constitutionnel(le)s ou des Cours suprêmes révèle différents types de compétence; à cet égard, les différences entre pays anglophones et francophones sont importantes. D'une manière générale, en Afrique de l'Ouest anglophone, les juridictions chargées du contrôle de constitutionnalité ou les Cours suprêmes sont, d'un point de 
vue constitutionnel, considérées comme des juridictions de droit commun. À l'inverse, les constitutions des pays francophones énumèrent de manière exhaustive leurs attributions ou compétences.

Sauf en cas d'exception spécifiquement prévue par la Constitution, les compétences ou attributions des Cours suprêmes de l'Afrique de l'Ouest anglophone s'étendent à l'ensemble des domaines qu'elle couvre. Par conséquent, cette dernière ne mentionne que les exceptions, généralement très limitées. De plus, chacune de ces constitutions prévoit la possibilité d'élargir par voie législative l'éventail des compétences et attributions des juridictions chargées du contrôle de constitutionnalité. Comme l'explique le chapitre 3, en Afrique de l'Ouest anglophone, les compétences constitutionnelles sont partagées entre l'institution suprême chargée du contrôle de constitutionnalité et les autres tribunaux (de rang supérieur) désignés au sein de l'appareil judiciaire : la Constitution et la législation nationale précisent quel niveau de juridiction a compétence en premier ressort ou en appel, et pour quels types d'affaires.

Par conséquent, dans les pays anglophones couverts par la présente étude, plusieurs tribunaux peuvent généralement être considérés comme des juridictions compétentes en matière de contrôle de constitutionnalité. Par exemple, en vertu de la Constitution nigériane, la Cour suprême a compétence en premier ressort pour un ensemble limité de cas : ceux qui impliquent un différend entre la fédération et un État ou entre États et portant sur les droits légaux, ou lorsque la compétence en premier ressort lui a été dévolue par la législation fédérale. La majeure partie de la compétence de la Cour suprême du Nigéria en matière constitutionnelle concerne les recours en appel; les tribunaux de rang inférieur, notamment la Cour d'appel fédérale et le tribunal de grande instance, exercent également une compétence constitutionnelle pour tous les cas qui doivent d'abord être soumis au tribunal de grande instance. La Cour suprême du Libéria est, elle aussi, principalement une Cour d'appel statuant en dernier ressort pour les questions de constitutionnalité; elle n'est compétente en premier ressort que lorsqu'un ministre ou un pays étranger est partie. Toutes les autres affaires constitutionnelles - y compris celles initiées à l'encontre du gouvernement pour violation d'un droit ou d'une liberté fondamentale - doivent d'abord être soumises à un tribunal d'instance.

À l'inverse, au Ghana et en Gambie, la Cour suprême est compétente en premier ressort pour connaître de toutes les questions constitutionnelles, sauf celles portant sur l'application des dispositions de la Constitution en matière de droits humains; ce type d'affaires doit d'abord être soumis au tribunal de grande instance et n'est transmis à la Cour suprême qu'en appel. La Cour 
suprême de la Sierra Leone, quant à elle, est compétente en premier ressort pour toutes les affaires (c'est-à-dire tout cas dénonçant la violation d'une disposition de la Constitution ou impliquant l'interprétation ou l'application d'une disposition de la Constitution), y compris celles pour lesquelles le requérant dénonce la violation ou le non-respect d'un droit ou d'une liberté garantis par la Constitution.

Une autre différence majeure entre les compétences des juridictions anglophones chargées du contrôle de constitutionnalité et leurs homologues francophones est que, comme nous l'avons vu au chapitre 7, la compétence constitutionnelle des tribunaux anglophones pour examiner les actes législatifs ne prend effet qu'une fois les projets de loi adoptés et promulgués. La seule exception est le Nigéria : l'article 4(8) de sa constitution dispose que "l'exercice du pouvoir législatif par l'Assemblée nationale ou une Chambre des représentants sera soumis à la compétence des tribunaux » et «l'Assemblée nationale ou une Chambre des représentants n'adopteront aucune loi excluant ou cherchant à exclure la compétence d'un tribunal ou d'une Cour de justice établie par la loi». En pratique, cela signifie qu'un projet de loi, dont la portée ou l'effet est, s'il est adopté, d'écarter la compétence des tribunaux sur une question donnée, peut être remis en question et déclaré inconstitutionnel avant sa promulgation.

En général, la compétence constitutionnelle dans les pays anglophones, contrairement aux pays francophones et lusophones de tradition civiliste, n'autorise pas les instances à émettre des avis; elles n'ont compétence que pour trancher les affaires qui leur sont soumises. L'article 122 de la Constitution de la Sierra Leone permet toutefois au président de solliciter «l'avis» de la Cour suprême sur les «recours pour lesquels il doit rendre une décision définitive».

Le reste de cette section analyse deux catégories de compétences dévolues aux instances chargées du contrôle de constitutionnalité dans les pays francophones et lusophones. La première porte sur leur compétence contentieuse (décisions) et, la seconde, sur la capacité d'émettre des avis (non contraignants) (Favoreu 2013 : 225; Salami 2014 : 371).

\section{Les compétences contentieuses}

Les juridictions chargées de la justice constitutionnelle dans les pays francophones et lusophones disposent d'une compétence contentieuse dans quatre domaines : (a) le contrôle de constitutionnalité (présenté au chapitre 7), (b) le contentieux électoral, (c) le contrôle des opérations référendaires, et (d) les conflits d'attribution entre autorités publiques. 


\section{Le contentieux électoral et la régulation du système politique}

Après le contrôle de constitutionnalité, le contentieux électoral et la régulation du système politique sont les compétences les plus importantes des Cours constitutionnelles ou suprêmes de la région, tant en termes qualitatifs que quantitatifs. À l'exception du Nigéria, où la Cour suprême n'exerce qu'une compétence en appel pour les questions électorales, toutes les constitutions étudiées confèrent à ces juridictions la compétence de connaître de certains aspects du contentieux électoral. L'étendue de cette compétence varie toutefois en fonction du type d'élection et de la juridiction concernée.

Il est important de noter que, bien que les juridictions chargées du contrôle de constitutionnalité exercent leur compétence sur certaines questions électorales, celle-ci n'est pas exclusive, étant donné que les tribunaux ordinaires traitent également de certaines de ces questions (voir tableau 8.1). C'est par exemple le cas des différends liés à l'enregistrement sur les listes électorales ou aux campagnes électorales. Dans certains pays, comme le Sénégal, la compétence $\mathrm{du}$ Conseil constitutionnel se limite à la publication de la liste des candidats et à la proclamation des résultats après le traitement du contentieux. Mais dans d'autres, la compétence est beaucoup plus large et inclut le contentieux lié à l'inscription des électeurs et à la tenue des élections.

En général, le principal type de contentieux électoral pour lequel les Cours constitutionnelles et les Cours suprêmes ont compétence porte sur les élections présidentielles et les élections législatives nationales. C'est le cas de la majorité des juridictions de la région, que ce soit dans les pays anglophones, francophones ou lusophones. Au Togo, l'article 104(2) de la Constitution et l'article 2 du règlement intérieur de la Cour datant du 26 janvier 2005 donnent compétence à la Cour constitutionnelle en matière de contentieux résultant des élections présidentielles, parlementaires et sénatoriales. De la même manière, en République de Guinée, la Cour suprême a compétence pour le contentieux relatif aux élections parlementaires et présidentielles, conformément à l'article 62 de la Constitution. Au Ghana, en Sierra Leone et au Nigéria, la Cour suprême a compétence pour le contentieux relatif aux élections présidentielles, mais pas parlementaires; au Ghana et en Sierra Leone, la Cour suprême est compétente en premier ressort pour les questions relatives aux élections présidentielles, tandis qu’au Nigéria, ces dernières doivent d'abord être soumises à la Cour d'appel fédérale, dont la décision peut être renvoyée en dernier ressort à la Cour suprême fédérale. Dans ces trois pays anglophones, la Cour d'appel, et non la Cour suprême, est la juridiction compétente en dernier ressort pour le contentieux électoral portant sur le résultat des élections législatives. Au Libéria, l'article 83 donne à la Cour suprême la compétence pour traiter le contentieux des élections présidentielles 
et législatives, mais ce contentieux doit en premier lieu être examiné par la commission électorale elle-même avant de pouvoir être soumis à la Cour suprême en appel. La Gambie est le seul pays anglophone à conférer à sa Cour suprême la compétence exclusive en premier ressort pour arbitrer les litiges relatifs aux élections présidentielles et législatives. La Cour constitutionnelle du Cabo Verde est elle aussi compétente pour connaître des recours relatifs aux élections présidentielles, législatives et locales conformément à l'article 215 de la Constitution, aux articles 252, 353 et 376 du Code électoral, et aux articles 109-22 de la loi 56/VI/2005 relative à la Cour constitutionnelle.

Il est rare que les pays confient la compétence relative au contentieux des élections locales au juge constitutionnel. Le Burkina Faso, qui faisait office d'exception à cet égard a, en 2012, dévolu cette compétence aux tribunaux administratifs.

Dans les pays anglophones de la région, les Cours suprêmes ne sont généralement pas impliquées dans le suivi du processus électoral lui-même ni dans la proclamation des résultats; ce rôle est plus communément exercé par les Cours constitutionnelles des pays francophones. Cependant, en raison de la compétence en appel très large exercée par les Cours suprêmes des pays anglophones, le contentieux portant sur certains aspects du processus électoral, y compris les litiges internes aux partis politiques, peut être soumis à la Cour suprême en dernier recours, après avoir été examiné par les tribunaux inférieurs. La Constitution du Libéria donne spécifiquement à la Cour suprême la compétence d'examiner les recours déposés à l'encontre de l'organe chargé de la gestion des élections en cas de refus d'inscription d'un candidat en tant que membre d'un parti politique ou en tant que candidat indépendant dans le cadre d'une élection.

Au Cabo Verde et en Guinée-Bissau lusophones, les Cours constitutionnelles ou Cours suprêmes peuvent examiner et statuer sur l'admissibilité des candidats à l'élection présidentielle et le contentieux électoral.

Dans les pays francophones, en plus de réglementer le processus électoral, les Cours constitutionnelles sont les seules institutions à disposer du pouvoir de constater et de déclarer une vacance de poste au sein du cabinet du président. Les Cours constitutionnelles exercent également d'autres compétences dont l'impact est plus large sur le fonctionnement du système politique. Par exemple, elles ont l'autorité de superviser le fonctionnement des partis politiques. Dans certains pays notamment, les Cours constitutionnelles ou suprêmes peuvent statuer sur la légalité de la création et du fonctionnement des partis politiques et ordonner la dissolution de ceux qui ne respectent pas les critères statutaires minimums. Au Cabo Verde par exemple, la Cour 
constitutionnelle vérifie la légalité de la constitution des partis politiques et des alliances qu'ils forment en vertu de l'article 215 de sa constitution et des articles 15 et 123 de la loi 56/VI/2005. De la même manière, aux termes des articles 156 de la Constitution du Burkina Faso et 26-27 de la loi organique portant organisation et fonctionnement de sa Cour constitutionnelle, celleci a compétence pour examiner la constitutionnalité des chartes des partis politiques. En outre, certaines constitutions, comme celle du Sénégal (article 37), autorisent le Conseil constitutionnel à accueillir le serment du président élu et à recevoir sa déclaration de patrimoine et à présider une éventuelle procédure de destitution, si nécessaire.

Les juridictions constitutionnelles bénéficient donc de larges compétences contentieuses qui leur permettent non seulement de statuer sur les litiges qui leur sont soumis, mais également de stabiliser et réguler le système politique dans les pays africains. Cet élargissement progressif de leur champ d'intervention a contribué à consolider leur envergure juridictionnelle.

\section{Le contrôle du référendum}

Dans les pays francophones, les Cours constitutionnelles ou suprêmes jouent en principe un double rôle dans la tenue d'un référendum. Outre un avis préliminaire obligatoire sur la procédure de consultation, après une saisine du président de la République, elles en proclament les résultats.

Au Cabo Verde, pays lusophone, la Constitution prévoit également un examen obligatoire a priori de la constitutionnalité ou de la légalité de tout référendum proposé par le Parlement ou le gouvernement. Dans les pays anglophones, étant donné que les compétences des juridictions compétentes en matière de contrôle de constitutionnalité sont énumérées de manière générale et non exhaustive, les Cours suprêmes ne se voient pas explicitement conférer de pouvoirs concernant la tenue de référendums. Cependant, étant donné que le recours à un référendum est généralement associé à une révision de la Constitution, la compétence constitutionnelle des Cours s'applique normalement aux cas invoquant une violation des dispositions relatives à la procédure de révision par référendum. Par exemple, les constitutions de la Gambie, du Ghana et de la Sierra Leone contiennent des dispositions désignant certaines "dispositions transitoires " portant sur les actions résultant des coups d'État antérieurs comme immuables, quel que soit le moyen - y compris, par extension, par référendum. 


\section{Les conflits d'attribution entre autorités publiques}

Dans certains pays d'Afrique de l'Ouest - notamment ceux ayant traversé des crises politiques, comme le Bénin -, les constitutions et le cadre juridique en place confèrent explicitement aux instances constitutionnelles le pouvoir de réglementer les relations entre autorités publiques. Dans d'autres pays en revanche, comme au Sénégal, ces attributions ne sont pas aussi clairement définies et doivent par conséquent être induites. Dans les pays anglophones, où la portée de la compétence constitutionnelle n'est généralement pas détaillée, les litiges entre branches du pouvoir ou entre juridictions font normalement partie des attributions des Cours suprêmes. Au Nigéria, la Cour suprême fédérale a une compétence exclusive en premier ressort pour les litiges entre le gouvernement fédéral et un État ou entre États concernant les questions juridiques.

Le rôle des instances constitutionnelles à cet égard est de veiller au respect du principe de séparation des pouvoirs, tant verticalement qu'horizontalement. Cela implique généralement de résoudre les litiges d'attribution entre les branches exécutive et législative. Toutefois, le nombre croissant de services et de commissions indépendant(e)s dans la plupart des pays de la région augmente le risque de conflits d'attribution et de litiges nécessitant l'intervention du juge. Dans les systèmes juridiques fondés sur une dualité de juridictions, la Cour constitutionnelle ou suprême joue également un rôle d'arbitre dans les différends opposant les tribunaux administratifs aux juridictions ordinaires.

\section{Les compétences consultatives}

En dehors de la sphère anglophone, les instances chargées du contrôle de constitutionnalité tendent à exercer une compétence consultative dans trois domaines - le contrôle des lois organiques, le processus référendaire, et le recours à l'état d'urgence par le président de la République.

\section{Les avis obligatoires sur les lois organiques}

Dans les pays francophones de la région, les constitutions et lois portant création des juridictions constitutionnelles obligent les autorités politiques, en particulier l'exécutif, à solliciter l'avis de celles-ci sur la constitutionnalité de toute loi organique avant sa promulgation. La seule exception est le Sénégal, où un tel examen juridictionnel avant promulgation n'est plus requis. Ce pouvoir de consultation est généralement inexistant dans les pays d'Afrique de l'Ouest anglophone. 


\section{Le contrôle du référendum}

Dans tous les pays étudiés, les textes juridiques donnent aux juridictions constitutionnelles la possibilité d'intervenir dans le processus référendaire. La définition de ces attributions n'est pas toujours précise, mais elles relèvent en général de deux catégories : l'une est consultative et porte sur le recours à la procédure référendaire, l'autre est contentieuse et porte sur l'organisation du référendum et la proclamation des résultats. Toutefois, la compétence contentieuse dans ce domaine est moins étendue que pour les affaires électorales et le rôle des juridictions est, de ce fait, limité. Au Burkina Faso par exemple, les articles 28 et 29 de la loi organique $011.1 \mathrm{~N} \mathrm{du} 27$ avril 2000 et l'article 152.2 de la Constitution prévoient simplement que le Conseil constitutionnel contrôle la régularité des opérations référendaires et en proclame les résultats.

Dans les pays anglophones, les Cours suprêmes exercent rarement une compétence consultative ou un rôle quelconque dans l'organisation des référendums. En revanche, elles ont, par extension, compétence pour statuer sur les litiges relatifs à la constitutionnalité d'une révision ou d'une procédure de révision constitutionnelle.

\section{La consultation avant la déclaration d'état d'urgence}

En dehors des pays anglophones, lorsque le président de la République décide d'appliquer l'état d'urgence et les pouvoirs exceptionnels qui lui sont conférés en vertu de la Constitution, il est obligé, pour garantir la validité de ces pouvoirs, de consulter la juridiction constitutionnelle, entre autres instances. L'objectif est de permettre à cette dernière de confirmer que l'exercice de prérogatives exceptionnelles qui pourraient limiter les droits des citoyens et influencer l'équilibre des institutions est conforme à la Constitution. Ce mécanisme est prévu à l'article 39 de la Constitution mauritanienne, à l'article 50 de la Constitution malienne, et à l'article 59 de la Constitution du Burkina Faso. Le non-respect de ces dispositions signifie que les lois adoptées et actes administratifs pris seront déclarés inconstitutionnels.

\section{Les limites à la compétence des juridictions chargées du contrôle de constitutionnalité}

En dépit de leur portée relativement générale, il existe certaines limites matérielles à la compétence des juridictions constitutionnelles en Afrique de l'Ouest. Il est utile de se pencher sur ces limites pour mesurer et évaluer les différences qu'elles révèlent entre pays et systèmes juridiques. 
Dans les pays francophones, les limitations matérielles à la compétence des juridictions chargées de la justice constitutionnelle ont deux origines. La première est la Constitution ou les lois organiques qui établissent et régissent les juridictions. Ces textes fournissent une liste exhaustive des compétences et donc excluent certains domaines des attributions des juridictions. La seconde source est l'interprétation que font les juridictions elles-mêmes de leur compétence, à partir de ce qui est explicitement prévu par la Constitution et de ce qui en découle. Les juges, en fonction des contextes (par exemple, en matière compétence), peuvent parfois interpréter les mêmes textes de manière différente.

Ces limites comprennent : le refus de se prononcer sur les cas résultant de l'inaction du pouvoir législatif, l'indétermination de la compétence au sujet des lois portant révision de la Constitution, l'exclusion de la compétence concernant les actes administratifs, la compétence implicite en matière de droits fondamentaux, les ambiguïtés relatives à l'interprétation de la Constitution, et les risques liés à la compétence pour statuer sur les décisions des autres tribunaux.

\section{Le rejet des cas résultant de l'inaction du pouvoir législatif}

Les constitutions et les lois organiques en Afrique de l'Ouest sont généralement silencieuses quant aux conséquences de l'inaction du pouvoir législatif, par exemple lorsqu'il ne prend pas les mesures d'application des dispositions prévues par la Constitution. De tels cas se produisent par exemple lorsqu'un citoyen bénéficie d'un droit en vertu de la Constitution, mais ne peut en jouir dans la pratique, car le Parlement n’a pas adopté la loi d'application requise. L'on peut alors estimer que le pouvoir législatif n'a pas rempli son obligation à agir et a donc porté atteinte aux droits du citoyen par omission ou inaction. Le Cabo Verde est l'un des rares pays dont la Constitution peut s'interpréter comme couvrant les cas d'inaction du pouvoir législatif. L'article 16 prévoit que «l'État et les autres autorités publiques sont responsables civilement des actions ou omissions de leurs agents dans l'exercice de leurs mandats publics lorsque celles-ci entraînent une violation des droits et libertés des personnes et autres tierces parties».

Lorsque la juridiction a reçu compétence à cet effet, elle peut répondre à l'inertie du pouvoir législatif en le forçant à adopter la législation nécessaire, faute de quoi il pourra être tenu de verser des indemnités à la partie lésée. C'est souvent le cas pour les litiges administratifs dans le cadre desquels une autorité administrative est poursuivie en justice pour n'avoir pas rempli ses obligations constitutionnelles. 
Les constitutions et textes juridiques de la plupart des pays étudiés n'accordent pas explicitement aux juridictions chargées de la justice constitutionnelle la compétence de statuer sur les cas d'omissions par le pouvoir législatif. Il existe cependant deux exemples notables d'une juridiction exerçant cette compétence. Dans son arrêt Mensah c. Mensah (2012), la Cour suprême ghanéenne a directement appliqué une disposition constitutionnelle allant dans ce sens et son principe sous-jacent à la résolution d'un litige. La disposition visait à conférer aux époux les mêmes droits lors de la répartition des biens au cours d'une procédure de divorce, mais la législation requise n'avait pas été adoptée, plus d'une décennie après l'entrée en vigueur de la Constitution. De la même manière, la Cour constitutionnelle béninoise a estimé qu'elle avait compétence pour connaître des actions résultant de l'incapacité du pouvoir législatif à mettre en œuvre des obligations constitutionnelles déterminées. En effet, le juge constitutionnel peut intimer à une institution de remplir ses obligations dans un délai fixé par la Cour. Dans sa décision DCC 08-072 du 25 juillet 2008, la Cour a fait valoir que le refus de légiférer constitue une violation de l'article 35 de la Constitution, qui oblige les citoyens élus à une fonction publique à s'acquitter de leurs responsabilités avec conscience, compétence, probité, dévouement et loyauté dans l'intérêt et le respect du bien commun.

\section{L'indétermination de la compétence relative aux révisions constitutionnelles}

En général, les constitutions et lois organiques des pays francophones et lusophones ne confèrent pas explicitement aux Cours constitutionnelles ou suprêmes la compétence de connaître des lois portant révision de la Constitution. Le Burkina Faso est la seule exception. Larticle 154 de sa Constitution prévoit que «le Conseil constitutionnel veille au respect de la procédure de révision de la Constitution». Ce silence quant à la justiciabilité des révisions constitutionnelles a eu pour conséquence l'émergence de deux grandes tendances de la jurisprudence dans ce domaine : certaines juridictions ont adopté une approche large dans l'interprétation du silence de la Constitution, tandis que d'autres ont choisi une approche plus restrictive. Dans le premier cas, les instances chargées de la justice constitutionnelle ont adopté une voie pragmatique; la tendance générale de la jurisprudence a été de soumettre les révisions constitutionnelles à un examen de leur constitutionnalité. C'est le cas au Bénin, au Burkina Faso, au Cabo Verde, au Ghana, en Guinée, au Libéria, au Mali, au Niger, en Sierra Leone et au Togo. L'étendue du contrôle est cependant différente. Dans certains pays, comme le Burkina Faso, les juges se contentent de vérifier la conformité de la procédure de révision. Dans d'autres, un examen de fond détaillé des modifications est effectué. 
Dans le deuxième cas, les juridictions chargées de la justice constitutionnelle ont adopté une approche restrictive dans l'interprétation du silence de la Constitution et des textes juridiques et excluent par conséquent les lois portant révision de la Constitution d'un examen. Le Conseil constitutionnel du Sénégal en est un exemple : par deux fois, lorsqu'il a eu à traiter cette question (en 2003 et 2006), le Conseil a systématiquement considéré que les juges constitutionnels n'ont pas compétence pour connaître de la constitutionnalité des lois portant révision constitutionnelle.

La situation est différente dans les pays anglophones. Étant donné que toutes les constitutions de ces pays permettent des modifications, la compétence constitutionnelle des tribunaux s'étend, par extension, aux cas portant sur une violation de la disposition concernant la procédure de révision. La Constitution nigériane prévoit une disposition, dans la section consacrée à la révision de la Constitution, interdisant l'adoption d'une religion officielle pour tous les États de la fédération. On peut penser qu'il s'agit d'une clause immuable ou non modifiable, étant donné que la Constitution dispose que le pouvoir de révision de l'Assemblée nationale est «soumis aux dispositions de la présente section». Les Constitutions de la Gambie, du Ghana et de la Sierra Leone contiennent également des dispositions désignant certaines «dispositions transitoires» relatives aux actions liées à des coups d'État antérieurs comme non modifiables. La révision de ces dispositions, le cas échéant, serait probablement soumise à l'examen des juridictions compétentes chargées du contrôle de constitutionnalité.

\section{L'exclusion des actes administratifs}

La plupart des pays étudiés excluent les actes administratifs de la compétence des juridictions chargées du contrôle de constitutionnalité. Cela semble être le cas dans les systèmes de civil law, où les tribunaux administratifs - soit des tribunaux spécialisés, soit des sections intégrées à l'ordre juridictionnel ordinaire - sont compétents en matière de contrôle de la légalité des actes administratifs. Toutefois, quelques constitutions accordent à ces institutions la possibilité d'examiner la constitutionnalité des actes administratifs s'ils présentent un risque pour les droits humains. Au Ghana, où le «droit à la justice administrative " fait partie des libertés et droits fondamentaux garantis par la Constitution, la compétence constitutionnelle (qui, dans ce cas, est confiée au tribunal de grande instance) couvre les cas relatifs à d'éventuelles violations du droit à la justice administrative. La Constitution du Libéria exige également une "audience, dans le respect de la loi» avant de refuser ou de nier les droits ou privilèges d'une personne. La compétence constitutionnelle s'étend donc aux cas de violation de la procédure établie au profit des citoyens dans la prise d’un acte. Au Bénin, la Cour constitutionnelle a décidé qu’elle 
avait compétence, en vertu de l'article 117 de la Constitution, pour examiner les actes administratifs. En théorie, la Cour constitutionnelle du Bénin ne devrait exercer cette attribution exceptionnelle que lorsque l'acte administratif en question contrevient aux droits humains garantis par la Constitution. En pratique, toutefois, les choses sont différentes : la décision DCC 08-113 du 9 septembre 2008 laisse apparaître une tendance à l'élargissement de la catégorie des actes administratifs susceptibles d'être juridiquement remis en cause devant la cour; tous les cas ne se référant pas nécessairement à des violations des droits fondamentaux (Mede 2012 : 74).

\section{La compétence implicite relative à la protection des droits humains}

Contrairement aux pays anglophones (y compris le Libéria), qui incluent une "charte des droits» ou une liste de certains droits et libertés humains fondamentaux dans leurs constitutions et déterminent explicitement la compétence de juger de leur application, les textes juridiques des États francophones de la région sont pour la plupart silencieux quant à la compétence des juridictions constitutionnelles ou ordinaires en matière de protection des droits fondamentaux. Les rares exceptions sont la Guinée (articles 93-94), le Togo (article 99) et le Bénin (article 114), où la Constitution accorde explicitement un rôle aux juridictions constitutionnelles dans la protection des droits humains. Dans les autres pays francophones, les constitutions incluent une longue liste de droits et libertés, mais ne confient aux juridictions constitutionnelles aucune compétence explicite pour leur protection. L'interprétation dominante, dans ce cas, estime que les Cours sont compétentes pour statuer dans ce domaine dans le cadre de leur contrôle ordinaire de la constitutionnalité des lois.

Au Cabo Verde, l'article 20 de la Constitution présente un instrument important et efficace de protection des droits fondamentaux des citoyens - le recurso de amparo (recours individuel), semblable à l'amparo espagnol et au Verfassungsbeschwerde en Allemagne - qui accorde aux individus la possibilité de saisir la Cour constitutionnelle pour faire valoir la protection de leurs droits fondamentaux. Un outil similaire est prévu par la Constitution du Bénin. La Cour constitutionnelle béninoise est également renommée pour sa jurisprudence penchant largement en faveur de la protection des droits fondamentaux, tandis que dans d'autres pays francophones, le rôle des juges se limite à vérifier la conformité de la législation remise en cause par rapport à la Constitution. Par conséquent, la protection des droits fondamentaux reste faible dans la plupart des pays de la région tant d'un point de vue normatif que pratique. 


\section{Litiges portant sur les aspects ambigus de la Constitution}

Il est important de distinguer deux types d'interprétation de la Constitution. Le premier concerne les interprétations qui font partie du travail quotidien du juge. Les juges exercent un pouvoir d'interprétation de manière routinière en statuant sur les affaires qui leur sont soumises, y compris la question de savoir si une loi est conforme à la constitution. Le second type porte sur les interprétations demandées par une autorité compétente ou un plaignant en vue de clarifier le sens d'une disposition contestée (Melin-Soucramanien 2005: 13).

La première catégorie de cas se réfère au rôle du juge dans le cours normal du contentieux. Si le juge rencontre un texte constitutionnel ambigu dans le cadre d'une affaire, il doit interpréter le texte et l'appliquer au cas d'espèce; aucune compétence spécifique ne doit lui être dévolue à cet effet, car cela fait partie de ses attributions. Le second type de pouvoir d'interprétation, en revanche, doit être explicitement attribué dans la mesure où il se réfère à un cas précis. Dans les pays anglophones, la compétence constitutionnelle inclut normalement le pouvoir d'interpréter les dispositions constitutionnelles faisant l'objet de controverse, mais seuls trois autres pays d'Afrique de l'Ouest semblent prévoir explicitement cette compétence dans leurs constitutions ou textes juridiques : le Niger (article 103), le Burkina Faso (article 152) et la Côte d'Ivoire (articles 90 et 94).

\section{Difficultés associées à la compétence d'examiner les décisions des tribunaux}

Dans les pays francophones, les Cours constitutionnelles sont généralement considérées comme des institutions judiciaires situées et opérant en dehors du système judiciaire ordinaire - par opposition à la tradition anglo-américaine, dans laquelle la Cour suprême se situe au sommet de l'appareil judiciaire ordinaire. Par conséquent, dans la plupart des pays d'héritage francophone, les Cours/Conseils constitutionnel(le)s sont considéré(e)s comme ayant une compétence spécialisée et sont traités séparément des tribunaux ordinaires dans la Constitution. Il en découle que ces juridictions constitutionnelles ne sont pas, en théorie, habilitées à examiner ou contrôler les décisions des tribunaux ordinaires en appel ou en cassation.

Le Bénin est une exception. Sa Cour constitutionnelle peut, au moins en vertu de sa jurisprudence, examiner des décisions rendues par d'autres instances, y compris la Cour suprême. Lorsqu'une Cour suprême coexiste avec une Cour constitutionnelle, comme au Bénin, ce type de compétence peut donner lieu à des difficultés dans la détermination de l'autorité de la chose jugée des 
décisions des Cours suprêmes. En outre, la Cour constitutionnelle du Bénin a confirmé sa compétence pour examiner non seulement les actes juridiques, mais également pour inclure les "évènements de société», y compris la projection d'une vidéo, une caricature de certaines activités ou de certains comportements qui ont des répercussions sur la Constitution (Mede 2012 : 3).

\section{Tableau 8.1. Autres attributions des juridictions chargées de la justice constitutionnelle en Afrique de l'Ouest}

\begin{tabular}{|c|c|c|c|c|c|c|c|c|c|c|}
\hline & 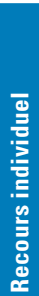 & 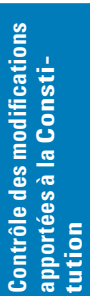 & 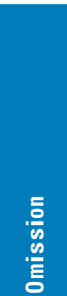 & 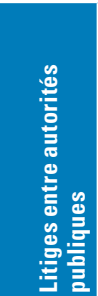 & 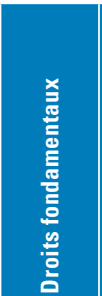 & 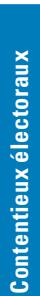 & 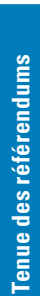 & 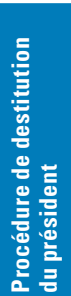 & 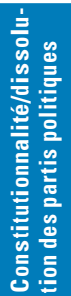 & 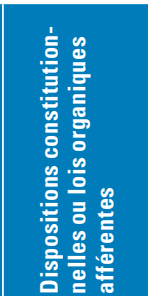 \\
\hline Bénin & + & $-\pi e^{-1}$ & + & + & + & + & + & $-\infty$ & $-\infty$ & $\begin{array}{l}\text { Articles 4, 3, } \\
177,121-2 \\
\text { (Constitution) } \\
\text { Articles 24, } \\
33,68 \text { (loi } \\
\text { organique) }\end{array}$ \\
\hline $\begin{array}{l}\text { Burkina } \\
\text { Faso }\end{array}$ & - & + & - & $\begin{array}{c}\quad+ \\
\text { limité } \\
\text { /cas par- } \\
\text { ticuliers } \\
\text { unique- } \\
\text { ment }\end{array}$ & - & + & + & - & + & $\begin{array}{l}\text { Articles 101, } \\
108,152,154, \\
156 \text { (Constitu- } \\
\text { tion) } \\
\text { Articles 26-8, } \\
38 \text { (loi orga- } \\
\text { nique) }\end{array}$ \\
\hline $\begin{array}{l}\text { Cabo } \\
\text { Verde }\end{array}$ & + & + & - & + & + & + & - & + & + & $\begin{array}{l}\text { Articles 20, } \\
132,215, \\
280,294 \\
\text { (Constitution) }\end{array}$ \\
\hline $\begin{array}{l}\text { Côte } \\
\text { d'Ivoire }\end{array}$ & - & + & - & + & - & + & + & - & - & $\begin{array}{l}\text { Articles 94-5, } \\
\text { 124-6, Titre V } \\
\text { (Constitution) }\end{array}$ \\
\hline Gambie & + & + & + & + & $\begin{array}{c}+ \\
\text { Sauf } \\
\text { droits } \\
\text { écono- } \\
\text { miques et } \\
\text { sociaux }\end{array}$ & + & + & - & - & $\begin{array}{l}\text { Articles 5, } \\
127,226 \\
\text { (Constitution) }\end{array}$ \\
\hline Ghana & + & + & $\stackrel{+}{+}$ & + & $\begin{array}{l}\text { Tribunal } \\
\text { de } \\
\text { grande } \\
\text { instance } \\
\text { en 1er } \\
\text { ressort }\end{array}$ & + & + & - & + & \begin{tabular}{|l|} 
Articles 2, 23, \\
$33,55,64,130$ \\
(Constitution)
\end{tabular} \\
\hline Guinée & - & + & - & $\stackrel{+}{+}$ & + & + & + & - & - & $\begin{array}{l}\text { Articles 93-5 } \\
\text { (Constitution) }\end{array}$ \\
\hline
\end{tabular}




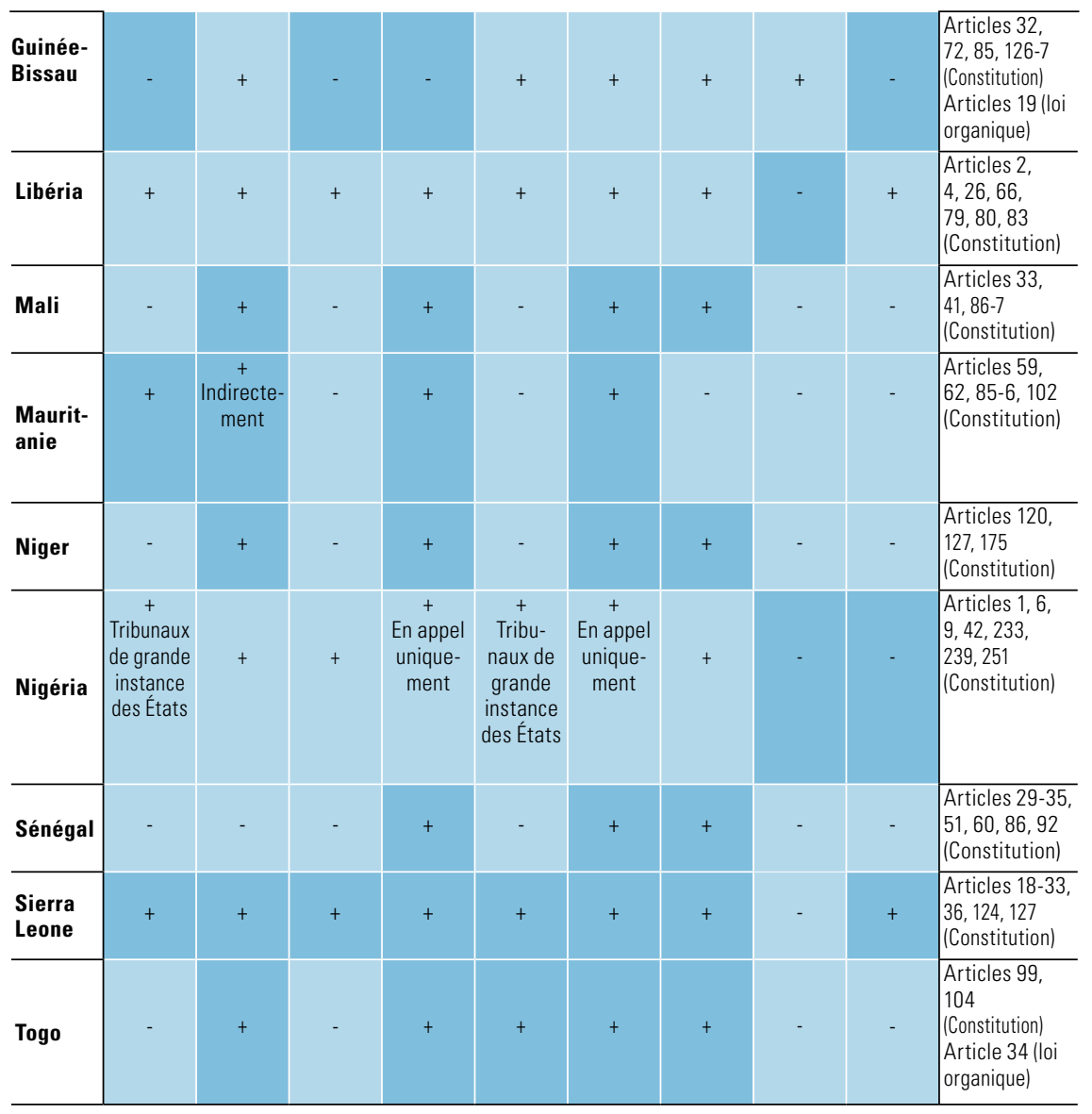

+ = Juridictions chargées de la justice constitutionnelle pleinement ou partiellement habilitées

- = Juridictions chargées de la justice constitutionnelle généralement pas habilitées

Remarque: Au Bénin, le pouvoir du juge constitutionnel de statuer sur la constitutionnalité des modifications apportées à la Constitution ainsi qu'en matière d'omission constitutionnelle est fondé non sur une disposition explicite de la Constitution, mais sur une interprétation constructive de la Constitution par la Cour. 
9. La saisine

des juridictions

compétentes

en matière

contrôle de

constitutionnalité

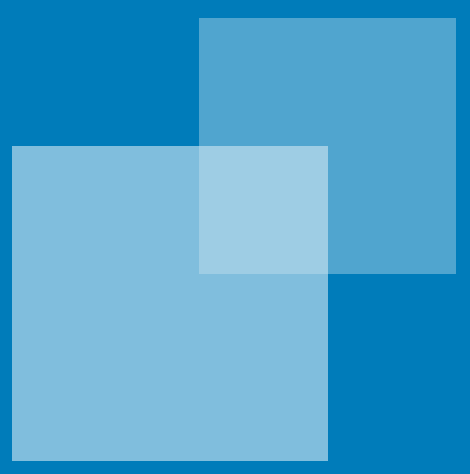




\title{
9. La saisine des juridictions compétentes en matière contrôle de constitutionnalité
}

\author{
Babacar Kante et H. Kwasi Prempeh
}

Mettre en place des juridictions spécialisées et leur attribuer la compétence pertinente forment la base du processus de contrôle de constitutionnalité. Pour autant, ces éléments ne permettent pas à eux seuls de garantir l'accès des requérants à ces instances pour faire constater les violations présumées, obtenir le respect des obligations légales et garantir la protection de leurs droits. Pour que les instances remplissent pleinement les fonctions prévues par les différentes constitutions, elles doivent être dotées des compétences nécessaires et pouvoir être saisies. Par conséquent, des règles doivent être élaborées pour faciliter l'accès des individus aux instances chargées de la justice constitutionnelle. Ces règles déterminent qui a le droit de saisine et quelle procédure doit être suivie pour accéder à la justice constitutionnelle (Conac et du Bois de Gaudusson 1989 : 299; jan 2000 : 689).

En Afrique de l'Ouest, où le renforcement et la consolidation de l'éthique démocratique restent un défi, la volonté d'établir et d'institutionnaliser le constitutionnalisme et l'État de droit au cours du processus de démocratisation des années 1990 a renouvelé l'intérêt porté aux juridictions chargées du contrôle de constitutionnalité. Ces nouvelles institutions ont été conçues pour répondre à deux objectifs principaux. En premier lieu, pour servir d'arbitre aux différends "politiques», y compris entre institutions politiques. En second lieu, pour jouer un rôle central dans la protection des droits humains garantis par les instruments constitutionnels et législatifs (Holo 2009 : 101; Aïvo 2006 : 222).

À cette fin, les constitutions et lois qui établissent et gouvernent le fonctionnement des instances chargées du contrôle de constitutionnalité en Afrique de l'Ouest prévoient également diverses règles, procédures et modalités d'accès à la justice constitutionnelle (Akerekoro 2013 : 59). Certaines admettent un droit de saisine généreux, ouvrant largement l'accès à la justice constitutionnelle, tandis que d'autres appliquent une politique plus restrictive en la matière. Par conséquent, l'analyse du droit de saisine (la capacité de saisir la justice et d'introduire une action) des juridictions 
chargées du contrôle de constitutionnalité dans la région doit se pencher sur deux points : quelles sont les parties ayant le droit ou la capacité d'introduire un recours (locus standi) et quelle procédure, le cas échéant, doit pour cela être suivie.

\section{La saisine des juridictions compétentes en matière de contrôle de constitutionnalité}

Pour évaluer l'efficacité d'un système judiciaire et sa capacité à résoudre les litiges, il est fondamental d'identifier les individus et les organes habilités à saisir une instance juridictionnelle. En matière de justice constitutionnelle, la capacité des individus à accéder à une juridiction compétente détermine le degré d'efficacité dans la protection des droits humains et des libertés fondamentales (Delpérée 1991 : 221). De même, cet accès est d'une importance cruciale pour les acteurs et intérêts politiques, car il contribue à garantir le respect des règles du jeu politique, de l'exercice de l'autorité publique et des limites de celle-ci.

Dans le contexte ouest-africain, la réponse apportée sur le plan constitutionnel et législatifà la question de l'accès ou du droit de saisine varie considérablement en fonction du pays et de sa tradition juridique. Dans les pays francophones, la saisine dépend souvent du type de litige ou de sa matière. En d'autres termes, la question de savoir qui peut saisir la justice pour faire appliquer la Constitution dépend de la nature des questions constitutionnelles soulevées. En fonction du litige, les autorités politiques, administratives ou judiciaires voire des individus ou des entreprises privées - peuvent introduire un recours auprès des juridictions constitutionnelles.

Dans les pays anglophones en revanche, l'accès à ces dernières dépend principalement de la relation entre le requérant et le recours. À l'exception des cas portant sur les droits constitutionnels, pour lesquels le droit de saisine ne concerne que les individus directement touchés par la violation présumée, il existe une distinction au sein même des pays anglophones en matière de saisine. En Gambie (article 5), au Ghana (article 2) et en Sierra Leone (article 127), la Constitution permet généralement à un individu considérant qu'une législation (ou tout autre acte ou omission de toute personne ou autorité) contrevient à une disposition de la Constitution d'invoquer la compétence constitutionnelle de la juridiction appropriée pour faire déclarer cet acte ou omission comme inconstitutionnel. Dans ces cas-là, le requérant ne doit pas prouver qu'il ou elle a un « intérêt suffisant » ou a souffert (ou risque de souffrir) de dommages du fait de l'acte ou de l'omission présumés inconstitutionnels pour faire appel à la compétence constitutionnelle de la Cour suprême. Si 
le requérant considère qu'une situation d'inconstitutionnalité s'est produite, il peut s'adresser à la Cour suprême pour obtenir une décision à cet effet. Cela s'applique aux personnes physiques comme morales, y compris les associations, entreprises et organisations non gouvernementales. Au Libéria et au Nigéria, à l'inverse, la saisine constitutionnelle nécessite dans tous les cas (et pas uniquement ceux portant sur les droits) que le requérant démontre un «intérêt suffisant» (par exemple une atteinte réelle ou imminente portée à ses intérêts) afin de pouvoir saisir la juridiction.

Au Ghana, bien que la Constitution prévoie que "tout individu» peut introduire un recours devant la juridiction compétente pour faire constater l'inconstitutionnalité d'un acte, d'une loi ou d'une commission, la Cour suprême considère que seuls les citoyens peuvent se présenter devant la Cour, sauf pour les cas relatifs aux droits humains, pour lesquels les non-citoyens peuvent également avoir accès à la justice constitutionnelle.

Devant les juridictions où la saisine est limitée et différenciée en fonction du type de litige ou de sa matière (notamment dans les pays francophones), afin de déterminer quelles sont les personnes ou les entités habilitées à présenter un recours devant un juge constitutionnel, il convient d'abord de distinguer les différents types de litiges. Trois grandes catégories de cas peuvent être identifiées à cet égard : les cas portant sur l'examen ou le contrôle de constitutionnalité, les litiges relatifs au fonctionnement des organes publics (conflits d'attribution) et les contentieux électoraux. Dans de rares cas, certains pays reconnaissent aux juridictions constitutionnelles la possibilité de s'autosaisir d'une question.

\section{Le contrôle de constitutionnalité}

Les recours visant à examiner ou à déterminer la constitutionnalité des actes ou omissions peuvent être déposés devant les juridictions constitutionnelles par les autorités politiques, administratives ou judiciaires, ainsi que par les individus ou entités légales agissant en leur nom propre ou au nom d'une tierce partie.

\section{Les autorités politiques, administratives et judiciaires}

Pour les cas concernant le contrôle de constitutionnalité, la règle générale est de donner aux autorités représentant l'État l'accès aux juridictions chargées du contrôle de constitutionnalité. Dans les pays francophones, les autorités habilitées sont quasiment toujours les mêmes. Lorsque l'objet du recours porte sur l'examen de la constitutionnalité des lois, des règlements intérieurs du pouvoir législatif, des lois organiques ou des traités, le droit de saisine 
est généralement limité au président, au Premier ministre, au président de l'Assemblée nationale et à un certain nombre de membres du Parlement (variable en fonction des pays) (Maus et Roux 2006 : 200). En Côte d'Ivoire, l'article 20 de la loi organique régissant le fonctionnement du Conseil constitutionnel donne aux associations nationales de défense des droits humains la possibilité de saisir le Conseil pour les cas de violation des droits fondamentaux et des libertés publiques. Des pays francophones, le Mali est celui dont le droit de saisine est le plus ouvert : le président du Haut conseil des autorités locales (ou un douzième de ses membres), le président de la Cour suprême et le président du Conseil économique, social et culturel peuvent eux aussi contester la constitutionnalité d'un acte juridique devant la Cour constitutionnelle.

Il est également possible d'effectuer un contrôle indirect, par ce qu'on appelle l'exception d'inconstitutionnalité. Les constitutions de la plupart des pays d'Afrique de l'Ouest permettent à une autorité judiciaire faisant office de juge de première instance (mais ne disposant pas de la compétence pour déterminer la constitutionnalité d'une loi ou fournir une interprétation de la Constitution dans le cadre d'une affaire) de renvoyer cette question à la juridiction constitutionnelle compétente. Ce type de recours est possible au Sénégal (article 92), au Togo (article 104), au Niger (article 132) et en Côte d'Ivoire (article 96). Les Constitutions de la Gambie (article 127), du Ghana (article 130), de la Sierra Leone (article 124) et du Nigéria (article 295) permettent également (et dans certains cas, imposent) aux tribunaux inférieurs de renvoyer les questions de constitutionnalité ou d'interprétation de la Constitution soulevées dans le cadre d'une affaire à la juridiction constitutionnelle compétente. Au Nigéria, la juridiction saisie n'est pas obligée de renvoyer une question constitutionnelle à l'instance supérieure sauf si, d'après elle, ce recours soulève "une question de droit substantielle» ou si l'une des parties demande un tel renvoi. Ce dernier est d'abord soumis à un tribunal de grande instance, qui peut résoudre la question s'il considère qu'il ne s'agit pas "d'une question de droit substantielle»; en revanche, il doit renvoyer le dossier à la Cour d'appel s'il considère que la question constitutionnelle soulevée est "substantielle». La Cour suprême du Ghana a également statué que, lorsqu'une question de constitutionnalité est soulevée dans le cadre d'une procédure devant un tribunal inférieur, le renvoi devant la Cour suprême n'est pas nécessaire si le sens de la disposition en question est "clair et sans ambiguïté».

Au Cabo Verde, le procureur général peut également renvoyer les questions à la Cour constitutionnelle, conformément à l'article 280 de la Constitution. Cette procédure indirecte de contrôle de constitutionnalité existe également dans 
tous les pays francophones étudiés à l'exception du Mali et de la Mauritanie. Il est important de souligner qu'en dépit de la forte influence du modèle français sur l'architecture des instances chargées du contrôle de constitutionnalité des pays africains francophones, le contrôle de constitutionnalité indirect a été introduit dans ces pays bien avant son acceptation par la France lors des réformes constitutionnelles de 2008, comme nous l'avons mentionné au chapitre 7. Par exemple, il apparaît dans la loi organique de 1992 portant organisation du Conseil constitutionnel du Sénégal et dans la Constitution béninoise de 1990 .

\section{Les personnes physiques et les personnes morales de droit privé}

Bien que cela ne soit pas la norme en Afrique de l'Ouest francophone, tous les pays de common law de la région, comme nous l'avons mentionné, permettent aux personnes physiques de saisir la Cour suprême (ou les juridictions ayant compétence en matière constitutionnelle). C'est notamment le cas lorsque le litige concerne une violation présumée de la Constitution ou d'un droit fondamental du requérant. Cependant, parmi les pays francophones, seuls le Bénin (articles 3 et 122 de la Constitution et article 24 de la loi organique relative à la Cour constitutionnelle), le Niger, le Mali et la Mauritanie permettent actuellement aux individus de saisir directement la juridiction constitutionnelle. Au Bénin, ce droit concerne tant les questions constitutionnelles portant sur les droits humains que celles relatives à un référendum ou un processus électoral, mais au Niger, au Mali et en Mauritanie, il ne s'applique quaux affaires électorales. L'article 20 de la Constitution du Cabo Verde, lusophone, donne aux personnes physiques accès aux juridictions constitutionnelles grâce à une procédure spéciale dénommée amparo, dont les modalités opérationnelles sont réglementées par la loi 109/IV/94 du 24 octobre 1994.

\section{Le règlement des conflits d'attribution}

Cette catégorie de cas porte sur les scénarios impliquant des conflits horizontaux ou verticaux entre autorités gouvernementales. Les conflits horizontaux surviennent entre institutions situées au même niveau dans la structure de l'État, par exemple entre le président et le Premier ministre, ou entre l'exécutif et d'autres branches du pouvoir, comme le pouvoir législatif. Les conflits verticaux concernent les litiges entre le gouvernement central et les autorités locales et se rencontrent généralement dans les États fédéraux.

Dans les pays francophones, seules les autorités politiques peuvent saisir la Cour ou le Conseil constitutionnel(le) sur ces questions. Ces autorités sont généralement le président de la République (ou son remplaçant), le président 
de l'Assemblée nationale, le Premier ministre et, lorsqu'il existe une seconde chambre, le président du Sénat. Dans les pays anglophones, comme nous l'avons précédemment mentionné, toute personne ayant un intérêt au litige, même s'il ne s'agit pas d'un intérêt personnel ou direct, peut soumettre une affaire devant la juridiction ayant compétence en matière constitutionnelle.

\section{Le contentieux électoral}

Les élections jouent un rôle central dans les politiques de démocratisation et le constitutionnalisme en Afrique de l'Ouest. Tout en représentant la voie la plus légitime et universellement acceptée vers le pouvoir politique, elles sont aussi extrêmement controversées - entraînant souvent, dans le contexte ouestafricain, des conflits, les différentes parties contestant fréquemment certains aspects du processus électoral ou son résultat. Par conséquent, les constitutions d'Afrique de l'Ouest ont établi un mandat clair en matière de contentieux électoral en faveur des juridictions chargées de la justice constitutionnelle. Les litiges électoraux se caractérisent par certains traits qui les isolent des autres types de litiges que les juridictions chargées de la justice constitutionnelle ont à résoudre. Ces caractéristiques portent sur le profil des personnes habilitées à soumettre les affaires électorales à un juge constitutionnel (qui agit dans ce cas en tant que juge électoral), la procédure à suivre, le mécanisme de résolution des différends et les mesures d'instruction à la disposition du juge.

En ce qui concerne les candidats éligibles, il est difficile d'effectuer un classement en fonction des différents systèmes juridiques en Afrique de l'Ouest. Par exemple, la Gambie, le Ghana, le Libéria, le Mali et la Côte d'Ivoire donnent aux partis politiques la possibilité de saisir la Cour concernant le processus électoral ou les élections. Les candidats peuvent également déposer un recours en Côte d'Ivoire, en Gambie, au Ghana, au Libéria, au Mali, en Mauritanie, au Nigéria et au Sénégal. Au Mali, au Niger, en Gambie, au Ghana, en Mauritanie, au Bénin, au Burkina Faso et en Côte d'Ivoire, les électeurs peuvent également soumettre un litige électoral au juge constitutionnel. Il est également important de noter que le Sénégal et le Mali sont les seuls pays de la région à autoriser également les délégués du gouvernement, les membres de la Commission électorale indépendante et les présidents de bureaux de vote à saisir la justice. D'autres pays, comme le Bénin (article 52 de la loi organique relative à la Cour constitutionnelle), ont étendu la liste des requérants possibles pour y inclure les autorités administratives ou organes chargés de l'organisation de l'élection. Dans tous les pays étudiés ou presque, au minimum les candidats et leurs représentants peuvent introduire des recours aux élections présidentielles et législatives devant le juge constitutionnel en sa qualité de juge électoral. 


\section{Le pouvoir d'autosaisine des juges constitutionnels}

Dans quelques-uns des 16 pays étudiés, les juridictions chargées de la justice constitutionnelle ont la possibilité de s'autosaisir de certaines questions, même en l'absence d'un recours introduit par un requérant. C'est le cas de la Cour constitutionnelle du Bénin (Soumanou 2006 : 67). En vertu de l'article 121(2) de la Constitution, elle «se prononce d'office sur la constitutionnalité des lois et de tout texte réglementaire censés porter atteinte aux droits fondamentaux de la personne humaine». L'article 22 du règlement intérieur de l'institution lui permet également de se saisir d'office d'une affaire pour rectifier toute erreur matérielle dans l'une de ses décisions ${ }^{19}$. En vertu de l'article 157(3) de la Constitution du Burkina Faso (révisée en 2012), le Conseil constitutionnel est également autorisé à «se saisir de toutes questions relevant de sa compétence s’il le juge nécessaire».

Au Libéria, la Cour suprême peut appliquer une procédure de saisine d'office sans initiative préalable d'un requérant si elle considère qu'une loi porte atteinte à l'indépendance de la justice. Elle peut ensuite décider que cette loi est contraire à la Constitution afin de protéger le pouvoir judiciaire. Une interprétation large de la section 4(8) de la Constitution nigériane peut également aboutir à l'existence d'une saisine d'office des juridictions compétentes.

19 Décision DCC 03-135 du 21 août 2003 et Décision de proclamation des résultats de l'élection présidentielle de 2001, Recueil, p. 261. 


\section{Lautorité des décisions des juridiotions compétentes en matière de contrôle de constitutionnalfié}

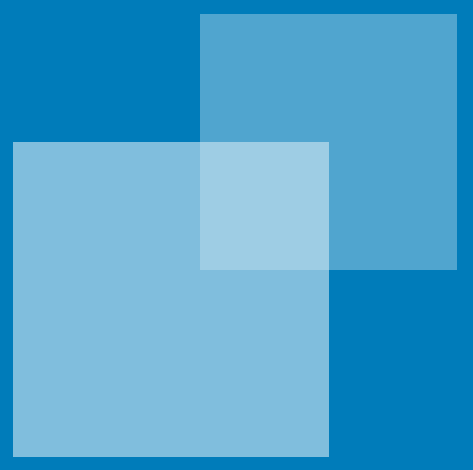




\title{
10. L'autorité des décisions des juridictions compétentes en matière de contrôle de constitutionnalité
}

\author{
Babacar Kante et H. Kwasi Prempeh
}

Lautorité des décisions des juridictions chargées du contrôle de constitutionnalité dépend de plusieurs facteurs, notamment du statut procédural de la requête, de la position hiérarchique de la juridiction ou du juge et de la portée du jugement. Compte tenu de la nature politique des questions qu'elles ont à trancher, le débat consiste souvent à déterminer si les décisions des instances chargées de la justice constitutionnelle, en particulier les Cours ou Conseils constitutionnel(le)s, ont la même autorité que celles des instances ordinaires. Même la nature judiciaire des Cours ou Conseils constitutionnel(le)s reste un sujet de controverse en Afrique francophone. La création du Conseil constitutionnel français a connu des discussions analogues. Selon certains, ces instances sont des entités politiques et elles ne peuvent donc adopter des décisions ayant l'autorité de la chose jugée (res judicata - caractère définitif et irréversible).

Ces débats sont désormais en grande partie académiques, car depuis la création de ces instances, de nouveaux développements ont fait disparaître les doutes initiaux concernant le statut judiciaire des instances chargées du contrôle de constitutionnalité dans la région. Cependant, le débat resurgit de temps à autre lorsque les résultats d'une élection présidentielle entraînent un litige juridique. Une étape importante de l'évolution des juridictions chargées du contrôle de constitutionnalité a été leur émergence en tant que garants des droits fondamentaux (Bon et Maus 2008 : préface). Avec l'affirmation de leur proéminence et de leur légitimité, ces juridictions sont largement reconnues et acceptées comme étant par nature réellement judiciaires. Dans certains pays disposant d'un Conseil constitutionnel et non d'une Cour, il a été suggéré de les renommer Cours constitutionnelles afin d'accroître leur légitimité judiciaire et de leur permettre d'asseoir davantage leur autorité. C'est notamment l'une des recommandations d'un rapport publié en 2013 par la Commission nationale de réforme institutionnelle du Sénégal. En droit positif africain, les Cours constitutionnelles - en raison de leur caractère judiciaire reconnu - rendent des décisions qui jouissent indubitablement de l'autorité de la chose jugée (Waline 2013 : XI). Cela signifie que leurs décisions 
sont définitives, ne peuvent faire l'objet d'un recours et sont absolument contraignantes. En dépit de l'autorité juridique incontestable de ces décisions, leur application se heurte souvent à des difficultés.

Compte tenu de la nature judiciaire des Cours/Conseils constitutionnel(le)s et de l'importance des décisions qu'ils/elles rendent, le droit positif régit la forme et la procédure que ces décisions doivent suivre. Cependant, en raison des différences dans les traditions juridiques entre les pays de common law et ceux de civil law, la forme des décisions diffère. Pour évaluer l'autorité conférée aux décisions des Cours constitutionnelles ou suprêmes, il faut d'abord examiner leur forme avant d'analyser leurs effets (Rousseau 2004 : 145; de Lamothe 2005 : 193 ; Renoux 2003 : 835).

\section{La forme des décisions}

La forme d'une décision peut affecter sa substance. Sa qualité peut dépendre de plusieurs facteurs, par exemple la composition de la juridiction (juge unique ou formation collégiale) ou le processus de prise de décision sousjacent. En Afrique de l'Ouest, les différentes traditions juridiques sont la principale explication des différentes formes que prennent les décisions. Suivant le système juridique en place, une classification en trois catégories des décisions est possible en fonction des modalités de leur préparation, de leur adoption et de leur présentation officielle.

\section{La préparation des décisions}

Dans l'ensemble des juridictions concernées, les juges siègent en formation collégiale, mais les instances de différents systèmes juridiques adoptent des méthodes variées d'élaboration de leurs décisions. Dans les systèmes de civil law, comme la Guinée ou le Sénégal, le président de la Cour désigne un juge qui fait office de rapporteur et prépare un projet de décision, que les membres de la Cour examinent ensuite. Dans les systèmes de common law, chacun des juges du collège ayant examiné l'affaire est habilité à préparer son propre jugement ou décision, que la décision de la Cour se prenne à l'unanimité ou non. Toutefois, les juges peuvent renoncer à ce droit et adopter ou cosigner le projet de décision d'un collègue s'ils sont d'accord avec le raisonnement et la résolution du cas. Lorsque tous ou la majorité des juges sont d'accord, celui dont le raisonnement est le plus pertinent peut être désigné pour préparer la décision principale au nom des autres juges. Larticle 294(2) de la Constitution nigériane décrit bien la pratique appliquée dans les pays de common law. 
Dans les deux pays lusophones, le Cabo Verde et la Guinée-Bissau, la procédure d'élaboration des décisions est similaire à celle des pays francophones : un rapporteur présente un projet de décision, qui est revu par l'ensemble des membres de la Cour.

Le contenu des décisions des instances chargées de la justice constitutionnelle dans les pays de common law s'inspire souvent du précédent, tandis que dans les systèmes de civil law le recours au précédent n'est pas autorisé. En pratique toutefois, de nombreux juges du système de civil law s'en inspirent malgré tout pour fonder leur décision, même s'ils ne sont pas directement applicables en l'espèce.

Le principe majoritaire est appliqué pratiquement partout pour l'adoption des décisions. Au moins sept des pays francophones s'y conforment : le Bénin, la Côte d'Ivoire, le Niger, le Togo, la Mauritanie, le Burkina Faso et le Sénégal. Ce dernier préfère toutefois le consensus. Si le vote aboutit à une égalité, la voix du président de la Cour est prépondérante. C'est la pratique au Togo (article 24 de la loi 04/04), au Sénégal (article 22 de la loi 92/23) et en Mauritanie (article 81 de la Constitution). Au Cabo Verde en revanche, l'article 29 de la loi 56/VI/2005 dispose qu'en cas d'égalité, une seconde délibération puis un second vote ont lieu; ce n'est que si ce second vote débouche aussi sur une égalité que la voix du président devient prépondérante.

Dans la majorité des pays francophones, il est impossible d'identifier le juge ayant préparé la décision ou la teneur des votes émis par les membres de la Cour. Dans les pays anglophones en revanche, chaque juge qui rédige ou adopte une opinion, y compris dissidente, est identifié nommément. C'est également le cas au Cabo Verde lusophone.

Au Togo, l'article 28 du règlement intérieur de la Cour constitutionnelle du 13 mai 1997 prohibe l'abstention; les juges doivent donc prendre position d'une manière ou d'une autre.

\section{La diffusion des décisions}

Dans la plupart des pays de civil law de la région, notamment le Sénégal, les décisions sont généralement publiées au journal officiel. Dans les pays de common law, la publication des décisions de la Cour est gérée par le pouvoir judiciaire ou confiée à un organe public déterminé (par exemple le conseil d'information sur la législation [Council on Law Reporting] au Ghana).

Les Constitutions de la Gambie, du Nigéria et de la Sierra Leone précisent explicitement le délai dans lequel doit intervenir la publication de la décision définitive sur une affaire. Lorsque la Cour suprême est sollicitée pour 
interpréter une disposition de la Constitution ou déterminer la validité d'une élection présidentielle ou législative, la Constitution gambienne requiert de la Cour qu'elle rende sa décision dans un délai de 30 jours. Dans tous les autres cas, les Cours doivent rendre leurs décisions dans les trois mois suivant les conclusions livrées par chacune des parties. Les juridictions de la Sierra Leone et du Nigéria (y compris la Cour suprême, la Cour d'appel et le tribunal de grande instance) doivent également rendre une décision écrite dans un délai de trois mois (Sierra Leone) ou 90 jours (Nigéria) après la présentation des preuves ou du réquisitoire final. En outre, toutes les parties doivent recevoir une copie officielle de la décision le jour de sa publication (Sierra Leone) ou dans un délai de sept jours (Nigéria). Les Constitutions du Libéria et du Ghana ne précisent pas de délai pour rendre une décision dans une affaire ce qui peut occasionner des retards inutiles dans la publication des décisions.

À l'exception du Niger, les constitutions des pays de civil law, notamment dans les pays de tradition juridique française, requièrent des juridictions chargées de la justice constitutionnelle qu'elles fassent connaître leur décision dans un délai de huit jours en cas d'urgence. Au Niger, toutes les décisions concernant l'examen préliminaire des projets de loi doivent être rendues dans un délai de 15 jours, qui peut être ramené à 5 jours dans le cas d'une demande urgente du gouvernement. Pour les cas non urgents, le délai est de 30 jours au Burkina Faso, au Mali, en Mauritanie, au Niger, au Sénégal et au Togo et de 15 jours au Bénin, en Côte d'Ivoire et en Guinée. Au Cabo Verde, le délai est généralement de 20 jours, quoique la Constitution prévoie - sans préciser le nombre de jours - un délai plus court en cas d'urgence sur demande du président de la République.

Il existe une différence marquée dans la structure des décisions des juridictions entre les pays anglophones et les autres. En Gambie, au Libéria, au Ghana, au Nigéria et en Sierra Leone, comme signalé précédemment, les juges sont libres de publier une opinion dissidente. Ils peuvent également rédiger des opinions (concordantes), y compris lorsque la décision est unanime. Des pays francophones, seul le Togo autorise les juges de la Cour constitutionnelle à rédiger des opinions individuelles (concordantes uniquement) pour accompagner les décisions de la Cour. Larticle $34 \mathrm{du}$ règlement intérieur de la Cour togolaise prévoit que : "Tout membre de la Cour peut, à tout moment, faire des commentaires et publications sur les décisions et avis de la Cour. Toutefois, conformément à l'article 17 de la loi organique portant organisation et fonctionnement de la Cour, ces commentaires et publications doivent avoir un caractère scientifique et aller dans le même sens que la position de la Cour.» 


\section{Les effets des décisions}

Afin d'évaluer l'effet des décisions, il est important de distinguer d'abord les différents types de jugements. Le premier type comprend les décisions déclarant une disposition comme constitutionnelle, avec des réserves. Dans ce type de décision, la disposition ou la loi est valide uniquement dans la mesure où son interprétation est conforme à celle donnée par la Cour dans sa décision. Le deuxième type concerne les rejets purs et simples des requêtes. Les décisions du troisième type commandent à l'autorité compétente de mettre la loi en conformité avec la Constitution, et dans certains cas, dans un délai imparti.

Le rejet des requêtes ne pose généralement pas de problème, car l'effet reste inter partes (limité aux parties à l'affaire). En revanche, l'effet des déclarations d'inconstitutionnalité est par nature erga omnes: ces décisions s'appliquent à tous (pas uniquement aux parties à l'affaire). L'article 87 de la Constitution mauritanienne interdit par exemple la promulgation et l'application d'un projet de loi déclaré inconstitutionnel. Il est également possible de distinguer les effets dans le temps de la portée des décisions.

\section{Les effets des décisions dans le temps}

En principe, les décisions de justice en matière de contentieux constitutionnel n'ont pas d'effet rétroactif (ex nunc). Cela se justifie par le souci de préserver la stabilité du système juridique et la sécurité des situations juridiques qui en découlent. En tant que tels, et conformément au principe d'inviolabilité, des droits déjà acquis ne peuvent être remis en cause (Yannakopoulos 1998 : 604).

Dans de nombreux systèmes juridiques en Afrique de l'Ouest, comme ailleurs, cette position fait partie des principes généraux du droit. En plus d'établir sa compétence en matière de contrôle de la constitutionnalité des lois, l'article 114 de la Constitution du Bénin prévoit par exemple que la Cour constitutionnelle "garantit les droits fondamentaux et les libertés publiques." Il en ressort deux conclusions. La première est qu'en principe les effets des décisions des instances constitutionnelles ne sont pas rétroactifs. La seconde est un corollaire de la première : elles prennent effet immédiatement. Au Cabo Verde en revanche, la situation est légèrement différente, puisque la Constitution opère une distinction entre l'inconstitutionnalité originelle et l'inconstitutionnalité ultérieure. Dans le premier cas, une déclaration d'inconstitutionnalité - sauf pour les traités - prend effet à la date de la décision, mais vaut également depuis la date de l'entrée en vigueur de la norme inconstitutionnelle. En d'autres termes, la décision a un effet rétroactif (ex tunc) (article 285 de la Constitution). Cela se justifie par la volonté de 
remédier aux conséquences négatives résultant de l'inconstitutionnalité originelle. En ce qui concerne le second cas (inconstitutionnalité résultant de la violation d'une règle constitutionnelle adoptée ultérieurement), la déclaration d'inconstitutionnalité prend effet à la date de la décision.

Dans le cas des juridictions de common law, l'un des aspects de l'effet dans le temps d'une décision constitutionnelle concerne son caractère obligatoire pour les affaires soumises ultérieurement à la Cour. En général, les Cours suprêmes sont censées, en vertu de la doctrine du précédent obligatoire (stare decisis), suivre leur jurisprudence et appliquer le même raisonnement juridique (ratio decidendi) aux cas ultérieurs soulevant les mêmes questions; toutefois, contrairement aux instances inférieures, elles ne sont pas obligées de suivre ces précédents. Les Constitutions de la Gambie (article 126), du Ghana (article 129) et de la Sierra Leone (article 122) mentionnent explicitement ce principe. Au Ghana, un requérant à l'encontre de qui une décision a été rendue par la Cour suprême peut solliciter un réexamen de la décision s'il estime qu'elle a été rendue par erreur.

\section{Le caractère non rétroactif des décisions}

Les constitutions des pays ouest-africains et les lois relatives à la création et à l'organisation des Cours constitutionnelles et suprêmes prévoient que leurs décisions n'ont pas d'effet rétroactif. C'est le cas tant des systèmes de common law que de ceux de tradition de civil law.

Dans tous les pays étudiés, les décisions des Cours constitutionnelles et suprêmes produisent des effets pour l'avenir. Cependant, au Togo, l'effet d'un jugement peut être différé. En vertu de l'article 31 de la loi organique portant organisation de la Cour, le juge peut donner au législateur un délai pour adapter la législation.

Il s'agit d'un principe général du droit qui s'applique à tous les systèmes juridiques respectant l'État de droit. Cependant, il existe une différence entre le type de litige et le contenu de la décision. La portée de l'autorité des décisions dépend de la matière soumise à la Cour. Dans le cas du contrôle de constitutionnalité par exemple, le principe est appliqué de manière absolue. Dans le cas d'un contentieux électoral en revanche, lorsque le résultat d'une élection est invalidé, l'application d'une telle décision rouvre le débat quant aux résultats déjà publiés (pour le Bénin, voir Mede 2012 : 32 ; pour le Sénégal, voir Fall 2008 : 233).

À l'inverse, les avis consultatifs obéissent à un ensemble différent de règles juridiques. Il existe trois types d'avis en droit : les avis consultatifs, les avis 
obligatoires et les avis conformes. Le droit positif des pays africains ne fait pas cette distinction et reste généralement silencieux quant à l'autorité des avis.

\section{Des décisions avec effets immédiats}

Il est important de distinguer les décisions qui rejettent une requête de celles qui censurent des dispositions contestées. Un rejet signifie une confirmation des dispositions contestées et le maintien du statu quo. Dans ces circonstances, l'on peut s'attendre à la ratification du traité contesté ou à l'application de la loi ou de la décision administrative ou de justice mise en cause. Lacte dont la constitutionnalité a été confirmée sera donc immédiatement applicable. Si, toutefois, la Cour invalide les dispositions contestées, celles-ci (et les autres dispositions afférentes encore sous forme de projet) seront écartées avec effet immédiat. Au Sénégal, ces deux situations sont régies par les articles 16 à 18 de la loi organique 92-23 du 31 mai 1992 sur le Conseil constitutionnel telle que modifiée par la loi 99-71 du 17 février 1999.

\section{La portée des décisions}

Étant donné que la Constitution représente la loi suprême du pays, les décisions rendues par les Cours constitutionnelles ou suprêmes dans l'exercice de leur compétence constitutionnelle engagent non seulement les parties à l'affaire, mais l'ensemble de la société, notamment tous les individus et autorités publiques, qu'elles soient politiques, administratives, judiciaires ou militaires. Ce principe s’applique à tous les pays étudiés.

\section{Les autorités administratives}

Les décisions des Cours constitutionnelles ou suprêmes affectent les autorités administratives pour au moins deux raisons. Premièrement, les autorités administratives sont établies et exercent leurs pouvoirs en vertu de la loi. Deuxièmement, étant donné que l'initiative législative des parlementaires est rare en Afrique, la quasi-totalité des lois adoptées par les parlements africains ont été initiées par le pouvoir exécutif. Il est donc important de veiller à ce que les autorités administratives, en tant qu'agents de mise en œuvre de la politique gouvernementale au sein du pouvoir exécutif, se conforment (et soient soumises) aux décisions des juridictions chargées du contrôle de constitutionnalité. Tous les pays en question obéissent à ce principe : la Mauritanie (article 87 de la Constitution), le Burkina Faso (article 159 de la Constitution) et la Guinée-Bissau (article 126 de la Constitution) en sont des exemples typiques. 


\section{Les autorités politiques}

L'autorité dont bénéficient les juridictions constitutionnelles pour prendre des décisions contraignantes pour les autorités politiques, à savoir le Parlement et l'exécutif, est un phénomène nouveau en Afrique. C'est l'un des objectifs et des résultats des transitions démocratiques, mais aussi des projets de réforme constitutionnelle mis en place depuis le début des années 1990. Le principe de primauté de la Constitution, qui soumet toutes les autres lois et tous les individus et autorités à ses dispositions, est explicitement affirmé dans la Constitution de plusieurs pays africains, notamment le Ghana (article 4), le Libéria (article 2) et le Nigéria (article 1). En outre, les Constitutions de la Gambie, du Ghana et de la Sierra Leone incluent une disposition qualifiant de crime le fait, pour tout individu, de désobéir ou de ne pas se conformer à une décision ou une instruction donnée par la Cour suprême dans le cadre d'une déclaration d'inconstitutionnalité portant sur une loi, un acte ou une omission. Lorsque le président ou vice-président de la République ne se conforme pas à ces décisions, les Constitutions du Ghana et de la Gambie en font un motif de destitution.

\section{Les autorités judiciaires}

Tous les systèmes juridiques africains, en particulier ceux de civil law suivant le modèle de contrôle centralisé, partagent le principe selon lequel les décisions des juridictions chargées de la justice constitutionnelle sont contraignantes pour les autres institutions judiciaires. Dans les pays de common law, l'application de ce principe ne pose aucune difficulté, étant donné que l'instance ayant la compétence définitive en matière constitutionnelle se situe au sommet de la hiérarchie judiciaire. Par conséquent, les décisions de la Cour suprême ont automatiquement force obligatoire pour toutes les autres juridictions du système, un fait explicitement réaffirmé dans les constitutions de la Gambie (article 126), du Ghana (article 129) et de la Sierra Leone (article 122). Cependant, dans les systèmes juridiques où une Cour constitutionnelle existe en parallèle à une Cour suprême, des difficultés peuvent apparaître quant à l'autorité de la chose jugée des décisions de la première sur la seconde. Dans ces cas, l'on peut en effet faire valoir que les décisions de ces deux instances sont définitives et qu'elles ont donc toutes deux l'autorité de la chose jugée, indépendamment l'une de l'autre. Par exemple, l'article 131 de la Constitution du Bénin prévoit que «les décisions de la Cour suprême ne sont susceptibles d'aucun recours» et qu'elles "s'imposent au pouvoir exécutif, au pouvoir législatif, ainsi qu'à toutes les juridictions". Larticle 124 de la Constitution contient une disposition similaire concernant l'autorité des décisions de la Cour constitutionnelle, qui «ne sont susceptibles d'aucun recours [et] s'imposent aux pouvoirs publics et à toutes les autorités 
[...] juridictionnelles». Dans un effort de résolution des litiges entre les deux, la Cour constitutionnelle a considéré que ses décisions relatives à son domaine de compétence s'imposent à la Cour suprême. Il n'est pas précisé comment les autres juridictions répondent au conflit opposant l'autorité des décisions des juridictions chargées de la justice constitutionnelle à celle des autorités judiciaires situées à un niveau équivalent, car parallèle, dans le système juridictionnel.

\section{Les autorités militaires}

Étant donné que la nature contraignante des décisions des instances chargées de la justice constitutionnelle sur l'armée pourrait sembler manifeste, celleci représentant un élément de l'autorité de l'État, ce principe n'est pas automatiquement affirmé en droit. Cependant, compte tenu de la propension historique à l'instabilité politique et aux coups d'État dans la région, certains pays ont décidé de mentionner explicitement dans leur Constitution le caractère contraignant des décisions judiciaires pour le pouvoir militaire : le Togo (article 106), le Burkina Faso (article 159), le Niger (article 115), la Côte d'Ivoire (article 98), la Guinée (article 99) et le Bénin (article 34 de la loi organique relative à la Cour constitutionnelle).

\section{Tableau 10.1. Décisions des juridictions chargées du contrôle de constitutionnalité en Afrique de l'Ouest}

\begin{tabular}{|c|c|c|c|c|c|c|c|}
\hline & \multicolumn{2}{|c|}{$\begin{array}{l}\text { Forme des } \\
\text { décisions }\end{array}$} & \multicolumn{2}{|c|}{$\begin{array}{l}\text { Effet des décisions } \\
\text { dans le temps }\end{array}$} & \multicolumn{2}{|c|}{ Portée des décisions } & \multirow[b]{2}{*}{$\begin{array}{c}\text { Dispositions } \\
\text { pertinentes } \\
\text { de la } \\
\text { Constitution/ } \\
\text { loi organique }\end{array}$} \\
\hline & Collégiale & $\begin{array}{l}\text { Opinions } \\
\text { individu- } \\
\text { el-les et } \\
\text { dissi- } \\
\text { dentes } \\
\text { possibles }\end{array}$ & $\begin{array}{c}\text { Ex nunc } \\
\text { (futur) }\end{array}$ & $\begin{array}{l}\text { Ex tunc } \\
\text { (rétroac- } \\
\text { tif) }\end{array}$ & Armée $^{1}$ & Autres & \\
\hline Bénin & Oui & Non & Oui & Non & Oui & $\begin{array}{l}\text { Citoyens, } \\
\text { administration, } \\
\text { institutions } \\
\text { juridiques et } \\
\text { politiques }\end{array}$ & $\begin{array}{l}\text { Articles 52, } \\
124 \\
\text { (Constitution) }\end{array}$ \\
\hline $\begin{array}{l}\text { Burkina } \\
\text { Faso }\end{array}$ & Oui & Non & Oui & Non & $\begin{array}{l}\text { Textes si- } \\
\text { lencieux, } \\
\text { mais } \\
\text { peut être } \\
\text { déduit }\end{array}$ & $\begin{array}{l}\text { Autorités } \\
\text { publiques et } \\
\text { toutes les } \\
\text { autorités ad- } \\
\text { ministratives } \\
\text { et judiciaires }\end{array}$ & $\begin{array}{l}\text { Article } 159 \\
\text { (Constitution) } \\
\text { Articles } 42-4 \\
\text { (loi organique) }\end{array}$ \\
\hline
\end{tabular}




\begin{tabular}{|c|c|c|c|c|c|c|c|}
\hline $\begin{array}{l}\text { Cabo } \\
\text { Verde }\end{array}$ & Oui & Non & Oui & Oui & Oui & $\begin{array}{l}\text { Citoyens, } \\
\text { administration, } \\
\text { institutions } \\
\text { juridiques et } \\
\text { politiques }\end{array}$ & $\begin{array}{l}\text { Article } 284 \\
\text { (Constitution) }\end{array}$ \\
\hline $\begin{array}{l}\text { Côte } \\
\text { d'Ivoire }\end{array}$ & Oui & Non & Oui & Non & Oui & $\begin{array}{l}\text { Tous les pou- } \\
\text { voirs publics et } \\
\text { autorités ad- } \\
\text { ministratives } \\
\text { et judiciaires }\end{array}$ & $\begin{array}{l}\text { Articles 95, } 98 \\
\text { (Constitution) }\end{array}$ \\
\hline Gambie & Oui & Oui & Oui & Oui & $\begin{array}{l}\text { Rien } \\
\text { dans les } \\
\text { textes, } \\
\text { mais } \\
\text { peut être } \\
\text { déduit }\end{array}$ & $\begin{array}{l}\text { Citoyens, ad- } \\
\text { ministration, } \\
\text { institutions } \\
\text { juridiques et } \\
\text { politiques }\end{array}$ & \\
\hline Ghana & $\begin{array}{l}\text { Seuls } \\
\text { les juges } \\
\text { peuvent } \\
\text { rédiger } \\
\text { décision } \\
\text { princi- } \\
\text { pale }\end{array}$ & Oui & Oui & Oui & $\begin{array}{l}\text { Rien } \\
\text { dans les } \\
\text { textes, } \\
\text { mais } \\
\text { peut être } \\
\text { déduit }\end{array}$ & $\begin{array}{l}\text { Tous les } \\
\text { citoyens et } \\
\text { autorités } \\
\text { publiques }\end{array}$ & $\begin{array}{l}\text { Article } 2 \\
\text { (Constitution) }\end{array}$ \\
\hline Guinée & Oui & Non & Oui & Non & Oui & $\begin{array}{l}\text { Citoyens, } \\
\text { administration, } \\
\text { institutions } \\
\text { juridiques et } \\
\text { politiques }\end{array}$ & $\begin{array}{l}\text { Article } 96 \\
\text { (Constitution) }\end{array}$ \\
\hline $\begin{array}{l}\text { Guinée- } \\
\text { Bissau }\end{array}$ & Oui & Non & Non & Oui & Oui & $\begin{array}{l}\text { Citoyens, } \\
\text { administration, } \\
\text { institutions } \\
\text { juridiques et } \\
\text { politiques }\end{array}$ & $\begin{array}{l}\text { Article } 126 \\
\text { (Constitution) }\end{array}$ \\
\hline Libéria & Oui & Oui & Oui & Non & $\begin{array}{l}\text { Rien } \\
\text { dans les } \\
\text { textes, } \\
\text { mais } \\
\text { peut être } \\
\text { déduit }\end{array}$ & $\begin{array}{l}\text { Tous sauf } \\
\text { président de } \\
\text { la république, } \\
\text { pouvoir } \\
\text { législatif et } \\
\text { magistrats }\end{array}$ & $\begin{array}{l}\text { Articles 2, 21, } \\
61 \\
\text { (Constitution) }\end{array}$ \\
\hline Mali & Oui & Non & Oui & Non & $\begin{array}{l}\text { Rien dans } \\
\text { les textes, } \\
\text { mais } \\
\text { peut être } \\
\text { déduit }\end{array}$ & $\begin{array}{l}\text { Citoyens, } \\
\text { administration, } \\
\text { institutions } \\
\text { juridiques et } \\
\text { politiques }\end{array}$ & $\begin{array}{l}\text { Articles 88, } 94 \\
\text { (Constitution) }\end{array}$ \\
\hline $\begin{array}{l}\text { Maurita- } \\
\text { nie }\end{array}$ & Oui & Non & Oui & Non & $\begin{array}{l}\text { Rien dans } \\
\text { les textes, } \\
\text { mais } \\
\text { peut être } \\
\text { déduit }\end{array}$ & $\begin{array}{l}\text { Autorités } \\
\text { publiques, ad- } \\
\text { ministratives } \\
\text { et judiciaires }\end{array}$ & $\begin{array}{l}\text { Articles 86-7 } \\
\text { (Constitution) }\end{array}$ \\
\hline
\end{tabular}




\begin{tabular}{|c|c|c|c|c|c|c|c|}
\hline Niger & Oui & Non & Oui & Non & Oui & $\begin{array}{l}\text { Citoyens, } \\
\text { administration, } \\
\text { institutions } \\
\text { juridiques et } \\
\text { politiques }\end{array}$ & $\begin{array}{l}\text { Article } 134 \\
\text { (Constitution) }\end{array}$ \\
\hline Nigéria & $\begin{array}{l}\text { Seuls } \\
\text { les juges } \\
\text { peuvent } \\
\text { rédiger } \\
\text { décision } \\
\text { princi- } \\
\text { pale }\end{array}$ & Oui & $\begin{array}{l}\text { Rien } \\
\text { dans les } \\
\text { textes }\end{array}$ & $\begin{array}{l}\text { Rien } \\
\text { dans les } \\
\text { textes }\end{array}$ & $\begin{array}{l}\text { Rien } \\
\text { dans les } \\
\text { textes, } \\
\text { mais } \\
\text { peut être } \\
\text { déduit }\end{array}$ & $\begin{array}{l}\text { Tous les } \\
\text { individus et } \\
\text { institutions } \\
\text { publiques }\end{array}$ & $\begin{array}{l}\text { Article } 294 \\
\text { (Constitution) }\end{array}$ \\
\hline Sénégal & Oui & Non & Oui & Non & $\begin{array}{l}\text { Rien dans } \\
\text { les textes, } \\
\text { mais } \\
\text { peut être } \\
\text { déduit }\end{array}$ & $\begin{array}{l}\text { Autorités } \\
\text { publiques et } \\
\text { individus }\end{array}$ & $\begin{array}{l}\text { Articles 16-20, } \\
92 \text { (loi } \\
\text { organique) } \\
\text { Article } 9 \\
\text { (règlement } \\
\text { intérieur) }\end{array}$ \\
\hline $\begin{array}{l}\text { Sierra } \\
\text { Leone }\end{array}$ & $\begin{array}{l}\text { Rien } \\
\text { dans les } \\
\text { textes }\end{array}$ & $\begin{array}{l}\text { Rien } \\
\text { dans les } \\
\text { textes }\end{array}$ & $\begin{array}{l}\text { Rien } \\
\text { dans les } \\
\text { textes }\end{array}$ & $\begin{array}{l}\text { Rien } \\
\text { dans les } \\
\text { textes }\end{array}$ & $\begin{array}{l}\text { Rien } \\
\text { dans les } \\
\text { textes, } \\
\text { mais } \\
\text { peut être } \\
\text { déduit }\end{array}$ & $\begin{array}{l}\text { Rien dans les } \\
\text { textes, mais } \\
\text { peut être } \\
\text { déduit }\end{array}$ & \\
\hline Togo & Oui & $\mathrm{Non}^{2}$ & $\begin{array}{l}\text { Rien dans } \\
\text { les textes }\end{array}$ & $\begin{array}{l}\text { Rien dans } \\
\text { les textes }\end{array}$ & $\begin{array}{l}\text { Rien dans } \\
\text { les textes, } \\
\text { mais } \\
\text { peut être } \\
\text { déduit }\end{array}$ & $\begin{array}{l}\text { Toutes } \\
\text { les autres } \\
\text { autorités } \\
\text { publiques et } \\
\text { individus }\end{array}$ & $\begin{array}{l}\text { Article } 106 \\
\text { (Constitution) } \\
\text { Article } 30 \\
\text { (règlement } \\
\text { intérieur) }\end{array}$ \\
\hline
\end{tabular}

\section{Notes :}

1 Outre les éléments couverts par les clauses générales, certains pays (en raison de leur histoire marquée par des régimes militaires incontrôlés) ont décidé de préciser explicitement l'effet de ces décisions sur l'armée en tant qu'institution publique.

2 Les juges constitutionnels togolais peuvent faire des commentaires sur la décision et l'opinion de la Cour, pour autant que cela aille dans le même sens que la décision de la Cour à laquelle ces commentaires se rapportent.

\section{Légende}

Afrique de l'Ouest francophone

Afrique de l'Ouest anglophone

Afrique de l'Ouest lusophone 


\section{Le contrôle et la responsabilité des instances chargées du contrôle de la constitutionnalité}




\section{Le contrôle et la \\ responsabilité des instances chargées du contrôle de la constitutionnalité}

Markus Böckenförde

Dans un régime de type autoritaire, le pouvoir judiciaire est soumis à de multiples pressions. La résolution des affaires est souvent dictée par une sorte de "justice par téléphone», système par lequel les politiciens prennent informellement contact avec les juges pour influencer leurs décisions (Dung 2003 : 8). Les juges (et autres fonctionnaires) sont nommés en fonction de leur loyauté à un parti ou à un dirigeant. Dans un tel régime, le pouvoir judiciaire est traité comme un organe subsidiaire de l'exécutif. Dans ce contexte, les réformes constitutionnelles lancées dans les années 1990 dans la région ont entrepris de modifier la réputation des juges, considérés comme influençables et à la solde de l'exécutif. Dans l'ensemble - comme nous l'avons souligné ailleurs dans cet ouvrage -, les constitutions existantes ont renforcé l'indépendance des juges en Afrique de l'Ouest et servi de base à des systèmes de contrôle de constitutionnalité plus crédibles.

Les juridictions chargées du contrôle de constitutionnalité, comme toute institution au sein d'une constitution démocratique construite sur le principe de la séparation des pouvoirs, doivent être dotées non seulement des moyens de défendre leur indépendance - ce qui est d'une importance capitale, comme nous l'avons déjà vu, pour leur pouvoir de contrôle -, mais également d'un mécanisme de responsabilité permettant de garantir qu'elles n'outrepassent pas leur mandat constitutionnel. Étant donné que le pouvoir judiciaire est souvent considéré comme la branche la moins dangereuse, les architectes et penseurs constitutionnels "ont eu tendance à focaliser leur attention quasi exclusivement sur la limitation des pouvoirs des fonctionnaires et des institutions contrôlant la bourse et le glaive» (Prempeh 2006 : 69).

Les juridictions chargées du contrôle de constitutionnalité se voient cependant souvent objecter que leurs membres ne sont pas élus. Toutefois, tant que les juges constitutionnels s'abstiennent de tout comportement lié à l'élaboration des lois et se concentrent sur l'interprétation de celles-ci par rapport à la Constitution, ils n'ont pas besoin d'un mandat démocratique. Idéalement, le juge n'est que la bouche qui dit la loi. Par conséquent, ils ne doivent pas 
être soumis aux mêmes exigences en matière de responsabilité que les autres membres (élus) du gouvernement. Cependant, plus l'institution participe à l'élaboration des lois, plus sa responsabilité et sa légitimité gagnent en importance : contrairement aux législateurs élus, les membres des juridictions chargées de la justice constitutionnelle ont la possibilité d'aller à l'encontre de la volonté de la majorité. C'est le rôle des juridictions que d'interpréter la loi lorsque l'intention du législateur est floue, ce qui peut résulter en des fonctions de type législatif qui, si elles ne sont pas contrôlées, peuvent leur accorder un pouvoir discrétionnaire trop étendu, voire arbitraire (ainsi qu'un pouvoir politique indépendant plus important que celui du pouvoir législatif). Bien que cette autorité soit essentielle à la préservation de l'État de droit contre la «tyrannie de la majorité», elle peut aussi se révéler dangereuse. Étant donné que son rôle est de rendre des décisions politiquement sensibles et qu'il n'existe pas d'interprétation objectivement neutre des normes constitutionnelles, une juridiction chargée de la justice constitutionnelle peut être perçue comme un acteur politique comme un autre plutôt que comme le "serviteur impartial des normes constitutionnelles» (Horowitz 2006 : 133). En outre, le pouvoir accordé aux présidents de ces institutions dans certains pays de common law - dans le cadre de leurs prérogatives administratives et de contrôle - d'assigner des juges à certaines affaires lorsque la Cour ne statue pas en plénière, peut également saper les efforts de limitation du caractère discrétionnaire de leurs attributions. Au Ghana et au Nigéria par exemple, un collège de cinq ou sept juges statue sur les questions de constitutionnalité, mais le président a seul l'autorité de décider quels juges examinent quelles affaires - une pratique qui ouvre la voie à des abus.

Les membres des instances chargées du contrôle de la constitutionnalité ne sont pas des relais passifs de la loi, mais des citoyens, avec leurs propres valeurs et convictions politiques qui influencent leur manière de comprendre et d'interpréter les normes constitutionnelles; dès lors, comment leur responsabilité individuelle et institutionnelle peut-elle être assurée, sans compromettre leur indépendance?

Le présent chapitre élargit l'angle d'examen aux aspects généraux du cadre constitutionnel susceptibles d'affecter l'usage arbitraire ou discrétionnaire du contrôle de constitutionnalité. Certains de ces aspects sont énumérés dans les dispositions de la Constitution relatives au pouvoir judiciaire, d'autres sont à chercher ailleurs - par exemple, dans les procédures de révision. Cette approche reconnaît que la Constitution doit être considérée comme un document global orchestrant le fonctionnement et l'articulation des différents éléments du cadre constitutionnel. Par conséquent, le chapitre examine les mécanismes suivants, susceptibles d'affecter la portée du pouvoir 
discrétionnaire du juge : les débats publics portant sur les décisions judiciaires, les révisions de la Constitution en vue d'" annuler» les décisions judiciaires, la réouverture des débats et enfin l'ajustement de l'équilibre des pouvoirs entre les trois branches.

\section{L'enrichissement du débat public}

L'un des fondements de la responsabilité judiciaire est l'accès du public, y compris les juristes de profession, aux décisions de justice et aux procès. Lorsque les jugements sont disponibles dans l'espace public et peuvent être examinés par les citoyens, les juges sont incités à détailler les motifs pertinents pour prouver que leur décision se fonde sur les règles adéquates. Cette transparence peut être encouragée par un cadre constitutionnel prévoyant des audiences publiques, des délais déterminés pour l'adoption des décisions et la publication des opinions des juges. La plupart des constitutions des pays de l'Afrique de l'Ouest étudiés exigent au moins l'un de ces critères (voir chapitre 10).

Un autre aspect de la transparence concerne la portée, la qualité et le contenu des motifs exposés dans les verdicts et opinions judiciaires. Comme nous l'avons vu au chapitre 10, il existe des différences dans la manière dont les décisions judiciaires sont rendues publiques, en particulier concernant la possibilité ou non pour les juges de publier des opinions dissidentes ou la publication d'une seule opinion reflétant le consensus au sein de l'instance. En particulier après la chute d'un régime autoritaire, les instances constitutionnelles ne peuvent pas se référer à une jurisprudence existante en la matière, mais doivent généralement mettre en place un nouveau système cohérent. Lorsque l'autorité et la légitimité de la Cour sont encore faibles, et avant l'émergence d'une culture juridique d'expression des opinions dissidentes au sein de la Cour (comme en Tunisie), il peut y avoir une certaine réticence à autoriser les membres d'une institution naissante à publier des opinions dissidentes. Dans une telle situation - et en particulier en ce qui concerne les Cours constitutionnelles spécialisées -, il peut être préférable pour les juges de présenter une opinion unique, afin de renforcer la réputation et la légitimité du pouvoir judiciaire par rapport au monde juridique dans son ensemble (Garoupa et Ginsburg 2015 : 148).

Les universitaires en faveur de la publication des opinions dissidentes (et certains juges) semblent d'accord pour dire qu'un système qui autorise une telle pluralité améliore la qualité de l'opinion majoritaire (Kelemen 2013 : 1364). Étant donné que l'instance chargée de la justice constitutionnelle est composée de membres qui, dans une certaine mesure, sont nommés 
par des politiciens, la nécessité d'une plus grande transparence s'impose (Kelemen 2013 : 1356). Les opinions dissidentes peuvent inciter les rédacteurs de l'opinion majoritaire à formuler leurs jugements consciencieusement et à fournir un raisonnement juridique exhaustif en appui de leur opinion. Le processus peut encourager un débat plus large sur la décision majoritaire et stimuler une discussion franche sur la décision.

Ces points de vue ne s'excluent pas nécessairement mutuellement : la publication d'opinions dissidentes peut être autorisée à un stade ultérieur, lorsque l'institution nouvellement établie a trouvé sa place dans le système et prouvé sa légitimité (par exemple, en Allemagne, les opinions dissidentes ont été introduites 20 ans après la création de la Cour constitutionnelle).

Un débat public plus ouvert sur les décisions pertinentes implique également moins de restrictions à la liberté d'expression lorsqu'une affaire est débattue ou un jugement critiqué, en particulier dans les contextes de common law, où certaines doctrines anciennes sont encore couramment appliquées. Par exemple, la règle sub judice punit la publication de déclarations portant sur des affaires en instance, même s'il ne s'agit pas d'un procès devant jury. Un autre exemple concerne le délit d' "outrage à la Cour ", existant dans le système de common law, qui punit l'expression d'opinions pouvant ternir la réputation de la Cour ou lui manquer de respect (Prempeh 2006 : 69).

\section{La réouverture des débats}

La responsabilité de la justice constitutionnelle repose également sur la possibilité, pour la Cour, de rouvrir les débats sur ses propres décisions. Cela a été le cas au Ghana, où la Cour suprême a interprété l'article 123 de la Constitution comme permettant aux requérants de demander à la Cour d'examiner ou de réexaminer une décision qu'elle a rendue. (L'article dispose : "La Cour suprême peut, tout en considérant ses propres décisions antérieures comme définitives, revenir sur une décision antérieure si cela lui paraît nécessaire. »)

Dans ce cas, la même instance statue à nouveau - et non une autre instance devant laquelle la Cour doit rendre des comptes, mais il est raisonnable de supposer que la possibilité de rouvrir les débats accroît l'intérêt du public pour l'affaire, ce qui renforce à son tour le contrôle et la responsabilité de la Cour. 


\section{Le contournement du contrôle par une révision de la Constitution}

La Constitution fournit le cadre dans lequel les branches du pouvoir sont censées opérer. Aucune d'entre elles ne se situe au-dessus de la Constitution, qui est la loi suprême d'un pays. Par conséquent, les juridictions chargées du contrôle de constitutionnalité comparent les actes de l'exécutif et/ou les lois avec la Constitution et déclarent l'acte ou la loi nuls s'ils sont considérés comme contraires à la Constitution. Ces institutions sont les ultimes garantes du texte constitutionnel, qui peut de temps à autre faire l'objet d'une révision officielle.

Proposer une révision de la Constitution constitue un moyen légitime d'ajuster le cadre juridique suprême régissant une société pour tenir compte de l'évolution du contexte ou de nouvelles difficultés. Ces modifications peuvent corriger des dispositions qui se sont révélées inadaptées au fil du temps ou abroger des effets institutionnels indésirables ou inattendus. Le texte modifié devient le nouveau point de référence du contrôle de constitutionnalité. Du point de vue de l'équilibre des pouvoirs, une Cour constitutionnelle ou suprême peut - pour ses décisions futures - être "mise au pas» par ceux disposant du pouvoir constituant de révision de la Constitution. Par exemple, confrontée à une décision de la Cour suprême d'annuler une loi ou une législation au motif de son inconstitutionnalité, une législature pourrait décider de réviser la Constitution de manière à permettre à la loi de perdurer (Tushnet $2011: 323{ }^{20}$. Toutes les constitutions de l'Afrique de l'Ouest prévoient des dispositions détaillées en matière de révision, précisant qui peut initier la procédure, les institutions impliquées, le type de majorité requise et le type de modification possible (ou non). Un débat toujours d'actualité porte sur le rôle que doivent jouer les juridictions chargées du contrôle de constitutionnalité dans ce processus. Par exemple, la mesure dans laquelle ces instances doivent veiller au strict respect des exigences procédurales au cours d'une procédure de révision est sujette à controverse. À l'exception du Burkina Faso, qui permet explicitement, en vertu de l'article 154 de sa Constitution, un contrôle "de la procédure de révision", toutes les constitutions ouestafricaines restent silencieuses sur cette question. Ce silence ne signifie pourtant pas nécessairement que les juridictions chargées du contrôle juridictionnel ne procèdent pas à ce type d'examen. La procédure de révision de la Constitution fait partie du cadre constitutionnel et doit être respectée

\footnotetext{
La plupart des juridictions en Afrique de l'Ouest francophone utilisent cette méthode. Afin de garantir la constitutionnalité des accords internationaux, les institutions chargées du contrôle de constitutionnalité peuvent vérifier si une constitution nécessite sa mise en conformité avec l'accord international avant la ratification de celui-ci.
} 
afin de protéger l'ordre constitutionnel. Les constitutions sont modifiées par une loi ou un acte portant révision de la Constitution, et l'on peut faire valoir que cette loi - comme toutes les autres lois - doit respecter le principe de la hiérarchie des normes et est donc, en tant que telle, soumise au contrôle de constitutionnalité.

Plusieurs constitutions cherchent à équilibrer cette possibilité offerte au pouvoir politique de modifier certaines dispositions constitutionnelles considérées comme d'une importance particulière. En général, les constitutions des pays de common law de notre étude - par exemple, la Gambie (article 226) et le Ghana (article 290) - tendent à consolider les dispositions pertinentes en requérant des majorités plus élevées pour leur modification, par exemple une majorité qualifiée. En revanche, dans les pays de civil law, comme au Bénin (articles 41 et 156) et au Niger (article 175), les dispositions concernées sont souvent rendues immuables et ne peuvent être modifiées en aucun cas. Les constitutions ouest-africaines, à l'exception de celle du Libéria, contiennent généralement des dispositions les protégeant d'une révision et toutes suivent le modèle établi par leurs familles juridiques respectives.

Une telle décision peut également affecter le rôle et les pouvoirs des instances chargées du contrôle de constitutionnalité au sein du système gouvernemental. Ce sujet a été largement débattu dans le cadre des clauses immuables, mais il s'applique également aux dispositions protégées ou «rigides». En général, les normes constitutionnelles sont au-dessus de toutes les autres lois, mais elles jouissent entre elles du même rang normatif. Cependant, les dispositions immuables ne peuvent être modifiées. En isolant différents principes et dispositions des règles de révision, une hiérarchie interne à la Constitution est créée : non seulement les dispositions «non modifiables" ne peuvent être abrogées ou altérées, mais d'autres dispositions constitutionnelles ne peuvent être modifiées ou introduites si elles entravent ou contredisent les dispositions immuables. C'est également le cas pour les dispositions «rigides": toute modification portant sur une disposition «ordinaire» et qui l'altérerait contreviendrait de fait au principe de protection accrue envisagé par les rédacteurs de la Constitution.

Dans une situation de ce type, la question est de savoir si les juridictions chargées de la justice constitutionnelle sont aussi implicitement habilitées à veiller au respect de la hiérarchie des normes établie par la Constitution, et à ce que ne soit adoptée aucune disposition constitutionnelle qui entrave les clauses immuables ou rigides sans que les majorités nécessaires à leur adoption n'aient été atteintes. 
Au Bénin, au Burkina Faso et au Niger, les Cours ou Conseils constitutionnel(le)s sont considéré(e)s comme étant implicitement habilité(e)s à contrôler la conformité des révisions de la Constitution aux limites formelles et/ou substantielles prévues par le texte législatif. Dans son arrêt 200906 1(JN), la Cour constitutionnelle du Niger s'est opposée à la tentative du président Mamadou Tandja de contourner les limites imposées aux mandats présidentiels, car la Constitution du pays prévoit l'immutabilité de la disposition relative à la durée du mandat présidentiel. La décision était principalement axée sur les aspects procéduraux (la Constitution n'autorise pas le président à initier la procédure envisagée par $\mathrm{M}$. Tandja), mais elle mentionne également la violation de l'immutabilité de la clause.

Une opinion plus progressiste que la perspective restrictive adoptée par le Conseil constitutionnel français, qui dans sa décision 2003-469DC, a renoncé à assumer la responsabilité du contrôle des révisions de la Constitution.

Il est raisonnable de penser que lorsque les cours disposent du pouvoir, ou se l'arrogent, de protéger des dispositions immuables ou rigides de la Constitution, cela rend celle-ci moins vulnérable à la volonté d'une large majorité. Mais cela peut également conférer aux juges un pouvoir discrétionnaire trop large, en particulier si les clauses immuables/rigides sont vagues et portent sur des principes fondamentaux ou des valeurs. Les constitutions qui précisent, concrétisent et justifient ces dispositions - privant ainsi tant le pouvoir législatif que le pouvoir judiciaire du pouvoir de décision - sont bien moins susceptibles d'attiser les craintes d'une "juristocratie».

Quelques cours audacieuses ont émis des interprétations novatrices parfois considérées comme des "coups d'État judiciaires». Dans certains pays - principalement de common law -, les instances chargées du contrôle de constitutionnalité se sont arrogé la possibilité de contrôler la substance des modifications apportées à la Constitution, et ce, bien que la Constitution n'ait pas prévu de dispositions rigides ou immuables et donc de hiérarchie interne. Elles se sont fondées sur la "doctrine de la structure de base» développée par la Cour suprême indienne (Roznai 2014 : 54) : elle lui permet de déclarer les modifications proposées contraires à la Constitution si, dans l'opinion de la Cour, elles violent la structure de base non écrite de la Constitution, dont la substance et les modalités ne se trouvent pas dans le texte constitutionnel, mais sont déterminées par la Cour. La Cour suprême du Kenya a appliqué cette doctrine, considérant qu'une révision ne peut modifier la structure de base de la Constitution. Il n'est pas du propos de cet ouvrage de débattre de la justification normative de ces "coups judiciaires", de leur cohérence méthodologique ou de leur nécessité pour prévenir les «coups d’État constitutionnels» de la part des autres branches du pouvoir. 


\section{Les autres moyens de contrôle politique}

Comme mentionné ci-dessus, réviser la Constitution est un moyen de modifier les paramètres juridiques encadrant le fonctionnement futur des instances chargées du contrôle de constitutionnalité. Certains pays sont allés plus loin : tout en continuant à s'appuyer sur le contrôle de constitutionnalité, ils ont introduit des éléments conceptuels permettant de limiter les risques éventuels de transformer l'État de droit en un État de juges (Tushnet 2011 : 323). Ces pays ont eu recours à deux approches différentes pour réaliser cet objectif. La première est la "clause nonobstant» du Canada, qui n'a pas encore été adoptée ailleurs, et en vertu de laquelle le pouvoir législatif peut donner force de loi à une législation, nonobstant une liste de dispositions constitutionnelles relatives aux droits humains (Tushnet 2011 : 325). La clause, prévue par la Charte des droits canadienne, expire au bout de cinq ans, mais peut être renouvelée. Étant donné que des élections législatives auront lieu dans cette période de cinq ans, les électeurs peuvent exercer un contrôle indirect sur le renouvellement ou non de cette clause.

La seconde approche à la limitation du pouvoir des juridictions chargées du contrôle de constitutionnalité est l'annulation de leurs décisions. Dans la Pologne postcommuniste, le pouvoir législatif, à la majorité qualifiée, pouvait mettre son veto aux décisions définitives de la Cour constitutionnelle, et le Sejm (la chambre basse) avait la possibilité d'adopter une loi invalidée par le tribunal constitutionnel à la majorité des deux tiers. Au Cabo Verde - seul pays d'Afrique de l'Ouest à avoir adopté une mesure de ce type -, le pouvoir législatif peut annuler une décision d'inconstitutionnalité de la Cour constitutionnelle prise a priori dans le cadre d'une procédure initiée par le président par un vote à la majorité des deux tiers (comme pour une révision de la Constitution). Le Parlement ne peut toutefois annuler cette décision que si le président n'émet pas son veto à la loi après le second vote; de fait, il n'est donc possible d'annuler par voie législative une décision de la cour que si le Parlement et l'exécutif coopèrent. 



\section{Conclusion et perspectives}




\title{
12. Conclusion et perspectives
}

\author{
Markus Böckenförde et Yuhniwo Ngenge
}

Le processus par lequel les lois et les actes des autorités publiques sont examinés pour en confirmer la conformité à un ordre normatif supérieur la Constitution - n'est plus ce qu'Alexis de Tocqueville considérait comme une caractéristique de l'exceptionnalisme américain (Ginsburg 2014 : 2). L'institutionnalisation du contrôle juridictionnel s'est développée partout dans le monde au cours des dernières décennies (Ginsburg 2003 : 6; 2014 : 2). Initié aux États-Unis, puis diffusé en Europe occidentale et au Japon, il s'est désormais établi comme une caractéristique commune de l'architecture constitutionnelle en Asie comme en Afrique (Ginsburg 2003 : 6-7). Axé uniquement sur les normes écrites (la Constitution et les lois organiques), l'ouvrage a comparé l'institutionnalisation et la modernisation des instances chargées de la justice constitutionnelle dans 16 pays d'Afrique de l'Ouest anglophones, francophones et lusophones et tant de tradition de civil law que de common law. Le chapitre 1 a rapidement évoqué le statut du droit traditionnel dans les structures constitutionnelles de ces pays et sa place dans le contexte du contrôle juridictionnel. Le chapitre 2 a retracé l'émergence de la justice constitutionnelle en Afrique de l'Ouest depuis l'ère précoloniale.

Les chapitres restants se sont penchés sur les différences et les similitudes dans la structure des juridictions chargées de la justice constitutionnelle en Afrique de l'Ouest contemporaine, examinant leur architecture institutionnelle (chapitre 3), leur indépendance (chapitre 4), les commissions auxiliaires telles que les Conseils supérieurs de la magistrature (chapitre 5), leur composition (chapitre 6), le contrôle de constitutionnalité (chapitre 7), leur compétence (chapitre 8), le droit de saisine (chapitre 9), l'autorité de leurs décisions (chapitre 10), et les limites de leurs attributions en tant que gardiennes de la Constitution (chapitre 11).

Cet ouvrage a cherché à approfondir la connaissance mutuelle des différents systèmes de justice constitutionnelle dans la région. Pour cela, nous avons effectué une analyse historique détaillée pour mettre au jour les fondements du contrôle juridictionnel en Afrique, généralement tenus pour acquis en 
tant que " marques " du passé ou produits de la migration constitutionnelle. Le chapitre 2 a examiné et révélé les tendances précoloniales dans l'héritage politique africain et la justice constitutionnelle, y compris le respect de l'État de droit, des institutions et des notions de responsabilité et la redevabilité, qui se sont traduites par la formation d'infrastructures institutionnelles et de procédures concrètes pour leur mise en œuvre. Il est par conséquent plus approprié de décrire l'expérience africaine comme une modernisation (plutôt que comme la création) de juridictions chargées du contrôle de constitutionnalité; des modèles plus innovants pour prendre en compte le droit traditionnel dans le cadre d'un système judiciaire officiel sont en train de voir le jour dans la région.

Le chapitre 9 avance une thèse similaire portant sur certaines règles anciennes et l'action constitutionnelle indirecte (exception d'inconstitutionnalité), qui ont été introduites en Afrique de l'Ouest francophone près de 18 ans avant la France. C'est également le cas de l'autosaisine, qui reste une caractéristique sui generis des Cours constitutionnelles du Bénin et du Burkina Faso et, dans une certaine mesure, de la Cour suprême du Libéria.

De la même manière, le chapitre 3 révèle que les modèles institutionnels suivis par les organes de contrôle de constitutionnalité de la région ne sont pas toujours liés à un système juridique spécifique étant en partie fonction de l'héritage colonial de la région. Certains pays associent de manière inattendue plusieurs éléments des modèles centralisés et déconcentrés. Par exemple, des pays de common law comme la Gambie, le Ghana et la Sierra Leone ont des modèles de Cour suprême en partie conçus pour fonctionner comme les Cours ou Conseils constitutionnel(le)s prédominants dans les systèmes de civil law. C'est également le cas du Cabo Verde, où le contrôle exercé par la Cour constitutionnelle s'effectue davantage sur le modèle d'une Cour suprême dans un système décentralisé : sa compétence n'est qu'en appel et définitive (et non en premier ressort et exclusive).

La présente étude souligne que l'institutionnalisation et la modernisation des juridictions chargées du contrôle de constitutionnalité - les Cours ou Conseils constitutionnel(le)s ainsi que les Cours suprêmes - en Afrique de l'Ouest, en particulier dans la foulée des transitions démocratiques des années 1990, se sont produites en réponse aux demandes en faveur d'une consolidation de la démocratie et du respect de l'État de droit et de la nécessité de renforcer la culture constitutionnaliste. Ces institutions, quoique présentes sous différentes formes, étaient généralement faibles avant 1990. En Afrique de l'Ouest francophone et lusophone, où les projets de modernisation exhaustifs (souvent surpassant les modèles occidentaux qui les ont influencés) à cet égard ont été réalisés dans la période de l'après-guerre froide, cet objectif 
sous-jacent est particulièrement évident et ce, de plusieurs manières. Il s'agit notamment de l'élargissement de leur compétence aux droits humains et au contentieux électoral, de la multiplication des acteurs bénéficiant d'un droit de recours (locus standi), de la création de mécanismes de sauvegarde pour garantir leur indépendance de toute influence extérieure et, dans certains cas comme au Bénin, de l'attribution aux instances chargées du contrôle de constitutionnalité du pouvoir de se saisir d'une question, même en l'absence de recours de la part d'un requérant (autosaisine). Avec la règle selon laquelle les décisions des juridictions chargées de la justice constitutionnelle s'imposent à l'ensemble du système politique sans exception, les Constitutions du Cabo Verde et de la Guinée-Bissau (dont les systèmes de justice constitutionnelle sont inspirés du modèle portugais) ont donné une force supplémentaire au principe d'égalité devant la loi, car les lois ou dispositions non conformes deviennent invalides et ne peuvent par conséquent être appliquées à quiconque. $\mathrm{Au}$ Portugal en revanche, la règle inter partes applicable à une déclaration d'inconstitutionnalité signifie que les lois ou dispositions contrevenantes restent dans le système juridique et peuvent être appliquées à d'autres cas.

L'accent mis dans cet ouvrage sur le cadre normatif soulève un certain nombre de questions pratiques à explorer lors de travaux ultérieurs. Le chapitre 2 note que le caractère africain inhérent de certaines valeurs - comme l'État de droit et une gouvernance limitée, responsable, transparente et démocratique - au lieu d'être considéré comme une importation occidentale, doit façonner et influencer le processus continu de modernisation et d'application de la justice sur le continent dans le cadre des efforts généraux de démocratisation. Il devient donc nécessaire de comprendre comment les juridictions chargées de la justice constitutionnelle ont intégré ces valeurs dans leur jurisprudence et comment elles peuvent être encouragées à mieux équilibrer les valeurs contradictoires - réelles ou imaginées - dans le processus de justice constitutionnelle. Appréhender ces questions de ce point de vue est pertinent pour essayer de jeter des ponts entre les traditions informelles et les techniques de contrôle institutionnalisées.

La sagesse populaire pourrait suggérer que la mise en place de mandats courts pour les juges constitutionnels sape leur indépendance, car les juges seraient alors poussés à céder aux intérêts politiques pour protéger la suite de leur carrière. Le chapitre 4 démontre que, bien que les juges constitutionnels béninois aient l'un des mandats les plus courts (cinq ans, renouvelable une fois), la Cour est devenue l'une des icônes du courage et de l'indépendance judiciaire. Sa réputation ne cesse de croître, fondée sur un militantisme sans précédent dans une région ou un exécutif dominant continue avec succès de miner l'indépendance des juridictions chargées du contrôle de 
constitutionnalité. D'autres travaux de recherche pourraient examiner si cette performance est le résultat d'un choix dans la conception (par exemple par rapport à la nomination des juges) ou d'une stratégie de la Cour - et les enseignements que peuvent en tirer les autres juridictions ouest-africaines.

De plus, gage supplémentaire de leur indépendance, différents acteurs politiques jouent un rôle dans la nomination des membres des instances chargées du contrôle de constitutionnalité, tant dans les systèmes de civil law que dans ceux de common law. Les seules exceptions, comme l'a illustré le chapitre 6, sont le Sénégal et le Cabo Verde, où le président de la République et le Parlement, respectivement, ont le monopole de la désignation des juges constitutionnels. Cependant, les méthodes de désignation utilisées dans les pays de civil law donnent une composition plus professionnellement hétérogène que dans les systèmes de common law, où chaque juge doit justifier d'une formation juridique et les différents acteurs du processus de désignation doivent s'entendre sur chacun des candidats proposés. Cette situation associée à l'interdiction des opinions dissidentes, en particulier dans les pays de civil law - affecte-t-elle la qualité des décisions dans leur ensemble ou l'efficacité des juridictions chargées du contrôle de constitutionnalité ?

De la même manière, tandis que la plupart des pays ont mis en place des organes auxiliaires (judicial service commissions dans les pays de common law et conseils supérieurs de la magistrature dans les systèmes de civil law), leur lien avec les différentes juridictions chargées du contrôle de constitutionnalité et le pouvoir exécutif varie considérablement (chapitre 5). Des études ultérieures pourraient examiner l'incidence de ces liens sur la justice constitutionnelle.

Enfin, quelle est l'autorité réelle des juridictions chargées du contrôle de constitutionnalité? Comme nous l'avons montré, toutes les juridictions étudiées reconnaissent largement l'applicabilité générale des décisions des instances supérieures chargées du contrôle de constitutionnalité. Dans les pays de civil law, la règle erga omnes rend les décisions des Cours ou Conseils constitutionnel(le)s contraignantes pour toutes les autorités. Dans les pays de common law, la doctrine du précédent obligatoire (stare decisis) rend les décisions de la Cour suprême applicables à l'ensemble du corps politique. Cependant, ces décisions ne s'appliquent pas toujours d'elles-mêmes : les Cours doivent compter sur d'autres acteurs au sein du système, généralement la branche exécutive du pouvoir. Dans un paysage politique dominé par l'exécutif, il est donc important de comprendre comment cela influence l'efficacité des décisions vis-à-vis des acteurs politiques, mais également quel poids cela a, le cas échéant, dans la manière dont les juridictions chargées du contrôle de constitutionnalité interprètent leurs pouvoirs constitutionnels ou déterminent en premier lieu quels cas examiner. 
Apporter des réponses à ces questions dépasse le cadre de cette publication, dont l'intention est d'initier un dialogue entre les juridictions chargées de la justice constitutionnelle des différents systèmes juridiques de la région sur la manière dont les règles, telles qu'édictées dans les textes, ont été appliquées en pratique par les différentes juridictions. Quels sont les facteurs de succès? Quelles sont les lacunes? Comment ces dernières ont-elles été prises en compte (ou comment pourraient-elles l'être)? De telles discussions peuvent encourager une pollinisation croisée des meilleures pratiques et idées de réforme en vue de renforcer l'État de droit, la démocratie et la gouvernance constitutionnelle. 
Annexe : Questionnaire

type

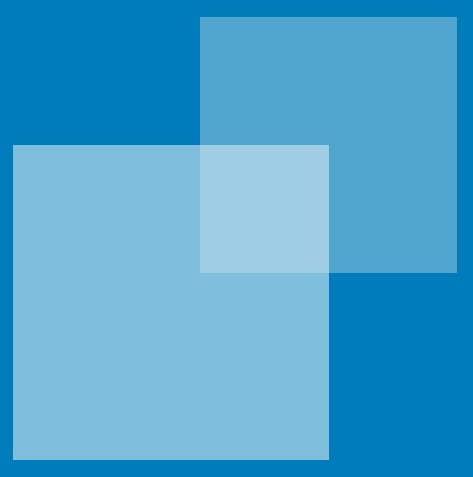




\section{Annexe : Questionnaire type}

\section{Introduction}

\section{La pertinence de différents systèmes juridiques en tant que source d'inspiration pour les systèmes judiciaires en Afrique de l'Ouest}

\begin{tabular}{|l|l|}
\hline Structure globale \\
\hline $\begin{array}{l}\text { Quelles sont les caractéristiques pertinentes du système de } \\
\text { common law en matière de contrôle de constitutionnalité et } \\
\text { d'architecture institutionnelle permettant ce contrôle? }\end{array}$ & \\
\hline $\begin{array}{l}\text { Dans quelle mesure et de quelle manière le système juridique } \\
\text { de votre pays est-il (toujours) influencé par le système de } \\
\text { common law (en ce qui concerne le contrôle de constitutionnalité et } \\
\text { l'architecture institutionnelle permettant ce contrôle)? }\end{array}$ & \\
\hline $\begin{array}{l}\text { Quelles sont les caractéristiques pertinentes du système de } \\
\text { common lawen ce qui concerne le pouvoir judiciaire? }\end{array}$ & \\
\hline
\end{tabular}

\section{Systèmes juridiques religieux/coutumiers/mixtes}

\section{Éléments de droit religieux/coutumier dans le système judiciaire}

\section{Le système judiciaire du pays prévoit-il des tribunaux religieux/}

coutumiers?

Les tribunaux (inférieurs) appliquent-ils ou acceptent-ils le droit coutumier ou religieux?

Le droit coutumier ou religieux bénéficie-t-il d'un statut officiel dans le pays (ou est-il exclusivement appliqué dans le cadre d'un système parallèle et n'est pas pris en compte dans la Constitution)?

Les tribunaux coutumiers sont-ils établis par la Constitution/ législation? Font-ils partie de l'ordre juridictionnel ordinaire? Les pourvois en appel de leurs décisions sont-ils traités par les tribunaux ordinaires? Si oui, quelle est la procédure en appel? 


\title{
III. Contexte historique de la justice constitutionnelle
}

\author{
Développement des systèmes judiciaires
}

Le système judiciaire/de contrôle par voie juridictionnelle (et les instances qui s'y rapportent) a-t-il évolué par rapport à celui prévu par la Constitution à l'indépendance? Si oui, dans quelle mesure?

Existe-t-il un contrôle de constitutionnalité indépendant dans le pays (uniquement axé sur l'aspect constitutionnel d'une affaire)? Si oui, depuis quelle date?

\section{Différents modèles de justice constitutionnelle}

\section{Différentes institutions de contrôle par voie juridictionnelle}

\begin{tabular}{|l|l|}
\hline Quels types d'institutions judiciaires existent dans le pays? \\
\hline Quelle institution est considérée comme la plus haute instance? & \\
\hline $\begin{array}{l}\text { Celle-ci est-elle également au sommet de l'ordre juridictionnel } \\
\text { ordinaire? Ou bien s'agit-il d'une institution distincte? }\end{array}$ & \\
\hline $\begin{array}{l}\text { Existe-t-il plusieurs tribunaux de grande instance dans le pays } \\
\text { en fonction de la matière à traiter (par ex. tribunal administratif, } \\
\text { tribunal des impôts)? }\end{array}$ & \\
\hline $\begin{array}{l}\text { Quelles juridictions ont la possibilité de remettre en question } \\
\text { la constitutionnalité des lois (actes réglementaires et textes } \\
\text { législatifs)? }\end{array}$ & \\
\hline $\begin{array}{l}\text { Existe-t-il dans le pays un Conseil supérieur de la magistrature } \\
\text { (organe d'autogouvernance du pouvoir judiciaire), etc.? }\end{array}$ & \\
\hline
\end{tabular}

\section{Systèmes de contrôle}

Si un tribunal inférieur considère une loi comme applicable à une affaire, puis estime qu'elle est contraire à la Constitution, de quels moyens dispose-t-il?

Aucun, il ne dispose d'aucun pouvoir pour remettre en cause la constitutionnalité de la loi/réglementation.

Si le tribunal a de sérieux doutes quant à la constitutionnalité de la loi/réglementation dans un cas précis, il peut suspendre la procédure et demander une déclaration de constitutionnalité auprès d'une autre instance (Cour ou Conseil constitutionnel[le], etc.), qui peut déclarer la loi/réglementation comme inconstitutionnelle. Quelle est la procédure de renvoi dans ce cas?

Le tribunal peut déclarer la réglementation (acte administratif/ législatif, législation, loi organique) inapplicable à l'affaire en question.

Le tribunal déclare que la réglementation/loi n'est pas conforme à la Constitution.

Autre type d'action. 
a. Système diffus de contrôle de constitutionnalité : la Cour suprême

b. Système de contrôle concentré : la Cour constitutionnelle

c. Systèmes hybrides de contrôle de constitutionnalité

\section{Aspects pertinents de l'indépendance de la justice}

\section{Indépendance de la justice et indépendance vis-à-vis de la justice : le pouvoir judiciaire en tant que législateur}

\section{Administration et budget de la plus haute instance}

\begin{tabular}{|l|l|}
\hline \multicolumn{2}{|l|}{ Administration du pouvoir judiciaire } \\
\hline Quel organe/institution gère la plus haute instance? & \\
\hline $\begin{array}{l}\text { Le ministère de la Justice est-il impliqué dans la gestion de } \\
\text { la plus haute instance? Si oui, dans quelle mesure? Ou est-elle } \\
\text { gérée par le pouvoir judiciaire (organe d'autogestion)? }\end{array}$ & \\
\hline $\begin{array}{l}\text { Existe-t-il au sein du pouvoir judiciaire/de la plus haute instance } \\
\text { un organe chargé de la gestion des ressources? À qui doit-il rendre } \\
\text { des comptes? Y a-t-il un mécanisme de supervision externe? }\end{array}$ & \\
\hline
\end{tabular}

Quel est le rôle du pouvoir judiciaire/de la Cour constitutionnelle dans le processus de préparation et d'adoption de son budget?

Quelle est l'implication de la plus haute juridiction dans la préparation de son budget (qui est en premier lieu responsable de sa soumission)?

Qui peut modifier le budget (de la plus haute juridiction) dans le cadre de la procédure d'adoption? La plus haute juridiction peut-elle solliciter des ressources supplémentaires pour remplir efficacement son mandat?

Dans quelle mesure les données relatives à la Cour (charge de travail, etc.) influencent-elles le montant du budget?

Le budget (de la plus haute juridiction) fait-il partie intégrante du budget global ou est-il distinct?

\section{Conseil supérieur de la magistrature}

\begin{tabular}{|l|l|}
\hline \multicolumn{2}{|l|}{ Conseil supérieur de la magistrature } \\
\hline $\begin{array}{l}\text { Existe-t-il un organe de type Conseil supérieur de la magistrature } \\
\text { (voir aussi IV.1 = organe d'autogestion) ? }\end{array}$ & \\
\hline $\begin{array}{l}\text { Si oui, quelles sont ses fonctions? (II peut exister de grandes } \\
\text { différences entre l'approche de civil law et celle de la common }\end{array}$ & \\
law.) & \\
\hline Quels sont les critères d'éligibilité des membres? & \\
\hline
\end{tabular}




\begin{tabular}{|l|l|}
\hline $\begin{array}{l}\text { Quelle est la composition du Conseil supérieur de la } \\
\text { magistrature? }\end{array}$ & \\
\hline $\begin{array}{l}\text { Les membres d'office ont-ils la même autorité que les autres } \\
\text { membres? }\end{array}$ & \\
\hline Qui choisit les membres du Conseil supérieur de la magistrature? & \\
\hline $\begin{array}{l}\text { Quels types de relations existe-t-il entre la plus haute juridiction } \\
\text { et le Conseil supérieur de la magistrature? }\end{array}$ & \\
\hline
\end{tabular}

\section{Défis en matière de neutralité et d'impartialité}

\section{Composition}

\section{Composition des Cours/Conseils constitutionnel(le)s et Cours suprêmes}

Éligibilité : (a) âge minimum/(b) âge maximum/(c) formation juridique/(d) formation juridique spécifique (par ex. juge en exercice; expert d'un système juridique (ex. droit de la charia)/(e) expérience professionnelle (années)//f) limites (membre d'aucun parti, pas d'autres fonctions au cours du mandat)/(g) autres exigences

Nomination des juges à la Cour suprême/constitutionnelle même procédure pour tous les juges? /qui/quelle institution est impliqué(e) dans le processus de désignation?/Les juges sont-ils tous remplacés ou uniquement une partie d'entre eux?

Nomination des juges à la Cour suprême/constitutionnelle : en cas de processus de désignation distincts, qui est/quelles institutions sont impliqué(es) dans ces différents processus?

Combien d'institutions sont impliquées dans le processus de désignation?

Séquençage du processus de désignation (recommandation, conseil, élection, consultation, nomination, cooptation)

Quelle est la durée du mandat?

Un renouvellement est-il possible?

La représentation des minorités est-elle garantie (les différences ethniques, linguistiques, religieuses sont-elles prises en compte)? Comment?

L'opposition est-elle impliquée dans le processus de désignation? 


\section{Critères d'éligibilité aux fonctions de juge au sein de la Cour suprême/ constitutionnelle}

\section{Désignation des juges de la Cour suprême/constitutionnelle}

\section{Durée du mandat}

\section{Représentation des minorités}

\section{Compétences}

\section{Introduction : contrôle par voie juridictionnelle}

\section{Examen préliminaire}

Examen préliminaire (contrôle de la constitutionnalité d'un projet de loi avant son adoption)

\begin{tabular}{|l|l|}
\hline Possible? & \\
\hline $\begin{array}{l}\text { Qui peut initier la procédure (ou le contrôle est-il intégré à la } \\
\text { procédure législative) (qui peut saisir le juge)? Quels sont les } \\
\text { prérequis? }\end{array}$ & \\
\hline $\begin{array}{l}\text { À quel moment de la procédure législative le contrôle peut-il } \\
\text { être effectué? }\end{array}$ & \\
\hline Concerne tous les projets de loi? & \\
\hline Les avis consultatifs sont-ils possibles? & \\
\hline
\end{tabular}

\section{Contrôle abstrait}

\section{Contrôle abstrait}

\begin{tabular}{|l|l|}
\hline Possible? & \\
\hline $\begin{array}{l}\text { Qui peut initier la procédure (qui peut saisir le juge)? Quels sont } \\
\text { les prérequis? }\end{array}$ & \\
\hline $\begin{array}{l}\text { Concerne toutes les lois (ou y a-t-il des restrictions (lois } \\
\text { organiques)? }\end{array}$ & \\
\hline $\begin{array}{l}\text { Quels types de décisions peuvent être rendus (abrogation, } \\
\text { instructions à l'attention du pouvoir législatif pour modifier la loi } \\
\text { dans un délai donné, autre)? }\end{array}$ & \\
\hline
\end{tabular}

\section{Contrôle concret ou incident}

\section{Contrôle concret}

Possible? (Les tribunaux peuvent-ils contrôler la constitutionnalité des lois?) 
Que se passe-t-il si le tribunal considère qu'une loi pertinente dans le cas d'espèce est inconstitutionnelle? Peut-il ne pas I'appliquer ou la déclarer anticonstitutionnelle?

La doctrine de stare decisis est-elle juridiquement appliquée (précédent)?

Existe-t-il des restrictions au contrôle concret (vérifier la constitutionnalité d'une réglementation/loi dans le cadre du jugement d'une affaire)?

\section{Recours direct devant la Cour constitutionnelle ou suprême (recours individuell}

\begin{tabular}{|l|l|}
\hline Recours direct & \\
\hline Possible? & \\
\hline Qui peut initier la procédure (droit de saisine)? & \\
\hline $\begin{array}{l}\text { Quels sont les prérequis (par ex. avoir épuisé tous les recours } \\
\text { devant les tribunaux ordinaires)? }\end{array}$ & \\
\hline $\begin{array}{l}\text { Existe-t-il des restrictions au droit de recours individuel? Les plus } \\
\text { hautes instances peuvent-elles décider d'accepter ou de refuser une } \\
\text { affaire? Si oui, sur quels critères? }\end{array}$ & \\
\hline
\end{tabular}

\section{Limites du contrôle de constitutionnalité}

\section{Limites du contrôle}

Existe-t-il des limites explicites au contrôle de constitutionnalité (par exemple traités internationaux, lois approuvées par référendum, lois valides avant l'entrée en vigueur de la Constitution, lois adoptées dans le cadre de l'état d'urgence,

limitation aux actes manifestement inconstitutionnels)?

\section{Contrôle des modifications apportées à la Constitution (sur le fond et la forme)}

\section{Contrôle des révisions de la Constitution}

Est-il possible de contrôler les modifications apportées à la Constitution?

Si oui, le contrôle se limite-t-il à un examen du processus appliqué à la révision? Ou bien un examen sur le fond est-il également possible?

La Constitution contient-elle des clauses immuables (dispositions qui ne peuvent faire l'objet d'une révision)?

Qui peut initier la procédure (droit de saisine)? Quels sont les prérequis? 


\section{Omission inconstitutionnelle}

\section{Omission inconstitutionnelle}

Est-il possible d'introduire un recours concernant les obligations constitutionnelles qui n'ont pas été respectées?

Qui peut initier la procédure (droit de saisine)? Quels sont les prérequis?

Quels types de décisions peuvent être rendus (instructions au pouvoir législatif/exécutif concernant les mesures à prendre (dans un délai donné), déclaration disposant qu'une loi ne satisfait pas suffisamment une obligation constitutionnelle, la Cour " applique " l'obligation en accordant un droit donné au requérant; autres)?

\section{Conflits entre organes publics}

\section{Confilits entre organes publics}

La Cour a-t-elle compétence pour décider si une fonction déterminée relève de l'autorité d'un organe public ou pour interpréter les limites de l'autorité publique, y compris entre différents organes, que ce soit horizontalement (entre différentes institutions de niveau national) ou verticalement (entre les institutions nationales et celles de niveau provincial ou local)?

Qui peut initier la procédure (droit de saisine)? Quels sont les prérequis (comment)?

\section{9. Élections}

\section{Élections}

La Cour a-t-elle compétence pour le contentieux électoral? Quelle est la portée de cette compétence : élections présidentielles, législatives ou de tout type? Quelles sont les matières concernées : déclaration des résultats, résolution des litiges portant sur les résultats, éligibilité des candidats, listes électorales, etc.?

Qui peut initier la procédure (droit de saisine)? Quels sont les prérequis?

Si la Cour n'est pas habilitée à traiter ces cas, existe-t-il une autre institution chargée de résoudre le contentieux électoral?

\section{Droits fondamentaux}

\section{Droits fondamentaux (voir également recours individuel)}

Les violations présumées des droits humains peuvent-elles (toutes) être soumises à l'attention d'un tribunal?

Existe-t-il d'autres institutions vers lesquelles un individu lésé peut se tourner (commission des droits humains, médiateur)? Quelles relations entretiennent-elles avec les (plus hautes) juridictions? 
Qui peut initier un recours (droit de saisine : également ONG/associations de protection des consommateurs au nom d'individus)? Quelle est la procédure (comment)?

Concernant les droits sociaux, la plus haute juridiction du pays peut-elle statuer de manière plus défavorable pour le requérant qu'une instance inférieure (reformation in peius) ? (exemple la Constitution garantit le droit d'accès à l'eau, mais sans en préciser le seuil (litres/jour) : si un tribunal de première instance considère ce seuil comme étant de $30 \mathrm{l} /$ jour, mais que le requérant espère $40 \mathrm{l} /$ jour et fait appel, la plus haute instance peut-elle annuler le jugement du tribunal dans la négative, et n'offrir que $25 \mathrm{I}$ ?)

\section{Autres attributions des Cours suprêmes/constitutionnelles}

\begin{tabular}{|l|l|}
\hline Autres attributions \\
\hline Organisation des référendums & \\
\hline $\begin{array}{l}\text { Détermination de la constitutionnalité des partis politiques et } \\
\text { dissolution éventuelle }\end{array}$ & \\
\hline Procédures de destitution du président & \\
\hline Interprétation de la Constitution (contraignante) & \\
\hline Autres? & \\
\hline
\end{tabular}

\section{Droit de saisine}

\section{Qui (voir section VII)}

\section{Comment (voir section VII)}

\section{Format et effets des décisions (autorité des décisions) de la plus haute juridiction}

\begin{tabular}{|l|l|}
\hline Autorité des décisions \\
\hline $\begin{array}{l}\text { Les décisions sont-elles rédigées collectivement ou composées de } \\
\text { plusieurs éléments individuels soumis par chacun des juges? }\end{array}$ & \\
\hline $\begin{array}{l}\text { Si les décisions sont collectives, est-il possible d'identifier } \\
\text { l'opinion de chacun des juges (en général ou au moyen d'opinions } \\
\text { dissidentes)? }\end{array}$ & \\
\hline $\begin{array}{l}\text { Les décisions ont-elles un effet erga omnes ou inter partes } \\
\text { (concernant VIII. 2-4; 7-8)? }\end{array}$ & \\
\hline $\begin{array}{l}\text { Les décisions ont-elles un effet immédiat uniquement (ex nunc), } \\
\text { un effet rétroactif (ex tunc), ou l'effet est-il différé pour permettre au } \\
\text { pouvoir législatif de modifier la législation en fonction de la décision } \\
\text { de la Cour? }\end{array}$ & \\
\hline
\end{tabular}


Quelle autorité légale la décision exerce-t-elle sur les différents groupes (ci-dessous) compte tenu de leur participation au processus?

En général, qui (voir ci-dessous) est affecté (et comment) par les décisions de la Cour constitutionnelle?

\section{Sur les citoyens}

\section{Sur les administrations}

3. Sur les autres institutions judiciaires

4. Sur les institutions politiques

5. Sur l'armée

\section{Contrôle des juridictions constitutionnelles}

\begin{tabular}{|l|l|}
\hline \multicolumn{2}{|l|}{ Contrôle des juridictions constitutionnelles } \\
\hline Contrôle politique(voir désignation des juges, durée du mandat) & \\
\hline $\begin{array}{l}\text { Révocation/destitution des juges les plus éminents (si possible/ } \\
\text { uniquement sur décision judiciaire au sein de la magistrature/par } \\
\text { des institutions externes?) }\end{array}$ & \\
\hline $\begin{array}{l}\text { Quels sont les motifs de révocation des juges les plus éminents } \\
\text { (par ex inconduite avérée)? }\end{array}$ & \\
\hline $\begin{array}{l}\text { Les décisions de la plus haute juridiction peuvent-elles être } \\
\text { annulées par une autre institution (pouvoir législatif)? À quelles } \\
\text { conditions? }\end{array}$ & \\
\hline $\begin{array}{l}\text { Révision constitutionnelle à la suite d'une décision de la plus haute } \\
\text { juridiction. }\end{array}$ & \\
\hline
\end{tabular}

\section{Indépendance et responsabilité}

\section{Contrôle politique}

\section{Révision de la Constitution}

4. Révocation/destitution des juges

\section{Annulation des décisions}

\section{Conclusion}




\section{Glossaire}

Abus de pouvoir (ultra vires) : Désigne l'exercice du pouvoir au-delà des limites prévues par la loi.

Acte administratif : Décision émanant d'une autorité publique sous contrôle d'un organe du pouvoir exécutif tel que l'autorité chargée des impôts ou de l'immigration.

Acte réglementaire : Acte normatif émanant de la branche exécutive du pouvoir. Il peut s'agir d'un décret, d'un arrêté ou d'une circulaire.

Afrique de l'Ouest : Ensemble des pays membres de la Communauté économique des États d'Afrique de l'Ouest (CEDEAO) et la Mauritanie. Pays membres de la CEDEAO : Bénin, Burkina Faso, Cabo Verde, Côte d'Ivoire, Gambie, Ghana, Guinée, Guinée-Bissau, Libéria, Mali, Mauritanie, Niger, Nigéria, Sénégal, Sierra Leone et Togo.

Afrique de l'Ouest anglophone : Désigne la Gambie, le Ghana, le Libéria, le Nigéria et la Sierra Leone.

Afrique de l'Ouest francophone : Désigne le Bénin, le Burkina Faso, la Côte d'Ivoire, le Mali, la Mauritanie, le Niger, la Guinée, le Togo et le Sénégal.

Afrique de l'Ouest lusophone : Désigne le Cabo Verde et la Guinée-Bissau.

Amparo (voir aussi recours individuel) : Équivalent hispanophone et lusophone du recours individuel. Axésur la protection des droitsfondamentaux, il permet à des personnes privées de saisir la justice constitutionnelle en cas de violation de ceux-ci, afin d'assurer la défense de leurs droits.

Arbitrage constitutionnel : Résolution juridique des litiges soulevés, en jugeant au fond au regard de la Constitution.

Autorité de la chose jugée (res judicata) : Principe selon lequel une décision de justice ne pouvant plus faire l'objet de recours, étant devenue définitive, $s^{\prime}$ impose à tous. 
Autosaisine : Capacité d'une juridiction à examiner une question sans en avoir été saisie par un requérant. Par exemple, au Bénin et au Burkina Faso, les instances chargées du contrôle de constitutionnalité peuvent s'autosaisir d'une question.

Civil law : Système juridique directement inspiré du droit romain et fondé sur des codes écrits. Ce modèle est en vigueur principalement dans les pays d'Europe continentale et dans leurs anciennes colonies ou protectorats.

Clause d'incompatibilité : Type de clause de limitation ou d'exclusion utilisée pour limiter ou exclure la portée de l'application d'une loi, en particulier d'une loi coutumière, en raison de son incompatibilité avec les principes des politiques publiques, de la justice naturelle (équité), ou de toute autre loi jugée comme plus acceptable.

Common law : historiquement, ensemble de lois dérivées de la jurisprudence des magistrats anglais. Il se fonde principalement sur les décisions de justice et les coutumes, par opposition aux textes législatifs adoptés par le Parlement. De nombreuses anciennes colonies ou protectorats britanniques ont basé leur système juridique sur la common law.

Conseil supérieur de la magistrature (Judicial service commission dans le système de common law) : Organe qui a pour responsabilité la gestion des ressources humaines judiciaires en proposant (ou dans certains cas en décidant) des nominations et avancements. C'est également le principal organe disciplinaire chargé des cas de conduites contraires à la déontologie et au professionnalisme parmi les membres de la magistrature.

Contrôle a posteriori : Contrôle intervenant après l'adoption et la promulgation d'une loi.

Contrôle a priori : Contrôle ou examen intervenant avant l'adoption d'une loi (ou, si elle a déjà été adoptée, avant sa promulgation).

Contrôle de constitutionnalité centralisé (également appelé modèle kelsénien, européen, ou modèle reposant sur une Cour ou un Conseil constitutionnel) : système de contrôle de constitutionnalité, généralement dans les pays de civil law/droit continental, dans lequel une institution détient le monopole de l'autorité pour évaluer et rendre un jugement contraignant sur la conformité ou la non-conformité des lois et des actions des pouvoirs législatifs et exécutifs, ou des autorités publiques, par rapport à la Constitution. Le Bénin, le Burkina Faso, la Côte d'Ivoire, la Guinée, la Mauritanie et le Niger sont des exemples de pays appliquant ce modèle. 
Contrôle de constitutionnalité décentralisé (ou modèle de la Cour suprême) : Système de contrôle de constitutionnalité, principalement dans les pays de common law, dans lequel plusieurs instances ont l'autorité d'examiner et de rendre un jugement quant à la conformité ou la non-conformité des lois et actions des pouvoirs législatifs et exécutifs et des pouvoirs publics, par rapport à la Constitution.

Contrôle de la constitutionnalité (voir aussi Contrôle par voie juridictionnelle) : Processus visant à vérifier la conformité ou la nonconformité des lois et actions des pouvoirs législatifs et exécutifs, ou des autorités publiques, par rapport à la Constitution. Sauf mention contraire, toutes les références au contrôle de constitutionnalité dans le texte désignent principalement le contrôle effectué par une autorité judiciaire.

Contrôle in abstracto (abstrait) : Forme de contrôle de constitutionnalité effectué en l'absence de tout litige juridique. Il a lieu a priori ou a posteriori.

Contrôle in concreto (concret) : Contrôle de constitutionnalité intervenant dans le contexte d'un litige pour lequel il est demandé à une juridiction de vérifier la constitutionnalité d'une loi ou d'un acte contesté(e) par l'une des parties, afin de déterminer les conditions de son application à l'affaire en cours. Il s'effectue nécessairement a posteriori.

Contrôle par voie juridictionnelle : Forme de contrôle de constitutionnalité effectué par un organe judiciaire tel qu'une Cour suprême ou une juridiction constitutionnelle.

D'office (ex officio) : Terme utilisé pour décrire des situations dans lesquelles la désignation d'un individu à un poste donné est basée non pas sur une nomination ou élection, mais est faite es qualités, c'est-à-dire en raison d'une fonction actuelle ou antérieure.

De facto : Référence à ce qui existe en pratique, par opposition à ce que prévoit la loi.

De jure : Référence à ce qui existe en droit sur la base de textes juridiques explicites, par opposition à ce qui se fait dans la pratique.

Droit de saisine (locus standi) : Désigne le droit ou la capacité à se pourvoir en justice.

En plénière : Se dit d'un organe ou d'une instance, en l'occurrence une juridiction, qui siège au complet, en présence de l'ensemble des juges.

Erga omnes : Désigne une décision qui s'impose à l'ensemble des justiciables. Il s'agit d'une décision qui s'applique à tous et non uniquement aux parties. Il s'oppose à inter partes. 
Examen/contrôle de constitutionnalité (voir contrôle de constitutionnalité)

Flagrant délit : Terme juridique désignant le fait d'être pris en train de commettre un acte illégal.

Inter partes : Désigne une décision se rapportant à un nombre restreint d'individus directement concernés. Il peut s'agir par exemple d'un jugement dont les effets se limitent aux parties, par opposition à erga omnes.

Juridiction chargée de la justice constitutionnelle (voir également instance chargée du contrôle de la constitutionnalité) : toute institution, généralement un organe judiciaire ou quasi judiciaire, chargée de rendre la justice constitutionnelle.

Juridiction chargée du contrôle de constitutionnalité (voir aussi également Instance chargée de la justice constitutionnelle) : toute institution, généralement un organe judiciaire ou quasi judiciaire, ayant compétence pour examiner et rendre une décision contraignante quant à la conformité ou la non-conformité des lois et actions des pouvoirs législatifs et exécutifs, ou des autorités publiques, par rapport à la Constitution.

Juridiction suprême chargée du contrôle de constitutionnalité : Toute institution, en particulier celle faisant office d'organe judiciaire ou quasi judiciaire, disposant de l'autorité finale pour examiner et rendre une décision quant à la conformité ou la non-conformité des lois et actions des pouvoirs législatifs et exécutifs et des pouvoirs publics par rapport à la Constitution. Il s'agit par exemple des Cours suprêmes et des Cours/Conseils constitutionnel(le)s.

Justice constitutionnelle : Branche exclusive et spécialisée de la justice qui n'est pas dotée des compétences des tribunaux ordinaires, s'occupant de la promotion du constitutionnalisme et de l'État de droit en veillant au respect de la Constitution et de sa primauté par rapport aux autres lois.

Laïcité : Conception française reconnaissant la pleine séparation des sphères publique et religieuse. Elle se définit comme la neutralité de l'État dans les affaires religieuses.

Législation : Ensemble des lois adoptées par la branche législative du pouvoir.

Loi ordinaire : Texte de loi de niveau inférieur à la loi organique ou à la Constitution, et qui, dans certains cas, se distingue de ces dernières par la facilité avec laquelle elle peut être modifiée. Ces lois peuvent réglementer les relations entre personnes privées, ou entre les individus et l'État. Par exemple, 
une loi ordinaire définit les catégories de délits et leurs sanctions respectives, ou réglemente la liberté d'expression ou d'association.

Loi organique : Texte de loi complétant la Constitution, notamment en précisant les détails de l'organisation et du fonctionnement des pouvoirs publics et des institutions. Dans la hiérarchie des normes, la loi organique se situe en dessous de la Constitution, mais au-dessus des lois ordinaires. Il s'agit par exemple d'une loi réglementant le fonctionnement et l'organisation d'une instance chargée du contrôle de constitutionnalité.

Modèle centralisé de Cour suprême : Sous-modèle de contrôle de constitutionnalité décentralisé (ou modèle de la Cour suprême) dans lequel la Cour suprême a compétence exclusive pour examiner et rendre une décision contraignante sur la conformité ou la non-conformité des lois et actions des pouvoirs législatifs et exécutifs et des pouvoirs publics, vis-à-vis de la Constitution. La Gambie, le Ghana, la Guinée-Bissau et la Sierra Leone sont des exemples de pays appliquant ce modèle.

Modèle décentralisé de Cour suprême : Sous-modèle du système de contrôle de constitutionnalité décentralisé (ou modèle de la Cour suprême) selon lequel la Cour suprême et d'autres juridictions du système judiciaire ont compétence pour examiner et rendre une décision contraignante quant à la conformité ou la non-conformité des lois et actions des pouvoirs législatifs et exécutifs et des pouvoirs publics, vis-à-vis de la Constitution. Dans ce modèle, la Cour suprême a compétence en dernier recours. Le Libéria et le Nigéria sont deux exemples de pays de la région à appliquer ce modèle.

Non rétroactif (ex nunc) : Utilisé en droit pour décrire des situations juridiques dont les effets s'appliquent pour l'avenir uniquement.

Primauté de la Constitution : Principe de suprématie de la Constitution, à laquelle doivent se conformer les lois et actions des individus et des pouvoirs publics.

Procédure consultative : Procédure dont l'issue est non-contraignante. C'est le cas lorsqu'une institution exerce une compétence consultative.

Question prioritaire de constitutionnalité (aussi exception d'inconstitutionnalité) : Désigne une exception soulevée dans le cadre d'une affaire soumise à juridiction et contestant la constitutionnalité d'une disposition légale ou d'un acte appliqué à l'affaire. Lorsque c'est le cas, la question de constitutionnalité doit d'abord être résolue, soit directement par la juridiction soit par une autre instance compétente, avant que l'affaire ne puisse être jugée. (Si la question soulevée devant la juridiction saisie peut être 
traitée par elle-même, il ne s'agit plus d'une exception, mais d'une question préalable).

Ratio decidendi : Désigne le raisonnement, la raison ou la justification soustendant une décision juridique. En d'autres termes, il s'agit des principes de fond sur lesquels se fonde la décision.

Recours individuel : Forme d'action permettant à une personne privée (physique ou morale) de saisir directement la justice constitutionnelle pour (a) demander réparation pour des violations de ses droits constitutionnels commises par les autorités publiques; et (b) contester une loi avant sa promulgation.

Réforme constitutionnelle : Processus visant à modifier la Constitution, de manière partielle/limitée (amendement constitutionnel) ou entière (remplacement de la Constitution).

Remplacement de la Constitution : Type de réforme constitutionnelle impliquant le remplacement d'une Constitution existante par un texte entièrement nouveau.

Rétroactif (extunc) : En droit, ce terme est utilisé pour décrire des situations juridiques dont les effets s'appliquent pour le passé.

Révision constitutionnelle : Forme restreinte de réforme constitutionnelle n'impliquant pas de modifier ou remplacer la constitution existante par un texte entièrement nouveau. Les modifications se limitent à certaines dispositions spécifiques.

Saisine d'office : Capacité d'une juridiction à traiter de sa propre initiative des questions incidentes posées par un recours dont elle a été saisie, mais qui n'ont pas été soulevées dans la requête.

Stare decisis : Du latin "rester sur la décision", ce terme désigne le principe juridique selon lequel une juridiction doit respecter ses propres précédents ou jugements antérieurs pour tous les cas présentant le même fondement (précédent horizontal), ou se conformer aux précédents ou jugements d'une instance supérieure sur la question (précédent vertical).

Sub judice : Désigne toute affaire soumise à un tribunal encore non résolue et en attente d'un jugement.

Tribunal cadi : Tribunal appliquant le droit religieux, courant dans les systèmes judiciaires des pays musulmans. 


\section{Références bibliographiques et lectures complémentaires}

Aïvo F. J., Le juge constitutionnel et l'État de droit en Afrique. L'exemple du modèle béninois, Paris, L'Harmattan, 2006

Ajayi J.F.A. et Espie, I. (dir.), A Thousand Years of West African History [Mille ans d'histoire ouest-africaine], Ibadan, Ibadan University Press, 1965

Akerekoro, H., "Le procès constitutionnel au Bénin », édité par l'Association béninoise de droit constitutionnel et le Centre de droit constitutionnel de l'Université d'Abomey-Calavi, ABJC, Revue de Contentieux constitutionnel, I-2013, Cotonou, Presses universitaires du Benin, 2013

Akinjide R. et Elias T. O. (dir.), Africa and the Development of International Law [L'Afrique et le développement du droit international], Leiden, Martinus Nijhoff Publishers, 1988

Alabi M. O. A., "Law making in pre-colonial Yorubaland " [L'élaboration des lois au Yorubaland précolonial], dans Falola T. et Genova A. (dir.), The Yoruba in Transition: History, Values and Modernity [La transition Yoruba : histoire, valeurs et modernité], Durham, Carolina Academic Press, 2006

Ayittey G. B. N., Indigenous African Institutions [Institutions africaines autochtones], Leiden, Martinus Nijhoff, 2006

Ayittey G. B. N., «La Cour constitutionnelle du Bénin », édité par l'Association béninoise de droit constitutionnel et le Centre de droit constitutionnel de l'Université d'Abomey-Calavi, ABJC, Revue de Contentieux constitutionnel, I-2013, Cotonou, Presses universitaires du Bénin, 2013

Badet G., Les Attributions originales de la Cour constitutionnelle du Bénin, Cotonou, Friedrich Ebert Stiftung, 2013

Baranger D., "The language of eternity: judicial review of the amending power in France (or the absence thereof) » [Le langage de l'éternité : le contrôle juridictionnel du pouvoir de modification (ou de son absence) en France], Israel Law Review, 44 (2011), pp. 389-428 
Bastos F. L., "Introduction to the Constitution of Guinea Bissau » [Introduction à la Constitution de la Guinée-Bissau], Document de travail, Pretoria, Université de Pretoria, 2013, <http://www.icla.up.ac.za/images/country_reports/guinea_ bissau_country_report.pdf $>$, consulté le 22 septembre 2014

Bing G., Reap the Whirlwind: An Account of Nkrumah's Ghana from 1950-1966 [Récolter la tempête : le Ghana de Nkrumah de 1950 à 1966], Londres, MacGibbon \& Kee, 1968

Bon P. et Maus D., Les grandes décisions des cours constitutionnelles européennes, Paris, Dalloz, 2008

Cappelletti M., "Judicial review in comparative perspective " [Contrôle juridictionnel : perspective comparée], California Law Review, 58/1 (1970), pp. 1017-1053

Chaskalson A., "Constitutional courts and supreme courts " [Cours constitutionnelles et cours suprêmes], dans Pernice I. et Kokott J. (dir.), The Future of The European Judicial System in a Comparative Perspective [L'avenir du système juridique européen dans une perspective comparative], Baden-Baden, Nomos Verlag, 2006

Chen A. Y. et Maduro M. P., "The judiciary and constitutional review » [La justice et le contrôle de constitutionnalité], dans Fleiner T. et Saunders C. (dir.), Handbook on Constitutional Law [Manuel de droit constitutionnel], Oxford, Oxford University Press, 2013

Choudhry S., Constitutional Review in New Democracies [Contrôle de constitutionnalité dans les nouvelles démocraties], New York, Centre for Constitutional Transitions, 2013, <http://constitutionaltransitions.org/ publications/constitutional-review-in-new-democracies/>, consulté le 25 octobre 2014

Commission européenne pour la démocratie par le droit (Commission de Venise), The Composition of Constitutional Courts [La composition des tribunaux constitutionnels], CDL-STD(1997)020, 1997

Comella V. F., "The rise of specialized constitutional courts " [Lascension des tribunaux constitutionnels spécialisés], dans Ginsburg T. et Dixon D. (dir.), [Droit constitutionnel comparé], Cheltenham, Edgar, 2011

Conac G. et du Bois de Gaudusson J. (dir.), Les Cours suprêmes en Afrique, Volume 2, Paris, Economica, 1989

Crook R., The Role of Traditional Institutions in Political Change and Development [Le rôle des institutions traditionnelles dans la transition politique et le développement], Accra, Centre for Democracy and Development, 2005, $<$ http://www.odi.org/publications/1325-role-traditional-institutions-politicalchange-development>, consulté le 29 janvier 2015 
Crowder M., "Indirect rule : French and British style " [Gouvernance indirecte : les styles français et britanniques], Journal of the International African Institute, 34/3 (1964), pp. 197-205

Dalloz-Sirey J. (dir.), Renouveau du droit constitutionnel : mélanges en l'honneur de Louis Favoreu, Paris, Dalloz, 2007

Davidson B., The Black Man's Burden: Africa and the Curse of Nation-State [Le fardeau de l'homme noir : l'Afrique et la malédiction de l'État-nation], New York, Times Books, 1992

De Andrade G. F., "Comparative constitutional law: judicial review » [Droit constitutionnel comparé : le contrôle juridictionnel], Journal of Constitutional Law, 3 (2001), pp. 977-989

De Lamothe O. D., "L'autorité de l'interprétation constitutionnelle », dans MélinSoucramanien F. (dir.), L'Interprétation constitutionnelle, Paris, Dalloz, 2005

Degu W. A., "The State, the Crisis of State Institutions and Refugee Migration in the Horn of Africa » [L'État, la crise des institutions gouvernementale et la migration des réfugiés dans la Corne de l'Afrique], Thèse de doctorat. Université d'Amsterdam, 2002, non publiée, <http://dare.uva.nl/document/66264>, consultée le 15 avril 2014

Delpérée F., Le recours des particuliers devant le juge constitutionnel, Paris, Economica-Bruylant, 1991

Diop E. H. O., La justice constitutionnelle au Sénégal, Dakar, Credila/Ovipa, 2013

Disant M., "L'autorité de la chose interprétée par le Conseil constitutionnel permanence et actualité(s) ", Les Cahiers du Conseil constitutionnel, 28, (2010), pp. 197-201

Djedjro M., Droit constitutionnel, Abidjan, ABC Édition, 2005

Drago G., L'exécution des décisions du Conseil constitutionnel. L'effectivité du contrôle de constitutionnalité des lois, Paris, Economica, 1999

Du Bois du Gaudusson J., « Défense et illustration du constitutionnalisme en Afrique après quinze ans de pratique du pouvoir ", dans Dalloz-Sirey J. (dir.), Renouveau du droit constitutionnel : mélanges en l'honneur de Louis Favoreu, Paris, Dalloz, 2007

Dung L.T., Judicial Independence in Transitional Countries [L'indépendance judiciaire dans les pays en transition], New York, Programme des Nations Unies pour le développement, 2003

Epstein L. et Shvetsova O. (dir.), "The role of constitutional courts in the establishment and maintenance of democratic systems of government " [Le rôle des tribunaux constitutionnels dans l'établissement et le maintien de systèmes démocratiques de gouvernance], Law and Society Review, 35/1 (2001), pp. 117164 
Fall I. M., Les décisions et avis du Conseil constitutionnel du Sénégal, Dakar, Credila, 2008

Favoreu L. (dir.), Droit constitutionnel, Paris, Dalloz, 2008

Favoreu L., «Les juges constitutionnels » dans Bigouroux F. et Soullière C. (dir.), La constitution et son juge, Paris, Economica, 2014

Favoreu L. et Philip L., Les grandes décisions du Conseil Constitutionnel, $17^{\circledR}$ édition, Paris, Dalloz, 2013

Finer S. E., Bogdanor V. et Rudden B. (dir.), Comparing Constitutions [Comparaisons entre constitutions], Oxford, Oxford University Press, 1985

Fleiner T. et Saunders C., "Constitutions embedded in different legal systems " [Les constitutions se réclamant de différents systèmes juridiques], dans Tushnet M. et Fleiner T. (dir.), Handbook on Constitutional Law [Manuel de droit constitutionnel], Abingdon, Routledge, 2013

Fombad C. M., "Constitutional reforms and constitutionalism in Africa: reflections on some current challenges and future prospects " [Réformes constitutionnelles et constitutionnalisme en Afrique : réflexions sur certains des défis actuels et sur les perspectives d'avenir], Buffalo Law Review, 59 (2011), pp. 1007-1108

Fromont M., Justice constitutionnelle comparée, Paris, Dalloz, 2013

Fulton R., "The political structures and functions of Poro in Kpelle society " [Les structures politiques et les fonctions du Poro dans la société Kpelle], American Anthropologist, 74/5 (1972), p. 1218-1233

Garoupa N. et Ginsburg T., Judicial Reputation: A Comparative Theory [Réputation judiciaire : théorie comparée], Chicago, University of Chicago Press, 2015

Gélard P., "Quelques conseils au constitutionnaliste de droit comparé », in DallozSirey J. (dir.), Mélanges en l'honneur de Louis Favoreu, Paris, Dalloz, 2007

Ginsburg T., Judicial Review in New Democracies: Constitutional Courts in Asian Cases [Le contrôle juridictionnel dans les nouvelles démocraties : tribunaux constitutionnels en Asie], Cambridge, Cambridge University Press, 2003

Ginsburg T., "The global spread of constitutional review » [La diffusion du contrôle de constitutionnalité à l'échelle mondiale], dans Caldeira G. et Keleman D. (dir.), The Oxford Handbook of Law and Politics [Le manuel d'Oxford sur le droit et la politique], Oxford, Oxford University Press, 2008

Ginsburg T., "The Tunisian judicial sector: analysis and recommendations " [Le secteur judiciaire tunisien : analyse et recommandations], dans Al-Ali Z. et Stacey R. (dir.), Consolidating the Arab Spring: Constitutional Transition in Egypt and Tunisia [Consolider le Printemps arabe : la transition constitutionnelle en Égypte et en Tunisie], Stockholm et New York, IDEA International et Center for Constitutional Transitions, 2013 
Ginsburg T., communication privée, 19 mai 2014

Ginsburg T. et Versteeg M., "Why do countries adopt constitutional review? » [Pourquoi les pays adoptent-ils le contrôle de constitutionnalité?], Journal of Law, Economics and Organization, 30/3 (2014), pp. 587-622

Glenn Bass K. et Choudhry S., Constitutional Review in New Democracies [Le contrôle de constitutionnalité dans les nouvelles démocraties], Berlin et New York, Democracy Reporting International et Center for Constitutional Transitions, 2013

Grimm D., "Constitutional issues in substantive law, limits of constitutional jurisdiction " [Questions de constitutionnalité dans le droit positif, limites de la compétence constitutionnelle], dans Pernice I., Kokott J. et Saunders C. (dir.), The Future of the European Judicial System in a Comparative Perspective [L'avenir du système juridique européen dans une perspective comparative], BadenBaden, Nomos Verlagsgesellschaft, 2006

Hein M., «Eternity clauses: never say never! » [Clauses d'éternité : il ne faut jamais dire jamais!], Katapult, 4 mai 2015

Holo T., "Émergence de la justice constitutionnelle », Pouvoirs, Revue Française d'études constitutionnelles et politiques, 129 (2009), pp. 101-114

Horowitz D. L., «Constitutional courts: a primer for decision makers » [Tribunaux constitutionnels : guide introductif à l'attention des décideurs politiques], Journal of Democracy, 17/4 (octobre 2006), pp. 125-137

Huntington S., The Third Wave: Democratization in the Late Twentieth Century [La troisième vague : démocratisation à la fin du XX $\mathrm{XX}^{\mathrm{e}}$ siècle], Norman, OK, et Londres, University of Oklahoma Press, 1991

Institut international pour la démocratie et l'assistance électorale (IDEA International), A Practical Guide to Constitution Building: The Design of the Judicial Branch [Guide pratique de l'élaboration constitutionnelle : l'organisation du pouvoir judiciaire], Stockholm, IDEA International, 2011

Jackson V. et Tushnet M., Comparative Constitutional Law [Droit constitutionnel comparé], St Paul, Foundation Press, 1999

Jan P., "L'accès au juge constitutionnel : modalités et procédures ", Conclusions $d u$ second congrès de l'ACCPUF, Libreville, 14-15 septembre 2000

Jan P. Le procès constitutionnel, Paris, LGDJ, 2010

Kante B., "Models of constitutional jurisdictions in francophone West Africa » [Modèles de juridictions constitutionnelles en Afrique de l'Ouest francophone], Journal of Comparative Law, 3/2 (2008), pp. 158-173

Kelemen K., "Dissenting opinions in constitutional courts " [Opinions dissidentes dans les tribunaux constitutionnels], German Law Journal, 14 (2013), pp. 13451372 
Kelsen H., "La garantie juridictionnelle de la constitution », Revue de Droit public et Science politique, 7 (1928), pp. 197-225

Kpodar A., Commentaire des grands avis et décisions de la Cour Constitutionnelle togolaise, Lomé, Presses de l'Université de Lomé, 2007

Le Pourhiet A.-M., "L'injustice constitutionnelle ", in Dalloz-Sirey J. (dir.), Mélanges en l'honneur de Louis Favoreu, Paris, Dalloz, 2007

Lima, A. R., O Recurso Constitucional de Amparo Alemáo e o Recurso de Amparo Cabo-verdiano: uma análise comparative [Le recours individuel en Allemagne et au Cabo Verde : étude comparée], Cabo Verde, Praia, 2004

Little K., "The political functions of the Poro, Part I " [Les fonctions politiques du Poro, première partie], Journal of the International Affairs Institute, 35/4 (1965), pp. 349-365

Little K. "The political functions of the Poro, Part II» [Les fonctions politiques du Poro, deuxième partie], Journal of the International Affairs Institute, 36/1 (1966), pp. $62-72$

Loada A., Avis et décisions commentés de la justice constitutionnelle burkinabé de 1960 à 2007, Ouagadougou, Burkina Faso, Centre pour la gouvernance démocratique, 2009

Lugard F., The Dual Mandate in British Tropical Africa [Le double mandat en Afrique tropicale britannique], Londres, W. Blackwood and Sons, 1922

Macdonald R. A. et Kong H., "Judicial independence as a constitutional virtue » [L'indépendance judiciaire, une vertu constitutionnelle], dans Rosenfeld M. et Sajó A., The Oxford Handbook of Comparative Constitutional Law [Manuel d'Oxford du droit constitutionnel comparé], Oxford, Oxford University Press, 2012

Mathieu B. et Verpeaux M., Contentieux constitutionnel des droits fondamentaux, Paris, LGDJ, 2002

Mathieu B. et Verpeaux M., L'autorité des décisions du Conseil constitutionnel, Paris, Dalloz, 2010

Maus D.et Roux A. (dir.), 30 ans de saisine parlementaire du Conseil Constitutionnel : colloque et publication en hommage à Louis Favoreu, Paris, Economica, 2006

Mborantsuo M.-M., La contribution des cours constitutionnelles à l'État de droit en Afrique, Paris, Economica, 2007

Mboup S. B., «An African cultural renaissance perspectives on constitutionalism, democracy, peace, justice and shared values: challenges and stakes, statehood and nation building " [Perspectives de la renaissance culturelle africaine sur le constitutionnalisme, la démocratie, la paix, la justice et les valeurs communes : défis et enjeux, État et édification de la nation], dans Gutto S. B. O. (dir.), 
Shared Values, Constitutionalism and Democracy in Africa [Valeurs partagées, constitutionnalisme et démocratie en Afrique du Sud], Pretoria, University of South Africa, 2011

Mede N., "Commentaire décision DCC 04-044 du 23 avril 2004 Tanimono Pascal ", dans Zinsou K. N. M. et Dossou (R.), Les grandes décisions de la Cour constitutionnelle du Bénin, Saarbrücken, Éditions universitaires européennes, 2012

Melin-Soucramanien F. (dir.), "L'interprétation constitutionnelle », actes de la table ronde de l'Association française des constitutionnalistes, Paris, Dalloz, 2005

Melin-Soucramanien F. et Pactet P., Droit constitutionnel, 33e édition, Paris, Sirey, 2014

Melton J. et Ginsburg T., « Does De Jure Judicial Independence Really Matter? A Reevaluation of Explanations for Judicial Independence " [L'indépendance judiciaire de jure a-t-elle réellement une valeur? Réexamen des justifications à l'indépendance judiciaire], Document de travail n 612, Chicago, Coase-Sandor Institute for Law \& Economics, 2014

Meunier J., "Le Conseil constitutionnel et l'autorité de ses décisions », dans Brunet P. et al., L'architecture du droit : mélanges en l'honneur de Michel Troper, Paris, Economica, 2006

Michelman F.L., "The interplay of constitutional ordinary jurisdiction " [L'interation de la juridiction constitutionnelle ordinaire], dans Ginsburg T. et Dixon R. (dir.), Comparative Constitutional Law [Droit constitutionnel comparé], Chicago, University of Chicago Law School, 2011

Monroe J. C., The Pre-Colonial State in West Africa: Building Power in Dahomey [L'État précolonial en Afrique de l'Ouest : l'édification du pouvoir au Dahomey], Cambridge, Cambridge University Press, 2014

Mouhamadou M. S., La protection constitutionnelle des droits fondamentaux en Afrique. L'exemple du Sénégal, Paris, L'Harmattan, 2007

Navia P. et Rios-Figueroa J., " The constitutional adjudication mosaic of Latin America » [La mosaïque du contentieux constitutionnel en Amérique latine], Comparative Political Studies, 38/2 (2005), pp. 189-217

Ngenge Y., "International influences and the design of judicial review institutions in francophone Africa " [Influences internationales et organisation des instances chargées du contrôle juridictionnel en Afrique francophone], American Journal of Comparative Law, 61/2 (2013), pp. 433-460

Nwabueze B. O., Judicialism in Commonwealth Africa: The Role of Courts in Government in Africa [Judiciarisme dans l'Afrique du Commonwealth : le rôle des tribunaux dans la gouvernance en Afrique], New York, St Martin's Press, 1977 
Nwabueze B. O., A Constitutional History of Nigeria [Une histoire constitutionnelle du Nigéria], Londres, Hurst and Co., 1982

Odinkalu C. A., "The judiciary and the legal protection of human rights in common law Africa: allocating responsibility for the failure of postindependence bills of rights " [Le pouvoir judiciaire et la protection juridique des droits humains en Afrique de la common law : déterminer les responsabilités dans la faillite des chartes des droits après les indépendances], African Society of International and Comparative Law, 8 (1996), pp. 124-137

Ohaegbulam F., Towards an Understanding of the African Experience from Historical and Contemporary Perspectives [Mieux comprendre l'expérience africaine d'un point de vue historique et contemporain], Lanham, University Press of America, 1990

Okoth A., A History of Africa: African Societies and the Establishment of Colonial Rule, 1800-1915 [Histoire de l'Afrique : les sociétés africaines et l'établissement de la gouvernance coloniale], Nairobi, East African Publishers, 2006

Peri A., " Judicial independence vs. judicial accountability: judicial selection models for constitutional courts: a comparative analysis " [Indépendance judiciaire contre responsabilité judiciaire : modèles de sélection judiciaire pour les tribunaux constitutionnels : étude comparée], Comparative Law Review, 3/1 (2012), pp. 1-30

Prempeh Kwasi H., "A new jurisprudence for Africa » [Une nouvelle jurisprudence pour l'Afrique], Journal of Democracy, 10/3 (1999), pp. 135-149

Prempeh Kwasi H., " Marbury in Africa: judicial review and the challenge of constitutionalism in contemporary Africa» [Marbury en Afrique : le contrôle juridictionnel et le défi du constitutionnalisme en Afrique contemporaine], Tulane Law Review, 80/4 (2006), pp. 1239-1323

Prempeh Kwasi H., Seton Hall University Law School, communication privée, 28 janvier 2015

Renoux T. S., «Autorité de la chose jugée ou autorité de la Constitution. À propos de l'effet des décisions du Conseil constitutionnel ", dans Pactet P. (dir.), L'esprit des institutions. L'équilibre des pouvoirs, Mélanges Pierre Pactet, Paris, Dalloz, 2003

Rousseau D. (dir.), La question de l'autorité des décisions du Conseil constitutionnel, Paris, L'Harmattan, 2004

Roznai Y., " Unconstitutional Constitutional Amendments: A Study of the Nature and Limits of Constitutional Amendment Powers " [Modifications constitutionnelles inconstitutionnelles : étude de la nature et des limites des pouvoirs de révision de la constitution], Thèse de doctorat, London School of Economics and Political Science (2014) 
Salami D. I. et Gandonou O. M., Droit constitutionnel et institutions du Bénin, Cotonou, CeDAT, 2014

Sarduski W., « Postcommunist Constitutional Courts in Search of Political Legitimacy " [Les tribunaux constitutionnels post-communistes à la recherche d'une légitimité politique], document de travail, Florence, European University Institute, 2001

Saunders C., "Judicial dialogue in common law countries " [Le dialogue judiciaire dans les pays de common law], dans Dalloz-Sirey J. (dir.), Mélanges en l'honneur de Louis Favoreu, Paris, Dalloz, 2007

Seidman R., " Judicial review and fundamental freedoms in anglophonic independent Africa » [Contrôle juridictionnel et libertés fondamentales dans l'Afrique Anglophone indépendante], Ohio State Law Journal, 35/4 (1974), pp. $820-850$

Sindjoun L., Les grandes décisions de la justice constitutionnelle africaine. Droit constitutionnel jurisprudentiel et politique constitutionnelle au prisme des systèmes politiques africains, Bruxelles, Bruylant, 2009

Skertchly J. A, Dahomey, As it Is: Being a Narrative of Eight Months Residence in That Country [Le Dahomey tel qu'il est : récit de huit mois passés dans le pays], Londres, Chapman and Hall, 1874

Smilov D., "The judiciary: The least dangerous branch » [La justice, le pouvoir le moins dangereux], dans Rosenfeld M. et Sajo A. (dir.), The Oxford Handbook of Comparative Constitutional Law [Manuel d'Oxford de droit constitutionnel comparé], Oxford, Oxford University Press, 2012

Soumanou I., La contribution de la Cour constitutionnelle à la consolidation de l'État de droit au Bénin, Cotonou, UNESCO, 2006

Stefanini M.F.-R., Le contrôle du référendum par la justice constitutionnelle, Paris, Economica, 2004

Stone Sweet A., "Constitutional courts " [Tribunaux constitutionnels], dans Rosenfeld M. et Sajó A. (dir.), The Oxford Handbook of Comparative Constitutional Law [Manuel d'Oxford de droit constitutionnel comparé], Oxford, Oxford University Press, 2012

Stroh A. et Heyl C., "Diffusion versus Strategic Action? The Creation of West African Constitutional Courts Revisited " [Diffusion ou action stratégique? Un nouveau regard sur la création des cours constitutionnelles en Afrique de l'Ouest], document de travail 239, Hambourg, German Institute for Global and Area Studies, 2013, <http://edoc.vifapol.de/opus/volltexte/2014/4986/pdf/ wp239_stroh_heyl.pdf> consulté le 1 ${ }^{\text {er }}$ avril 2015

Stroh A. et Heyl C., "Institutional diffusion, strategic insurance and the creation of West African constitutional courts » [Diffusion institutionnelle, assurance stratégique et établissement des cours constitutionnelles ouest-africaines], Comparative Politics, 47/2 (2015), pp.169-187 
Suret-Canale J., French Colonialism in Tropical Africa [Colonialisme français en Afrique tropicale], Londres, Hurst, 1971

Tushnet M., « Marbury v. Madison around the world » [L'arrêt Marbury c. Madison à travers le monde], Tennessee Law Review, 71 (2004), pp. 251-274

Tushnet M., "The rise of weak form judicial review » [L'émergence de formes affaiblies de contrôle juridictionnel], dans Ginsburg T. et Dixon R., Comparative Constitutional Law, Research Handbooks in Comparative Law Series [Droit constitutionnel comparé, collection des manuels de recherche en droit comparé] (2011), pp. 321-333

Verpeaux M., «Les avatars récents de l'indépendance des membres du Conseil constitutionnel ", in Dalloz-Sirey J. (dir.), Mélanges en l'honneur de Louis Favoreu, Paris, Dalloz, 2007

Waline M., Préface aux grandes décisions du Conseil constitutionnel, $17^{\circledR}$ édition, Paris, Dalloz, 2013

Wodie F. Institutions politiques et droit constitutionnel, Abidjan, Presses universitaires de Côte d'Ivoire, 1996

Yannakopoulos C., La notion de droit acquis en droit administratiffrançais, Paris, LGDJ, 1998 


\section{À propos des auteurs}

Markus Böckenförde est actuellement directeur général/chercheur au sein du Centre for Global Cooperation Research (Université de Duisburg-Essen) en Allemagne et professeur invité à l'Université d'Europe centrale (CEU) de Budapest. Entre 2011 et 2012, il a dirigé une équipe de conseillers en poste auprès des fonctionnaires chargés de la planification des politiques au sein du ministère de la Coopération économique et du Développement (Bonn-Berlin), et a travaillé en tant que chercheur principal pour l'Institut allemand du développement, basé à Bonn. De 2009 à 2011, il a été chargé de programme et responsable de programme par intérim pour le programme sur les processus d'élaboration constitutionnelle d'IDEA International. De 2001 à 2008, il a été chef des projets pour l'Afrique et chercheur confirmé au sein du Max Planck Institute for Comparative Public Law and International Law d'Heidelberg. En 2006-2007, il a été détaché par le ministère des Affaires étrangères allemand en tant qu'expert juridique au sein de la Commission d'évaluation du Soudan.

M. Böckenförde est titulaire d'un diplôme de droit et d'un doctorat de l'Université d'Heidelberg et d'un master en droit de l'Université du Minnesota, ainsi que de l'équivalent d'une licence en science politique de l'Université de Fribourg. Il a participé à de nombreux processus d'élaboration constitutionnelle, notamment en Afghanistan, au Népal, au Soudan, en Somalie, en Tunisie et en Libye, en collaboration avec les assemblées constituantes concernées. Il a publié de nombreux ouvrages ou articles dans le domaine du droit international, du droit constitutionnel, et de l'élaboration constitutionnelle, et il a coécrit le Practical Guide to Constitution Building [Guide pratique de l'élaboration constitutionnelle] publié par IDEA International.

Au cours des 15 dernières années, il a travaillé comme consultant pour les Nations Unies, le PNUD, l'association allemande pour la coopération internationale, le service d'échange universitaire allemand, IDEA International, le ministère allemand des Affaires étrangères, la fondation 
Friedrich Ebert, la fondation Konrad Adenauer, l'institut allemand des droits humains, et Democracy Reporting International. Il dirige également l'université d'été du CEU sur l'élaboration constitutionnelle en Afrique.

Babacar Kante est professeur de droit public à l'Université Gaston Berger de Saint Louis (Sénégal) et doyen honoraire de la faculté de droit et de sciences politiques de l'université. Il est le fondateur et président honoraire du réseau africain de droit constitutionnel. M. Kante siège également au conseil scientifique/éditorial de plusieurs publications et est consultant auprès de nombreuses organisations internationales et non gouvernementales. Auparavant, il a été vice-président du Conseil constitutionnel du Sénégal, membre de l'Assemblée générale consultative de la Cour suprême du Sénégal, et vice-président de l'Association internationale de droit constitutionnel.

M. Kante a publié de nombreux articles et ouvrages portant sur un large éventail de questions, notamment la démocratie en Afrique, les élections, la décentralisation et la gestion des ressources naturelles, l'éthique en matière de gestion des conflits, les droits humains et le SIDA, la justice constitutionnelle et les droits culturels.

Henry Kwasi Prempeh est un universitaire spécialiste du droit constitutionnel comparé basé à Accra, au Ghana, où il a fondé et dirige Constitution Watch, une organisation non gouvernementale dont l'objectif est de promouvoir l'État de droit et le constitutionnalisme au travers de recherches, publications, activités de plaidoyer et programmes d'alphabétisation. Il a été professeur à la Seton Hall University School of Law de New Jersey, aux États-Unis, de 2003 à 2015 et professeur invité à la GIMPA Law School d'Accra, au Ghana, en 20102011. M. Prempeh co-enseigne le cours sur l'élaboration constitutionnelle en Afrique à la CEU depuis 2014. Entre 2013 et 2014, il a été conseiller constitutionnel auprès de l'Envoyé spécial des Nations Unies au Yémen et, au travers de cette fonction, a fourni un appui technique à la Conférence sur le dialogue national yéménite et la commission de rédaction de la Constitution pour l'élaboration et la formulation d'une nouvelle Constitution fédérale.

M. Prempeh a également apporté son expertise sur une large gamme de questions relatives à l'État de droit et à la gouvernance à différents organes nationaux, organisations internationales de la société civile et agences multilatérales de développement, telles que le PNUD, le DFID, le GIZ, la Banque mondiale, Transparency International et la magistrature kényane. Il a écrit de nombreux articles, chapitres de livres et monographies couvrant différents aspects du développement constitutionnel, de la gouvernance démocratique et des réformes juridiques au Ghana et en Afrique; ses travaux ont plusieurs fois été publiés dans l'International Journal of Constitutional Law 
et the Journal of Democracy. M. Prempeh est diplômé de la Yale Law School et titulaire d'une licence et d'un master en gestion de l'Université Baylor (Texas, États-Unis) et de l'Université du Ghana, respectivement.

Yuhniwo Ngenge est un juriste camerounais chargé de programme pour le programme sur les processus d'élaboration constitutionnelle d'IDEA International. Ses recherches se concentrent actuellement sur le rôle des tribunaux dans la démocratisation et les processus de transition constitutionnelle. Auparavant, il a coordonné et géré, entre autres, le développement de l'un des sites Internet d'IDEA International, ConstitutionNet. Il a écrit et édité plusieurs articles de fond sur les transitions constitutionnelles, y compris les tribunaux en Afrique, qui ont été publiés par différents journaux, notamment Foreign Policy. Parmi ses principaux travaux, l'on peut citer l'article «International Influences and the Design of Judicial Review Institutions in Francophone Africa " [Influences internationales et architecture des instances chargées du contrôle juridictionnel en Afrique francophone] publié dans l'American Journal of Comparative Law, 61/2 (2013). Ses autres travaux, notamment sur le rôle des tribunaux dans les processus d'élaboration constitutionnelle et sur la durée des mandats présidentiels, ont été publiés dans la série Annual Review of Constitution-Building Processes éditée par IDEA International. M. Ngenge est titulaire d'une licence et d'une maitrise en droit de l'Université de Yaoundé II (Cameroun) ainsi que d'un master en droit (LL.M) de l'Université d'Europe centrale (CEU). 


\section{À propos d'IDEA International}

L'Institut international pour la démocratie et l'assistance électorale (IDEA International) est une organisation intergouvernementale dont la mission est de promouvoir la démocratie durable dans le monde. IDEA International soutient l'évolution démocratique durable en proposant des analyses comparatives, en encourageant les réformes démocratiques et en influençant les politiques et processus politiques.

\section{Quelles sont les activités d'IDEA International?}

Nos travaux portent sur les élections, l'élaboration constitutionnelle, les partis politiques, les perspectives de genre dans la démocratie et l'autonomisation politique des femmes, l'autoévaluation démocratique, et sur la démocratie et le développement. Dans ces domaines, nos interventions s'articulent autour de trois axes :

1. Fournir des analyses comparées tirées de l'expérience pratique des processus de consolidation démocratique dans différents contextes dans le monde;

2. Épauler les acteurs politiques dans la réforme des institutions et des processus démocratiques, et participer aux processus politiques lorsque nous y sommes invités;

3. Influencer les politiques de consolidation de la démocratie en mettant à disposition nos ressources et nos connaissances comparatives et en proposant une aide aux acteurs politiques.

\section{Dans quels pays intervient IDEA International ?}

IDEA International intervient dans le monde entier. Basés à Stockholm, nous disposons de bureaux en Afrique, en Asie-Pacifique, et en Amérique latine et aux Caraïbes. IDEA International a le statut d'observateur permanent auprès des Nations Unies.

$<$ http://www.idea.int> 


\section{À propos de la Fondation Hanns Seidel}

Depuis sa création le 11 avril 1967, la Fondation Hanns Seidel effectue un travail d'éducation civique dans le but de promouvoir «l'éducation civique et démocratique du peuple allemand sur la base des principes du christianisme ", comme le précisent les statuts de la Fondation. Par conséquent, le travail d'éducation politique de la Fondation Hanns Seidel est fondé sur une conception de l'homme qui prend en compte tant le libre développement de sa personnalité et de son autonomie que les notions de responsabilité sociale et de solidarité. Aujourd'hui, cette mission est plus pertinente que jamais compte tenu de la demande croissante pour une plus grande responsabilité personnelle, pour une " culture de l'autosuffisance " et une "société civile active ", qui sont les caractéristiques de notre temps.

$<$ http://www.hss.de/> 


\section{Autres ressources d'IDEA International sur les processus d'élaboration constitutionnelle}

Assessing the Performance of the South African Constitution 2016, 120 pp.

Constitutional Change and Participation of LGBTI Groups: A case study of Nepal

2015, 27 pp.

Constitutional Change and Participation of LGBTI Groups: A case study of South Africa

2015, 32 pp.

Annual Review of Constitution-Building Processes: 2014-2015, 136 pp.

Interim Constitutions: Peacekeeping and Democracy-Building Tools 2015, 36 pp.

Contesting Patriarchy: The gender gap and gender-based violence in Nepali politics and the Constituent Assembly Elections 2013

2015, 150 pp.

Combating Corruption: Constitutional Frameworks for the Middle East and North Africa [en anglais et en arabe]

2015, 164 pp.

Toutes ces publications peuvent être téléchargées sur notre site Internet : $<$ http://www.idea.int/cbp>

Pour plus d'informations en matière constitutionnelle, consultez ConstitutionNet : <http://www.constitutionnet.org/resources> 


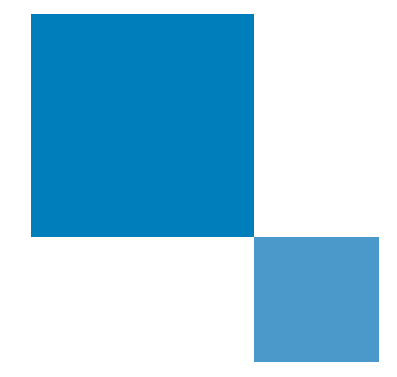

Les systèmes juridiques des pays de l'Afrique de l'Ouest sont uniques dans leur diversité. Ils se fondent sur différentes traditions héritées de la colonisation et ont été influencés par de multiples normes coutumières et religieuses, qui affectent la structure du système judiciaire de chaque pays. Parallèlement, cette région se développe collectivement sous les auspices de la Communauté économique des États de l'Afrique de l'Ouest (CEDEAO).

Le présent ouvrage compare les différentes instances chargées de la justice constitutionnelle dans 16 pays d'Afrique de l'Ouest et analyse les différentes manières selon lesquelles elles rendent la justice et encouragent le développement de la démocratie. Il n'existe pas d'approche unique optimale : différentes traditions juridiques donnent généralement naissance à différentes configurations. Il cherche également à faciliter l'apprentissage et la compréhension mutuelle entre les pays de la région, en particulier ceux dont les systèmes juridiques differrent, dans le but de tracer les grandes lignes d'un système commun ouest-africain.

Les auteurs analysent un large éventail de questions liées à la justice constitutionnelle en Afrique de l'Ouest. Tout en examinant les points techniques liés à la compétence, à la composition, à l'accès, au statut des juges, à l'autorité de ces instances et à leurs relations avec d'autres institutions, ils portent également un regard nouveau sur les instances analogues de l'Afrique précoloniale, ainsi que sur le sujet généralement tabou du contrôle et de la responsabilité de ces institutions elles-mêmes.

Institut international pour la démocratie et l'assistance électorale

(IDEA International)

Strömsborg, SE-103 34 Stockholm, Suède

Tél. : +46869837 00, fax : +468202422

Courriel : info@idea.int, site Internet : www.idea.int

Fondation Hanns Seidel

Lazarettstraße 33

80636 Munich, Allemagne

Tél. : +49 89 1258-0 | Fax : -356

Courriel : info@hss.de, site Internet : www.hss.de 